\title{
White collars green sleeves: an interorganizational comparison of determinants of energy-related behaviors among office workers
}

Citation for published version (APA):

Lo, S. H. (2011). White collars green sleeves: an interorganizational comparison of determinants of energy-related behaviors among office workers. [Doctoral Thesis, Maastricht University]. Maastricht University. https://doi.org/10.26481/dis.20110224sl

Document status and date:

Published: 01/01/2011

DOI:

10.26481/dis.20110224sl

Document Version:

Publisher's PDF, also known as Version of record

Please check the document version of this publication:

- A submitted manuscript is the version of the article upon submission and before peer-review. There can be important differences between the submitted version and the official published version of record.

People interested in the research are advised to contact the author for the final version of the publication, or visit the DOI to the publisher's website.

- The final author version and the galley proof are versions of the publication after peer review.

- The final published version features the final layout of the paper including the volume, issue and page numbers.

Link to publication

\footnotetext{
General rights rights.

- You may freely distribute the URL identifying the publication in the public portal. please follow below link for the End User Agreement:

www.umlib.nl/taverne-license

Take down policy

If you believe that this document breaches copyright please contact us at:

repository@maastrichtuniversity.nl

providing details and we will investigate your claim.
}

Copyright and moral rights for the publications made accessible in the public portal are retained by the authors and/or other copyright owners and it is a condition of accessing publications that users recognise and abide by the legal requirements associated with these

- Users may download and print one copy of any publication from the public portal for the purpose of private study or research.

- You may not further distribute the material or use it for any profit-making activity or commercial gain

If the publication is distributed under the terms of Article 25fa of the Dutch Copyright Act, indicated by the "Taverne" license above, 


\section{White Collars Green Sleeves}

an Interorganizational Comparison of Determinants of Energy-Related Behaviors among Office Workers 
White Collars Green Sleeves: an Interorganizational Comparison of Determinants of Energy-Related Behaviors among Office Workers

(C) 2011 Siu Hing Lo

ISBN 9789086661893

Printed in the Netherlands by Boekenplan, Maastricht

All rights reserved. No part of this publication may be reproduced, stored in a retrieval system, or transmitted, in any form, or by any means, electronic, mechanical, photocopying, recording or otherwise, without the prior permission in writing from the author. 


\section{White Collars Green Sleeves}

\section{an Interorganizational Comparison of Determinants of Energy-Related Behaviors among Office Workers}

Proefschrift ter verkrijging van de graad van doctor aan de Universiteit Maastricht, op gezag van de Rector Magnificus, Prof. Mr. G. P. M. F. Mols, volgens het besluit van het College van Decanen, in het openbaar te verdedigen op Donderdag 24 februari 2011 om 16:00 uur

$$
\text { door }
$$

Siu Hing Lo

geboren op 28 juni 1983

te 's Gravenhage 
Promotor:

Prof. dr. G.J. Kok

Copromotor:

Dr. G.J.Y. Peters

Beoordelingscommissie:

Prof. dr. F.R.H.. Zijlstra (voorzitter)

Prof. dr. P. Martens

Dr. R.M. Meertens

Dr. R.A.C. Ruiter

Prof. dr. M. van Vugt (Vrije Universiteit Amsterdam) 


\section{Table of Contents}

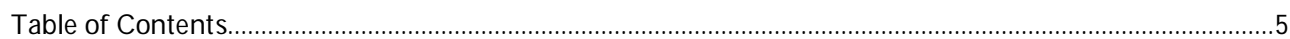

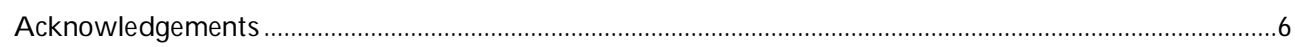

Chapter 1: General Introduction ...................................................................................................................

Chapter 2: A Review of Determinants of and Interventions for Proenvironmental Behaviors in

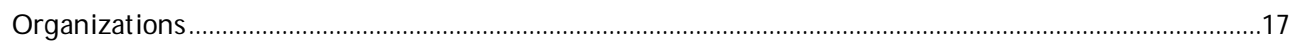

Chapter 3: Energy-Related Behaviors in Office Buildings: a Qualitative Study on Individual and

Organizational Determinants ..............................................................................................................................

Chapter 4: Proenvironmental Travel Behaviors among Office Workers: a Qualitative Study of

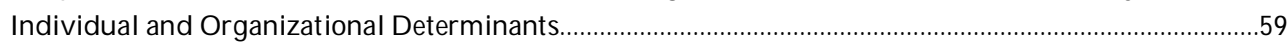

Chapter 5: Energy-Related Behaviors in Office Buildings: an Interorganizational Comparison of a

Model of Individual Determinants...........................................................................................................75

Chapter 6: Proenvironmental Commuting Behaviors among Office Workers: An Interregional and

Intersectoral Comparison of a Model of Individual Determinants ............................................................... 101

Chapter 7: Business Travel Behaviors among Office Workers: An Interregional and Intersectoral

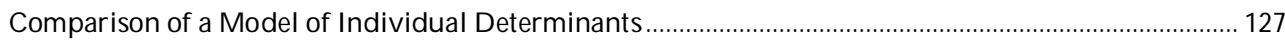

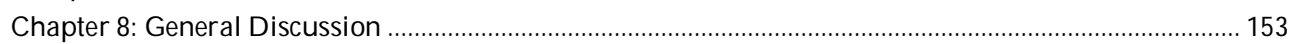

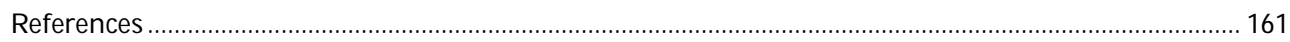

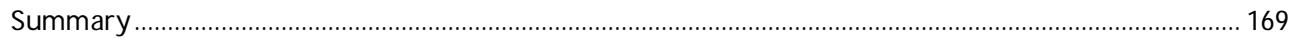

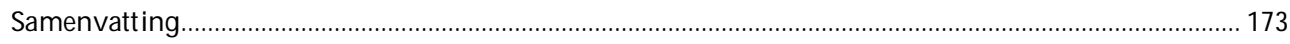

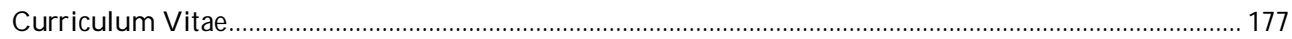




\section{Acknowledgements}

I will begin this book with my favorite part. I cannot think of a more pleasurable subject to write about than the people who have contributed to the completion of my $\mathrm{PhD}$ thesis and my general well-being during my time in Maastricht. After having spent six years abroad, I could not have wished for a softer landing back in my home country. This was not only thanks to the "soft g", but also to the people I met the past three-and-a-half years at work and outside of work.

First of all, thanks to the three (not always so soft) G's:

I would especially like to thank my supervisors Gerjo and Gjalt-Jorn. The completion of my thesis would simply not have been possible without your continued support. I count the day I met you as one of the luckiest in my life: thank you for embarking on this ride with me.

Gerjo, thank you for not living up to any of the Piled Higher and Deeper stereotypes. For your information, you can find some examples of his comics on the wall next to our printer. I would write Jorge Cham a letter to ask him to adjust his typology of supervisors, but I am afraid he would be reluctant to do so. After all, who wants to read about calm, reliable, supportive supervisors? Thank you so much for everything you have done for my research and so much more.

GJ, thank you for never dropping your trademark smile. If you ever need a recommendation for a position as toothpaste-advertisement model or actor, please do not hesitate to contact me. It certainly was the most powerful anti-depressant at nerve-wrecking moments, and a great relaxant after working hours. And last but not least, thank you for having patience with my computer illiteracy.

I am also indebted to my co-author Gerard. Your depth of knowledge, critical mind, attention for detail, and constructive feedback were indispensable to the quality of my last three papers. I am very fortunate to have had the opportunity to collaborate with you.

I am blessed with the number of people whom I am grateful to have (had) in my (Maastricht) life which is also the perfect excuse for me to continue in my preferred bullet-point-style. In alphabetical order:

Alissa \& Michael:

Thank you for all chicken-related wisdom and humor. Your presence in Maastricht is dearly missed.

Dance teachers:

Brigitte, Jason, Mautje, Yvette, I just wanted to let you know how much spending my evening hours dancing have helped me to stay healthy in mind and body during my time in Maastricht. Thank you!

ESPP 2007 cohort:

Cheng, Dorcas, Kwan, Lenka, Nyasha, Sonila, I will miss our dinner tradition! The memories of those evenings are among the best I have of Maastricht. 
Family:

Chi Ming, Hoi Wa, Koe Tje, Small Uncle, thank you for taking care of mum when I was/am not around. Daddy and Mamie, thank you for loving me and putting me first, always.

Floris:

Floortje, thank you for having been there for me at very difficult moments - you are a real man.

Friends:

To those whom I haven't mentioned by name, thank you for having made my time in Maastricht memorable! I enjoyed your company, and appreciated your helping hand and advice when I needed it.

Office mates (long-term):

Kwanpadh - Quannie, it was a pleasure to boss you around. I still miss your curries.

Sarah - thank you for having been an angelic roommate; only the wings are missing.

Organizations:

To ensure the anonymity of the organizations who participated in my research project, I will not mention names. However, I would like to thank the contact persons of each organization for their cooperation and trust in me. Your help was crucial to the successful completion of my PhD.

Paranymphs:

Stéphanie - Steph, thank you for being such an enthusiastic paranymph. It is my honor having been in the PhD Academy board with you, and above all to be your friend.

Cheng - My smiley counterpart, I am very happy to have you help me through the day. I hope Cheng Hing still has a long and bright future in front of her.

PhD Academy:

Adrienne, Daniel, Erik, Marco, thank you for your support (even after you "retired")!

Alejandro, Iryna, Michael, Nevena, Tanja, thank you for caring for and nurturing my baby now I had to give up motherhood.

Philipp:

Thank you for co-authoring the title of this book, and always being delightful and "delicious" company.

Student-assistants:

Aart, Ilona, Karin, Kimberly, Mariska: thank you for sparing me hours and hours of transcription work.

Work \& Social Psychology colleagues:

Thank you for being such wonderful colleagues; you made my workplace feel like home. 



\section{Chapter 1: General Introduction}

In the 1970s, the first oil crisis put fossil fuel consumption firmly onto the public agenda. More recently, the climate change issue also boosted public interest in energy consumption. Although concerns about climate change had been raised much earlier, the first decade of the 21st Century saw a substantial increase in its visibility. Few in Western societies, if not the world at large, will have escaped the news on the increasingly alarming reports of the Intergovernmental Panel on Climate Change (IPCC), the apocalyptic message of Al Gore's documentary An Inconvenient Truth, or the countless other news reports and public appeals related to climate change. In brief, energy use has societal and political relevance for both environmental and economical reasons.

\section{Proenvironmental behavior}

Generally speaking, energy-saving behavior is considered to be and studied as a proenvironmental behavior in the research literature. However, this ignores the issue of heterogeneity within the category of proenvironmental behaviors. Thus, it is important to first establish that the study of such behaviors as one category is meaningful. To a certain extent, the common aim, namely environmental sustainability, is the practical justification for doing so. On a conceptual level, it could also be argued that proenvironmental behaviors have in common that they can be, and probably are, motivated by a combination of self-interest and concern for the environment and others. Furthermore, environmental issues are typically long-term concerns that frequently clash with people's short-term interests which can result in a "tragedy of the commons" (Hardin, 1968; Weber, 2006). It is therefore unsurprising that many have argued that awareness of environmental problems per se may not lead to behavioral change (e.g. Staats, Wit, \& Midden, 1996).

Another question that needs to be addressed is how proenvironmental behavior can be further subcategorized meaningfully. For this, it is useful to reflect on what classifications of behavior one can make in general. An important feature of behaviors is the frequency with which they are (supposed to be) performed. Roughly speaking, a distinction between investment behaviors and repeated behaviors can be made. Investment behaviors are here defined as one-shot behaviors whereas repeated behaviors are performed on a more regular basis (cf. Uitdenbogerd, Egmond, Jonkers, \& Kok, 2007). The distinction between these types of behaviors is important because the determinants and the effectiveness of interventions differ across two related but distinct dimensions, namely that of the repetitiveness and habit strength of the behavior of interest (Verplanken \& Orbell, 2003). Research has shown that habitual behaviors differ in their determinants from less ingrained behaviors (Aarts \& Dijksterhuis, 2000; Wood, Tam, \& Guerrero Witt, 2005).

Besides (desired) frequency of performance, another crucial difference between behaviors is the degree of effort, or "sacrifice" they entail. Especially in the light of conflicting interests, behavioral difficulty may greatly influence the extent to which people can reconcile common and personal interests. Furthermore, to bring about behavioral change, different strategies may need to be employed for lowcost and high-cost behaviors. It has also been suggested that the magnitude of association between psychosocial determinants and behavior may vary depending on behavioral difficulty (Corraliza \& 
Berenguer, 2000; cf. Kaiser \& Schultz, 2009). All things considered, behavioral difficulty should at least be taken into account when comparing empirical results of different proenvironmental behaviors.

\section{Theoretical perspectives on energy-saving and other proenvironmental behaviors}

Considering the societal relevance of energy conservation, it is unsurprising that it has attracted the interest of psychologists from the 1970s onwards (Becker \& Seligman, 1981). Not uncommonly, these researchers have stressed how reducing energy consumption can, at least partially, be framed as a behavioral problem (e.g. Nickerson, 2003; Oskamp, 2000). The relevance of (social) psychology to the study of environmental problems has also been frequently argued for by demonstrating how psychological concepts and theories can shed light on the behavioral aspects of these issues (e.g. Stern, 2000; van der Pligt, 1996; Winter, 2000).

Roughly speaking, empirical research on proenvironmental behavior has focused on the concept of environmental concern itself, the determinants of proenvironmental behavior, or the effectiveness of proenvironmental interventions. These research foci are complementary to each other from a practical point of view. Environmental concern is an obvious candidate for a relevant, though not necessarily most important, domain-specific determinant of proenvironmental behavior (e.g. Dunlap, Van Liere, Mertig, \& Jones, 2000). Identification of relevant determinants more generally, in turn, can inform the design of interventions and also the understanding of mechanisms that underlie their effectiveness. Considering the state-of-the-art as described in Chapter 2, the main concern of this thesis is to identify and examine determinants of energy-related behaviors.

Various theoretical frameworks have been employed to study determinants of proenvironmental behavior - with theory choice often depending on whether one emphasizes self-interest, or concern for others and nature as a motivation for acting proenvironmentally. On the one hand, the Theory of Planned Behavior (TPB) and its precursor the Theory of Reasoned Action (TRA), have been most frequently used as a model when stressing rational, self-interested motivations (Ajzen, 1991; Fishbein \& Ajzen, 1975). On the other hand, the Norm-Activation Model (NAM) and its successor in the environmental domain, the Value-Belief-Norm Theory (VBN), have been used for examining the role of norms (Schwartz, 1973; Stern, Dietz, Abel, \& Guagnano, 1999). Viewing proenvironmental behavior as being motivated by a combination of self-interest and altruism, some researchers have also integrated these models. A brief overview of each strand of research is provided below.

\section{Reasoned Action}

The reasoned action framework has been applied to the study of a wide range proenvironmental behaviors, ranging from recycling (e.g. Boldero, 1995) to travel mode choice (e.g. Bamberg, Ajzen, \& Schmidt, 2003), and proenvironmental behavior in general (e.g. Kaiser \& Gutscher, 2003).

Reasoned action was intended as a parsimonious framework for explaining human social behavior. Recently, Fishbein and Ajzen have reviewed and synthesized research findings since the publication of their seminal work (Fishbein \& Ajzen, 2010). A central tenet of their model is that (behavioral) intention is the most important immediate antecedent of behavior. On its turn, intention is determined by attitude, perceived norm, and perceived behavioral control. Perceived behavioral control is also postulated to have a direct effect on behavior, although empirical support for this hypothesis is mixed. 
Attitude can be defined as one's general evaluation of a behavior. Perceived norm - also known as social norm or subjective norm - is defined as the perception of what other (relevant) people think one should do. Perceived behavioral control - which is conceptually identical to Bandura's self-efficacy - is the perceived ability to perform a behavior or carry out a certain course of action (Fishbein et al., 2010). Attitude, perceived norm, and perceived behavioral control are informed by behavioral, normative, and control beliefs respectively. Further distinctions could be made between instrumental and experiential attitude, injunctive and descriptive norms, and capacity and autonomy aspects of perceived behavioral control. Instrumental attitude refers to the outcome of a behavior, while experiential attitude refers to the experience of engaging in a behavior. Injunctive norms are related to others' (dis)approval of one's own behavior, and descriptive norms to others' behavior. Capacity is concerned with the (inherent) ability to perform a behavior, and autonomy with the (situational) control one has over whether to perform a behavior or not.

\section{Norm Activation}

Normatively oriented frameworks have also been extensively employed in the study of diverse proenvironmental behaviors such as recycling (Hopper \& Nielsen, 1991), energy-conservation (Scherbaum, Popovich, \& Finlinson, 2008), and the acceptance of energy policies (Steg, Dreijerink, \& Abrahamse, 2005).

The Norm Activation Model (NAM) was proposed to explain helping behavior (Schwartz, 1977). As such, it is a more domain-specific than the reasoned action approach. A key assumption of the model is that personal norm - the intensity of moral obligation felt by an individual to perform a behavior - is an important immediate antecedent of behavior. Thus, personal norm has at times been perceived as similar to intention, be it only in the context of prosocial behavior (Fishbein et al., 2010). Others have suggested it to be an antecedent of attitude or an antecedent of intention (Kaiser, 2006; Parker, Manstead, \& Stradling, 1995). Other distinguishing features of NAM are the roles awareness of consequences (AC) and ascription of responsibility (AR) play in explaining helping behavior. The former refers to consequences to the welfare of others, whereas the latter is defined as a capability to control the relevant action and its outcomes. In other words, AC is conceptually similar to a subset of Fishbein and Ajzen's (instrumental) behavioral beliefs (i.e. those that refer to the welfare of others), whereas AR is a combination of perceived behavioral control and instrumental attitude.

As proenvironmental behavior is often seen to be motivated by the common good, the ValueBelief-Norm Theory (VBN) integrated Dunlap and Van Liere's scale of environmental concern, the New-Environmental Paradigm (NEP), with the NAM to create a model of proenvironmental behavior (Stern et al., 1999). VBN is thus an even more domain-specific model than NAM. Its main appeal is in its attempt to explicate the link between distal determinants- namely values and environmental concern to that of the more proximal NAM determinants of behavior.

\section{Comparative and integrative models}

The truth usually lies somewhere in the middle. More recently, researchers have therefore attempted to compare or integrate the various models. The work described in this thesis has followed this recent trend and has used an extended version of the TPB, including personal norm and habit, as its general theoretical framework. 
As noted earlier, the models used for explaining proenvironmental behavior not only differ in what they assume to be the primary motivation for people to engage in these behaviors, but also in their degree of specificity. This has implications for the comparability of the models. Considering that the reasoned action approach is a generic framework, its relative success to account for behavior is heavily dependent on whether the relevant beliefs are identified and measured. If TPB has less explanatory power than VBN, the superiority of VBN can only be established if it is indeed reasonable to assume that all important relevant beliefs have been taken into account - which is frequently not the case (Fishbein et al., 2010). Correct measurement is obviously also a concern for VBN, but the theory provides more concrete guidelines than the TPB, which recommends pilot work to identify relevant beliefs. Furthermore, although the reasoned action approach has often been interpreted as a rational, self-interest model of behavior, the framework has not been intended as such and is general enough to allow for other motivations (Fishbein et al., 2010).

Bearing these caveats in mind, it is telling that the TPB has fared well in explaining proenvironmental behaviors compared to VBN (Kaiser, Hubner, \& Bogner, 2005). Also because the TPB is the most general framework, attempts to integrate the models have therefore naturally taken TPB as the basic model, adding personal norm, or moral norm, as an additional variable.

Results of such integrated models are mixed. Some have found personal norm to account for additional explained variance (Abrahamse \& Steg, 2009; Bamberg, Hunecke, \& Blobaum, 2007; Harland, Staats, \& Wilke, 1999). Others found that the addition of a personal norm variable did not add to the total explained variance of the behavior because moral norms seemed to be reflected in people's attitude (Kaiser \& Scheuthle, 2003).

Closer inspection of the attitude measures used in the studies that found personal norm to be an independent significant predictor revealed that these were general (i.e. "bad"-"good") or experiential attitude measures (e.g. "unpleasant"-"pleasant"). Although the distinction between experiential and instrumental attitude may be blurred, the measures used in these studies only refer to the personal consequences of performing proenvironmental behaviors. In contrast, attitude measures in the study that found moral norm to be reflect in attitude, also contained measures that could be interpreted as normative (i.e. "inappropriate"-"appropriate").

Thus, depending on the composition of attitudinal measures, we can expect personal norm to be a component of attitude or an independent predictor. What all the studies discussed do have in common is that environmental concern, or moral concern, was found to be a relevant determinant of behavior. For the sake of parsimony, it may be advisable to incorporate moral concern in the attitude concept, although further empirical research should determine whether this is indeed desirable.

\section{The role of context}

So far, we have reviewed theoretical models of psychosocial determinants that can influence proenvironmental behavior. One question that remains unanswered is what affects these psychosocial determinants and possibly behavior itself. These could be personal characteristics or external factors. With regard to personal or sociodemographic characteristics, it is for instance known that income largely determines differences in total energy consumption and expenditure per consumer category (e.g. transport, heating, food etc.) due to a positive relationship between income and opportunities to consume (Moll et al., 2005). One obvious implication is that results of empirical studies on proenvironmental behavior should not be generalized across samples with different personal characteristics. 
The list of external or contextual factors is obviously endless, with many influences on the interpersonal, regional, national, and global level that may affect individuals' energy consumption in some way. A discussion of all such influences is clearly out of the scope of this thesis. Nevertheless, it remains important to acknowledge the role external and contextual factors play in proenvironmental behavior. Results of empirical studies on psychosocial determinants of proenvironmental behavior may largely depend on these factors. Even when we consider a single individual, this person may not behave the same in different contexts.

One contextual change that many people encounter on a day-to-day basis is that between home and work. In private household contexts, proenvironmental behavior have been studied relatively extensively (for reviews see Abrahamse, Steg, Vlek, \& Rothengatter, 2005; Bamberg \& Moser, 2007; Uitdenbogerd et al., 2007). In contrast, little research has addressed energy use in organizations at the individual, behavioral level of analysis (Bansal \& Gao, 2006). Previous research on organizations and the environment has mainly investigated the effects of external determinants and organizational characteristics on organizational engagement with environmental sustainability (Etzion, 2007).

Thus, it is unclear how organizations influence individual behavior. First, the question whether organizational influences on behavior are mediated through known psychosocial determinants - as is contended by the TPB - needs to be addressed (Fishbein et al., 2010). If so, further questions can be asked about the mechanisms through which this occurs. Do differences in context change the relative importance of psychosocial determinants? Do they affect the strength of relevant beliefs? Or do they affect the weight of specific beliefs relevant to each psychosocial determinant? Second, what organizational characteristics are most relevant to the understanding of proenvironmental behavior at the workplace? Answers to these questions could facilitate the development of more targeted behavior change interventions in (organizational) contexts. It is for these and other practical, environmental reasons that this thesis will focus on proenvironmental behavior in organizational contexts.

\section{Organizations: energy facts and figures}

As noted previously, relatively little research has been conducted on proenvironmental behavior in organizations. One possible concern is that this paucity of research is actually reflecting low energy saving potentials. According to the Dutch National Institute for Public Health and the Environment (RIVM), industry accounts for over $50 \%$ of the total national energy consumption, followed by transport $(17 \%)$, households $(17 \%)$, the tertiary sector consisting of the trade, services, and governmental sectors $(12 \%)$, and agriculture (5\%) (van Dril \& Elzenga, 2005). A more recent RIVM report revealed that although not the largest energy consuming sector - the tertiary sector did show the largest energy saving potential when considering their share in building- and transport-related energy consumption (de Groot \& Morgenstern, 2009).

Thus, it seems that industry energy saving is worthwhile due to its sheer proportion in total energy use, whereas tertiary sector energy saving is interesting because of the high saving potential. For the purposes of comparing the private household and work contexts, however, studying the tertiary sector may provide more meaningful comparisons. Firstly, industry energy use is largely influenced by organizational decision-making of a select group of professionals and may not lend itself to large-scale survey research of social-cognitive determinants. A comparison, with research methods and general theoretical framework kept constant, may thus not be possible or desirable. Secondly, in Western societies, the working population of the tertiary sector is larger than that in other sectors. For comparing 
the effect of context on individuals in general, this working population is more representative of the general population who are targeted in household research.

Within the tertiary sector and the working population more generally, it appears that most people do office work. According to Statistics Netherlands (CBS), in 2009, employees spent on average 3.8 hours a day behind a (computer)screen for work-related purposes. If the average Dutch employee spends roughly half his working day doing computer-based work, it is plausible that office-based jobs are the most prevalent form of employment. This is even more so, if one assumes that employees who reside full-time in an office environment spend a substantial amount of time away from the computer as well. In contrast, only $18.2 \%$ of Dutch employees indicated to use substantial physical force at work on a regular basis (Statistics Netherlands [CBS], 2010). It is for these and aforementioned reasons that the empirical studies described in this thesis will focus on office workers as the target group.

\section{Theory and practice}

\section{Rationale for a research focus on determinants}

The practical aim of this thesis is to use theory and empirical findings of determinants of energy-related behaviors to inform practice, and more specifically behavior change interventions. In order to achieve this aim, we followed the Intervention Mapping (IM) protocol, which contains guidelines for the development of theory- and evidence-informed interventions (Bartholomew, Parcel, Kok, Gottlieb, \& Fernández, 2011). Perhaps most importantly, IM emphasizes the importance of examining the determinants of the target behavior in the relevant context before designing and implementing an intervention.

An additional, practical reason for laying emphasis on research of determinants, is that individuals prefer small measures spread over different categories of activities (Uitdenbogerd et al., 2007). Thus, if the total energy consumption is the practical concern, a comprehensive set of measures should be considered rather than a selected few. Furthermore, it is highly likely that the effect of a change in any one specific behavior out of countless energy-related behaviors would have a low to insignificant impact on total energy consumption (Abrahamse, Steg, Vlek, \& Rothengatter, 2007; Staats, Harland, \& Wilke, 2004). Within the scope of our research project, however, it was not possible to develop an intervention which targeted many different energy-related behaviors in the workplace. Also for this reason, we preferred to focus our research on determinants of a wide range of energy-related behaviors.

\section{Intervention Mapping}

On a practical level, IM specifies the steps that need to be taken in order to develop an intervention. It describes an iterative path from problem identification to problem solving or mitigation. In total, six steps are distinguished but only the first two are relevant for understanding the overall rationale behind the determinant-focused research project described in this thesis. The first step is a needs assessment. This comprises an analysis of the problem, its consequences, behaviors that are related to the problem and relevant external conditions. In the case of energy consumption, no elaborate analysis of the desirability of its reduction is needed given the well-known environmental issues associated with it. However, it is less clear what the relevant behaviors in an organizational context are, and how external factors influence these. 
It logically follows, that for research purposes, the needs assessment required us to perform three tasks. First, we needed to estimate the potential energy savings in organizations and identify relevant energy-related behaviors. For this, we consulted energy advisors and environmental scientists who directed us to relevant information sources. Second, we needed to avoid reinventing the wheel. Further research on the determinants of energy conservation would have been redundant if previous work proved to be sufficient for designing interventions. Therefore, our second research task was to conduct a systematic literature review of research on proenvironmental behaviors in organizational contexts. Third, we needed to familiarize ourselves with external factors and specific organizational features that may play a role in energy-related behaviors of the organizational members. A combination of interviews, informal communication, and examination of organizational reports and the physical environment of organizations provided relevant information for this task.

The second step prescribed by the IM protocol is the creation of performance objectives, which specify who should do what, and why they would do so. In other words, (a) target population(s), desirable behaviors, and the psychosocial and external determinants of these behaviors should be identified. For our research project, we therefore had to identify a target population, what behaviors were relevant for this population, and what determined whether they performed these behaviors. The first two tasks, identification of a target population and relevant behaviors could be accomplished at the same time as the second and third task of step one, the needs assessment. For the third and last task, gaining an insight into the determinants of relevant behaviors, we conducted empirical studies that are the subject of the bulk of this thesis.

\section{Thesis Overview}

This thesis presents a collection of research papers on energy-related behaviors in organizational contexts. First, a literature review of determinants of and interventions for energy-related and other proenvironmental behaviors in organizations is given in Chapter 2. In all subsequent chapters, empirical studies which have been conducted among office workers of organizations from different sectors and regions are presented. Two chapters describe qualitative studies on determinants of energyrelated behaviors. Chapter 3 presents an analysis of determinants of energy use in the office building. A methodologically similar analysis of work-related travel behaviors is described in Chapter 4. Building on the empirical findings of the two preceding chapters, the next three chapters present quantitative studies which compare a model of individual determinants of energy-related behaviors between organizational contexts. The results in relation to energy-related behaviors in office buildings, commuting behaviors, and business travel behaviors are described in Chapter 5, Chapter 6, and Chapter 7 respectively. Chapter 8 concludes with a general discussion of results presented in the preceding chapters. 



\title{
Chapter 2: \\ A Review of Determinants of and Interventions for Proenvironmental Behaviors in Organizations ${ }^{1}$
}

\begin{abstract}
Introduction
Organizations are increasingly involved in environmental sustainability issues, as part of their organizational strategy, perceived organizational responsibility or both. Most research on this subject has addressed environmental performance on the aggregate, organizational level (for recent reviews see Bansal et al., 2006; Etzion, 2007). Concrete, individual behaviors that contribute to environmental performance are often not researched, and generally there is an emphasis on the (top) management. However, an understanding at the behavioral level of analysis may be essential to a better understanding of the precise mechanisms that underlie aggregate environmental performance. Since there is currently no overview of research on proenvironmental behaviors in organizational contexts, the aim of the present paper is to provide a critical review of the state-of-the-art in order to identify research gaps and inform future research. The term organizational proenvironmental behavior will be used as shorthand for proenvironmental behavior in organizational contexts.

Generally speaking, a distinctive feature of proenvironmental behaviors is that they are probably best viewed as motivated by a combination of self-interest and concern for others and the environment. This is reflected in research efforts to integrate self-interest and moral concern in theoretical models of proenvironmental behavior (e.g. Bamberg, Hunecke et al., 2007; Kaiser, 2006). To be more specific, concepts related to moral concern, such as personal norm from the Norm-Activation Model (NAM) of prosocial behavior, were incorporated into a Theory of Planned Behavior (TPB) framework (TPB: Ajzen, 1991; NAM: Schwartz, 1977).

In contrast to organizational proenvironmental behavior, environmental behavior in individual and household contexts has been more systematically researched and synthesized (Abrahamse et al., 2005; Bamberg \& Moser, 2007; Uitdenbogerd et al., 2007). Unfortunately, the research on household energy-conservation and other proenvironmental behaviors cannot be easily generalized to organizational contexts. As argued similarly by S. Siero, Boon, Kok and Siero (1989), at least two considerations need to be taken into account. Firstly, costs arising out of consumption are usually borne
\end{abstract}

1 This chapter will be published as:

Lo, S.H., Peters, G.J. \& G. Kok, A Review of Determinants of and Interventions for Proenvironmental Behaviors in Organizations, Journal of Applied Social Psychology, in press. 
more directly by household members than users in organizations. This may imply different motivations to consume or conserve resources within the two contexts. Secondly, an organization's size, structure, goals, culture, market positioning and other organization-specific influences might form additional obstacles to, or opportunities for behavioral modifications. Having said that, the research on households can provide insights into relevant individual determinants, which may be reinforced or attenuated in the organizational context. These individual determinants either originate from general social psychological literature or share similarities with broader social psychological concepts. In order to enable comparison of proenvironmental behavior across different contexts and with other organizational behaviors, general social psychological concepts used in the household and individual contexts (i.e. intentions; attitudes; beliefs; personal norms; social norms; self-efficacy; past behavior; habit) will be used as a framework to organize the findings on individual-level determinants. For organizational-level determinants, a distinction between general and environment-specific determinants will be made.

The focus of this review will be on organizations in the secondary and tertiary sector. Primary sector activities are related to nature in a very direct, and sometimes idiosyncratic manner, so that primary sector organizations may be less representative for organizations in general. In addition, environmental organizations (i.e. public agencies, NGOs, and businesses whose primary organizational aim is to contribute to environmental sustainability) are excluded. Since their primary aim is to contribute to environmental sustainability, these organizations are also unrepresentative. Furthermore, the review focuses on empirical evidence. Except for reviews, articles were only included if they reported original empirical analyses. To be more precise, articles were excluded if no new analysis of data was presented, but included if they conducted a different analysis on a dataset which had been analyzed before. Finally, only studies that report behavior, intention or both measures are included in the analysis. Excluding studies which only have a measure of intention would lead to a bias of examining familiar behaviors whereas relevant novel behaviors would be excluded.

\section{Methods}

\section{Selection Procedure}

Relevant literature was collected through searches, and iterative applications of ascendancy and descendancy approaches in the PsycINFO and Web of Science databases. In other words, the bibliography and articles citing the relevant articles that were found in the database search were used to identify further relevant articles. The database search aimed at identifying all articles with (synonyms of) "environment" and "behavior" in the same sentence in the title, abstract or subject field. In addition, (synonyms of) "determinant" and "organization" had to be present in the same field. (See Appendix A for more details on the search).

\section{Evaluation Criteria}

The following set of hierarchically-applied exclusion criteria was used to obtain relevant articles:

1. Not about proenvironmental behavior

2. Not about the determinants of proenvironmental behavior 
3. No original empirical data analysis reported; review articles were exempted from the application of this exclusion criterion

4. Not organizational context: the behavior of interest does not take place within an organizational context

5. Not the right target group: the population examined is not working (i.e. pupils or students), related to the primary economic sector, or has environmental sustainability as their main organizational goal

6. Not concrete behavior: the dependent variable is not measured on the level of (aggregate outcomes of) concrete behavior; for review articles: no discussion of the behavioral level of analysis.

The classification process stopped as soon as an article fit an exclusion criterion. Included articles were divided into four types of studies for comparative purposes. Where possible, studies were quantitatively compared. For this, effect size measures (or statistics from which these could be derived) were needed as well as a study design and a dependent variable which were similar to those of the other studies. This resulted in four categories of studies (numbers between parentheses indicate the number of articles included in the category):

7. Relevant reviews (1)

8. Descriptive studies: studies with effect sizes of quantitative correlational data (7)

9. This category consists of cross-sectional survey studies or parts of studies with cross-sectional survey data which relied on self-report of respondents.

10. Intervention studies: studies with effect sizes of quantitative intervention data (6)

11. This category consists of intervention studies which conducted field experiments, with experimental or quasi-experimental designs.

12. Miscellaneous studies: not quantitatively comparable articles (7)

13. This category also includes studies or parts of descriptive or intervention studies which were not suitable for quantitative comparison due to the lack of effect sizes (see also under "analysis procedure" and Appendix B for the evaluation criteria used for each miscellaneous study).

For the descriptive studies, effect sizes were given qualitative labels according to Rosenthal (1996)'s and Kirk (2007)'s guidelines. For example, for Pearson's correlations, $r=.10$ is a weak effect size, $r=.30$ a moderate effect size, and $\mathrm{r}=.50$ a large effect size. In the remainder of this paper, comments on the magnitude of the effect size are always made based on these guidelines. The labels used are "small" or "weak", "medium" or "moderate", and "large" or "strong". The qualitative labels of effect sizes will be used throughout the discussion of the results; the precise effect size statistics will be reported in the tables.

Each set of studies was further classified according to the environmental aim (e.g., energy conservation or recycling) and the type of behavior ("investment" vs. "repeated" behaviors). Investment behaviors are here defined as one-shot behaviors whereas repeated behaviors are performed on a more regular basis (cf. Uitdenbogerd et al., 2007). The distinction between these types of behaviors is important because the determinants and the effectiveness of interventions differ across two related but distinct dimensions, namely that of the repetitiveness and habit strength of the behavior of interest (Verplanken et al., 2003). Research has shown that habitual behaviors differ in their determinants from less ingrained behaviors (Aarts et al., 2000; Wood et al., 2005). As the studies reviewed did not measure the degree to which repeated behaviors were habitual, it is only possible to 
assume that habit may have affected the repeated behaviors but should not influence investment behaviors.

Most studies targeted the whole organizational population. Where specific organizational subgroups were targeted, this was systematically noted.

\section{Analysis Procedure}

Following the procedure described earlier, a total of 21 publications were included in the review, 13 of which were incorporated in quantitative comparative analyses. The only included review article was an overview of the type of studies on organizations and environmental sustainability published in management journals which noted that there were few studies which addressed the individual behavioral level of analysis (Bansal et al., 2006). No further information relevant within the scope of the current review was reported. The remaining 20 articles were independently reviewed by the three authors. Quantitatively measured variables were categorized and relabeled based on the three reviewers' analyses. This relabeling of variables was necessary for comparative purposes because some studies used different terminology but were in fact referring to conceptually similar variables or vice versa. Authors of the original studies were contacted whenever there was uncertainty about either the original measurements or reverse coding of an item. The analysis was adapted if the original authors provided additional information. Where possible, effect sizes of bivariate analyses were calculated from other statistical information if effect size statistics were unavailable (Marans \& Lee, 1993; Ramus \& Steger, 2000). Finally, determinants were checked for their degree of correspondence with the dependent variable. The degree of correspondence is important, because whenever the level of specificity between the two variables differs, one can expect a smaller effect size than if the variables had been measured on the same level (cf. TPB's principle of compatibility: Ajzen \& Fishbein, 2005).

\section{Results}

The results will be presented per type of determinant or intervention. The evidence from intervention studies will not be discussed in conjunction with that of specific determinants when it is uncertain which determinants are targeted by the intervention. Evidence of miscellaneous studies can be concerned with either determinants or interventions - these will be presented where appropriate. Quantitative results and qualitative labels of the effect sizes for the descriptive studies and intervention studies are presented in Table 1 and Table 2 respectively. Unless explicitly stated otherwise, all the reported relationships between variables are in the anticipated, usually positive, direction. An overview of the descriptive studies and intervention studies is presented in Appendix C and Appendix D respectively. 


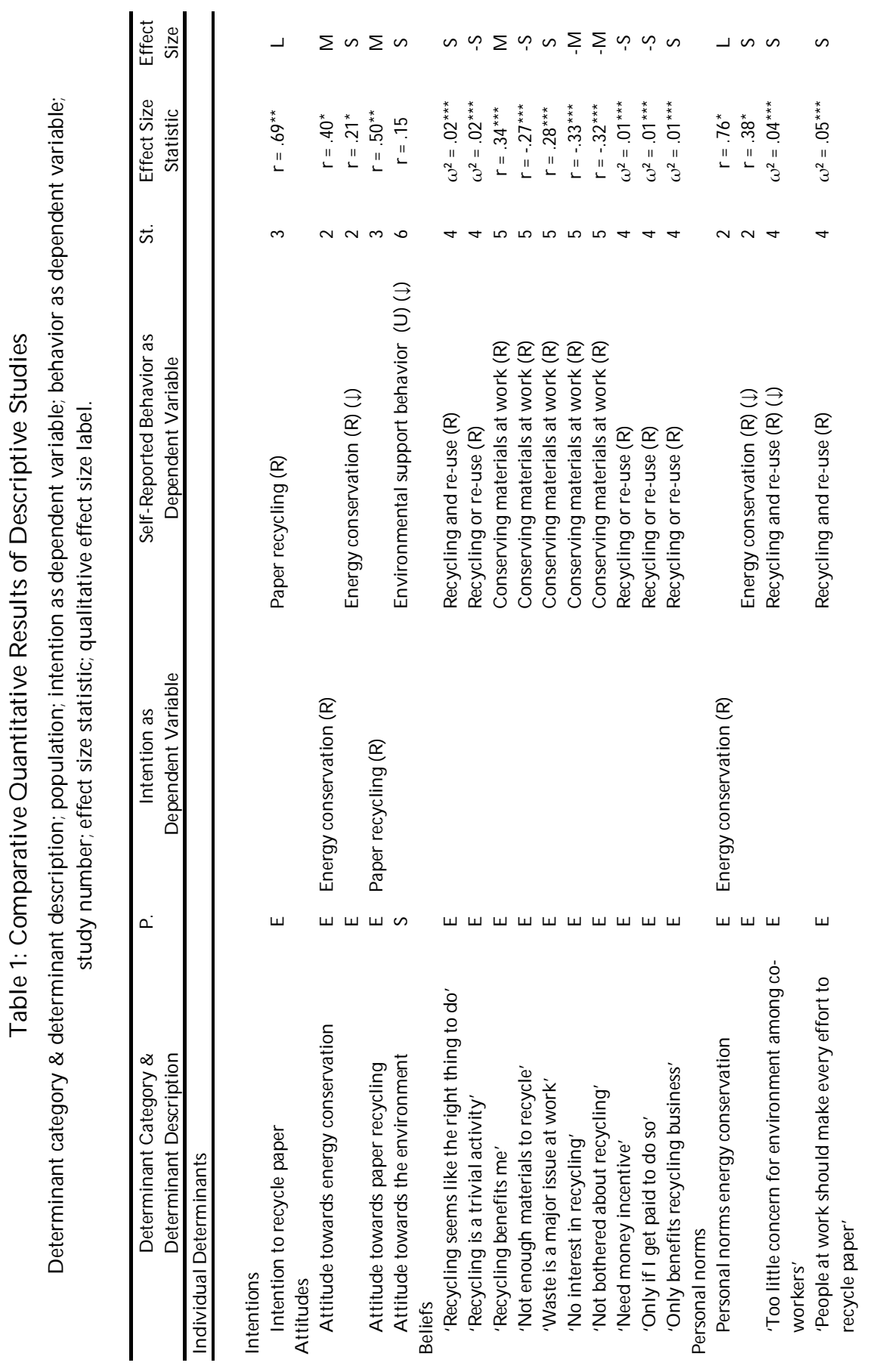



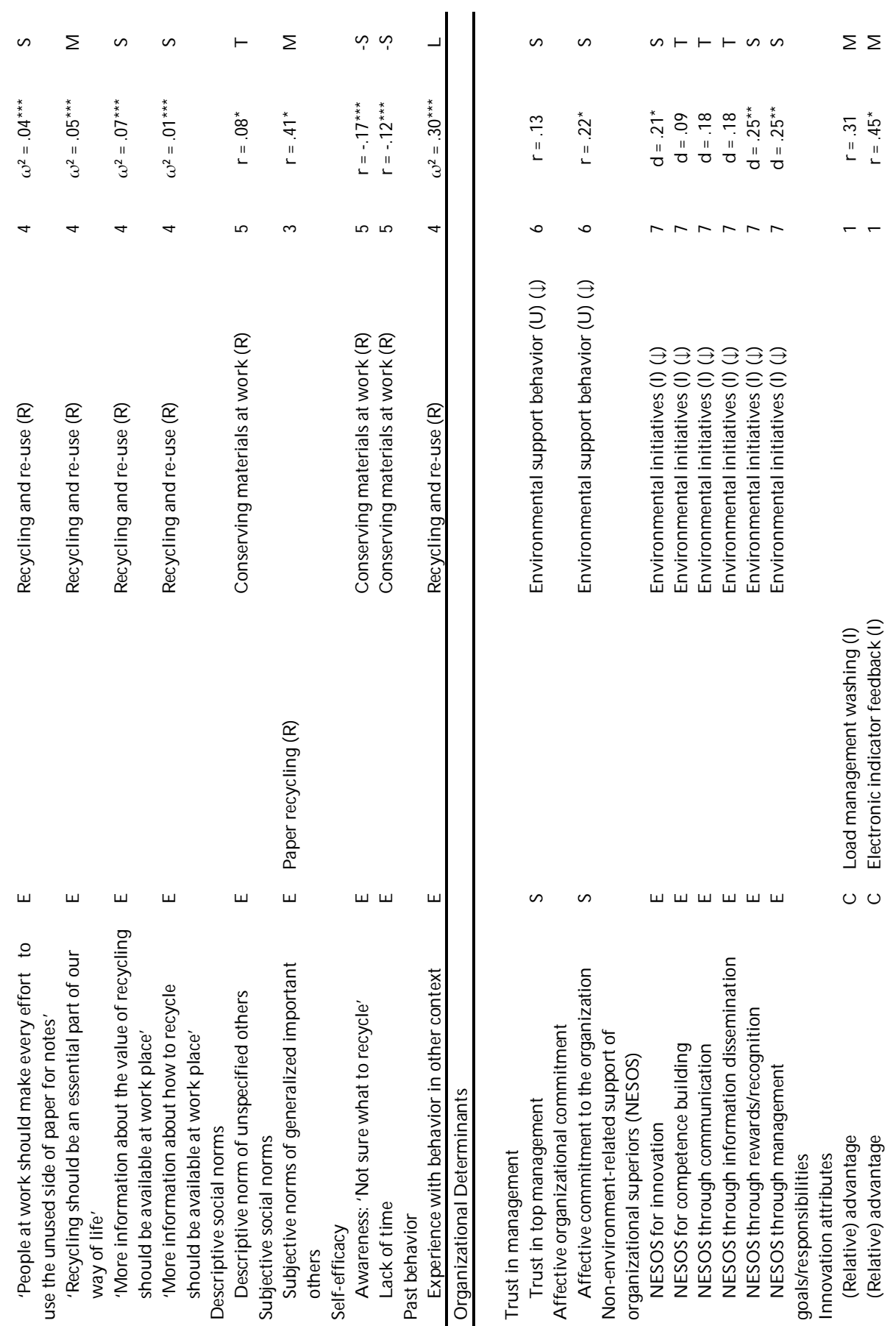

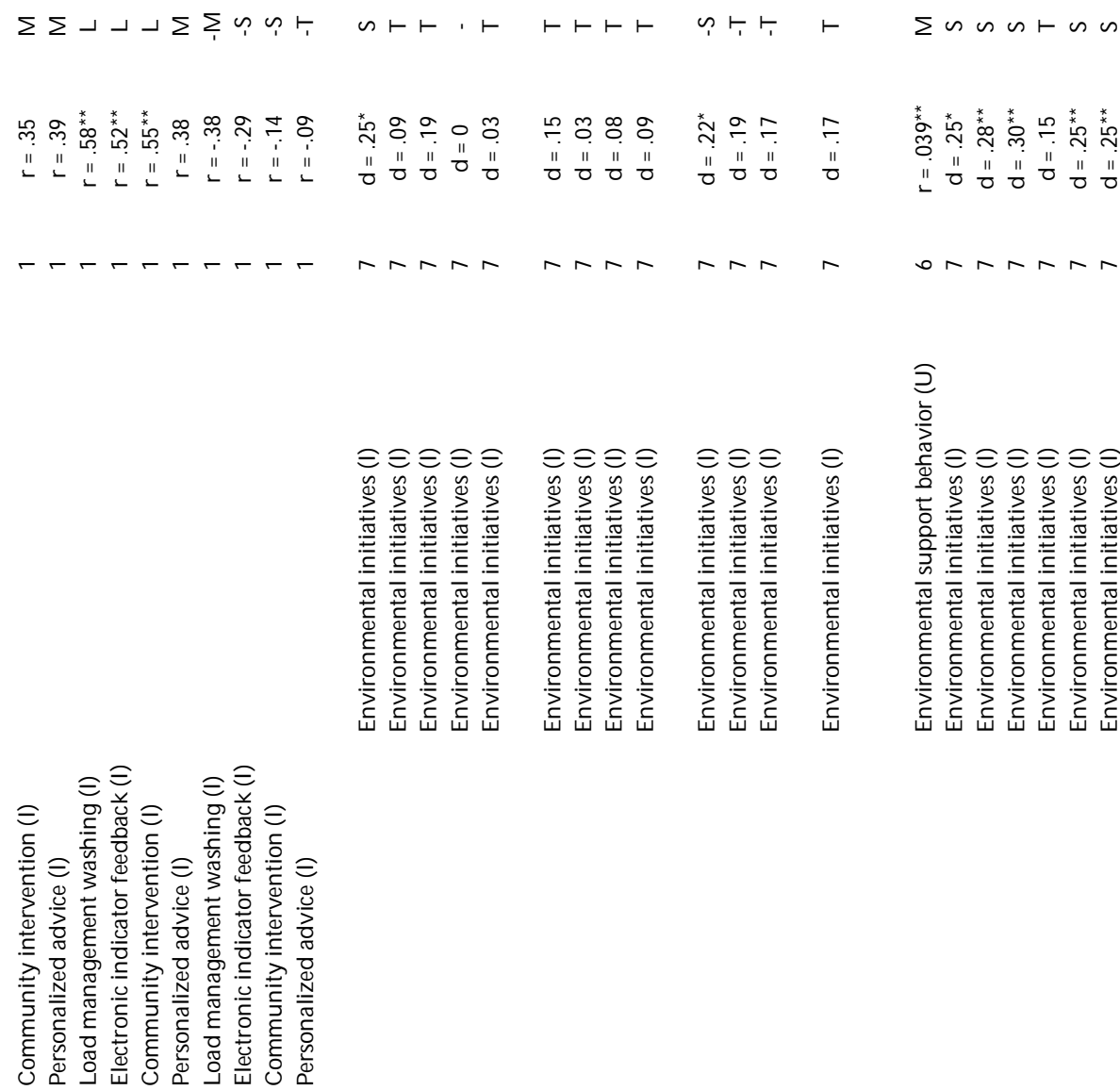

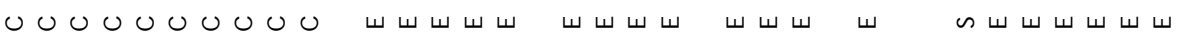

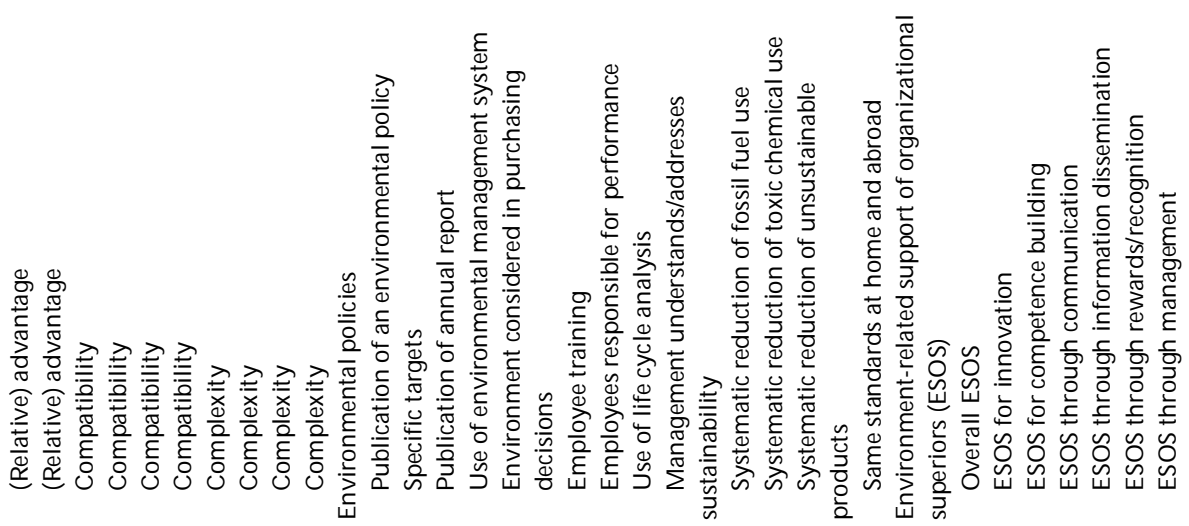




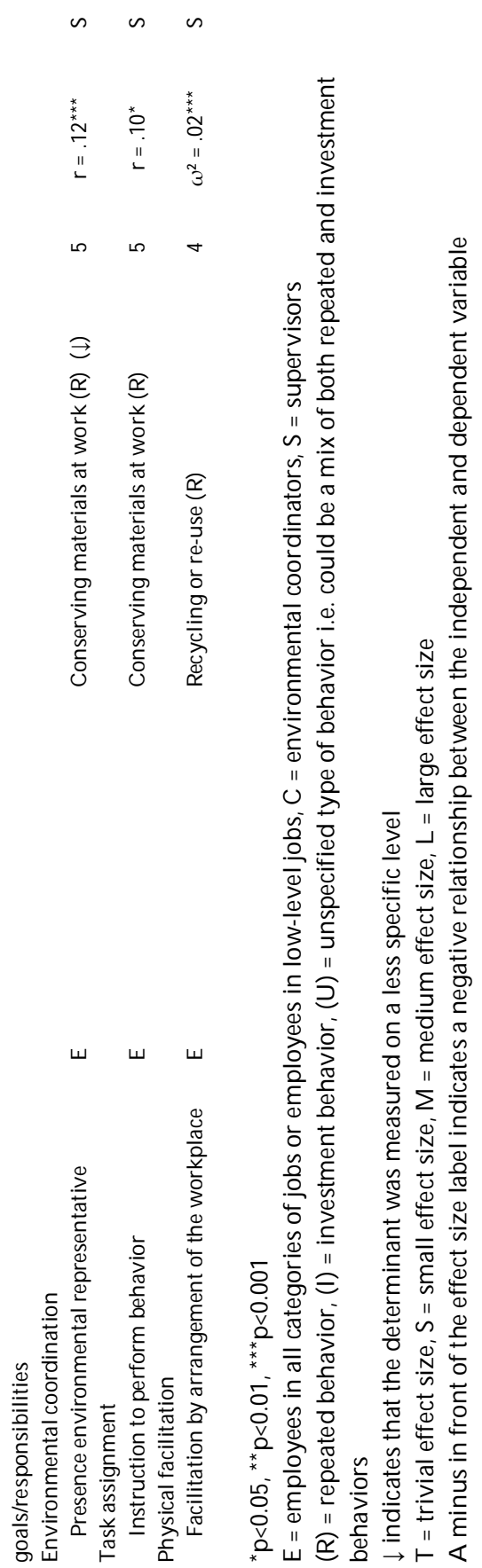




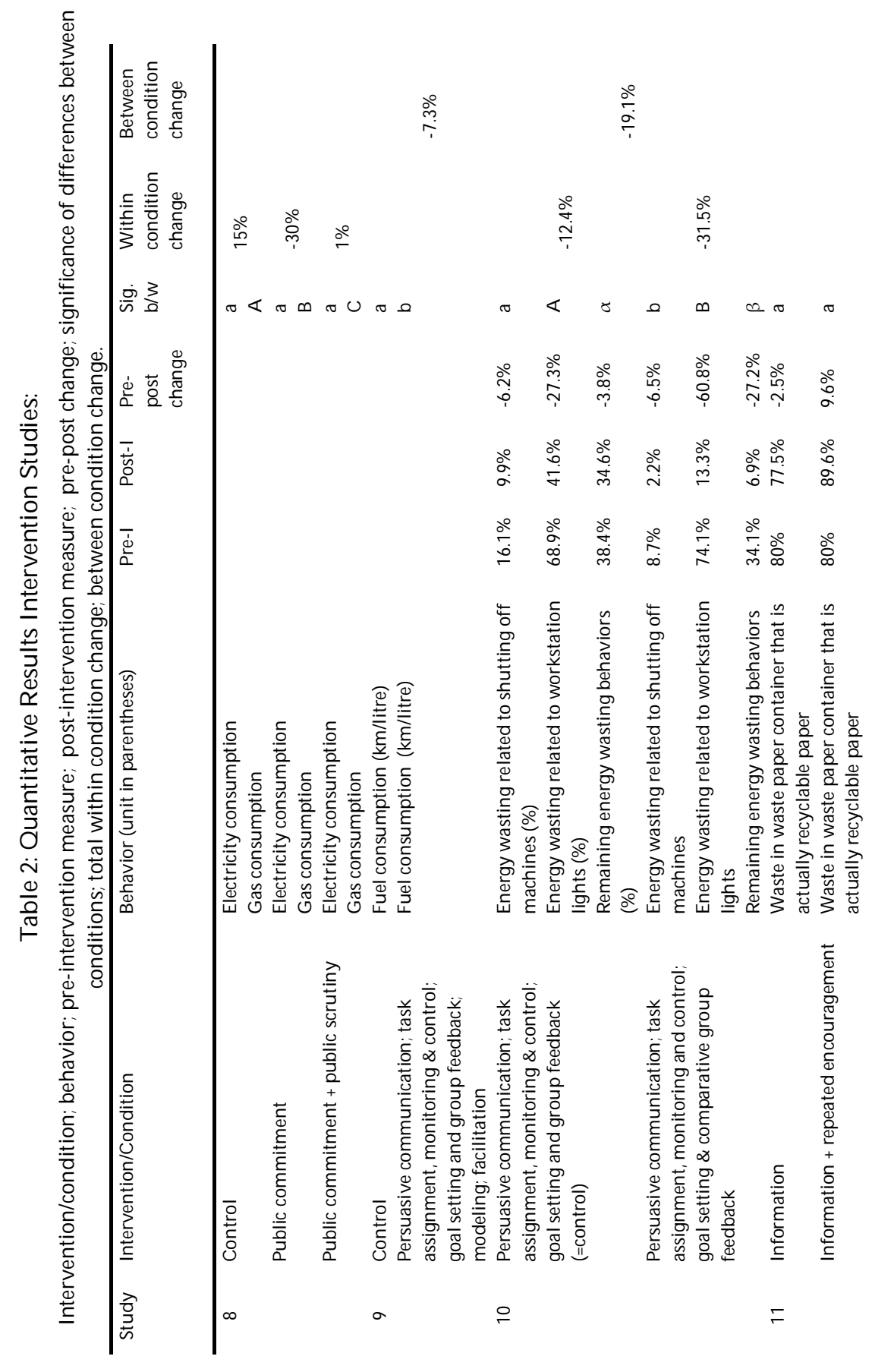




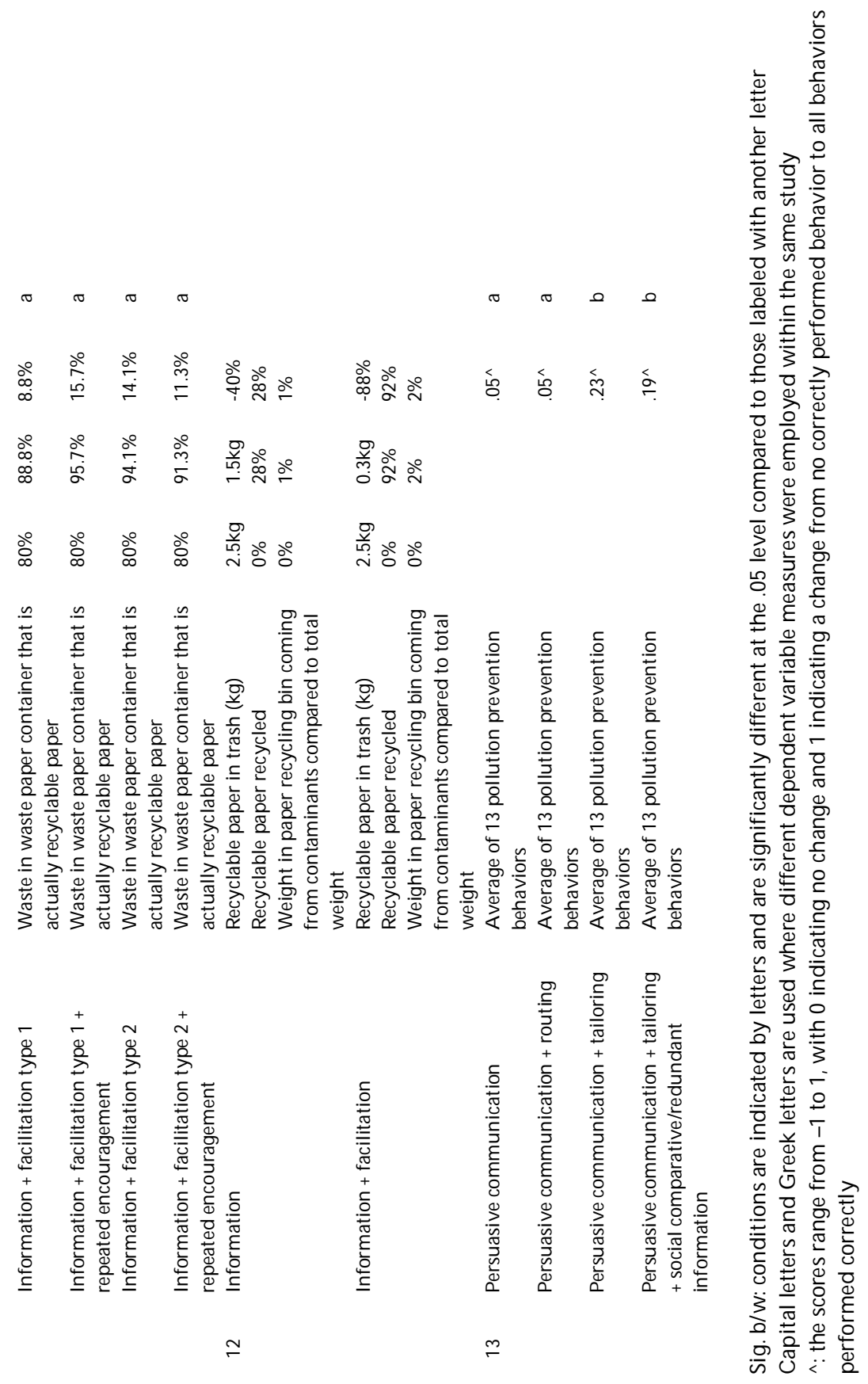


We found only two studies which examined an investment behavior. Therefore, all behaviors discussed are (partially) repeated behaviors, unless stated otherwise.

\section{Individual Determinants}

Individual determinants are here defined as determinants which bear a direct relationship with the individual respondent, but which do not directly refer to the organizational context.

\section{Intentions}

Only one descriptive study investigated the relationship between intention and behavior. Intention to recycle paper was indeed strongly correlated to self-reported paper recycling (Jones, 1990).

\section{Attitudinal determinants}

Attitudinal determinants were divided into three categories. "Attitudes" refer to the overall evaluation of a particular or set of environmental behaviors (Eagly \& Chaiken, 1993). "Beliefs" are concerned with a specific characteristic attributed to a behavior rather than an overall evaluation. "Personal norms" are defined as moral norms concerning one's own responsibility, which are composed of "personal normative beliefs" (Schwartz, 1973).

\section{Attitudes}

Attitudes were found to be moderately correlated with behavioral intentions, and weakly correlated to behaviors, which all available studies measured more specifically.

Attitudes towards paper recycling and energy conservation were moderately correlated to the respective behavioral intentions (Jones, 1990; Scherbaum et al., 2008). Among a population of supervisors and lower-level employees, attitudes towards energy conservation and the environment generally were weakly correlated to more specific behaviors (Andersson, Shivarajan, \& Blau, 2005; Scherbaum et al., 2008).

\section{Beliefs}

The findings for beliefs were far less consistent, with effect sizes ranging from trivial to large.

Respondents' interest and perceived personal benefit to perform the behavior were moderately correlated to recycling behavior (Tudor, Barr, \& Gilg, 2007). In another study, however, respondents' value judgment of and perceived usefulness of recycling behavior were only weakly correlated to recycling behavior (Marans et al., 1993). In this same study, beliefs about the quantity needed for recycling to be useful and need for economic incentives to recycling were also weakly negatively correlated to behavior. In contrast to economic motivations, intrinsic satisfaction was found to be positively correlated to recycling behavior, but effect sizes could not be obtained (Lee \& DeYoung, 1994). Finally, some but not all positive beliefs about a thrifty driving style were positively correlated to thrifty driving behavior among van drivers, but no effect sizes were available (Siero et al., 1989).

Some studies point out the role interactions play in explaining these diverse findings. This is illustrated in an experiment with hypothetical scenarios, where the belief "severity of consequences", the independent variable, was found to significantly interact with other predictors of pollution management decisions - an investment behavior (Flannery \& May, 2000). The more severely the environmental consequences were described, the less influence TPB variables had on environmental 
decision-making. Furthermore, organization-related beliefs also showed significant interactions with adoption of energy innovations, which is also an investment behavior (Völlink, Meertens, \& Midden, 2002). See "innovation attributes" under "Organizational Determinants" for further information.

\section{Personal norms}

The effect size of personal norm varied according to the degree of correspondence between personal norm and the dependent variable, and whether the dependent variable was intention or behavior.

Personal norms regarding energy conservation were strongly correlated to energy-conservation intentions (Scherbaum et al., 2008). More specific recycling norms about recycling were weakly correlated to recycling behavior. Broader recycling norms, which matched the level of specificity of the reported behavior, were moderately correlated to recycling behavior (Marans et al., 1993).

\section{Social Norms}

Social norms can be subdivided into injunctive and descriptive norms. Injunctive social norms are concerned with the perceived (dis)approval of others, whereas descriptive social norms refer to what others do rather than think (Nolan, Schultz, Cialdini, Goldstein, \& Griskevicius, 2008).

The evidence available is too limited to draw any general conclusions. However, the available findings might suggest areas for further investigation:

One study found a moderate effect of subjective norms of unspecified important individuals on intended paper recycling (Jones, 1990). Another study reported a significant but trivial correlation between a descriptive norm measure, which did not specify who the "others" were, and waste management behavior (Tudor et al., 2007). Interestingly, qualitative findings of S. Siero et al.(1984) suggest that it might not only be the content of the prevailing social norms that influences environmental behavior, but also the lack of clear social norms.

\section{Self-Efficacy}

Self-efficacy measures are related to whether one perceives to have the necessary resources, knowledge or skills to perform the desired behavior (also known as "perceived behavioral control" in TPB, Ajzen, 1991).

Tudor et al.(2007) incorporated two self-efficacy variables in their study. Lack of knowledge about what to recycle and perceived time constraints showed a weak negative correlation with waste management behavior. Somewhat contradicting these findings, Cordano and Frieze (2000) found a negative significant relationship between perceived behavioral control and environmental managers' preference for implementing source reduction activities in the future. This might be due to the fact that preference rather than intention or behavior was the dependent variable. Since self-efficacy is about the perception of control over one's behavior, it probably does not make sense to link self-efficacy to preference, which is in principle not subject to external constraints. Finally, related to self-efficacy, $\mathrm{S}$. Siero et al. (1984) found qualitative evidence that forgetfulness was a reason for failing to conserve energy for office workers.

\section{Past Behavior}

Relevant past behavior is arguably also linked to self-efficacy. Past behavior can either contribute to self-efficacy via learning effects or function as an indicator of past self-efficacy. 
Experience with recycling in a household context was found to have a large effect on recycling in offices (Marans et al., 1993). However, the effect of experience with recycling one type of material did not generalize to other recycling and waste management behaviors (Lee, DeYoung, \& Marans, 1995). Finally, in contrast to their findings regarding perceived behavioral control, Cordano and Frieze (2000) did find a positive relationship between past behavior and environmental managers' preference for implementing future source reduction activities.

\section{Organizational Determinants}

Organizational determinants are those which explicitly refer to the organizational context. These can be either objective or subjective determinants. Objective determinants are independent of individual respondents' perception, whereas subjective determinants are concerned with individuals' perception of (an aspect of) the organizational context.

\section{General Organizational Determinants}

Overall, organization-related determinants that are not specifically related to environmental sustainability have weak effects on organizational proenvironmental behavior.

In a population of supervisors, Andersson et al. (2005) looked at the effect of general trust in management and respondents' affective commitment to the organization on supervisory environmental support behaviors. Weak effects were found for both factors but only affective commitment reached significance. Ramus and Steger (2000) also found that some forms of general support of organizational superiors for employee initiatives had small, significant effects on the likelihood of employees undertaking environmental initiatives -which was defined an investment behavior. Qualitative evidence indicates that organizational determinants which are less easily quantifiable such as organizational culture, organizational structure, and organizational focus (i.e. what are considered core activities) are nevertheless crucial to a real understanding of the behaviors of interest (Tudor, Barr, \& Gilg, 2008).

\section{Environment-Related Organizational Determinants}

The effects of organizational determinants that specifically relate to proenvironmental behavior vary widely. Two factors that have consistently been found to affect organizational proenvironmental behavior are environment-related involvement of superiors and physical facilitation of proenvironmental behavior. Furthermore, the relevance of interactions involving beliefs to understanding organizational proenvironmental behavior is further underscored by research on innovation attributes of environmental innovations.

\section{Innovation attributes}

Adoption of environmentally-relevant innovations, such as new facilities and policies, usually occurs at the organizational rather than the individual level. Roger's Diffusion Theory postulates that the decision to adopt or reject an innovation is affected by five innovation attributes: observability, relative advantage, compatibility, trialability, and complexity (Rogers, 1995). Observability refers to the visibility of an innovation to potential adopters. Relative advantage is the degree to which an innovation is perceived as superior to the status quo. Compatibility of an innovation is the extent to which it is perceived to be consistent with the pre-existing culture and infrastructure. Trialability refers to the perceived possibilities to conduct a (small-scale) pilot. And finally, complexity is how difficult implementing and using the innovation is perceived to be. Thus, innovation attributes are perceptions 
of various features of an innovation that influence adoption decisions, and could therefore be viewed as beliefs on an organizational level. As discussed earlier, beliefs, regardless of whether they are individual-specific or organization-related, sometimes interact with other variables.

Examination of innovation attributes in the context of adoption of energy innovations - an investment behavior - shows that the "perceived compatibility" of an energy innovation with the preexisting socio-cultural context tended to have a large effect on the intention to adopt an energy innovation (Völlink et al., 2002). Other innovation attributes, "(relative) advantage", "complexity", and "trialability", were trivially to moderately correlated to adoption of energy innovations, and only "(relative) advantage" reached significance once. Völlink et al. (2002)'s analysis of qualitative interview data supports the idea of a stepwise decision-making process, where perceived advantage of an energyconserving innovation has a gatekeeper function. The qualitative evidence is supported by significant interactions between the innovation attributes "(relative) advantage" and "compatibility" for two out of four innovations, and could thus be one explanation why findings on the relevance of beliefs are inconsistent.

\section{Environmental policies}

In general, the presence of specific environmental policies did not have a significant effect on the likelihood of employees undertaking environmental initiatives, an investment behavior (Ramus et al., 2000). Only a significant, small positive effect was found for the presence of a general environmental policy. In contrast, policies which aimed at a reduction of fossil fuel use had a significant, small negative relationship with employee initiatives. However, this could be a statistical artifact caused by an underrepresentation of companies in the sample which actually had a fossil fuel reduction policy.

Related to policies, is the appointment of an environmental coordinator, which was found to have a weak positive effect on waste reduction behavior in a descriptive study (Tudor et al., 2007).

\section{Environment-related involvement of superiors}

Research on organizational environmental performance at the aggregate level has emphasized the role of leadership (Egri \& Herman, 2000; Fineman, 1996; Sharma, 2000). On the behavioral level of analysis, environment-related involvement of superiors had weak to medium effects on organizational proenvironmental behavior.

Most measures for environment-related support of superiors were found to be weakly to moderately correlated to (investment) organizational proenvironmental behavior in descriptive studies (Andersson et al., 2005; Ramus et al., 2000). Thus, environment-related support of superiors sometimes showed a stronger relationship to employee environmental initiatives than general support of superiors. Evidence from an intervention study also points towards the same direction, although the positive effect of repeated encouragement by supervisors did not reach significance here (Humphrey, Bord, Hammond, \& Mann, 1977).

A small, significant relationship was found between task assignment (i.e. superior's instruction) and waste reduction behavior in a descriptive study (Tudor et al., 2007). Furthermore, intervention studies suggest that task assignment, and monitoring and control by superiors had an impact on the effectiveness of interventions, although these elements were integrated in a bigger intervention package (Humphrey et al., 1977; Siero, Bakker, Dekker, \& vandenBurg, 1996; Siero et al., 1989). Qualitative findings also suggest that task assignment is important. S. Siero et al. (1989) noted that the direct 
influence superiors have over other organizational members via task assignment and control could have been crucial to the overall effectiveness of their energy-conservation intervention package.

Finally, the role superiors play in the overall success of a proenvironmental intervention is emphasized by qualitative evidence. Shippee and Gregory (1982) reported that electricity savings in shops investigated in their study were not achieved due to shop owners' perceived importance of display lighting to sales.

\section{Physical facilitation}

The effect of physical facilitation on organizational proenvironmental behavior ranged from small to large.

One descriptive study reported a weak but positive significant effect of physical facilitation on recycling (Marans et al., 1993).

In two intervention studies, facilitation of performance of the relevant behaviors has been found to increase recycling behavior (Brothers, Krantz, \& McClannahan, 1994; Humphrey et al., 1977). Facilities that made recycling more convenient showed effect sizes ranging from small to large, although no significant results were reported either because the effects did not reach significance or no significance tests were conducted.

\section{Legitimacy of environmental measures}

Finally, one issue that complicates the understanding of environment-related organizational determinants is the perceived legitimacy of organizational enforcement.

S. Siero et al. (1984) found that enforcement of energy-conservation measures was differently received by van drivers and office workers within the same company. Thus, it is possible that differences in perceived legitimacy of environmental measures cause diverse effects of an intervention on different populations.

\section{Interventions}

\section{Information, Persuasive Communication, and Tailoring}

Information provision usually serves two goals: correcting false beliefs and increasing behavioral competence (cf. the section on attitudinal and self-efficacy determinants). As information provision has often proven ineffective in mass media campaigns, the effect of tailoring information has been a major research interest in this field (cf. in the household context: Abrahamse et al., 2005; for evidence of the ineffectiveness of mass media campaigns, see e.g., Staats et al., 1996). Tailored information can be subdivided into antecedent information provision and feedback. Antecedent information provision is provided before the desired behavioral change, whereas feedback is provided after a behavior has been performed (Abrahamse et al., 2005).

Three of the five studies reviewed with antecedent information provision have examined the information needs and knowledge gaps of the target population beforehand (Daamen, Staats, Wilke, \& Engelen, 2001; Siero et al., 1996; Siero et al., 1989). All three studies were providing information which aimed at persuading the target group to change their behavior, if it was not environment-friendly. This "persuasive communication" was presented in a textual format, audiovisual format, or by means of a real-life demonstration. However, only one study actually tailored the information to the individual responses given at a pre-test, and compared this effect to the effect of information which was directed at 
the target population in general (Daamen et al., 2001). Higher degrees of tailoring of persuasive communication had larger effects on the behavior of interest. However, tailoring only worked when the information recipient received tailored information without actively engaging in tailoring themselves. Persuasive communication in the two other aforementioned studies was part of a larger intervention package, which overall had a significant effect on repeated energy-conservation behaviors.

The remaining two studies with antecedent information provision did not examine the information needs beforehand (Brothers et al., 1994; Humphrey et al., 1977). Both were recycling studies conducted in a single organization for which the persuasive communication was restricted to the location of recycling containers, which materials to recycle, and a written encouragement to participate in the organizational recycling scheme. No statistically significant results were reported, either because none were found or no significance tests were conducted.

Finally, qualitative findings support the importance of tailoring information. S. Siero, Boon, Kok, Siero and Veen (1984) found that lack of specific knowledge about the consequences of energy-relevant behavior, and how to perform the appropriate behaviors were important barriers to energyconservation behavior among van drivers and office workers. Humphrey et al. (1977) and S. Siero et al. (1989) reported similar qualitative findings.

\section{Goal Setting and (Group) Feedback}

Goal setting in combination with feedback to the individual or a group appears to have a positive influence on organizational energy-conservation behavior, but no studies were found in which the effect of feedback was isolated from other intervention components (Siero et al., 1996; Siero et al., 1989).

\section{Public Commitment and Public Scrutiny}

Only one study examined the effects of public commitment on organizational energy-conservation behavior (Shippee et al., 1982). Significant differences were found for public commitment with or without public scrutiny compared to a control group. However, the possibility to be exposed to public scrutiny of actual energy conservation performance was in fact associated with smaller effects than a mere public acknowledgement of participation (i.e. public commitment only).

\section{Social Comparison, Goal Setting and Comparative Group Feedback}

Social comparison has a larger effect when the comparison is made with another organizational subgroup than when it is made with general others.

Comparison with one other unit of the same company had a significant, moderate positive effect on energy-conservation behavior compared to a control group (Siero et al., 1996). In contrast, no significant effect was found for social comparison with generalized others (Daamen et al., 2001). The fact that the message with social comparison information was much longer than the message without this information might have been a confounding factor.

\section{Time and Relapse Effects}

Some evidence suggests that "relapse" phenomena are a major challenge to interventions targeting repeated environmental behaviors. One intervention study investigated the effect of time on the quality of recycling behavior and found that as time passes, contamination of recycling bins with nonrecyclable materials increased significantly in all conditions (Humphrey et al., 1977). 


\section{Discussion}

This review's aim was to provide an overview of research on proenvironmental behaviors in organizational contexts in order to identify research gaps and inform future research. For this purpose, we systematically reviewed empirical studies on the determinants of and interventions for organizational proenvironmental behavior. Given the heterogeneity and relatively small number of studies, generalizations and conclusions cannot be made easily. Nevertheless, the review shows relatively consistent effects across several studies for attitudinal determinants, and relevant past behavior. Differences in strength of association could largely be explained by differences in the degree of correspondence between the determinant and the behavior. For investment behaviors, interaction effects of specific beliefs with other determinants were frequently found. Moreover, superiors and physical facilitation have been found to play a role in organizational environment behavior.

\section{Evaluation of the Reviewed Studies}

Although there is some congruence of findings, the current understanding of the determinants of organizational proenvironmental behaviors is still far from comprehensive:

\section{Lack of Integrated Analysis between Individual and Organizational Determinants}

In particular, it remains unclear how the individual determinants interact with organizational determinants. Even though it appears that similar individual determinants influence proenvironmental behavior in both household and organizational contexts, the question how this influence differs between contexts remains largely unresolved. In other words, there is no systematic analysis of the interplay between individual and organizational determinants, with the exception of Tudor et al.(2007; , 2008)'s attempt at an integrated analysis. For instance, it would be interesting to know whether the effects of superiors' behaviors and physical facilitation on employees' proenvironmental behavior are (fully) mediated through individual determinants, and if so which. Related to this, is the fact that there were very few studies which compared subgroups of organizational members, despite the fact that possible contrasts could be at the core of the difference between environmental behavior in organizational contexts and other contexts (except: Shippee et al., 1982; Siero et al., 1984).

\section{Inconclusive Evidence: Individual Determinants}

There are insufficient studies that have examined the role of social norms in organizational proenvironmental behavior. Schultz et al.'s (2007) study on household energy consumption found that effects of social norms were weaker for self-report than real behavior measures. Given that only two cross-sectional survey studies investigated the role of social norms, there is insufficient evidence to support general statements concerning the role of social norms in organizational proenvironmental behavior. One issue that should be further examined is the possibility of absence of social norms having a negative influence on behavior (Siero et al., 1984). Admittedly, the perceived lack of social norms could signal that the issue in question is unimportant to the organization. Nevertheless, absence of a social norm does not necessarily imply a negative social norm. Thus, it may be interesting to compare the effects of mere absence of social norms with negative social norms.

Furthermore, self-efficacy needs further investigation. In effect, only one study examined its effect on behavior (Tudor et al., 2007). The lack of research on this determinant is particularly striking in the light of the number of interventions that focus on enhancing behavioral competence. 


\section{Inconclusive Evidence: Organizational Determinants}

Furthermore, the role of determinants such as various types of commitment, social comparison, innovation attributes, and organizational variables such as organizational culture and organizational structure is still hardly understood within the context of organizational environmental behavior. Findings in these areas are mixed or ambiguous. For example, while it cannot be denied that organizational culture and structure influence the reviewed behaviors, there is little that can be said in general about how they influence specific behaviors. The only study that has attempted to relate organizational culture and structure to organizational proenvironmental behavior is based on a case study of one organization (Tudor et al., 2008). Based on the findings of this case study, one can at most make an educated guess as to which findings are more widely applicable and which are more contextspecific. Admittedly, more precise concepts such as perceived support of organizational superiors for environmental sustainability are part of organizational culture (Andersson et al., 2005; Ramus et al., 2000). Nevertheless, they are only one relevant but small part of the construct named "organizational culture", and there may be many other relevant aspects of it that have remained under-researched.

\section{Study-Specific Limitations}

Several shortcomings and limitations were (repeatedly) found in the individual studies reviewed:

In relation to the intervention studies, the effect of interventions was often not easily interpretable.

One intervention study had several components which were implemented in one group which, as S.

Siero et al. (1989) noted, made it impossible to disentangle the effects of each component by itself. It is plausible that the combination of intervention components led to a significant difference, but there remains a possibility that some components did not contribute to the overall intervention effect. Another issue that was encountered were interventions, which were implemented consecutively on the same population (Brothers et al., 1994). Yet another problem was that the experimental manipulation involved a confounding variable (Daamen et al., 2001).

As mentioned earlier, one difficulty which was pertinent to descriptive studies was the modification of theories such as the TPB, sometimes with an explicit justification and other times without, which created difficulties for the interpretation and comparison of results (Cordano et al., 2000; Tudor et al., 2007). Related to this, is the use of alternative theories without comparing the findings to studies that employ a different theoretical perspective, or discussing the relative merits of competing theories (e.g. Scherbaum et al., 2008).

Another limitation is that most available evidence relies on self-report methods. Tudor et al. (2007) noted that despite the fact that there were high levels of self-reported recycling/waste management behaviors of certain materials, waste bin analyses still showed a high degree of contamination with recyclable materials. It is unclear to what extent this is evidence of false self-reports, but it does show that a discrepancy between self-reports and actual behavior may exist in this context.

Finally, with respect to the studies which had a substantial component of qualitative results, it was often unclear how the authors had arrived at their conclusions due to the incomplete description of the data collection and analysis methods (Siero et al., 1984; Tudor et al., 2008).

\section{Recommendations for Interventions}

Despite the limited available evidence, some general recommendations for interventions will be made based on two criteria. Firstly, findings of the effect of a determinant or intervention should be relatively consistent and strong. Secondly, the implementation of an intervention should be feasible. However, 
given that feasibility is very much context-dependent, interventions that are within the normal range of organizational measures will here be considered "feasible".

Interventions are most likely to be effective if organizations provide appropriate physical facilities, employ tailored persuasive communication, and actively engage middle management in the intervention. Some intervention studies have shown large effect sizes for physical facilitation. Providing physical facilities can be relatively straightforward and remove obvious barriers to implementing proenvironmental behavior. More so than in household contexts, employees are usually not responsible for the facilities available at work, so that providing adequate facilities may need more attention. Tailored persuasive communication focused on changing negative outcome beliefs and improving practical knowledge about the desired behavior has also proven to be effective. Such an intervention might benefit from existing channels of internal organizational communication for implementation. Finally, specifically targeting management to engage in proenvironmental efforts is likely to be effective. Although feasibility of implementation may vary widely between organizations, engaging middle management in organizational measures is obviously a routine organizational process.

\section{Future Research Directions}

Three major themes for future research emerge from the discussion above. Firstly, a more thorough integration of the analyses of individual and organizational determinants is desirable. The relationship between organizational determinants and behavior is a major challenge for future research as it has proven difficult to uncover the precise dynamics that underlie the influence of the former on the latter, and vice versa. As argued earlier, more research on the role of organizational subgroups could contribute to this aim. Another complementary way of tackling this challenge is a more extensive and rigorous use of qualitative methods. In fact, few studies have employed qualitative research at all. The reason for this lack of relevant qualitative research is probably the nature of the query and especially the criterion that it should be concerned with concrete behavior rather than aggregate organizational performance. As qualitative research is typically less structured than quantitative research, it is inherently tending towards describing the overall picture rather than the specifics. This is not to say that qualitative research cannot address concrete behaviors. In fact, it is more suitable for eliciting responses which provide contextualized examples of how various determinants together shape the behavioral outcome. Therefore, more use of qualitative methods in the future might contribute to the integration of the two levels of analysis, especially if employed in conjunction with quantitative methods, which are valuable for determining the magnitude of effect sizes.

Secondly, as hinted at earlier, despite the fact that interorganizational comparison is crucial to the generalizability of research findings, there are no studies on organizational environmental behavior which have integrated individual and organizational variables in their analysis and used more than one organization in their sample. Future studies should aim at addressing this need for interorganizational comparison in their efforts of integrating the analysis of individual and organizational determinants. Finally, studies should make more thorough use of previous research both as an informative and a comparative source so that research can fill knowledge gaps more systematically. Similarly, more comprehensive descriptions of research methods may support the optimal use of earlier research. 


\section{Appendix A: Search Details}

On 8 October 2008, the following search query was entered into PsycINFO via the Silverplatter WebSPIRS interface:

((environment* ${ }^{*}$ or ecolog* ${ }^{*}$ or energy*) NEAR (behavior* or behaviour $\left.{ }^{*}\right)$ WITH (determinant* or antecedent* or correlate $^{*}$ or attitude* or value* or normative or norms or norm or opinion* ${ }^{*}$ or responsib*)

AND (organization* or organisation* or work* or compan* or firm* or office*)) IN TI, AB, SU AND

((LA=English) OR (LA=Dutch) OR (LA=French) OR (LA=Spanish)) AND (PT=PEER-REVIEWEDJOURNAL)

This query was designed to identify all records with (synonyms of) the words "energy" or "environment" and "behavior" in the same sentence in the title, abstract or subject field. In addition, (synonyms of) "determinant" and "organization" had to be present in at least the same fields. The more specific term "office" was added as one of the concepts similar to "organization" because of the major contribution of offices to total energy consumption by organizations (18\% in the United States; PerezLombard, Ortiz, \& Pout, 2008).

These records were downloaded into a reference management program (Endnote 9) which automatically detected and removed duplicates. The titles and abstracts of the remaining entries were used to determine the relevance of the articles, which were categorized according to the evaluation criteria as discussed under 2.2. The full-text article was consulted for articles that appeared relevant as well as those of which the relevance could not be determined from the title and the abstract. Following the first search, all titles of references in the included articles were checked for their relevance (i.e. ancestry approach). Titles which suggested that one of the inclusion criteria might be met were retrieved, evaluated, and categorized according to the evaluation criteria. Finally, the relevant articles obtained from step one and step two (the "source articles") were used in Web of Science to conduct a cited reference search (i.e. descendancy approach). Duplicates among the articles found through the descendancy approach were automatically removed by Web of Science. Articles which were the source articles for the search were manually removed. The rest of the procedure followed was identical to that for the first search. Results of the ancestry and descendancy search were combined with those of the first search. The ancestry and descendancy approaches were repeated until no new entries were found. In practice, this meant that a second and a third round were conducted. Due to a termination of services by the Silverplatter WebSPIRS interface, the search query had to be repeated via the EBSCO Host interface. On 23 August 2009, an equivalent search query was repeated in PsychINFO via the EBSCO Host interface. However, this did not yield any relevant hits between October 2008 and August 2009. A descendancy search with the original source articles was repeated in Web of Science which also led to no new studies that met the inclusion criteria. 


\section{Appendix B: Miscellaneous Studies}

As a result of the comparability criteria, various studies that met some but not all criteria of quantitative comparability were classified under miscellaneous studies:

14. One experimental study which used hypothetical scenarios was excluded from the intervention comparison as the other studies were all field-experiments which had implemented a real-life intervention (Flannery et al., 2000).

15. For the descriptive studies, effect sizes of bivariate analyses were calculated from other statistical information if effect size statistics were unavailable. However, since this was not always possible, four articles which would otherwise have been included in the descriptive studies category, were classified under the miscellaneous studies category and thus excluded from the comparative analysis (Lee et al., 1994; Lee et al., 1995; Siero et al., 1984; Tudor et al., 2008).

16. One study was excluded from the descriptive studies category because it used a preference measure as its dependent variable instead of an intention or a behavior measure (Cordano et al., 2000). However, because the theoretical framework was an adapted version of the Theory of Planned Behavior (TPB), the study was included in the review under miscellaneous studies as the level of analysis was still that of (preferences for) concrete individual behavior.

17. One study was included in the miscellaneous category because it reported exclusively qualitative data and did therefore not have any effect size measures. 


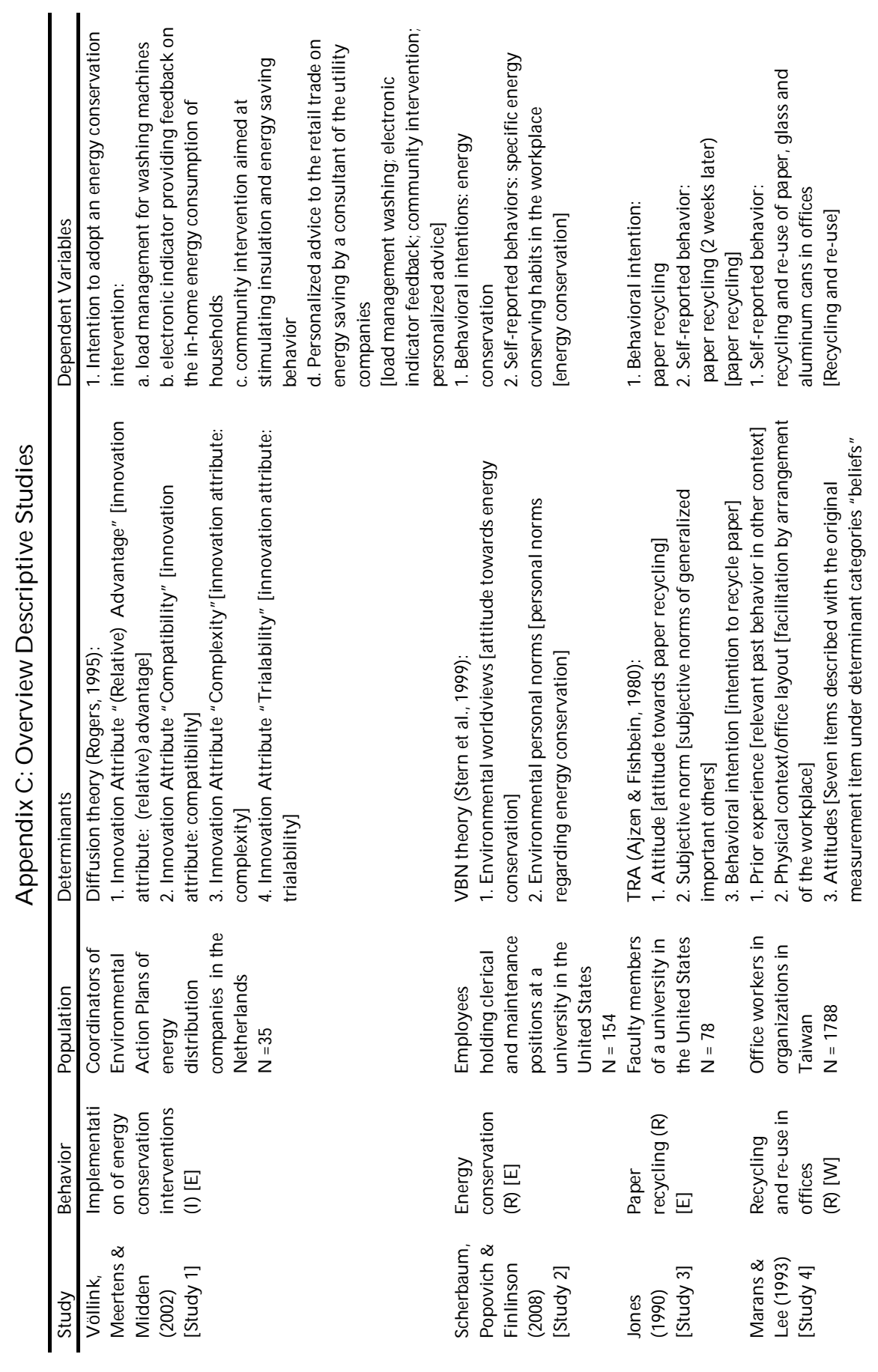



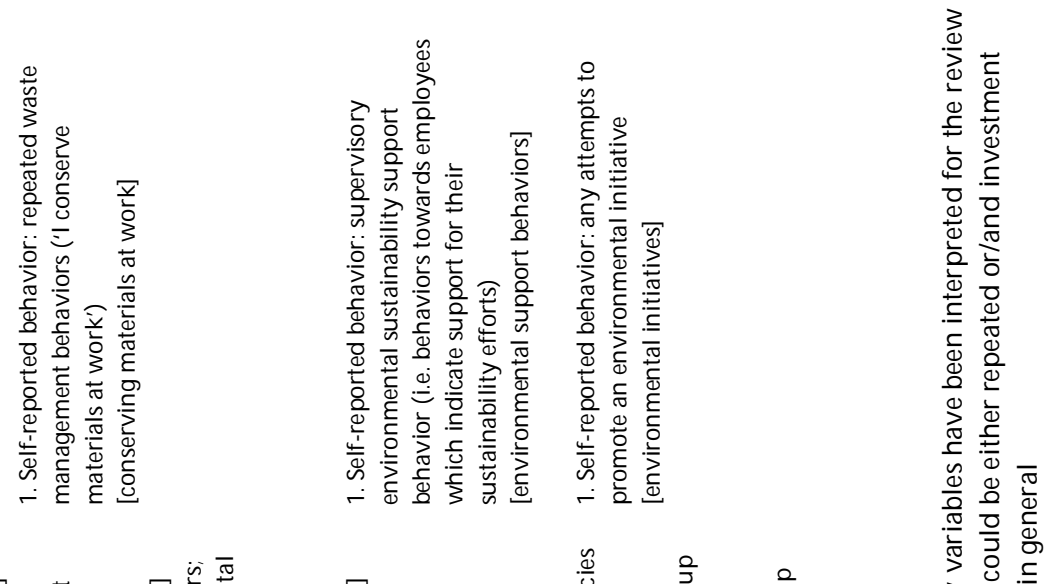

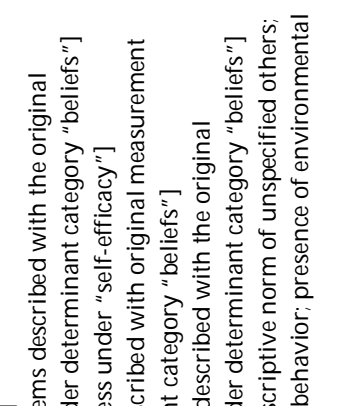

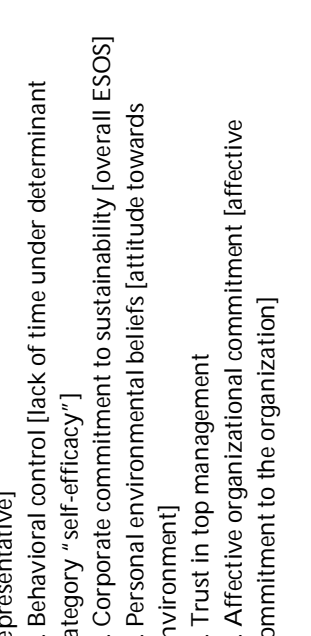

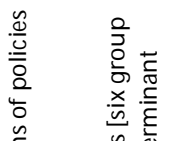

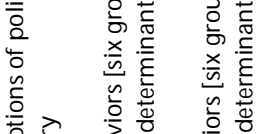

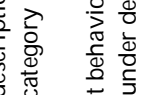

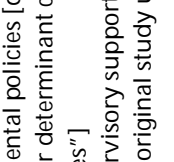

एक

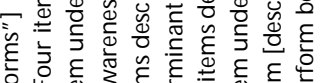

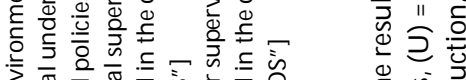

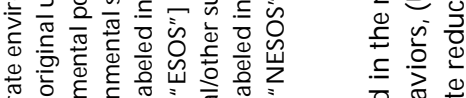

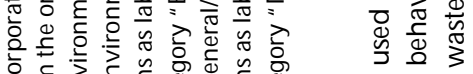

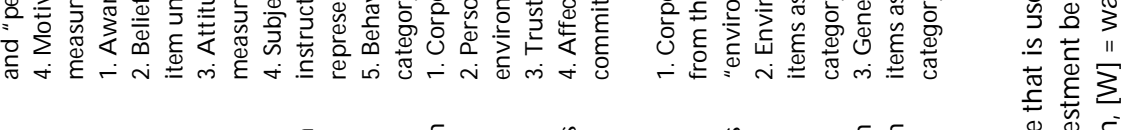

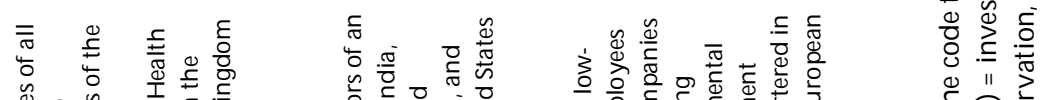

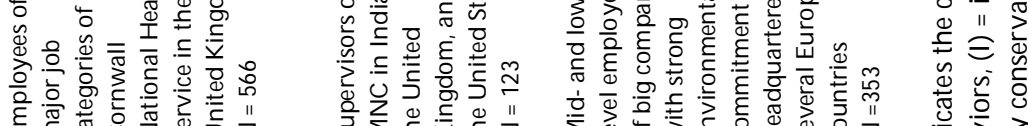

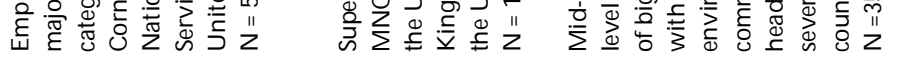

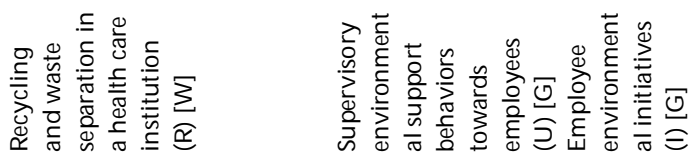

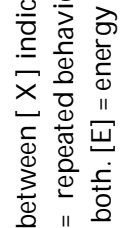

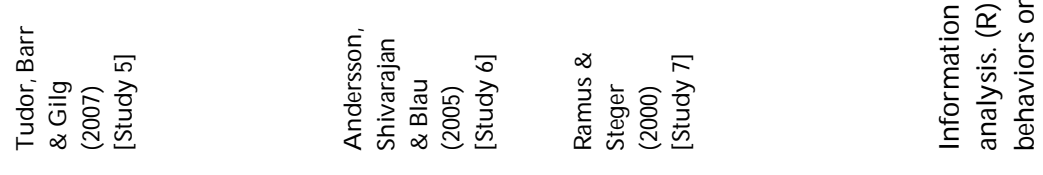




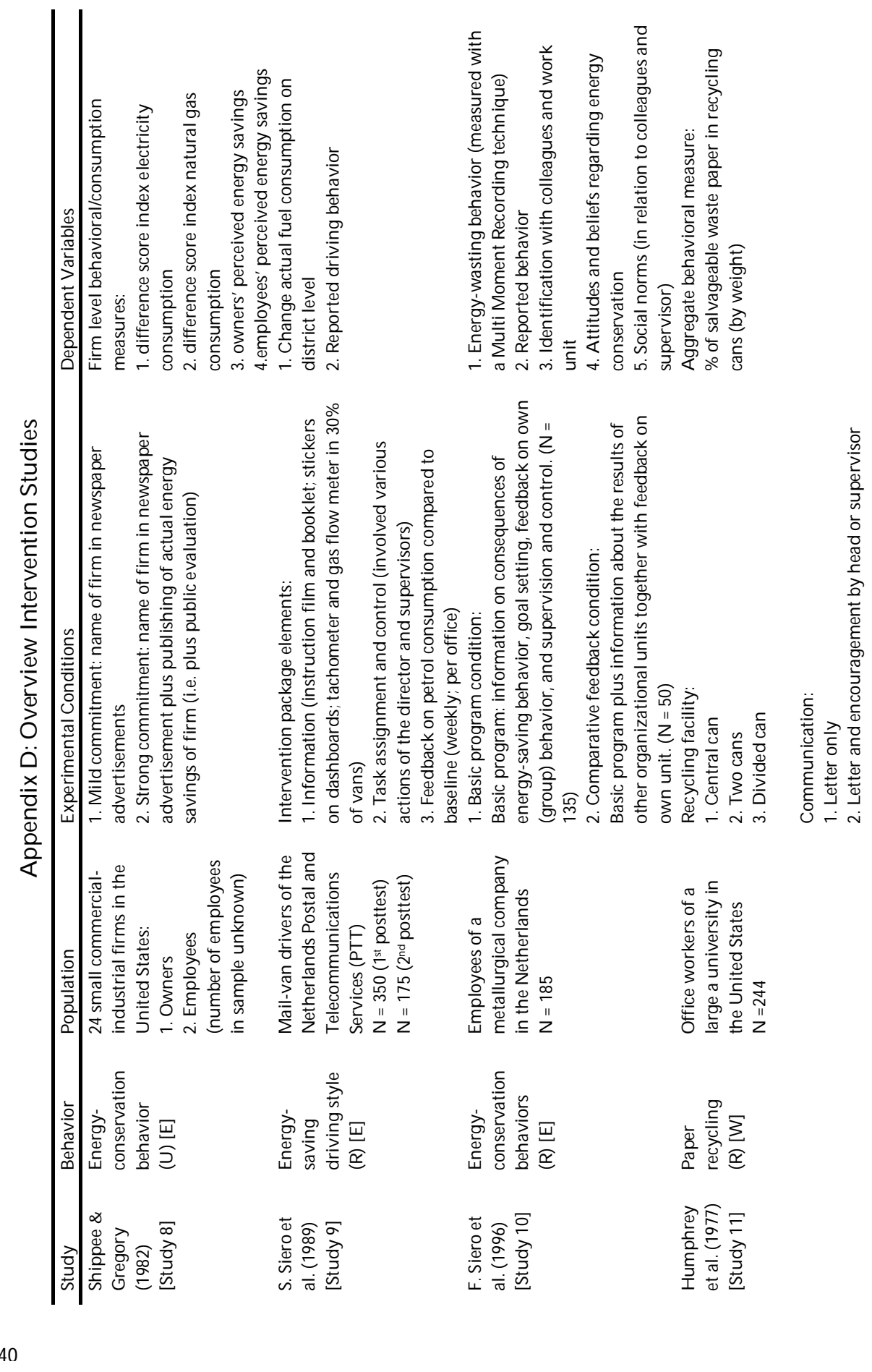




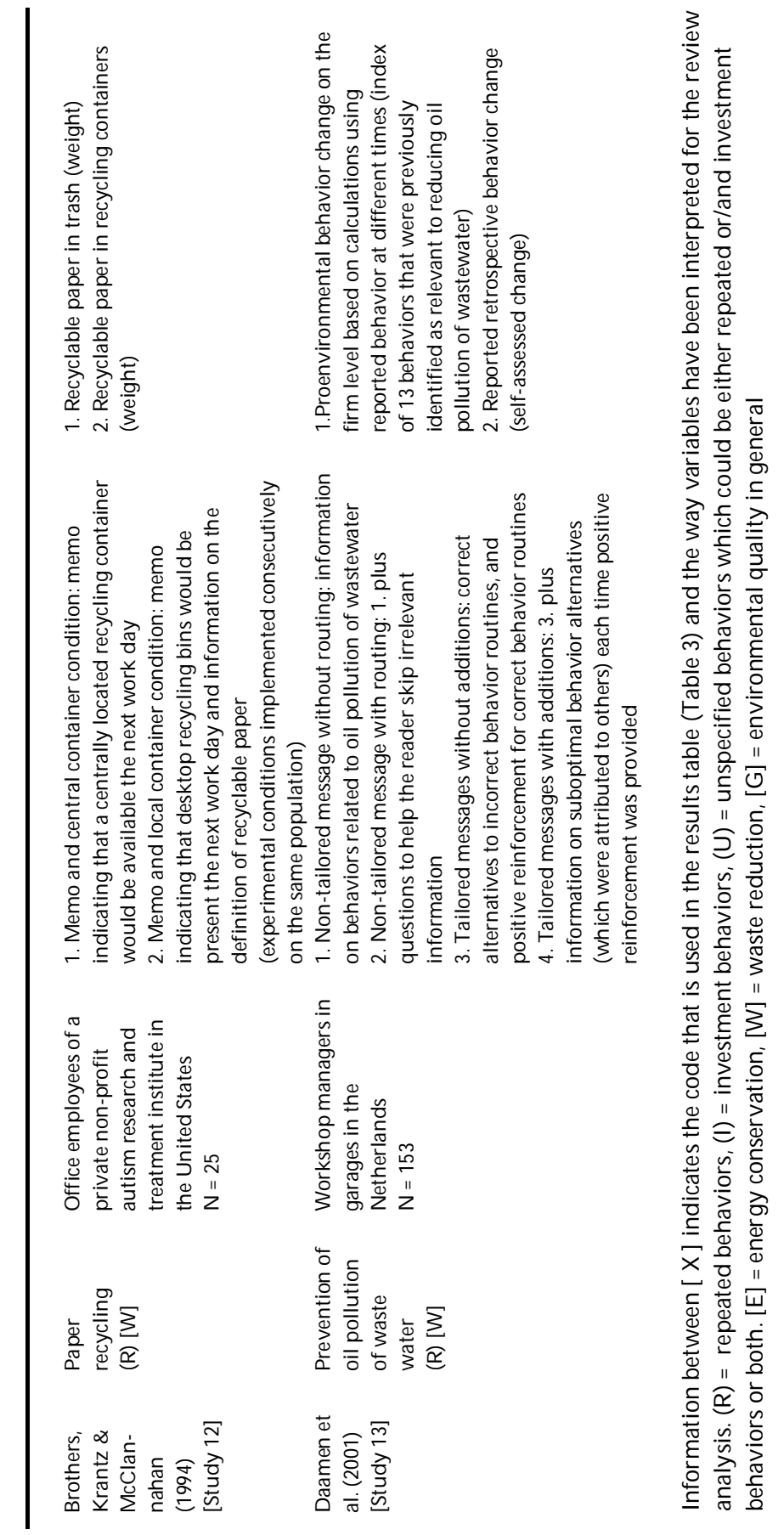





\title{
Chapter 3: \\ Energy-Related Behaviors in Office Buildings: \\ a Qualitative Study on Individual and Organizational Determinants $^{2}$
}

\begin{abstract}
Introduction
Fossil fuel use is a main contributor to human-induced carbon dioxide emissions, which are aggravating global climate change (IPCC, 2007). For this and other environmental reasons, energy conservation is one of the most important means to a more sustainable environment.

For the purposes of reducing energy use, in addition to technological efficiency, it is of substantial interest to gain an understanding of the psychosocial determinants of energy consumers for two reasons. First, there is evidence that substantial energy consumption reductions by means of behavioral measures alone are feasible (Dietz, Gardner, Gilligan, Stern, \& Vandenbergh, 2009). Second, the behavior of individuals can strengthen or undermine the effectiveness of technical measures which have been implemented with energy conservation and efficiency considerations in mind. It is for these and other reasons, that the psychosocial determinants of pro-environmental behavior have been studied relatively extensively in private contexts (for reviews see Abrahamse et al., 2005; Bamberg \& Moser, 2007; Uitdenbogerd et al., 2007).

However, previous research on organizations and the environment has mainly investigated the effects of external determinants and organizational characteristics on organizational engagement with environmental sustainability (Etzion, 2007). Compared to household contexts, little research has addressed energy use in organizations at the individual, behavioral level of analysis (Bansal et al., 2006). In particular, a systematic analysis of interactions between the individual and the organization was found to be lacking in a recent review (Lo, Peters, \& Kok, in press). Although Tudor et al. (2008) did present a framework for examining environmental behavior in organizations, this was solely based on a case study of waste management behavior at one organization. It is yet unknown whether the findings would generalize to other environmental behaviors and organizations.
\end{abstract}

2 This chapter has been submitted for publication as:

Lo, S.H., Peters, G.J. \& G. Kok, Energy-Related Behaviors in Office Buildings: a Qualitative Study on Individual and Organizational Determinants. 
Another consideration is the target population within organizations. Different organizational members have distinct influences on office energy use. Firstly, previous research found that top and middle management play a crucial role in organizational pro-environmental behavior through their impact on employees (Ramus et al., 2000; Siero et al., 1989; Tudor et al., 2007). Indeed, the specific role of managers in organizational environmental practices has been relatively often studied interorganizationally (e.g. Branzei, Ursacki-Bryant, Vertinsky, \& Zhang, 2004; Fineman, 1996; GonzalezBenito \& Gonzalez-Benito, 2006; Sharma, 2000).

Secondly, employees with specific energy-related job responsibilities, such as facility managers and environmental coordinators, clearly have a distinct function in organizational energy use. Their views on energy-saving measures, the organization, and the compatibility between the two, can have a comparatively large impact on total organizational energy use, and have thus been an area of research interest (Egmond, Jonkers, \& Kok, 2006; Vermeulen \& Hovens, 2006; Völlink et al., 2002).

Thirdly, all other employees, or "general employees", affect total energy use directly through their day-to-day behaviors and indirectly through the possibilities and constraints they pose on management and key environmental actors. Relatively few studies have hitherto examined the determinants of proenvironmental behavior of this group. The majority of the few studies on general employees' proenvironmental behavior have examined recycling behavior in the context of a single organization (Lo et al., in press). To the best of our knowledge, very few empirical studies have investigated employee energy-related behaviors and none of those involved interorganizational comparisons (Scherbaum et al., 2008; Siero et al., 1996; Siero et al., 1989). Thus, to date, there are no comparative analyses of the relationship between organizational determinants and employee proenvironmental behaviors.

It can therefore be concluded that there is a lack of research on proenvironmental behavior of general employees in organizations. One area in which energy conservation efforts in organizational contexts may lead to substantial results are office buildings, because they are the largest energy consumers in the non-domestic sector, together with retail establishments. (Perez-Lombard et al., 2008). The current paper will therefore aim to address this research gap by presenting an analysis of psychosocial determinants of office energy-related behaviors, and the interplay between these determinants and the organizational context. The conceptual framework used for examining individual determinants and a discussion of organizational determinants are presented below.

\section{Individual Determinants}

Individual determinants are defined as determinants of a psychosocial nature that are relevant on the individual level. In order to fully benefit from the qualitative format of our study, we chose to employ a framework which only contained general theoretical concepts which are commonly used to explain a wide range of social behaviors. Concepts that have been proposed to explain proenvironmental behavior specifically have been excluded to avoid biased prompting of interviewees as far as possible. Furthermore, research has not established the superiority of more domain-specific theories such as Stern's Value-Belief-Norm Theory (Kaiser et al., 2005; Stern et al., 1999). As a result, we have included evaluative variables (i.e. attitudes; subjective norms; self-efficacy) and habit in our framework for individual determinants:

“Attitudes" are an individual's overall evaluation of a behavior (Eagly et al., 1993). Several subcomponents of attitudes can be distinguished. One distinction is that between instrumental and 
experiential aspects of attitudes (Fishbein et al., 2010). The former is connected to the outcome of a behavior while the latter is linked to the experience of engaging in a behavior. For certain categories of social behavior, it has also been found useful to emphasize the role of an individual's moral evaluation of a behavior. The moral component has often been referred to as "personal norm" or "moral norm"(Kaiser, 2006; Parker et al., 1995).

Another evaluative component related to the individual in question is "self-efficacy" which refers to a person's evaluation of whether one has the necessary resources, knowledge and/or skills to attain a goal (Bandura, 1997), or more narrowly conceived, to perform a behavior (Ajzen, 1991).

On the other hand, the influences of other people on the individual are reflected in "subjective norms" which are defined as the perception of other people's evaluation of a behavior. A useful distinction is that between injunctive norms, which concern others' approval/disapproval, and descriptive norms, which refer to others' behavior (Schultz et al., 2007).

For evaluative variables to play a role in behavior, the behavior needs to be under volitional control (Fishbein et al., 2010). Furthermore, awareness of its personal, social, or environmental relevance is also prerequisite for evaluative variables to explain behavior meaningfully. When behaviors are repeatedly performed, they no longer require deliberative evaluation which has led many to argue that they become "habits", which are characterized by a degree of automaticity and unconsciousness (Fishbein et al., 2010; Verplanken et al., 2003). In this phase, contextual cues like time and place may play a more salient role in determining behavior (Wood et al., 2005).

\section{Organizational Determinants}

According to Tudor and colleagues, who presented a framework of factors influencing proenvironmental management behavior, five organizational determinants are of relevance: organizational focus, organizational structure, organizational/site type and size, departmental type and size, and organizational culture (Tudor et al., 2008). Although Tudor and colleagues have outlined such a framework, we believe it to consist mainly of indirect determinants of behavior or determinants which may be too broad to be meaningful. Organizational size, for instance, can be hypothesized to affect the degree of interaction between organizational members and therefore indirectly influence the salience of subjective norms regarding proenvironmental behavior. Nevertheless, Tudor et al.'s proposed framework does provide a valuable tool for the search of organizational characteristics directly related to proenvironmental behavior. Of the factors included in their framework, organizational focus and organizational culture may be the ones that most straightforwardly affect individual determinants.

Organizational focus, defined as the primary aim of an organization, may be directly related to proenvironmental behavior in the sense that it, at least on the organizational level, sets the priorities, which may or may not be aligned with environmental sustainability. In the present study, we employed variations in organizational focus to further explore its role in proenvironmental behavior.

Organizational culture comprises those elements that are shared by organizational members. It could indeed be seen as a broader concept which includes, or is at least interlinked with, organizational focus (Tudor et al., 2008). In Schein's model of organizational culture, organizations can be understood on three levels (Schein, 1992). The first level is that of artifacts, such as physical facilities in the office building and formal organizational policies, which are tangible and explicit. The second level is that of values, which are intangible but (partially) explicit. Examples are informal rules, and perceived values and ideal types. The third level of basic assumptions are intangible and taken for granted, such as 
unwritten norms. In our study, we will mainly focus on the distinction between the formal level, that of artifacts, and the informal level, that of values and basic assumptions.

\section{Implications for Research}

To conclude, it was possible to establish a general conceptual framework of individual determinants that may play a role in determining proenvironmental behavior from previous research in private contexts. However, the existing literature did not provide sufficient tools for the construction of a solid framework for organizational determinants that directly affect individual proenvironmental behavior. Given this lack of knowledge, we considered qualitative research methods most appropriate for examining individual-organization interactions as fewer constraints would be imposed on exploring possible relevant organizational influences. Consequently, we conducted semi-structured interviews and focus groups among employees from four different organizations in both the private and the public sector.

\section{Methods}

We conducted a qualitative exploratory study in four Dutch organizations as part of a larger research project on energy-related behaviors of office workers. Ethical approval was obtained from the faculty's standing ethical committee before data collection. Interviews were conducted in Dutch by the first author between December 2008 and November 2009.

\section{Sample Characteristics}

Interviewees were recruited from four organizations located in the Dutch provinces of Zuid-Holland (ZH) and Limburg (LB). Two commercial companies (company ZH; company LB), a university (university LB), and a non-governmental organization (NGO ZH) took part in the research project. The two companies and the NGO each participated with one large office building. For the university, three buildings were involved in the data collection.

All organizations had some form of public commitment to environmental sustainability, but none had energy conservation as their primary organizational aim. Nevertheless, the NGO's core task, development aid, was increasingly perceived to be related to environmental sustainability because climate change had become a pressing issue in the countries where they operated.

Interviewees roughly fell into two groups: "key informants", who fulfilled a special role in organizational energy use (e.g. facility managers, environmental policy coordinators, internal communication officers), and "general office workers" or "employees".

\section{Recruitment}

We approached organizations with the request to take part in the research project, promising participating organizations a report of the anonymized, general results. A key informant in each organization served as a contact person. Contact persons identified other key informants, and invited a representative sample of general office workers. 


\section{Procedure}

\section{Phase one: key informants}

At each organization, four to five informal interviews were conducted with key informants. We informed them that we were interested in organization-specific background information and their views on organizational energy use so that we could identify suitable questions for the interviews with general employees. Where possible and needed, we asked key informants to provide additional documentation such as organizational reports, internal communication materials, and press articles. In addition, a few key informants were also contacted by phone and e-mail for specific information.

\section{Phase two: general office workers}

Six to nine individual semi-structured interviews of 45 to 75 minutes were conducted at each organization. One focus group of 90 to 120 minutes consisting of four to eight participants was conducted at each office building. Before interviewing, participants received oral and written information about the research aim, data confidentiality, and the voluntary nature of their participation. Following this, they were requested to sign informed consent and asked permission for recording the conversation.

\section{Interview Topics}

\section{Key informants}

Each key informant was interviewed about his or her area of responsibility related to organizational energy use. For instance, a facility manager would be asked about energy consumption figures and past energy conservation measures. In addition, key informants were asked more generally about their views on determinants of and opportunities for energy conservation in their organization.

\section{General office workers}

Interviews with general employees were solely concerned with their views on facilitators and barriers to, and opportunities for energy conservation (see Appendix A for a sample topic guide). We first asked open-ended general questions about energy use and conservation in general which were followed by questions about work-related energy use.

\section{Data Analysis}

All interviews were recorded with a digital recorder and transcribed verbatim. Qualitative research software (QSR NVivo 8) was used to facilitate coding and analysis.

First, the transcripts were divided into text fragments based on the energy consumption categories as outlined in the topic guide. Second, the relevant behaviors of each category were further subjected to a basic analysis that identified facilitators, barriers, change potentials and strategies for change. Third, all text fragments with organization-individual interactions were identified. General patterns of interactions between the individual and the organization were extracted and described with theoretical individual determinants as the organizing unit. Finally, salient interactions for each specific office energy consumption category were identified to illustrate these general interaction patterns. 


\section{Results and Discussion}

\section{General Interaction Patterns}

\section{Awareness}

In general, it was found that an initial necessary condition for employees to engage in energy-saving behavior is awareness of its personal, social, organizational or environmental relevance.

Lack of organizational communication about energy saving was common to all organizations. Although interviewees, except for the university employees, were often aware that their organization had an active policy regarding environmental sustainability, they tended to be ill-informed about concrete benefits of relevant behaviors and what behaviors they could perform themselves. Even though some argued that everyone knows what they should do, the same individuals would later admit that they were unaware of the energy-related consequences of some behaviors.

Furthermore, feedback on personal behavior was frequently seen as an effective communication strategy to raise awareness. Feedback mechanisms, however, usually go beyond mere awareness raising. They result from organizational measures and can range from informative feedback to temporary removal of electronic appliances when left on stand-by. The lack of feedback and to a lesser extent financial incentives, both of which one usually gets through home energy bills, were seen as important differences between the household and organizational context.

Finally, if a facility was hard to access, some workers assumed that they were expected not to interfere with its default settings (e.g. printer and thermostat settings). Interestingly, these assumptions occasionally contradicted with what facility managers claimed.

\section{Attitudes}

General attitudes towards energy conservation were mildly to strongly positive. Although some favored an emphasis on alternative energy sources, there was a broad consensus that one should conserve energy when there are no competing and overriding motivations to do otherwise. However, the degree to which other motivations were considered "competing" and "overriding" varied.

These other motivations included organizational, work, and personal interest. Energy-conserving behaviors are generally seen as compatible to direct organizational interest. In fact, energy saving is often seen as a way to reduce costs or to achieve aims like corporate social responsibility. In contrast, it is frequently perceived to be incompatible with optimal work quality and efficiency, and employees' personal comfort, convenience and interest. Thus, energy conservation is often seen as harming the organizational interest indirectly through their employees.

Individual differences were mainly found in the relative salience of three types of motivational orientations: a normative orientation was characterized by considering moral issues and people's responsibility, a gain orientation emphasized cost-benefit analyses and efficiency, and a hedonic orientation focused on personal convenience and comfort. Typically, employees identified themselves with more than one motivational orientation. Gain-oriented motivations were often found to coincide with either normative or hedonic motivations, but normative and hedonic motivations co-occurred less frequently.

The salient interorganizational differences in individual determinants were also found in this area. The NGO's organizational focus on development aid in climate change-affected countries appeared to 
be related to the uniform normative orientation of their employees. In contrast, gain-oriented motivations were more strongly represented among company employees. Finally, individual differences were largest among university employees, where no distinct pattern of motivational orientation was found.

\section{Self-efficacy}

A dominant theme was that job responsibilities determine to a large extent what one can and should do. Key actors such as facility managers, but also top management were seen as primarily responsible for office energy use. General employees rarely intended to approach and influence key actors.

Furthermore, the word "control" was sometimes synonymous to "effort" needed to perform a behavior. This latter definition of control clearly overlaps with attitudes. Nevertheless, words like "control" rather than "(im)practical" or "(in)convenient" appeared to be used when an interviewee wanted to convey that he or she did (not) feel responsible. Finally, although self-efficacy was generally an important theme, it was particularly emphasized in the context of behavioral change and the distinction between energy use at home and at work.

\section{Subjective norms}

Subjective norms were found to be an important but relatively implicit theme. Few employees would discuss social norms of colleagues or superiors elaborately when asked to talk freely about office energy use. When prompted, some people would have a relatively clear idea of what their direct colleagues and superior thought and how they behaved, but others would express ignorance or difficulty with gauging norms. Assessment of the impact of norms on one's own behavior also varied.

In contrast, social norms were frequently discussed when talking about effective behavioral change strategies in the future. Especially middle and top management's behavior and their influence on organizational initiatives were seen as crucial to success.

Only the NGO employees assumed that (nearly) all other organizational members would support office energy saving. Injunctive norms in the two companies and the university varied more widely. Departments that were involved in organizational environmental policies or actions were more likely to have a positive injunctive norm than uninvolved departments.

\section{Habit}

Habits were discussed in two different ways. Firstly, by employing the word "habit", interviewees often acknowledged an irrational element in their behavior, sometimes serving to prevent further investigation because the behavior was by definition illogical. Secondly, habits at home were usually seen to have spill-over effects to behaviors at work and vice versa.

Nevertheless, differences in habits across contexts were common. Comparisons between office workers with access to similar or different facilities, or belonging to the same or different department(s) indeed suggest that facilities, formal policies, and norms of direct colleagues may partially account for these differences. Furthermore, employees sometimes also explained how the organizational context hindered a spill-over effect. However, interviewees equally often lacked explanations. After deliberating on a possible cause, some admitted they could not think of a real reason. 


\section{Office Energy Use}

Overall, office workers perceived their influence on office energy use to be minimal. As one interviewee expressed himself:

“...especially in the office environment, not a lot of energy use there, at least not what I can influence, I can refrain from turning on the lights when I come in, but that's about the only thing"

(I, male employee at company LB)

However, action in the organization was usually perceived to be more promising than in the private household context:

“...within NGO ZH it has more impact... if wetalk about insulation and solar panels and that kind of things, then there's more possibilities at NGO ZH than at home." (VII, male employee at NGO ZH)

\section{Climate control}

Organizations can often make relatively large energy savings in the domain of climate control (e.g. better insulation, more energy-efficient heaters, or accepting a wider range of temperatures).

Concerning central organizational measures, many employees thought that a lot of energy was wasted through inefficient heating systems. Some implied this affected their overall attitude to office energy-saving behaviors. In fact, climate control is one of the most frequent sources of complaints among employees. An insightful example is the case of insulation in historical buildings. Many office workers in historical buildings advocate better insulation, but are unaware that the organization is bound to external regulations that severely restrict possibilities to insulate.

Acceptability of cold and hot temperatures, willingness to adapt clothing, and opinions about the impact of office temperatures on personal productivity varied substantially. The case of temperature acceptability also shows that organizational policies and the way they are implemented might lead to counteractive results. At the university, where a policy change led to lower temperature settings during winter time, some employees decided to bring electric heaters to work:

“...I I thought how is it possible that it's cold all the time?... And then I heard that the university had chosen... The default temperature... is now set back to 20 degrees. They thought it was warm enough... They chose for savings... but it wasn't communicated... I thought, okay, let's bring in a heater ourselves... I think it's too cold, because you're sitting quietly behind your desk. I can't function like that [italics added]."

(VIII, female employee at university LB)

Connected to temperature range is temperature controllability. Besides discomfort, temperature uncontrollability also led employees to engage in energy-wasting behaviors such as opening windows when the heating or cooling system was active. Many company and NGO employees suggested that the issue was not average temperature per se, but an inability to regulate temperatures so that it was either too cold or too hot.

At the formal organizational level, this inability was either due to a perceived insensitivity of the thermostat or the belief that one should not operate the thermostat because it is out of sight. The former 
is a case of an interaction between the organizational physical facilities and self-efficacy. The latter illustrates how the arrangement of facilities can influence normative beliefs about a behavior. Other social organizational factors also played an important role. For those sharing an office, conflicting comfort levels were a common phenomenon.

\section{Lights}

Overall, the act of switching lights on and off was perceived as relatively straightforward. Despite this, many noted that lights were frequently left on. One regularly-encountered belief was that switching lights off and on within a short timeframe, consumes more energy than leaving them on. Also the location of light switches mattered: the likelihood of switching a light off when passing the light switch on the way out is higher than when it is a detour. However, most identified barriers had a social organizational origin. Perceived informal rules and social norms affected behavior. For instance, some employees left the lights on during daytime, because it would signal to others that they were in office.

Finally, although there was a consensus on the crucial role of facilities, there were different views on the optimal use of technology to save energy. One striking contrast were the diverging views on motion-sensor light control in company $\mathrm{ZH}$, which was the only organization employing this technology at the time of the interviews. One of the facility managers was contemplating a reintroduction of manual light switches, because the lights switched back on when people walked passed empty rooms. However, general employees did not share this view. Some did not mention that particular drawback at all, but even those who had noticed it, did not suggest installing manual switches. Consider the facility manager's view:

“...we have sensors now. It was a hot item in the past. But now there's something going for controlling [the lights] yourself... the rooms are empty, but you walk passed the corridors, then the lights will turn on again," (III, facility manager at company $\mathrm{ZH}$ )

Compared to that of a general employee:

"I mean when you go home...you just close the door, a lot of people go home and leave the door open... someone passes by the corridor and it turns on again...l close the doors, that's very easy [to do]..." (IV, male employee at company ZH)

\section{Computer and printer use}

Although habits varied considerably, all employees imply that energy saving should not lead to a significant productivity loss. The difference between office workers who print little, use power management, or turn off their computers compared to those who do not, is that the former perceive their energy-saving habits to be compatible with a productive work routine. Consider a typical line of argumentation for economical printing habits:

“...I always work, I try to do everything digitally... you get used to it. I split the screen, then I have the pdf on top and my Word at the bottom....also because, at a certain point you have so much shit lying around, it is eventually also practical..." (IX, male employee at university LB) 
Whereas wasteful printing habits are also explained in terms of work efficiency:

“...they [documents] are so large, to really go through it well, I have to print it ... Behind the PC it's difficult to find the relevant passages ..."

(II, male employee at company LB)

The case of printing also shows that facilities and informal rules may have equal weight in determining the amount employees print. On the one hand, double-sided printing is a clear example of the substantial impact technology can make. Overall, employees were strongly in favor of default doublesided printer settings because the potential savings were perceived to be substantial and easy to realize. Even if they initially considered double-sided prints to be awkward, employees reported that they got used to it after the default settings had been changed. The obvious contrast is formed by those from other organizations or departments who are willing to print double-sided, but cannot due to lack of suitable facilities.

On the other hand, informal norms, and habits of other organizational members were perceived to have a sizeable, mostly negative impact on personal printing behavior too. Examples are printer-unfriendly documents that lead to prints with many pages, and information overload due to overuse of the CC-e-mail option. Nevertheless, except managers who were more likely to comment on others' printer use, employees tended to believe they were not entitled to judge others' printing behavior if it did not directly affect themselves.

\section{Private electric appliances}

The use of privately-owned electric appliances was only addressed in company ZH and the university. Attitudes towards private appliances varied among employees, but the starkest contrasts could be found between key informants and general office workers. Compare the facility manager's view:

\section{“...So no own coffee machines, no fridges ... that's very important: back-to-basic, yes the behaviour of people means, hey, we have housekeeping rules, and if everyone sticks to them then the total building will no doubt reduce [energy use]." (III, facility manager at company $\mathrm{ZH}$ )}

With that of a general employee:

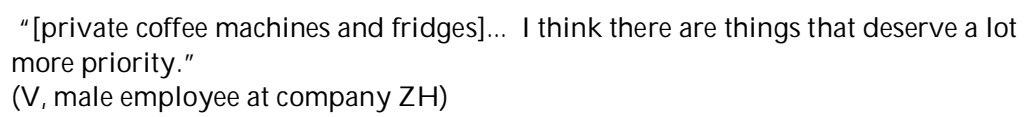

Three themes arose out of a comparative analysis. Firstly, although general employees tend to underestimate the impact of their own behaviors on total energy consumption, facility managers saw considerable potential for employee behavioral change. Secondly, descriptive norms are crucial to compliance with organizational policies. Inconsistent adherence across the organization was argued to negatively affect attitude towards removing private appliances. Thirdly, organizational interests other than energy saving may be more persuasive. Aesthetic appearance of the office environment and fire risks were mentioned as sufficient motivations to ban private appliances. Furthermore, this case further underscores the need to consider employees' personal interest. Employees sometimes compensated for what were, in their eyes, inadequate centrally-provided facilities by bringing private equipment. 


\section{Flexible office spaces}

Unlike other topics covered, determinants of employees' views on flexible office spaces, rather than behaviors, were examined because most interviewees were not working on a flex desk (yet). Also, the organizational stakes were perceived to be higher because of considerable potential savings from both housing and energy costs. There was a consensus that some job profiles were less suited for "flexing" than others. The three common criteria were need for access to specific materials, the degree of concentration needed for daily work, and the extent to which confidentiality was an issue.

However, there was disagreement about the proportion of the total organizational population suited for flexing. When considering (reasonably) widespread introduction of flexible office spaces, ardent advocates argued that in addition to cost reductions, it would stimulate interaction between employees. Private offices were perceived to be motivated by status rather than actual job-related needs. Provided adequate facilities such as a digital archiving system and silence rooms are in place, they believed that work efficiency could be maintained after a short habituation period. In contrast, opponents predicted productivity loss and little saving potential. Lack of a place of their own was also considered unpleasant. On average, interviewees with personal flexing experience had a more positive attitude than those who had not.

Finally, this case shows that employees can prioritize organizational over personal interests. If the organizational advantage was truly believed to be large, those who saw both organizational advantages and personal disadvantages would tend to have an overall positive attitude:

"I think it's fine... what I would find unpleasant is that you'll becomea kind of a nomad ... No, I think it's out-of-date...to appropriate a spot for yourself... research has shown that...something like $50 \%$ of the office spaces are not fully occupied..." (VI, female employee at company ZH)

\section{General Discussion}

Salient individual and organizational determinants as well as individual-organizational interactions become apparent in the interorganizational similarities and differences found.

The results indicate that there were many similarities between the four organizations, despite diverging organizational foci. First, work was seen as the chief interest. This suggests that Tudor et al. (2008)'s finding that "low levels of motivation among staff toward noncore activities" was not specific to their case study (p.434). Therefore, employees were found to most strongly support energy saving in areas that were perceived to be compatible with or enhancing work interest. In contrast, the relative absence of social norms towards specific energy-related behaviors is arguably another facet of the prioritization of work over energy saving.

Second, the predominance of self-efficacy as a determinant of office energy-saving behavior was common to all organizations. Knowledge about desired behaviors and their consequences was important. Poor organizational communication was found to be a main contributor to low self-efficacy in this domain. In addition, there was a general sense of uncontrollability due to organizational division of labor and a (perceived) inability to influence central organizational policy. This supports previous research findings that emphasized the role of management and employees with environmental job responsibilities (Andersson et al., 2005; Ramus et al., 2000; Tudor et al., 2007).

Third, interviewees had relatively similar views on strategies to promote office energy saving. Contrary to descriptions of the present situation, social norm elements were frequently encountered in 
employees' proposed strategies for the future. This is in congruence with an intervention study that found a larger effect for feedback with descriptive norms on employee energy-saving behaviors than for other measures (Siero et al., 1996). However, many employees also suggested that providing practical information on energy-saving behaviors would be effective, whereas evidence from intervention studies suggests the insufficiency of this strategy (Brothers et al., 1994; Humphrey et al., 1977; Staats et al., 1996).

Interorganizational differences were less numerous, although those differences that did exist might have led to considerable disparities in office energy use. First, differences in organizational facilities were found to influence the range of relevant behaviors and the likelihood of opting for energy-saving behaviors. Although interviewees generally favored change of facilities, interorganizational comparison of motion-sensor light control also showed that satisfaction levels concerning "technological fixes" might vary in the pre- and post-implementation phases. Sensors received uniform support in the three organizations that had not implemented the technology, whereas opinions were more divided in the one organization where sensors had been installed already.

Second, organizational foci were linked to differences between the relative salience of normative, gain, and hedonic motivations that underlie attitudes. The NGO's organizational focus was related to a strong normative orientation of their employees, whereas gain-oriented motivations were more salient among company employees. In contrast, no distinct pattern of motivational orientation was found among university employees. It is important to stress that gain motivations do not necessarily entail personal interest. At least in the office energy use context, unlike in goal frame theory, it was more useful to interpret gain as cost-benefit that could encompass personal, organizational and even environmental interest (Lindenberg \& Steg, 2007).

\section{Limitations and future research directions}

As noted earlier, many similarities were found between the organizations despite their diverse organizational foci. This result might at least partially reflect the stage in which participating organizations find themselves with respect to office energy conservation. They participated because they wanted to target employee behavior, but had done little in that respect so far. However, this should not hinder the findings to inform organization-initiated interventions because those organizations would be at the same stage as the organizations studied.

Another limitation was incomplete objective information on relevant organizational determinants and overall organizational performance with regard to office energy use. It was therefore impossible to determine to what extent differences in formal and informal organizational features really affected office energy use.

Moreover, the choice to focus on individual-organizational interactions led to a neglect of other relevant interactions like those between external and organizational factors, and formal and informal organizational aspects.

Finally, the dynamics between individual and organizational determinants over time were left relatively unexplored. For instance, it remains unclear what the nature of the connection found between organizational focus and motivational orientation is. Although some evidence can be derived from cross-sectional interview data, comparisons of individuals and organizations over time are methodologically superior and may lead to better insights into the individual-organization dynamics. 


\section{Implications for interventions}

Four major conclusions for interventions can be drawn. The primacy of work interest suggests that interventions compatible with or supportive of work quality and efficiency have the most potential to be successful. The evidence suggests that skills training in low-energy work routines and change of organizational work procedures and norms are promising avenues to explore. Furthermore, feedback could increase awareness of employees' own behavior and its consequences (cf. research in household contexts, Abrahamse et al., 2007; Staats et al., 2004). Also, interventions to change social norms may have a relatively large impact given a commonly perceived absence of social norms in organizations and results from previous studies. Finally, overall strong employee support and previous research findings speak for adapting facilities to encourage energy-saving behaviors where possible, provided facilities are pre-tested. On a cautionary note, differences in key actors' and general office workers' views on facilities existed. General employees' views should therefore be considered in the choice of facilities, although direct implementation of their ideas might not be fruitful as illustrated earlier by the comparison between employees' proposed strategies and intervention study findings. 


\section{Appendix A: Sample Topic Guide (translated from a Dutch-language topic guide)}

\section{Part I: Introduction}

\section{Explanation of interview aim}

\section{Introducing the interviewer and the research aims:}

- I work for University $X$ on a scientific research project about energy use by office workers. This research project is conducted, among others, with employees of organization $Y$, but also a few other organizations.

- In practice, this means that we interview people to gain insights into the factors that influence energy use and where potential possibilities for change lie. In a couple of months time an online survey will be send to all employees.

- The aim is to deliver a report with the general findings and recommendations to organization $\mathrm{Y}$ as well as to gather data for scientific publications

\section{Participation:}

- I do not expect specialist knowledge or that you have prepared for this conversation, I am only interested in your opinion.

- Everything you tell me is confidential and your name and job title will not be recognizable in quotations that I might want to use in the report. You can also decide to withdraw your consent later. In that case, I will destroy your data.

- Do you still have questions?

- In order to make a report that is as accurate as possible, I would like to record the conversation. Do you have objections against this?

\section{Introducing the interviewee:}

- Could you please introduce yourself? (check for name, job profile, duration of employment at the organization, educational background)

\section{Structure of the interview:}

- I will first ask you a couple of general questions about energy use and energy saving and then treat issues that are more specifically relevant for organization $\mathrm{Y}$.

\section{Part II: Energy Saving in General}

- What comes to your mind when you think of energy use or energy saving?

- What do you think of energy saving?

- Do you have ideas about how to save energy?

- What are according to you differences and similarities between energy saving in the organization and at home? 


\section{Part III: Energy Saving in the Organization}

- Energy can be used in a lot of different ways, be it directly or indirectly. I have a list of categories of energy use that are relevant to energy use of organization Y. I would like to go over them with you. There are a couple that you have mentioned earlier:

18. Energy use

19. Lighting

20. Heating

21. Electrical equipment: computers, printers, lift, etc.

22. Paper use

23. Printing

24. Paper mail

25. Travel

26. Commuting

27. Flexible office spaces \& telework

28. National \& European \& intercontinental business trips

29. Teleconference use with national and international contacts

30. Food consumption: meat, waste, food miles

31. Water use

32. Recycling and waste

- What are factors that can increase or reduce [energy use X]?

- How can [energy use $\mathrm{X}$ ] be increased or reduced?

- What are the advantages and disadvantages of using these strategies?

- What do you think of colleagues who do [energy behavior X]?

- Do you talk about [energy use X]?

- Do others speak to a person when he/she does not do [energy behavior X]?

- Do you have objections against measures that were taken in the past or are taken centrally?

\section{Part IV: Conclusion}

- Do you have other comments?

- Do you still have questions?

- I would like to thank you for your participation (hand out debriefing form with contact details) 



\title{
Chapter 4: \\ Proenvironmental Travel Behaviors among Office Workers: \\ a Qualitative Study of Individual and Organizational Determinants $^{3}$
}

\begin{abstract}
Introduction
Fossil fuel use is a main contributor to human-induced carbon dioxide emissions, which are aggravating global climate change (IPCC, 2007). For this and other environmental and societal reasons, such as air pollution and traffic jams, promoting more sustainable and energy-efficient travel behaviors is of practical interest.

Although reviews of "soft" transport policy measures, which include behavioral change programs, indicate that these tend to be effective, the mechanisms underlying their effectiveness are under-researched (Cairns et al., 2008; Richter, Friman, \& Garling, 2010). Moreover, most reported (nonpeer-reviewed) intervention studies lack methodological rigor and are likely to show reporting bias (Moser \& Bamberg, 2008). In other words, it is still unclear which soft policy measures are truly effective, and if effective, why this is so.

A recent meta-analysis of the psychological determinants of car use revealed that socialcognitive variables - as derived from the Theory of Planned Behavior - and habit were good predictors of intention and behavior (Ajzen, 1991; Gardner \& Abraham, 2008). However, less is known about how factors external to the individual, such as region and the type of organization at which one is employed, impact on these individual determinants of behavior.

Previous research on travel behavior has mostly examined travel mode choice for private or commuting purposes of individuals within a confined geographical region (Aarts et al., 2000; Bamberg, 2006; Davidov, 2007; Van Vugt, Van Lange, \& Meertens, 1996; Verplanken, Walker, Davis, \& Jurasek, 2008). Although some have studied residents from diverse geographical locations, regional differences were usually not examined (Steg, 2005; Thogersen, 2006). A notable exception is Bamberg et al.'s study
\end{abstract}

3 This chapter has been submitted for publication as:

Lo, S.H., Peters, G.J. \& G. Kok, Proenvironmental Travel Behaviors among Office Workers: a Qualitative Study on Individual and Organizational Determinants. 
on public transportation use in two distinct urban areas which allowed exploring the influence of regional contextual factors on psycho-social determinants (Bamberg, Hunecke et al., 2007).

Furthermore, little known about the role of organizations because many commuting behavior studies almost exclusively focus on individual-level influences (Domarchi, Tudela, \& Gonzalez, 2008; Mann \& Abraham, 2006). In fact, compared to household contexts and private individuals, few studies have examined (other) proenvironmental behaviors in organizations at the individual, behavioral level of analysis (Abrahamse et al., 2005; Bamberg \& Moser, 2007; Bansal et al., 2006). Previous research on organizations and the environment has mainly investigated the effects of external determinants and organizational characteristics on organizational engagement with environmental sustainability (Etzion, 2007). In a recent review, a systematic analysis of interactions between the individual employee and the organization was found to be lacking in empirical research (Lo et al., in press). This is in sharp contrast with the substantial proportion of soft policy measures that have been initiated through the workplace (Cairns et al., 2008; Kearney \& De Young, 1995-1996).

Finally, it should be emphasized that the environmental impact of transportation is not confined to travel mode choice for commuting purposes. Within the organizational context, relatively little research has examined the determinants of other work-related travel behaviors such as business trip frequency, and more sustainable behavioral alternatives to traveling like teleworking and teleconferencing (Aguilera, 2008; Kearney et al., 1995-1996; Moos, Andrey, \& Johnson, 2006; Toffel \& Horvath, 2004). For instance, a review of telework research concluded that employees' motivations for teleworking remained unclear, and research on organizational level influences was called for (Bailey \& Kurland, 2002). In order to maximize the effectiveness of organizational interventions, it can be insightful to study the whole array of work-related travel behaviors. One benefit of examining various behaviors in one study is that their relative potential for change can be compared while keeping organizational context constant.

The current paper aims to address the above-mentioned research gaps by analyzing individual determinants and organizational determinants relevant to a wide range of work-related travel behaviors among office workers in four organizations with different organizational foci from two distinct regions in the Netherlands. Where appropriate, we will further investigate the interactions between the individual and the organizational influences. Topics of interest included commuting travel mode choice and frequency, national and international business trip travel mode choice and frequency, teleworking, and teleconferencing.

\section{Individual Determinants}

Individual determinants are defined as determinants of a psychosocial nature that are relevant on the individual level. We chose to employ a framework - similar to the one used in Gardner and Abraham's (2008) meta-analysis - which only contained general theoretical concepts that are commonly used to explain a wide range of social behaviors. Research has not established the superiority of more domainspecific theories such as Stern's Value-Belief-Norm Theory (Kaiser et al., 2005; Stern et al., 1999). Thus, we have included social-cognitive variables (i.e. attitudes; subjective norms; self-efficacy) and habit in our framework for individual determinants:

"Attitudes" are an individual's overall evaluation of a behavior (Eagly et al., 1993). In the specific context of travel mode choice, it is important to note that attitudes towards behavioral alternatives may also significantly influence one's choice (Gardner \& Abraham, 2010). Several subcomponents of 
attitudes can be distinguished. One distinction is that between instrumental and experiential aspects of attitudes (Fishbein et al., 2010). The former is connected to the outcome of a behavior while the latter is linked to the experience of engaging in a behavior. For certain categories of social behavior, it has also been found useful to emphasize the role of an individual's moral evaluation of a behavior. The moral component has often been referred to as the "personal norm" or "moral norm"(Kaiser, 2006; Parker et al., 1995).

Another social-cognitive component related to the individual in question is "self-efficacy" which refers to a person's evaluation of whether one has the necessary resources, knowledge and/or skills to attain a goal (Bandura, 1997), or more narrowly conceived, to perform a behavior (Ajzen, 1991). Evidently, perceptions of control are linked to objective external circumstances. In the context of commuting behaviors, for instance, it is clear that travel mode options are influenced by the individual's commuting distance and the regional infrastructural constraints.

In contrast to attitudes, the influences of other people on the individual are reflected in "perceived norms", which are defined as the perception of other people's evaluation of a behavior. A useful distinction is that between injunctive norms, which concern others' approval/disapproval of one's own behavior, and descriptive norms, which refer to others' behavior (Schultz et al., 2007).

For social-cognitive variables to play a role in behavior, it should be possible to (partially) control the behavior on a volitional basis (Fishbein et al., 2010). Furthermore, awareness of its personal, social, or environmental relevance is also prerequisite. When such behaviors are repeatedly performed, they no longer require deliberative evaluation which has led many to argue that they become "habits", which are characterized by a degree of automaticity and unconsciousness (Fishbein et al., 2010; Verplanken et al., 2003). In this phase, contextual cues like time and place may play a more salient role in determining behavior than social-cognitive variables (Wood et al., 2005).

\section{Organizational Determinants}

Organizational determinants are defined as those influences on behavior specific to the organizational context. According to Tudor and colleagues, who presented a framework of factors influencing proenvironmental (management) behavior, five organizational determinants are of relevance: organizational focus, organizational structure, organizational/site type and size, departmental type and size, and organizational culture (Tudor et al., 2008). Although Tudor and colleagues have outlined such a framework, we believe it to consist mainly of indirect determinants of behavior or determinants which may be too broad to be meaningful. Organizational size, for instance, can be hypothesized to affect the degree of interaction between organizational members and therefore indirectly influence the salience of subjective norms regarding proenvironmental behavior. Nevertheless, Tudor et al.'s proposed framework does provide a valuable tool for the search of organizational characteristics directly related to proenvironmental behavior. Of the factors included in their framework, organizational focus and organizational culture may be the ones that most straightforwardly affect individual determinants.

Organizational focus, defined as the primary aim of an organization, may be directly related to proenvironmental behavior in the sense that it, at least on the organizational level, sets the priorities, which may or may not be aligned with environmental sustainability. In the present study, we employed variations in organizational focus to further explore its role in proenvironmental behavior.

Organizational culture comprises those elements that are shared by organizational members. It could indeed be seen as a broader concept which includes, or is at least interlinked with, organizational focus (Tudor et al., 2008). In Schein's model of organizational culture, organizations can be understood 
on three levels (Schein, 1992). The first level is that of artifacts, such as physical facilities like parking spaces and formal organizational policies, which are tangible and explicit. The second level is that of values, which are intangible but (partially) explicit. Examples are informal rules, and perceived values and ideal types. The third level of basic assumptions are intangible and taken for granted, such as unwritten norms. In our study, we will mainly focus on the distinction between the formal level, that of artifacts, and the informal level, that of values and basic assumptions.

Another consideration to take into account are the different roles organizational members play within organizations. Three types of distinctions are relevant. Firstly, previous research found that top and middle management play a distinctive and important role in organizational proenvironmental behavior through their views, policy decisions, and behaviors towards employees (Ramus et al., 2000; Siero et al., 1989; Tudor et al., 2007). Indeed, the specific role of managers in organizational environmental practices has relatively often been studied interorganizationally (Branzei et al., 2004; Fineman, 1996; Sharma, 2000).

Secondly, employees with specific job responsibilities, such as human resource managers responsible for compensation of travel expenses and environmental coordinators, evidently have a distinct function. Their views on policy measures, the organization, and the compatibility between the two, can have a comparatively large impact. These have thus been a research focus in studies on proenvironmental behavior in organizations (Egmond et al., 2006; Vermeulen et al., 2006; Völlink et al., 2002).

Thirdly, all other employees, or "general employees", have a direct influence through their daily travel-related choices and indirectly through the possibilities and constraints they impose on management and key actors. To the best of our knowledge, there are no comparative, interorganizational analyses of the relationship between organizational determinants and employee proenvironmental behaviors (Lo et al., in press). In other words, there is a lack of research on proenvironmental behavior of general employees in organizations.

\section{Implications for Current Research}

To conclude, it was possible to establish a general conceptual framework of individual determinants that may play a role in determining work-related travel behaviors from previous research on proenvironmental behavior. However, the existing literature did not provide sufficient tools for the construction of a solid framework for organizational determinants that directly affect proenvironmental behavior. Given this lack of knowledge, we considered qualitative research methods most appropriate for examining individual and organizational determinants as well as the interactions between these influences because fewer constraints would be imposed on exploring possible relevant organizational influences. Consequently, we conducted semi-structured interviews and focus groups among employees and key actors from the organizations in our sample.

\section{Methods}

We conducted a qualitative exploratory study in four Dutch organizations as part of a wider research project on energy-related behaviors of office workers. Ethical approval was obtained from the faculty's standing ethical committee before data collection. Interviews were conducted in Dutch by the first author between December 2008 and November 2009. 


\section{Sample Characteristics}

Interviewees were recruited from four organizations located in the Dutch provinces of Zuid-Holland $(\mathrm{ZH})$ and Limburg (LB). The two regions were selected because of their differences in population density and possibly culture, with Zuid-Holland being the more urbanized region. Two commercial companies (company $\mathrm{ZH}$; company LB), a university (LB), and a non-profit organization (ZH) participated.

All organizations had some form of public commitment to environmental sustainability, but none had energy conservation as their primary organizational aim.

Interviewees roughly fell into two groups: "key informants", who fulfilled a special role in the energy use of the organization (e.g. facility managers or environmental policy coordinators), and "general employees" or "office workers" (i.e. all other office workers).

\section{Recruitment}

We approached organizations with the request to take part in the research project, promising participating organizations a report of the anonymized, general results. A key informant in each organization served as a contact person. Contact persons identified other key informants, and invited a representative sample of general employees.

\section{Procedure}

\section{Phase one: key informants}

At each organization, four to five informal interviews were conducted with key informants. We informed them that we were interested in organization-specific background information and their views about organizational energy use so that we could identify suitable questions for the interviews with general employees. We also requested key informants to provide additional documentation (e.g. policy documents, internal communication materials, and press articles). In addition, a few key informants were also contacted by phone and e-mail for specific information.

\section{Phase two: general office workers}

Six to nine individual semi-structured interviews of 45 to 75 minutes were conducted at each organization. In addition, one to three focus groups of 90 to 120 minutes, each consisting of four to eight participants, were conducted at each organization. Before interviewing, participants received oral and written information concerning the research aim, data confidentiality, and the voluntary nature of their participation. Following this, they were requested to sign informed consent and asked permission for recording the conversation.

\section{Interview Topics}

\section{Key informants}

Interviews with key informants served to gather information about the organization in general, and energy use more specifically. In addition, key informants were asked more generally about their views on determinants of and opportunities for energy conservation in their organization.

\section{General office workers}


Interviews with general employees were solely concerned with their views on facilitators and barriers to and opportunities for energy conservation (see Appendix A for a sample topic guide). We first asked open-ended general questions about energy use and conservation which were followed by questions about work-related energy use.

\section{Data Analysis}

All interviews were recorded with a digital recorder and transcribed verbatim. Qualitative research software (QSR NVivo 8) was used to facilitate coding and analysis.

First, the transcripts were divided into text fragments based on the energy consumption categories as outlined in the topic guide. Second, facilitators, barriers, change potentials, and strategies for change were identified for all relevant behaviors. Third, all fragments with organization-individual interactions were identified. General patterns of interactions between the individual and the organization were extracted and described with theoretical individual determinants as the organizing unit. Finally, salient determinants for each specific travel-related energy use category were identified.

\section{Results and Discussion}

\section{General Interaction Patterns}

\section{Awareness}

In general, office workers are well-aware of the relative environmental impact of their travel behavior. Furthermore, thanks to the fact that most organizational policies and regulations have visible, practical or financial consequences for their employees, office workers tend to be well-informed about these even if they do not consider them environmental policies as such. This conclusion is justified because not only did employees say they knew about such policies and regulations, but their description of the situation was remarkably consistent with information obtained from key informants. A marginal exception is awareness of the full range of transport alternatives. Employees do not always explore all possibilities for new travel destinations or novel alternatives for familiar routes.

\section{Attitudes}

General attitude towards environmentally-conscious travel behavior varied widely among office workers. More specifically, office workers differed in the importance they attached to a particular attribute of a travel mode or consequence of a behavior, such as financial costs or (lack of) privacy. Personal environmental concern did not seem to be a strong determinant of travel choices. In fact, interviewees tended to emphasize other motivations even if they chose for the environment-friendlier option. Perceived infrastructural constraints, organizational influences, and non-environmental personal considerations, were more important influences on employees' overall evaluation of travel options. All these factors could roughly be related to two dominant themes, namely time and comfort. Office workers assessed both the relative impact of travel choices on these two factors, and the importance attributed to either one of them, differently. Furthermore, time and comfort may not be of equal importance to the same individual across the range of relevant travel behaviors as the following case shows:

"[commuting by train] would cost me too much time... [it would take] half an hour longer than by car... Working at home can be of added value...you can do things 


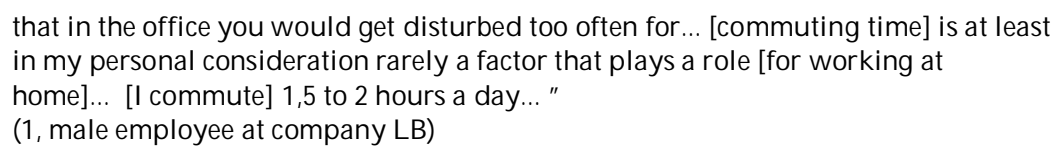

Three salient themes characterized individual-organization interactions. Firstly, financial (dis)incentives created by organizational regulations had diverging impacts on individuals' overall attitudes toward travel choices. Linked to this, is the inverse relationship between disposable income and the importance of personal financial considerations that was apparent from comparing employees with junior and (more) senior job profiles. Secondly, frequency and duration influenced whether employees found traveling enjoyable. Thirdly, one level of determinants was often found to dominate over the other. The impact of organizational influences could be such that opposite individual preferences had no effect on behavior or vice versa as illustrated by the following cases:

"I find it rather pleasant, even if it's just for taking some stuff to read... Yeah, it's really like that...l'd really like to take the train... but the car is free, because it is a company car, and I have to pay for the train."

(5, male employee at company ZH)

“[I commute] by car... with public transport it would take me... longer... Besides, it's much more pleasant because you're a lot more flexible... have my own car and it's partially reimbursed..."

Q: "thetrain is fully reimbursed?"

"Yes that's right."

(2, male employee at company LB)

This suggests it is crucial to examine the relative strength of both levels of determinants.

\section{Self-efficacy}

(Perceived) ability to perform the relevant behaviors per se was largely irrelevant (except for adopting a fuel-saving driving style and using teleconference facilities), but the extent to which office workers felt they could cope with constraints imposed by external factors such as infrastructure, demands of clients, and organizational facilities and policies was important. Especially the impact of societal trends and infrastructure was often argued to determine which options were viable. The second salient theme was the extent to which travel behavior was perceived to affect control over work efficiency and quality.

\section{Social norms}

Interviewees generally did not acknowledge an influence of social norms on their own travel behaviors. Nevertheless, most employees were conscious of the descriptive social norms regarding travel behaviors. In contrast to the role of other organizational members in general, superiors' preferences were acknowledged to influence, and in some case even dictate, whether and how employees commuted and made business trips.

Of specific relevance to the companies, were norms regarding company cars. Some company employees implied that there was a negative social norm towards energy-efficient cars because colleagues, especially managers, were perceived to value big cars and oppose environmentally-inspired restrictions on the range of cars one could choose from. Another related claim was that company cars were part of employment terms, rendering employee choice restriction inappropriate. 
For the NGO, its organizational focus, development aid, had strongly conflicting normative influences on travel behaviors. On the one hand, development aid was increasingly perceived as related to environmental issues because climate change had become a pressing issue in the countries where they operated. On the other hand, relatively frequent intercontinental air travel was considered crucial to the proper execution of their core task.

\section{Habit}

The role of habit in travel behaviors was rarely discussed extensively by office workers. Although they would acknowledge certain behaviors had become habitual, they mainly discussed the reasons for this. Furthermore, they often explicitly stated that more or better information would not motivate them to change their habits. In fact, small-scale interventions were rarely perceived to have the potential to change travel-related habits (except for adopting a fuel-saving driving style). This supports the previously reported finding that lack of awareness is not a major obstacle to energy-efficient travel behaviors. Nevertheless, it was apparent that habit may influence the perceived relevance of travelrelated beliefs. For example, interviewees whose living or working circumstances had altered and who consequently adapted their travel habits, evaluated the attractiveness of alternatives differently when they returned to the original (or almost equivalent) circumstances, as illustrated by the following case:

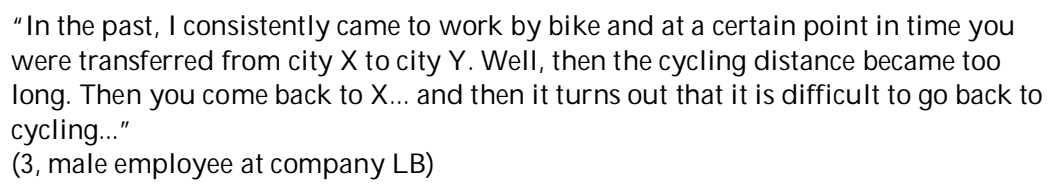

\section{Commuting}

\section{Commuting: Travel Mode}

Travel mode options are obviously restrained by the distance between home and work. Office workers living nearby have the widest range of options to choose from: they can go to work by car, public transport, bicycle, or on foot. For employees living slightly further away walking was not a viable option anymore, and those living far way could not even cycle. Another obvious external constraint is the regional infrastructure. It is generally known that in Zuid-Holland, traffic jams are more common and public transport more extensively-developed than in Limburg.

However, even bearing distance and regional differences in mind, other individual and organizational differences still accounted for substantial variation in travel mode for commuting purposes. On the individual level, personal preferences, family responsibilities, but also work habits and job requirements influenced commuting behavior. Both employees who brought young children to school and who made frequent trips for work during the day were more likely to drive, because the car is perceived as a quicker and more flexible transportation mode. Preferences unrelated to objective circumstances can also be determining factors. Public transport users were generally of the opinion that not having to pay attention to traffic is a major advantage of public transport, whereas car drivers enjoyed their privacy. Train riders preferred having the opportunity to read and work on their laptop during their commute, whereas car drivers often used their commute to make phone calls as illustrated by the following contrasting cases: 
"[I like the train] a lot. Yes, even more so because, one, I think it's relatively relaxing, and two... reading things in advance...e-mails... I do all those things in the train...I love it. And while driving a car you can obviously not do that."

(6, male employee at company ZH)

"I go home after the traffic jams... But I think calling in the train, well, I think, for calling the car is a lot easier. And then I can also spend my time in a useful way..." (7, male employee at company ZH)

At the organizational level, policies and facilities mainly influenced commuting preferences through financial incentives. All organizations (partially) compensated for commuting costs. The most important differences were parking restrictions imposed by the Zuid-Holland organizations, and the provision of company cars by both companies. Few interviewees commuted by car if they had no access to free parking. Company car drivers were not compensated for commuting costs if they travelled by other means so few considered alternative transportation, although some walked or cycled to work when the weather was nice.

\section{Teleworking}

Teleworking was defined as working elsewhere, usually at home. Advocates of teleworking could be purely motivated by work-related advantages but also by the desire to combine work with private life. Work-related reasons were the need for a quiet environment to work efficiently, reduction of travel time on days one is making business trips, and better equipment for work-related tasks at home. Private reasons were combining child care with work and reducing overall commuting time. Although some noted that teleworking would be beneficial to the environment, no one claimed it was the primary reason for them personally to telework. Overall, interviewees were in favor of the possibility to telework, although organizational differences were apparent. The NGO employees were most positive about working at home. Company employees tended to mention the need to be present for colleagues, superiors or clients, whereas some university employees expressed the fear of losing work-life balance if teleworking were to be introduced more structurally.

In all four organizations, there were some employees who teleworked on a sporadic or regular basis. There were no general, well-known organizational policies, except at the NGO where employees knew that the official policy forbade regular teleworking. In practice, teleworking in all organizations depended on one's direct superior's approval and adequate facilities to telework (e.g. ability to log on to the organizational server from home), which replicates previous research findings (Bailey et al., 2002). Some claimed that managerial disapproval was associated with distrust of employees and the manager's age.

It is evident that the interaction between organizational approval and employee attitude towards telework determine whether and how often people telework. In addition, interorganizational comparison shows that rather similar outcomes could be the result of very different individualorganization interactions. Compare the case of the NGO to that of company LB:

“...being flexible with working at home... I think NGO ZH could handle it differently. Officially we are very strict and old-fashioned in this matter. But in practice it does happen."

(8, female employee at N GO ZH) 


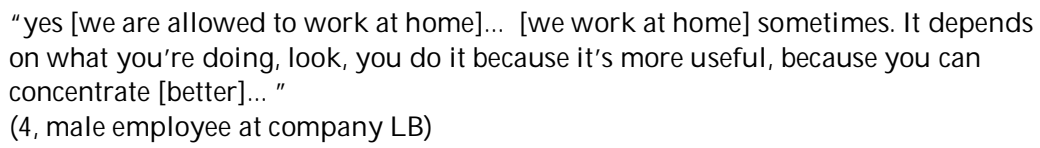

\section{Business Trips}

\section{Business Trips: Frequency}

The number of national and international business trips varied greatly depending on individual-specific job profiles, the organizational focus, and geographical spread of the organization. With regard to the last factor, it should be noted that both companies were widely dispersed across the Netherlands and internationally (although employees of only one of the company's office buildings were interviewed). In contrast, the vast majority of NGO and university employees were working in the same city.

Although office workers often used travel time for work, time loss was still considered a major disadvantage of traveling. Paradoxically, for business trips made within the Netherlands or border regions, time loss was a more salient consideration than for more distant foreign destinations. This is partially due to the higher number of trips most employees make to national or equidistant destinations. Another reason is that more short-distance trips can be substituted by communication via telephone, email or teleconference because many are made solely for relatively short discussions. Finally, there are fewer personal motivations for making national trips. In contrast, some who travel to distant destinations enjoy the opportunity to visit a foreign country. For example, at the university, it was common to combine a work-related trip with a holiday.

An employees' average travel frequency was negatively related to experiential attitudes. In addition to time loss, frequent travelers also considered the high financial costs (especially of international trips) and work-life balance issues to be disadvantageous.

Nevertheless, experiential attitudes towards business trips were not perceived as the dominant personal driver for making international trips. The most important explicit motivation was conducting work-related tasks that required physical presence. Especially the NGO employees indicated that intercontinental trips usually lasted for weeks and included many activities other than formal meetings. Company employees who did travel internationally for business meetings only, indicated that these tended to last for days. Furthermore, at the time of the interviews, they indicated that their companies had reduced international travel budgets due to the economic crisis.

However, some also noted that not all work-related purposes were equally important and colleagues were occasionally accused of traveling more than necessary. Thus, as one office worker put it:

"A nd you can ask yourself: is it truly necessary to attend that conference? Do you really get the result out of it that is important to you?"

(9, male employee at NGO ZH)

Overall, it was concluded that the question was not whether one should travel but how often.

\section{Business Trips: Travel Mode}

Similar to commutes, time, comfort, and personal work habits were perceived to have a significant influence on travel mode choice for business trips. Compensation for first class train tickets could 
therefore be relevant if it meant that employees could secure a seat during rush hours. Combining visits to different national or equidistant foreign destinations was a common reason for traveling by car because it was perceived to increase flexibility and reduce travel duration.

For employees of company ZH, financial incentives also mattered. Those who had a company car were not compensated for public transport costs made for business trips. Nevertheless, some managers still opted for public transport when it was faster or more convenient for them. Lower-level employees were more deterred by the costs they would incur personally. Thus, financial disincentives may have a selective impact on employee travel choices for business trips. Interestingly, positive incentives may have a similarly selective effect. The case of company LB shows that although full compensation for business trips made by first class public transport did seem to be linked to higher rates of public transport use, employees claimed they were only traveling by train if they perceived it to be quicker and more comfortable (possible because car use was also compensated for). Arguably, only a sound combination of financial incentives for public transport and disincentives for car use would lead to more consistent results, which was the case at the NGO. However, it is possible and even highly probable that NGO employees were generally more inclined to use public transport than company employees.

In addition, business trips were more influenced by organizational social norms than were commutes. For example, at the university and company LB, some employees, who commuted by car, traveled by train for business trips because they thought they were supposed to. However, others at the same organizations still made frequent business trips by car. Thus, informal norms rather than strict formal rules, influenced the train riders:

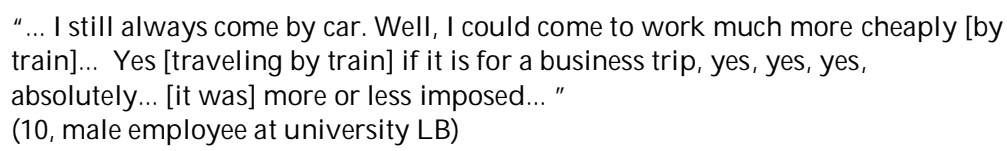

Time and work habits also played a prominent role in travel mode choice for international business trips. It is possible to travel by train to European destinations, but it is generally only opted for if travel time is not perceived to be longer compared to flying. Sometimes increased opportunity to work during travel time was considered in the cost-benefit analysis. The only possible exceptions were the NGO employees who were to some extent willing to travel longer by train. Their organizational focus seemed to influence their attitude, because they referred to other NGOs who had already implemented policies regarding train travel for European destinations. An additional obstacle perceived by some university employees, who had a limited personal travel budget, were the higher costs of train tickets.

\section{Teleconferencing}

Teleconference facilities were defined as all modern communication facilities except for phone and email. On the one hand, there was a broad consensus among office workers that teleconference facilities had the potential to improve work quality by providing a better alternative to the phone or to reduce the travel frequency. Teleconferencing was sometimes seen to improve work because of superior sound quality, less prohibitive costs compared to international phone calls, and increased speed of communication thanks to images. Perceived potential for reducing the number of trips seemed to be largely dependent on current travel frequency. On the other hand, interviewees also agreed 
teleconferencing should be complementary to physical contact. In short, travel would remain necessary or at least desirable, but teleconferencing could reduce its frequency or improve work quality.

Familiarity, trust, limited length of a session, and moderate complexity of the subject matter were often stated as necessary conditions for teleconferencing. Most office workers who had experience with teleconferencing claimed it was necessary to have met contacts in real life or that it worked best with people they knew well. A few disagreed but did believe that physical contact is needed when trustrelated issues are involved. Additionally, others pointed out that teleconferencing required novel technical and social skills.

Technical complexity was also the reason why facilities like conference calls and Skype were in higher demand than videoconference, which is more complex to operate. Therefore, most perceived videoconference only to have added value when discussions are relatively complex and visual images need to be presented.

At the time of the interviews, all organizations were still in the process of expanding and/or piloting teleconference facilities. Many employees believed that they could use teleconference more intensively in future. Some still had no or limited access to the facilities they would want to use. An equally decisive, current obstacle was external contacts' lack of access to facilities.

\section{General Discussion}

Despite the wide range of organizational foci, organizations were found to share various similarities. Changeability of travel mode was perceived to be relatively low irrespective of the individual's preferred mode of travel. Employees were often convinced that their travel habits reflected the optimal choice for them. Attitudes and beliefs towards car and train use varied substantially, despite the fact that time and comfort played a decisive role for most employees. This finding may not be surprising as previous studies have found travel mode changes to be high-cost behaviors (Kaiser et al., 2009). In contrast, the potential for teleworking and teleconferencing was perceived to be relatively high. Although employees saw the limitations of these practices, most believed that they had potential to increase work efficiency and quality in the future. Another important, but largely implicit theme was that the definition of "necessary travel" was highly subjective. Although employees frequently believed that work-related trips were necessary or at least desirable, no common criterion to evaluate necessity or desirability emerged.

Where similarities between organizations show common individual-organizational interactions, differences between organizations illustrate the diverging effects these interactions can have on workrelated travel behavior. First, organizational financial incentives (and their corresponding formal organizational policies) did not have a uniform effect on employee choices which could partially be explained by differences in personal income and attitude strength. The effects of non-financial organizational policies and guidelines also interacted with attitudes. Similar to conclusions from previous qualitative research, this implies that determining the relative strength of individual and organizational determinants is paramount to understanding travel behavior; very strong (dis)incentives on either the personal or organizational level can render determinants at the other level irrelevant to the behavioral outcome (Mann et al., 2006). Secondly, differences in organizational focus were related to tolerance of time loss and travel frequency. Time efficiency of a transport mode was considered more important among company employees than among NGO employees. The organizational focus, and geographical spread of the organization obviously also affected travel frequency and travel destinations of employees. Frequency, in turn, was negatively related to employees' attitude towards business trips. 
Thus, organizational policies aimed at minimizing the number of trips may have diverging effects depending on employees' individual travel frequency. The less employees travel, the smaller the effect organizational measures may have. Generalizing to the organizational level, it would imply that organizations with generally higher travel frequency might see larger effects for the same measures. Finally, interorganizational differences between general employees were found, to some extent, to correspond to organizational culture differences at the organizational level. For instance, more key informants from the NGO were willing to put time and effort into providing (detailed) background information for the research project than key informants from other organizations. As a result, more detailed background information was obtained from the NGO than the other organizations. More importantly, this clearly raises the issue of determining cause and effect when analyzing the interaction between individual and organizational determinants.

\section{Limitations and future research directions}

Despite the fact that organizations in two distinct regions in the Netherlands were sampled, some shared external influences were found. For instance, all organizations partially shared the same infrastructure.

Related to this, was the choice to focus on individual-organizational interactions that led to a neglect of influences on the regional, national or global level, and within-organization interactions such as between formal and informal organizational aspects. Furthermore, the dynamics between individual and organizational determinants over time were left relatively unexplored. Although some evidence can be derived from cross-sectional interview data, comparisons over time are methodologically superior and may lead to better insights into individual-organization dynamics.

Another limitation was that precise and objective information on relevant organizational determinants, and overall organizational performance with respect to travel energy use was often not available. It was therefore difficult to determine to what extent differences in formal and informal organizational features actually affected work-related travel behaviors.

Finally, it is unclear to what extent environmentally-relevant work-related travel behaviors share common determinants with other proenvironmental behaviors. Future research could address this issue as it may be informative for developing interventions aimed at environmental sustainability in general.

\section{Implications for interventions}

Our findings, also consistent with previous research findings, have two main implications for interventions. First, measures other than general information and/or small to medium financial incentives may be needed for changing employee travel mode substantially (Jakobsson, Fujii, \& Garling, 2002; Kearney et al., 1995-1996). The results or the current study further show that it is imperative to gauge, in the specific context of interest, the relative strength of obstacles on the individual, organizational, and societal level in order to determine appropriate interventions. Second, teleworking and teleconferencing have the potential to reduce travel frequency with voluntary employee cooperation because they may be compatible or increase work efficiency and life quality. On a cautionary note, these are relatively novel practices which may require skills-training and substantial organizational adaption before they are successfully employed. 


\section{Acknowledgements}

We would like to thank Zamira Gurabardhi for her valuable comments on an earlier version of this article which led to substantial improvements of this paper. 


\section{Appendix A: Sample Topic Guide (translated from a Dutch-language topic guide)}

\section{Part I: Introduction}

\section{Explanation of interview aim}

Introducing the interviewer and the research aims:

- I work for University $X$ on a scientific research project about energy use by office workers. This research project is conducted, among others, with employees of organization $Y$, but also a few other organizations.

- In practice, this means that we interview people to gain insights into the factors that influence energy use and where potential possibilities for change lie. In a couple of months time an online survey will be send to all employees.

- The aim is to deliver a report with the general findings and recommendations to organization $\mathrm{Y}$ as well as to gather data for scientific publications

\section{Participation:}

- I do not expect specialist knowledge or that you have prepared for this conversation, I am only interested in your opinion.

- Everything you tell me is confidential and your name and job title will not be recognizable in quotations that I might want to use in the report. You can also decide to withdraw your consent later. In that case, I will destroy your data.

- Do you still have questions?

- In order to make a report that is as accurate as possible, I would like to record the conversation. Do you have objections against this?

Introducing the interviewee:

- Could you please introduce yourself? (check for name, job profile, duration of employment at the organization, educational background)

\section{Structure of the interview:}

- I will first ask you a couple of general questions about energy use and energy saving and then treat issues that are more specifically relevant for organization $Y$.

\section{Part II: Energy Saving in General}

- What comes to your mind when you think of energy use or energy saving?

- What do you think of energy saving?

- Do you have ideas about how to save energy?

- What are according to you differences and similarities between energy saving in the organization and at home? 


\section{Part III: Energy Saving in the Organization}

- Energy can be used in a lot of different ways, be it directly or indirectly. I have a list of categories of energy use that are relevant to energy use of organization Y. I would like to go over them with you. There are a couple that you have mentioned earlier:

33. Energy use

34. Lighting

35. Heating

36. Electrical equipment: computers, printers, lift, etc.

37. Paper use

38. Printing

39. Paper mail

40. Travel

41. Commuting

42. Flexible office spaces \& telework

43. National \& European \& intercontinental business trips

44. Teleconference use with national and international contacts

45. Food consumption: meat, waste, food miles

46. Water use

47. Recycling and waste

- What are factors that can increase or reduce [energy use X]?

- How can [energy use $X]$ be increased or reduced?

- What are the advantages and disadvantages of using these strategies?

- What do you think of colleagues who do [energy behavior X]?

- Do you talk about [energy use X]?

- Do others speak to a person when he/she does not do [energy behavior X]?

- Do you have objections against measures that were taken in the past or are taken centrally?

\section{Part IV: Conclusion}

- Do you have other comments?

- Do you still have questions?

- I would like to thank you for your participation (hand out debriefing form with contact details) 


\title{
Chapter 5: \\ Energy-Related Behaviors in Office Buildings: an Interorganizational Comparison of a Model of Individual Determinants ${ }^{4}$
}

\begin{abstract}
Introduction
Environmental sustainability has received increasing media, commercial, and political attention over the past decades. Energy use has possibly been the most prominent environmental issue because of energy security considerations as well as the environmental pollutants released by fossil fuel consumption. Carbon dioxide emissions, for instance, are linked to global climate change (IPCC, 2007).

In addition to improvements in technological efficiency and the use of renewable resources, it is of substantial interest to understand psychosocial determinants of behaviors related to energy use for two reasons. First, it has been estimated that substantial energy consumption reductions by means of behavioral measures alone are feasible (Dietz et al., 2009). Second, people's behavior can (adversely) affect the effectiveness of technical measures that have been implemented to reduce energy use. For these and other reasons, the psychosocial determinants of energy-related and other proenvironmental behaviors have been studied relatively extensively in private contexts (for reviews see Abrahamse et al., 2005; Bamberg \& Moser, 2007).

However, previous research on organizations and the environment has mainly investigated the effects of external determinants and organizational characteristics on organizational engagement with environmental sustainability (Etzion, 2007). Compared to household contexts, little research has addressed energy use in organizations at the individual, behavioral level of analysis (Bansal et al., 2006). More specifically, a recent review identified a lack of empirical interorganizational research examining interactions between the employee and the organization (Lo et al., in press). To the best of our knowledge, few empirical studies have investigated employee energy-related behaviors, and none of those involved interorganizational comparisons (Scherbaum et al., 2008; Siero et al., 1996; Siero et al., 1989).
\end{abstract}

${ }^{4}$ This chapter has been submitted for publication as:

Lo, S.H., van Breukelen, G.J.P., Peters, G.J. \& G. Kok, Energy-Related Behaviors in Office Buildings: an Interorganizational Comparison of a Model of Individual Determinants. 
To address this research gap, we conducted a study on energy-related behaviors among office workers. Buildings are one of the main areas in which energy conservation efforts may lead to substantial energy savings in organizational contexts (de Groot et al., 2009). Together with retail establishments, office buildings are the largest energy consumers in the non-domestic sector (PerezLombard et al., 2008). This paper's aim is to present a model of individual determinants for office energy-related behaviors, and to test in which respects this model differs across organizations. We will first examine whether our model of individual determinants fits the data well. Then, we will investigate whether sociodemographic and individual-specific organizational variables can further improve prediction of behavior. Finally, we will investigate similarities and differences between organizations. In particular, we are interested in how the results of the models of individual determinants vary across organizations. The conceptual framework used for examining individual determinants and a discussion of organizational determinants are presented below.

\section{Individual Determinants}

Individual determinants are defined as determinants of a psychosocial nature that are relevant on the individual, personal level. Although specific theories of proenvironmental behavior have been proposed in the literature, we chose to employ a framework that only contained general theoretical concepts commonly used to explain a wide range of social behaviors because of two reasons. First, domain-specific theories such as Stern's Value-Belief-Norm Theory (VBN) have so far accounted for a smaller proportion of the variance in behavior than generic theories like the Theory of Planned Behavior (TPB) (Ajzen, 1991; Kaiser et al., 2005; Stern et al., 1999). Second, commonly used, generic concepts may have the additional advantage of facilitating comparison with findings of behaviors from other domains, and thus lead to greater parsimony. As a result, we have included social-cognitive variables (i.e. attitudes; perceived norms; self-efficacy), and habit in our framework for individual determinants:

"Attitudes" are an individual's overall evaluation of a behavior (Eagly et al., 1993). Several subcomponents of attitudes may be distinguished. One distinction is that between instrumental and experiential aspects of attitudes (Fishbein et al., 2010). The former is connected to the outcome of a behavior while the latter is linked to the experience of engaging in a behavior. For certain categories of behavior, it has also been found useful to emphasize the role of an individual's moral evaluation of a behavior. The moral component has often been referred to as "personal norm" or "moral norm"(Kaiser, 2006; Parker et al., 1995). While some suggest a lack of discriminant validity between personal norm and attitude, others maintain it should be considered a distinct construct (Bamberg, Hunecke et al., 2007; Kaiser, 2006).

Another social-cognitive component related to the individual in question is "self-efficacy" which refers to a person's evaluation of whether one has the necessary resources, knowledge and/or skills to attain a goal (Bandura, 1997), or more narrowly conceived, to perform a behavior (Ajzen, 1991).

In contrast to attitudes, the influences of other people on the individual are reflected in "perceived norms" which are defined as the perception of other people's evaluation of a behavior. A useful distinction is that between injunctive norms, which concern others' approval/disapproval of one's own behavior, and descriptive norms, which refer to others' behavior (Schultz et al., 2007). For proenvironmental behaviors, one should also consider the possibility of absence of perceived norm, i.e. not knowing what others think and do (Siero et al., 1984).

For social-cognitive variables to play a role in behavior, it should be possible to (partially) control the behavior on a volitional basis (Fishbein et al., 2010). Furthermore, awareness of its personal, social, 
or environmental relevance is also prerequisite. When such behaviors are repeatedly performed, they no longer require deliberative evaluation which has led many to argue that they become "habits", which are characterized by a degree of automaticity and unconsciousness (Fishbein et al., 2010; Verplanken et al., 2003). In this phase, contextual cues like time and place could play a more salient role in determining behavior than social-cognitive variables (Wood et al., 2005).

\section{Organizational Determinants}

Organizational determinants are defined as those influences on behavior that are specific to the organizational context. According to Tudor and colleagues, who presented a framework of proenvironmental management behavior, five organizational factors are of relevance: organizational focus, organizational structure, organizational/site type and size, departmental type and size, and organizational culture (Tudor et al., 2008). Although the proposed framework provides a valuable tool for identifying relevant organizational characteristics, it only outlines indirect determinants, and determinants which may be too broad to be meaningfully related to individual behavior.

Organizational size, for instance, can be hypothesized to affect the degree of interaction between organizational members and therefore indirectly influence the salience of perceived norms regarding proenvironmental behavior. In a similar fashion, organizational structure may also facilitate or hinder communication and interactions between organizational members.

Of the factors included in their framework, organizational focus and organizational culture may be the ones that are the broadest but most straightforwardly affecting individual determinants of proenvironmental behavior. Organizational focus, defined as the primary aim of an organization, might be directly related to proenvironmental behavior. At least on the organizational level, it sets the priorities, which may or may not be aligned with environmental sustainability. Organizational culture comprises all formal and informal elements of an organization that are shared by its members (Schein, 1992). It could indeed be seen as a broader concept which includes, or is at least interlinked with, organizational focus (Fernandez, Junquera, \& Ordiz, 2003; Tudor et al., 2008).

More specific crucial influences include that of the roles of top and middle management, who may disproportionately affect organizational culture (Fernandez et al., 2003). Other relevant influences are employees' affective commitment to the organization, and aspects of the organizational physical context that are specifically relevant to (an) energy-related behavior(s) (Andersson et al., 2005; Marans et al., 1993).

Finally, possible differences between subpopulations within an organization have not been researched to the best of our knowledge. Organizational subpopulations can, but not exclusively, be defined on the basis of managerial status, employment duration, part-time versus full-time status, and departmental affiliations. In this paper, characteristics that define organizational subpopulations will be termed "individual-specific organizational variables".

\section{Research Questions}

In the light of the identified research gaps, the current paper will address the following questions for a range of office energy-related behaviors:

\section{Organizational differences in behavior}

(RQ1a) Are there interorganizational differences in the average of each behavior? 
(RQ1b) If so, can these differences be explained by individual-specific influences?

\section{Individual-specific influences}

(RQ2a) Are the identified individual determinants predictors of office energy-related intentions and behaviors? What is the magnitude of significant relationships?

(RQ2b) Does the magnitude of relationships between individual determinants, and intention and behavior differ for the subgroup of employees who were familiar with the relevant social norm?

(RQ3) Do sociodemographic and individual-specific organizational variables explain additional variance in behaviors, over and above the individual determinants and intention?

\section{Organization-specific influences}

(RQ4) Is the factor structure of our models of individual determinants of office energy-related behaviors adequate for each organization in our sample?

(RQ5) Do individual determinants manifest themselves differently across organizations? More specifically, are the loadings of indicators on corresponding latent factors equal across organizations?

(RQ6) Do the average scores on relevant beliefs differ across organizations?

(RQ7) Do the regression coefficients for predicting intention and behavior from individual determinants differ across organizations?

\section{Methods}

\section{Participants and Procedure}

Employees from four organizations located in cities in the Dutch provinces Zuid-Holland (ZH) and Limburg (LB) took part in an online survey study. The sample of organizations consisted of two commercial companies (company ZH; company LB), a university (university LB), and a nongovernmental organization (NGO ZH). We selected these organizations because of their diversity in organizational focus and location. Any similarities between these organizations are more likely to be generalizable to other organizations in similar societies, whereas differences may indicate which parameters may vary between organizations. Company ZH, university LB, company LB, and NGO ZH each participated with one to three office buildings, with a (combined) capacity of approximately 1000, 700,450 , and 350 people respectively. All organizations had some form of public commitment to environmental sustainability, but none had energy conservation as their primary organizational aim. Nevertheless, the NGO's core task, development aid, was increasingly perceived to be related to environmental sustainability because climate change had become a pressing issue in the countries where they operated.

Employees were approached by their own organization with the request to fill out the online survey. It was emphasized that the study was conducted by independent researchers, and only the general anonymized results would be reported to the organization. Except for company LB employees, respondents could participate in a raffle contest for $€ 20$ gift vouchers.

\section{Measures}

Energy-related behaviors and measures of their individual determinants were chosen based on an earlier qualitative study conducted at the same organizations (Lo, Peters, \& Kok, under review-a). Interviews and focus groups with key informants and employees of the four organizations were conducted to identify office workers' energy-related behaviors and their possible determinants. Based 
on these findings, we selected a small number of behaviors for further investigation in the survey, relevant adjectives for the semantic differential scales for attitude measures, social referents for perceived norm measures, and beliefs to measure determinants. Due to survey-length constraints, some determinants were measured with only one item.

\section{Proenvironmental behavior in the office}

Selected behaviors were identified as highly relevant to office workers' daily routines, and showed most evidence of variation across people's behavior. The examined behaviors were (1) 'printing smaller' ("print more than one page on one A4 sheet"), (2) 'not printing e-mails' ("read e-mails without printing them out"), (3) 'switching off lights' ("switch off the lights in my office when I (and my office mates) are absent for a longer period of time during the day"), and (4) 'switching off monitors' ("switch off my monitor when I go home"). Printing smaller and not printing e-mails will be referred to as 'printing behaviors', and switching off lights and monitors as 'switching behaviors'. Unless stated otherwise, all measures were rated on a five-point scale ranging from 1 to 5 , with 1 being the least proenvironmental and 5 the most proenvironmental.

Behavior was measured with one item beginning with "The past month, I have...", rated on a scale ranging from never to always. Because of our cross-sectional survey design, we used behavior of the past month as a proxy for current behavior.

\section{Intention}

Behavioral intention was measured with two indicators, starting with "Next month/in future, I expect..." (I1) and "Next month/in future, I want..." (I2) (range from never to always).

\section{Attitude}

Attitude towards each of the behaviors was measured on a semantic differential scale with the adjective pairs "negative-positive" (IA1), "useless-useful" (IA2), "unpleasant-pleasant" (EA1), and "difficulteasy" (EA2). ${ }^{5}$ We hypothesized that the former two pairs reflected instrumental aspects, whereas the latter would reflect experiential aspects. Instrumental and experiential attitude were modeled as firstorder factors of an overarching second-order attitude factor.

${ }^{5}$ The adjective pair "difficult-easy" is often used to measure self-efficacy, but has been found to correlate much more highly with experiential attitude in some studies (Fishbein et al., 2010). In the present study we also found this to be the case (e.g. $\mathrm{r}=0.39 \mathrm{cf}$. $\mathrm{r}=0.65$ for printing smaller). 


\section{Personal norm}

In addition, we included a one-item morally evaluative measure, "I think employees of organization $X$ ought to..." (PN1) (range from disagree to agree). ${ }^{6}$

\section{Perceived norms}

Injunctive and descriptive norm were modeled as first-order factors of a second-order perceived norm factor. The injunctive norm measure consisted of "My superior(s) think I should..." (ISN1), "My colleagues ..." (ISN2), and "People in my private life who are important to me..." (ISN3), rated on a scale ranging from disagree to agree, with an additional option I really do not know. The descriptive norm items included "My superiors [behavior X]" (DSN1) and "My colleagues..." (DSN2) (ranging from never to always; I really do not know). The answer category I really do not know could be recoded into the scale center (neutral for injunctive norm, and sometimes for descriptive norm) for the total sample analyses, while allowing for a subgroup analysis of those respondents who were familiar with the relevant norm. This made examination of possible attenuation effects due to (frequent) absence of perceived norm possible. The operational definition of this subgroup was ability to gauge the injunctive norm of one's superiors.

\section{Self-efficacy}

Self-efficacy was measured with the item "If I want to, I think I can manage to..." (C1) (ranging from disagree to agree).

\section{Habit}

Habit was measured with two items selected from Verplanken's index of habit strength, namely "I [behavior X] without consciously thinking about it" (H1) and "I routinely..." (H2) (ranging from disagree to agree) (Verplanken et al., 2003).

\section{Background variables}

Sociodemographic and individual-specific organizational variables were considered background variables. The sociodemographic variables examined were gender, age, and educational level. A dummy variable for managerial status, employment duration (i.e. year of joining the organization), full-

\footnotetext{
${ }^{6}$ When speaking of the moral/normative dimension of relevant behaviors, results of the qualitative study showed that it was more natural for employees to speak of all employees rather than they themselves personally. As noted in the introduction, there is disagreement in the literature on whether personal norm is a component of attitude. Given that our personal norm-item refers to one's evaluation of what other people should do we kept it as a separate factor because it is conceptually different from the attitude items.
} 
time equivalent (FTE) ranging from 0 to 1 , and number of office mates were included as individualspecific organizational variables.

\section{Data Analysis}

We tested for interorganizational differences in average behavior with one-way ANOVA (RQ1a). We also tested whether such differences, if found, could be explained by individual-specific differences (i.e. scores on individual determinants and individual-specific organizational variables) by adding individual-specific variables as covariates with ANCOVA (RQ1b). Such differences would warrant further examination of how organizational differences may influence individual determinants of these behaviors, and thus indirectly influence behavior.

Once we had tested for organizational differences in behavior and examined to what extent these differences could be attributed to individual differences, we continued with testing explanatory models of these behaviors. We used confirmatory factor analysis (CFA) and structural equation modeling (SEM) with MPlus version 6 for testing our model of individual determinants of office energy-related behaviors (Muthén \& Muthén, 1998-2010). First, we verified whether our baseline model fitted the data well (RQ2a). We also tested the baseline model on the subgroup of employees who were all familiar with the social norm (RQ2b). Then, we examined the effect of including background variables in our baseline model (RQ3).

Following this, we could test for interorganizational differences in the individual determinants model with multigroup analyses. For a model to be compared across organizations, a first necessary condition is equality of factor structure, or configural invariance, which entails that items are associated with the same common factors in all groups (RQ4).

If equality of factor structure is tenable, further group comparisons can be meaningfully made. We tested for equality of factor loadings, or metric invariance, which means that latent constructs manifest themselves similarly across groups (RQ5). If equality of factor loadings is rejected, the substantial implication is that the relevance of at least some indicators differs across organizations. In that case, partial invariance tests can identify which factors have items that load differently across organizations. Also, we tested for equality of item intercepts which indicates whether groups have significantly different item means (RQ6). Again, partial invariance tests were conducted to examine which item means differed across organizations. Finally, we tested for equality of the structural model to determine whether the regression coefficients of the individual determinants (exogenous latent factors) as predictors of intention and behavior (endogenous latent factors) had equal magnitudes across organizations (RQ7).

\section{Results}

\section{Sample characteristics}

Of those who had started the questionnaire, the completion rates for company $\mathrm{ZH}$, company LB, university $\mathrm{LB}$, and NGO ZH were $55 \%, 65 \%, 69 \%$, and $84 \%$ respectively. Response rates were not calculated because the number of employees reached by the invitation could not be reliably established. Of the total sample, $54 \%$ was female, the mean age was $42(\mathrm{SD}=10.9)$, and $69 \%$ had received higher education. On average, respondents were employed for 0.9 FTE (full-time equivalent) (SD=0.16), mean employment duration was 12 years $(\mathrm{SD}=11.8), 17 \%$ of the respondents had a (senior) managerial 
position, and $22 \%$ had an office to themselves. Sociodemographic and individual-specific organizational characteristics of each organization's respondents are presented in Table 1.

Table 1

Sample characteristics by organization

\begin{tabular}{|c|c|c|c|c|c|}
\hline & Total & $\mathrm{NGO} \mathrm{ZH}$ & Company $\mathrm{ZH}$ & University LB & Company LB \\
\hline Sex (\% female) & $54 \%$ & $62 \%$ & $41 \%$ & $69 \%$ & $44 \%$ \\
\hline $\begin{array}{l}\text { Education } \\
\text { (\% higher education) }\end{array}$ & $69 \%$ & $81 \%$ & $78 \%$ & $82 \%$ & $75 \%$ \\
\hline Age (years) & 42 & 43 & 42 & 40 & 46 \\
\hline$S D$ & 10.9 & 9.8 & 10.9 & 11.5 & 10.3 \\
\hline FTE $(0-1)$ & 0.9 & 0.88 & 0.95 & 0.87 & 0.92 \\
\hline$S D$ & 0.16 & 0.14 & 0.13 & 0.20 & 0.17 \\
\hline $\begin{array}{l}\text { Employment duration } \\
\text { (years) }\end{array}$ & 12 & 8 & 15 & 9 & 18 \\
\hline$S D$ & 11.8 & 7.8 & 12.9 & 8.4 & 12.1 \\
\hline Managerial position & $17 \%$ & $25 \%$ & $20 \%$ & $17 \%$ & $22 \%$ \\
\hline $\begin{array}{l}\text { Single-occupancy } \\
\text { office }\end{array}$ & $22 \%$ & $5 \%$ & $18 \%$ & $21 \%$ & $56 \%$ \\
\hline
\end{tabular}

\section{Organizational differences in behavior}

Descriptive and basic inferential statistics of each investigated behavior are presented by organization in Table 2, and descriptive statistics of beliefs are presented in Table 3. We conducted one-way ANOVA tests to examine whether mean differences in the behaviors between the organizations were significant (RQ1a). Although the null hypothesis was rejected for all four behaviors, the effect sizes of organization on behavior were small (i.e. $\left.\eta^{2} \leq .023\right)$, except for a close to large effect size for switching off lights $\left(\eta^{2}=\right.$ 0.117).

We tested with ANCOVA whether the observed interorganizational differences in behavior could be explained by differences in individual determinants (RQ1b; see Table 2). This was indeed the case for both printing behaviors: the effect of organization was non-significant after including indicators of individual determinants as covariates. However, for switching behaviors, individual determinants and significant organization-related individual-specific background variables (i.e. number of office mates for switching off lights) only partially explained the interorganizational differences. Differences in switching off lights were reduced to a medium effect size $\left(\eta^{2}=0.056\right)$, but did not disappear altogether after covariate adjustment. For switching off monitors, the organization effect was also reduced while remaining significant $\left(\eta^{2}=0.018\right)$. 
Table 2

Means, SDs and sample size of behaviors by organization

\begin{tabular}{|c|c|c|c|c|c|c|c|c|}
\hline & Total & NGO ZH & $\begin{array}{c}\text { Company } \\
\text { ZH }\end{array}$ & $\begin{array}{c}\text { University } \\
\text { LB }\end{array}$ & $\begin{array}{c}\text { Company } \\
\text { LB }\end{array}$ & $\mathrm{F}$ & $\begin{array}{c}\mathrm{p}^{-} \\
\text {value }\end{array}$ & $\eta^{2}$ \\
\hline Print smaller & 3.24 & 3.13 & 3.45 & 3.04 & 3.34 & 5.95 & $<001$ & .018 \\
\hline$S D$ & 1.26 & 1.38 & 1.16 & 1.28 & 1.19 & 1.08 & ns. & \\
\hline$N$ & 970 & 245 & 290 & 275 & 160 & & & \\
\hline Not print e-mails & 3.98 & 3.87 & 4.00 & 4.12 & 3.89 & 7.43 & $<001$ & .023 \\
\hline$S D$ & 0.67 & 0.69 & 0.68 & 0.65 & 0.61 & 0.36 & ns. & \\
\hline$N$ & 970 & 245 & 290 & 275 & 160 & & & \\
\hline Switch off monitor & 4.09 & 3.85 & 4.26 & 4.08 & 4.41 & 5.39 & $<001$ & .023 \\
\hline$S D$ & 1.44 & 1.58 & 1.30 & 1.41 & 1.21 & 3.96 & $<001$ & .018 \\
\hline$N$ & 687 & 249 & 68 & 209 & 161 & & & \\
\hline Switch off lights & 3.63 & 3.04 & N/A & 3.86 & 4.14 & 41.54 & $<001$ & .117 \\
\hline$S D$ & 1.34 & 1.40 & & 1.20 & 1.11 & 17.68 & $<001$ & .056 \\
\hline$N$ & 631 & 231 & & 251 & 149 & & & \\
\hline
\end{tabular}

Italics: corrected for differences in individual determinants using ANCOVA

\section{Table 3}

Descriptive statistics beliefs

\begin{tabular}{lcccccccc}
\hline & \multicolumn{2}{c}{ Print smaller } & \multicolumn{2}{c}{ Not print e-mails } & \multicolumn{2}{c}{ Switch off lights } & \multicolumn{3}{c}{ Switch off monitor } \\
& M & SD & M & SD & M & SD & M & SD \\
\hline N & 895 & & 895 & & 612 & & 658 & \\
Intention (I1) & 3.45 & 1.13 & 4.00 & 0.63 & 4.74 & 0.66 & 4.69 & 0.82 \\
Intention (I2) & 3.41 & 1.15 & 3.98 & 0.65 & 4.34 & 1.01 & 4.57 & 0.90 \\
(Instrumental) attitude & & & 4.45 & 0.84 & 4.68 & 0.77 & 4.76 & 0.67 \\
(A1) & 4.24 & 1.11 & & & & & & \\
(Instrumental) attitude & & & & & & & & \\
(A3) & 4.23 & 1.03 & 4.44 & 0.78 & 3.54 & 1.02 & 4.72 & 0.77 \\
(Experiential) attitude (A2) & 3.39 & 1.34 & 3.82 & 1.12 & 4.54 & 0.88 & 4.34 & 1.04 \\
(Experiential) attitude (A4) & 3.72 & 1.28 & 3.96 & 1.09 & 3.60 & 1.07 & 4.57 & 0.90 \\
Injunctive norm (ISN1) & 3.19 & 1.10 & 3.25 & 1.04 & 3.54 & 1.49 & 3.38 & 1.21 \\
Injunctive norm (ISN2) & 3.17 & 1.06 & 3.29 & 1.04 & 3.60 & 1.51 & 3.37 & 1.21 \\
Injunctive norm (ISN3) & 3.18 & 1.09 & 3.34 & 1.11 & 4.53 & 0.82 & 3.35 & 1.19 \\
Descriptive norm (DSN1) & 3.07 & 0.86 & 3.40 & 0.70 & 3.32 & 0.92 & 3.47 & 1.00 \\
Descriptive norm (DSN2) & 3.12 & 0.87 & 3.53 & 0.65 & 3.34 & 0.91 & 3.55 & 1.01 \\
Personal norm (PN1) & 3.92 & 1.07 & 3.97 & 0.95 & 3.73 & 1.13 & 4.68 & 0.73 \\
Self-efficacy (SE1) & 4.17 & 1.12 & 4.26 & 1.05 & 4.51 & 0.83 & 4.65 & 0.91 \\
Habit (H1) & $2.19 \wedge$ & 1.40 & $3.36^{\wedge}$ & 1.04 & 3.32 & 0.92 & 3.67 & 1.64 \\
Habit (H2) & $2.33^{\wedge}$ & 1.50 & $3.48^{\wedge}$ & .96 & 3.34 & 0.91 & 3.81 & 1.63 \\
\hline
\end{tabular}




\section{Individual-specific influences}

All investigated behaviors had a few to most items violating the normality assumption (i.e. skewness and/or kurtosis values $>1$ ). Because non-normality of indicators can lead to inflated ML $\chi^{2}$ goodness-offit statistics and underestimated standard errors, we chose to estimate the models with robust maximum likelihood (MLM) (Satorra \& Bentler, 1994). Unless stated otherwise, we followed Hu and Bentler's recommendations for evaluating goodness of fit, with around .95 and above for CFI and TLI, and around .08 and below for RMSEA and SRMR as indicators of good fit (Hu \& Bentler, 1999). Goodness-of-fit indices of all models are presented in Table 4 for printing behaviors and Table 5 for switching behaviors. In the remainder of this results section, these models will be further discussed.

Before we addressed our primary research concerns, we first tested our measurement models on the total sample with CFA to confirm the relationship between the latent factors (i.e. the individual determinants) and their observed indicators (i.e. the measurement items). We specified indicators of individual determinants and intention to only load on their own factor. Measurement errors were assumed to be uncorrelated, while all factors were allowed to correlate with each other. The CFA models had an acceptable fit for all behaviors (see model 1 in Table 4-5).

Subsequently, we specified a SEM model to test the hypothesized relationships between the individual determinants, intention and behavior. We hypothesized that 1) the latent factors attitude, personal norm, social norm and self-efficacy all affected intention; and 2) the latent factor habit affected both intention and behavior 3) intention affected behavior. Exogenous latent factors were allowed to correlate freely because there were no hypotheses concerning the relationships between these factors. We tested the baseline model on the total sample (RQ2a; see model 2 in Tables 4-5) and the group of respondents familiar with social norms (RQ2b).

For printing behaviors, a model with a second-order attitude factor showed a satisfactory fit. However, for switching behaviors, a model with a second-order attitude factor gave negative residual variances in some organizations. We therefore collapsed the instrumental and experiential attitude factor into a single attitude factor, which provided admissible solutions for these behaviors. In addition, for switching off lights, we allowed for correlated errors between the injunctive and descriptive norm items of the same social referents for the same reason.

Figures 1-4 show the standardized factor loadings and path coefficients of the baseline models for printing smaller (behavior $\mathrm{R}^{2}=0.63$ ), not printing e-mails (behavior $\mathrm{R}^{2}=0.63$ ), switching off lights (behavior $\mathrm{R}^{2}=0.53$ ), and switching off monitors (behavior $\mathrm{R}^{2}=0.74$ ) respectively. Path coefficients between parentheses indicate the estimated coefficients of individual determinants on intention and behavior for the subgroup familiar with the social norm.

Returning to RQ2a, most hypothesized effects were significant at the .05 level. The strongest direct predictor of printing behaviors was intention, whereas that of switching behaviors was habit. In the total sample, attitude had the strongest effect on intention for all behaviors. Habit was also a significant direct predictor of intention for all behaviors. The effects of perceived norm, personal norm and selfefficacy were less consistent across behaviors.

Compared to the total sample, standardized regression coefficients for the subgroup familiar with social norms tended to differ slightly (i.e. difference <10; RQ2b). However, there were a few substantial differences. Firstly, for not printing e-mails, the effect of perceived norm on intention was higher than in the total sample, and was larger than the effect of attitude (see Figure 2). Also, personal norm did not 


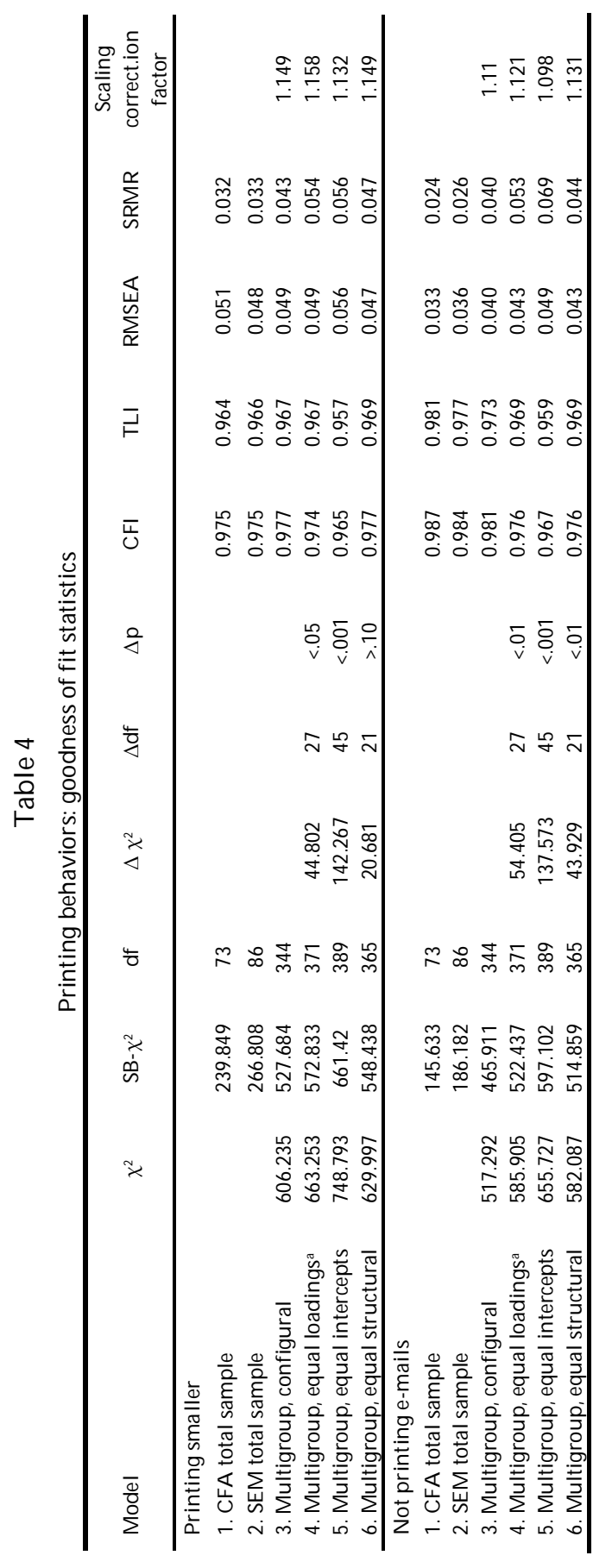




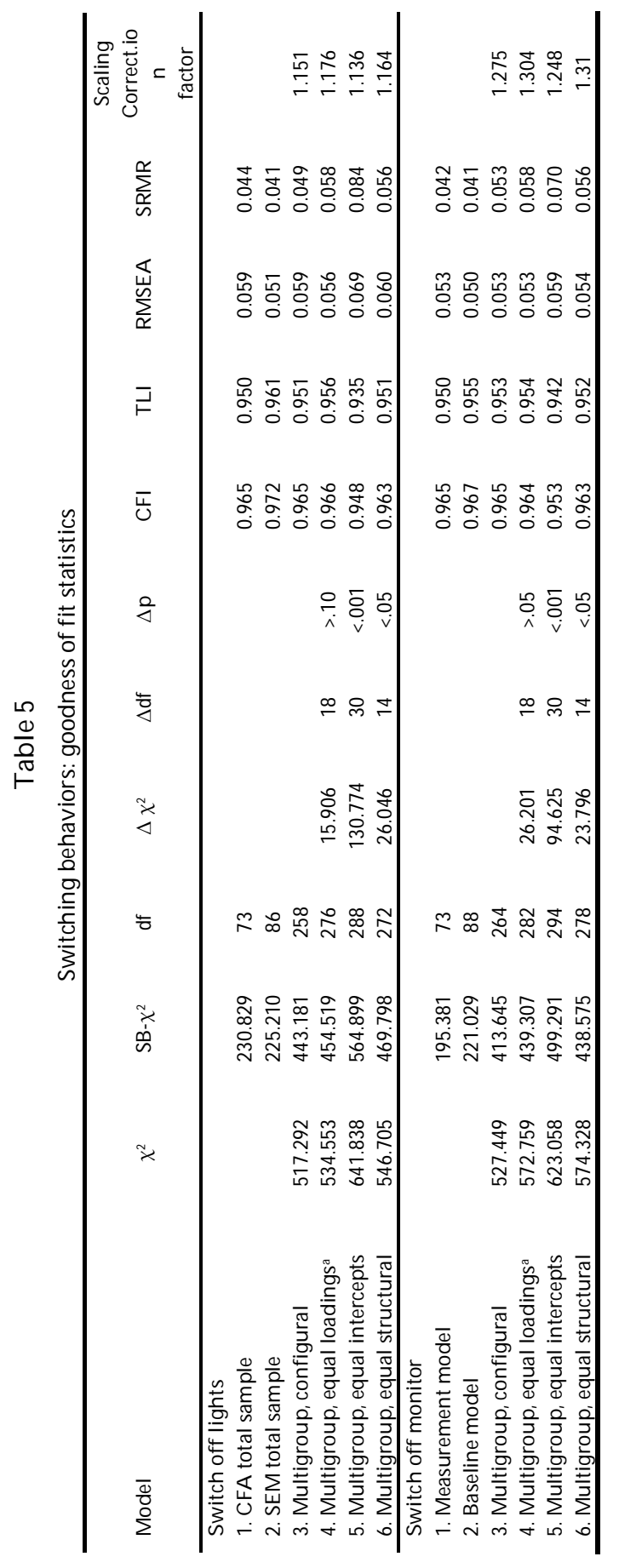




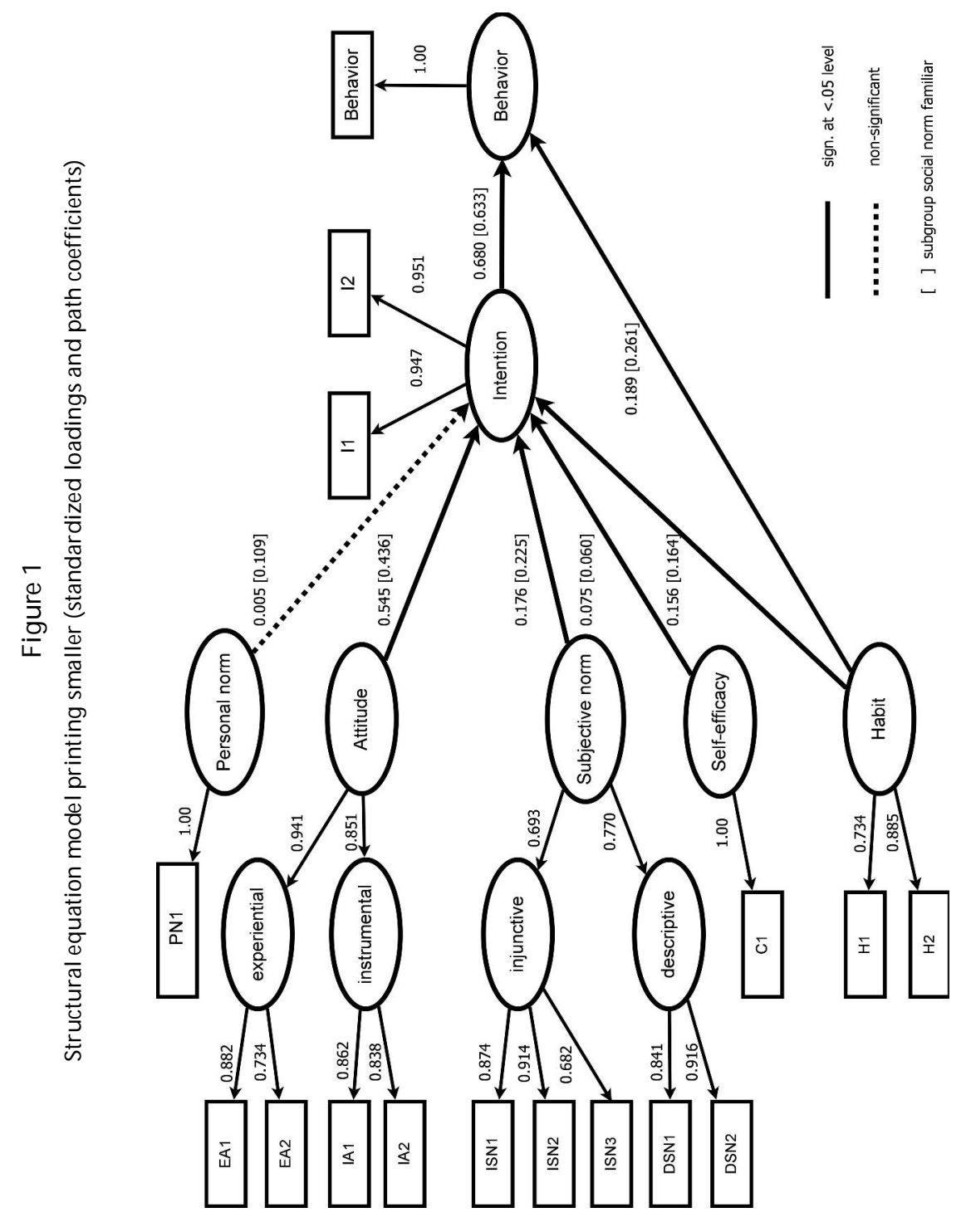




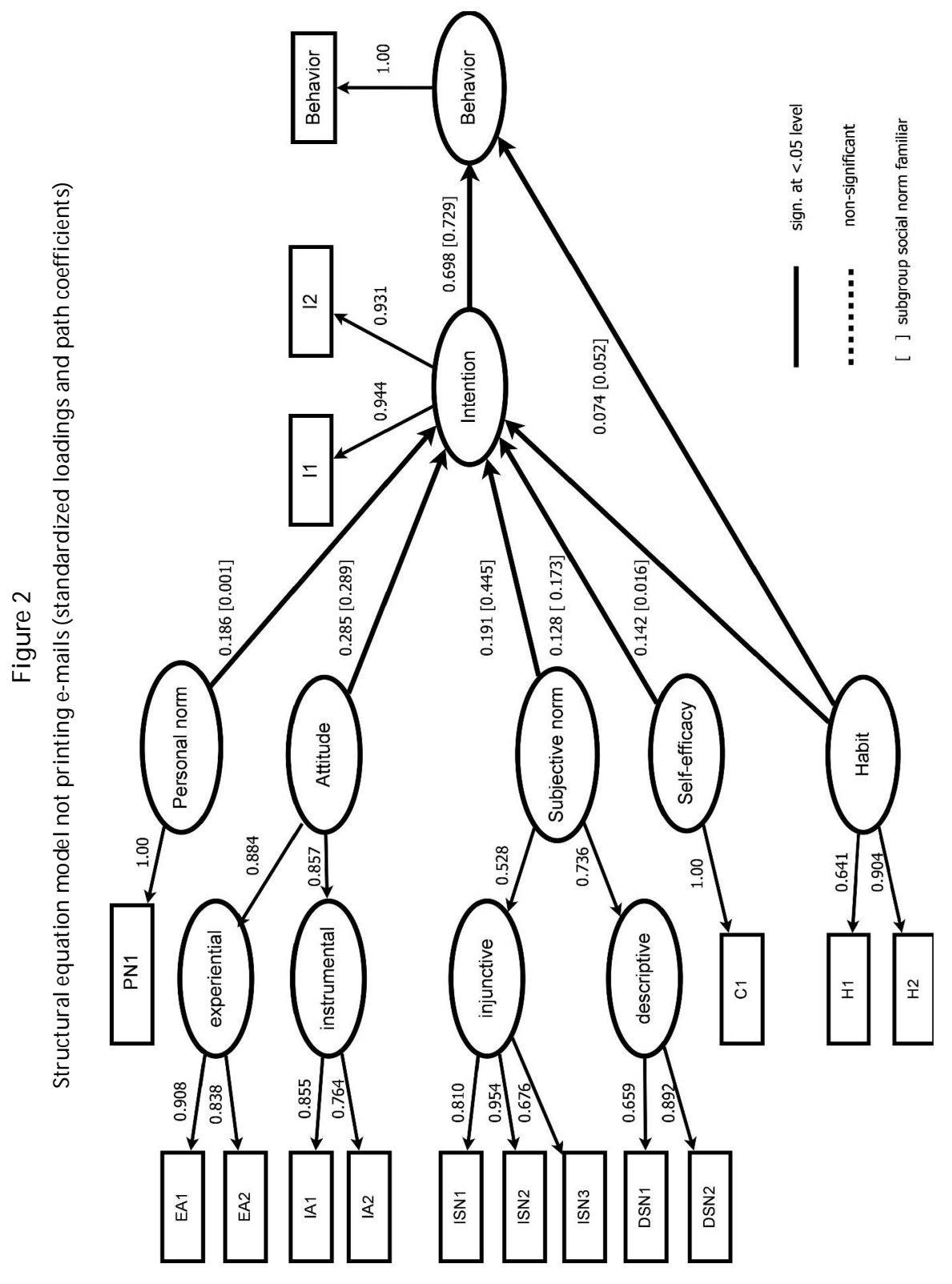




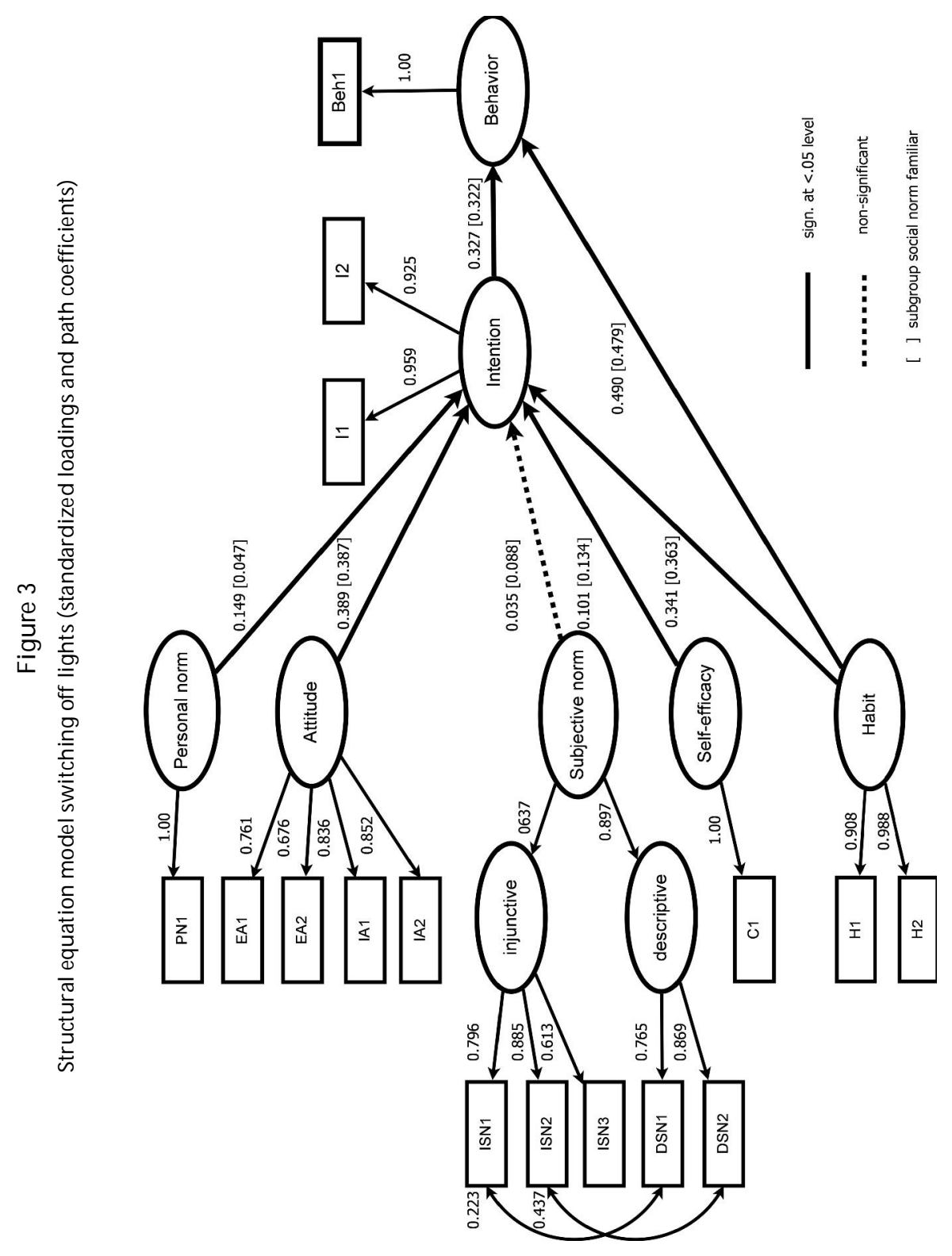




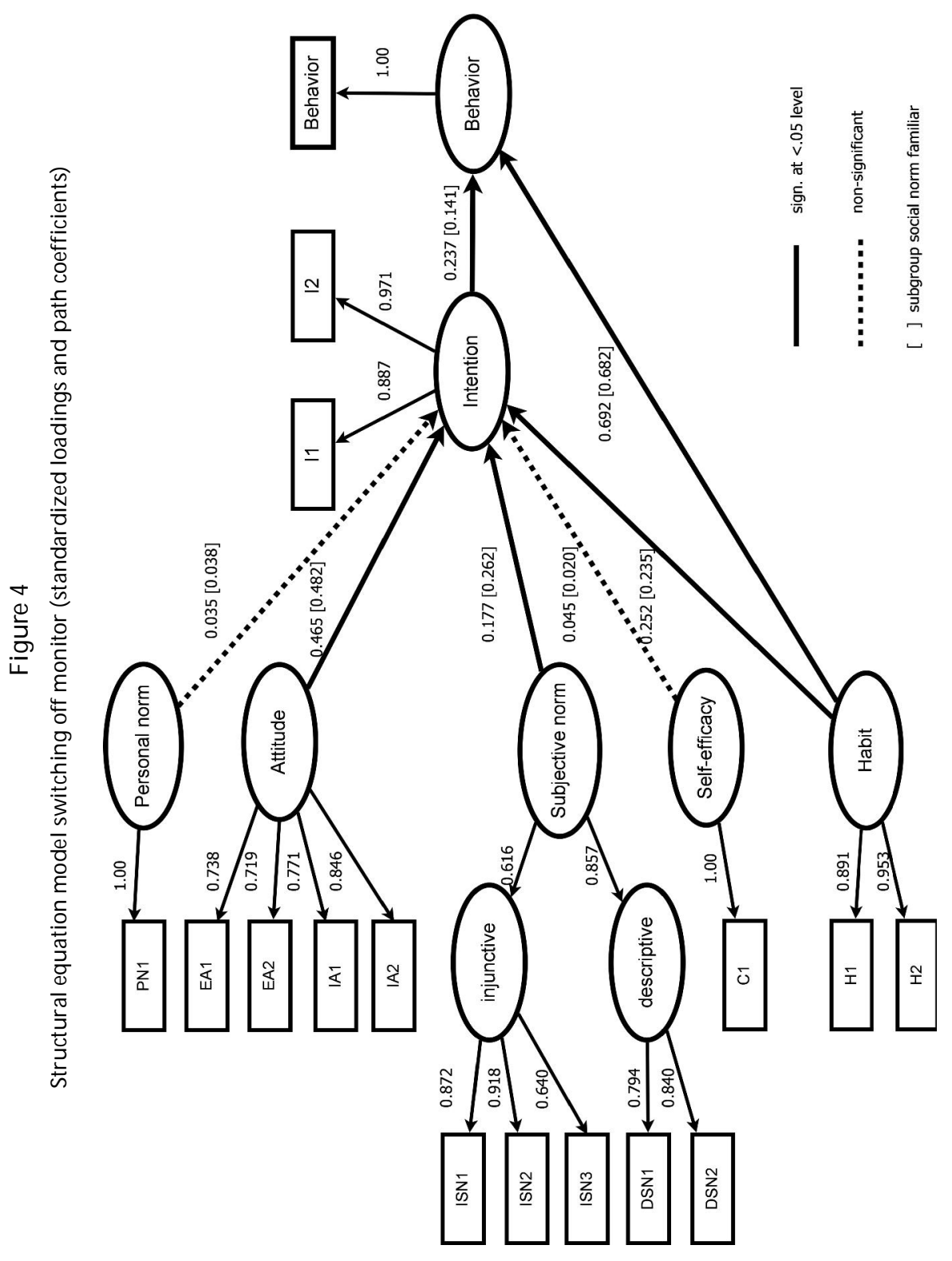


have a significant effect on intention to not print e-mails in this subgroup. Secondly, for printing smaller, there was an increase in the perceived and personal norm coefficients and a decrease in the attitude coefficient. As a result, contrary to the total sample, personal norm did have a significant effect in this subgroup. Thirdly, the effects of habit on intention not to print e-mails, and personal norm on intention to switch off lights were non-significant in this subgroup.

\section{Background variables}

We tested for effects of background variables on the baseline models to examine whether background variables accounted for variance in behaviors that individual determinants could not (RQ3). If so, effects of background variables on behavior are not (fully) mediated by individual determinants. We conducted tests on the total sample with all background variables as predictors of determinants, intentions and behavior. Insignificant paths were removed; the model with the remaining paths was used to address our research questions.

The individual determinants mediated the effects of all background variables, except three that achieved small but significant effects: having a managerial status had a positive effect on printing smaller (standardized $b=.088, p<01$ ), age had a negative effect on printing smaller (standardized $b=-$ $.078, \mathrm{p}<05$ ), and number of office mates had a negative effect on switching off lights (standardized $b=-$ $.103, \mathrm{p}<01)(\mathrm{RQ} 3)$. As all significant background variable effects on behavior were unique to a single behavior, and including these background variables did not alter the significance and direction of regression weights of the paths from determinants to intention and behavior, we excluded background variables from our multigroup analyses to facilitate comparison between behaviors.

\section{Organization-specific influences}

The aim of the multigroup analyses was to test whether and where interorganizational differences existed in the model of individual determinants of office energy-related behaviors.

\section{Configural model}

For a model to be compared across organizations, a first necessary condition is configural invariance. Wge tested for configural invariance in a Multigroup SEM, which is an omnibus test for the baseline model fit in each organization (RQ4; see model 3 in Tables 4-5). Company ZH was excluded from multigroup analyses of switching behaviors because it had motion-sensor lighting control in most parts of its office building and few employees had a monitor separate from their computer. The models show acceptable goodness-of-fit indices which entails that items are associated with the same common factors in all groups. The configural invariance model functioned as the reference model for all further multigroup analyses.

\section{Factor loadings}

We tested for equality of factor loadings in a Multigroup SEM by constraining these loadings to be equal across organizations (RQ5a; see model 4 in Tables 4-5). A scaled SB $\chi^{2}$ difference test revealed that the metric invariant models for printing smaller $\left(\triangle \mathrm{SB} \chi^{2}=44.80, \mathrm{df}=27, \mathrm{p}<05\right)$ and not printing e-mails $\left(\Delta \mathrm{SB} \chi^{2}=54.41, \mathrm{df}=27, \mathrm{p}<01\right)$ had a significantly worse fit compared to the reference models (Satorra \& Bentler, 2001), which implies that the factor loadings were not equal between organizations. In contrast, equality of factor loadings was not rejected for switching off lights $\left(\Delta \mathrm{SB} \chi^{2}=15.91, \mathrm{df}=18, \mathrm{~ns}\right.$. $)$ and switching off monitors $\left(\triangle \mathrm{SB} \chi^{2}=26.20, \mathrm{df}=18, \mathrm{~ns}\right.$.). These findings suggest that the validity of measured 
beliefs as indicators of the theoretical determinants is similar across organizations for switching behaviors, but different in some ways for printing behaviors.

\section{Partial invariance of factor loadings}

To identify which factor loadings of printing behaviors differed across organizations, we conducted partial invariance tests by constraining factor loadings of a single latent factor one at a time (see Appendices A-B). For factors with significantly different factor loadings, we calculated the ratio between the lowest, and the highest standardized factor loading (taken from the reference model) per item, and used this as an indicator of the magnitude of differences. We report the lowest ratio of each factor and a qualitative interpretation of interorganizational differences.

Equality of factor loadings was violated for descriptive norm in both printing behaviors (smaller: $\Delta \mathrm{SB} \chi^{2}=13.66, \mathrm{df}=3, \mathrm{p}<01$, diff. ratio=0.80; e-mails: $\Delta \mathrm{SB} \chi^{2}=10.02, \mathrm{df}=3, \mathrm{p}<05$, diff. ratio=0.63), and the injunctive norm in not printing e-mails $\left(\Delta \mathrm{SB} \chi^{2}=19.27, \mathrm{df}=6, \mathrm{p}<01\right.$, diff. ratio=0.71). Inspection of factor loadings in the reference model revealed that the descriptive norm of colleagues had considerably stronger loadings than that of superiors in most organizations. However, in company $\mathrm{ZH}$, loadings of superiors and colleagues were similar for both printing behaviors, and NGO ZH showed similar loadings for printing smaller. Similar to the descriptive norm findings, factor loadings of the injunctive norm for not printing e-mails showed that superiors' opinion was more important in company ZH than in other organizations. In addition, importance of people's opinion in the private sphere was markedly lower for NGO ZH compared to other organizations.

Equality of loadings was also violated for experiential and instrumental attitude in printing smaller (experiential: $\Delta \mathrm{SB} \chi^{2}=13.29, \mathrm{df}=3, \mathrm{p}<01$, diff. ratio $=0.74$; instrumental: $\Delta \mathrm{SB} \chi^{2}=8.64, \mathrm{df}=3, \mathrm{p}<05$, diff. ratio=0.84). For experiential attitude, the "difficult-easy" and "unpleasant-pleasant" item loaded almost equally higher in NGO ZH, whereas in other organizations, "unpleasant-pleasant" loaded much higher. For instrumental attitude, the "useless-useful" item loaded highest in company LB and lowest in university LB.

To conclude, metric invariance of printing behaviors was most strongly violated in the perceived norm factors, and to a lesser extent in the attitude factors. Bearing these exceptions in mind, factor loadings as reported in Figures 1-4 should be informative for all examined organizations.

\section{Intercepts}

We had already established that the intercept (i.e. mean) of behavior itself differed across organizations (RQ1a), and that individual determinants could account for these (RQ1b). We would therefore expect item intercepts to differ significantly across organizations. Equality of intercepts was tested by constraining item intercepts (except that of the behavior itself) to be equal across organizations in a Multigroup SEM (RQ6; see model 5 in Tables 4-5). A scaled SB $\chi^{2}$ difference test indeed revealed that the equal intercepts model had a much worse fit compared to the reference models for printing behaviors (smaller: $\Delta \mathrm{SB} \chi^{2}=142.27, \mathrm{df}=45, \mathrm{p}<.001$; e-mails: $\Delta \mathrm{SB} \chi^{2}=137.57, \mathrm{df}=45, \mathrm{p}<001$ ). Invariance of intercepts was also strongly rejected for switching behaviors (lights: $\Delta \mathrm{SB} \chi^{2}=130.77, \mathrm{df}=30, \mathrm{p}<.001$; monitors: $\left.\Delta \mathrm{SB} \chi^{2}=94.63, \mathrm{df}=30, \mathrm{p}<001\right)$. In sum, means of relevant beliefs were found to differ across organizations for all behaviors.

\section{Partial invariance of item intercepts}

Partial invariance tests were conducted to check whether intercept equality could be upheld for some parts of the model. Violations were found for most individual determinants (see Appendices A-B). For 
printing smaller, the only exceptions were the instrumental attitude, self-efficacy, and personal norm factors. Equality of intercepts was rejected for all individual determinants of not printing e-mails, although equality of instrumental attitude intercepts was rejected by a relatively small margin. Similarly, for both switching behaviors, the attitude factor was the exception. Finally, intercept equality of the intention factor was not rejected for switching off monitors.

In brief, respondents of different organizations hold beliefs about office energy-relevant behaviors in varying degrees of strength. Only (instrumental) attitudinal beliefs have, on the whole, similar high values across all organizations (see Table 3). This implies that respondents had a uniformly positive (instrumental) attitude towards office energy-related behaviors.

\section{Structural model}

Equality of the structural model was tested by imposing equality constraints on path coefficients between latent factors (RQ7; see model 6 in Tables 4-5). Compared to the reference model, structural invariance held for printing smaller, but not for not printing e-mails and both switching behaviors (printing smaller: $\Delta \mathrm{SB} \chi^{2}=20.68, \mathrm{df}=21$, ns.; not printing e-mails: $\Delta \mathrm{SB} \chi^{2}=43.93, \mathrm{df}=21, \mathrm{p}<01$; lights $\Delta \mathrm{SB} \chi^{2}=26.05, \mathrm{df}=14, \mathrm{p}<.05$; monitor: $\Delta \mathrm{SB} \chi^{2}=23.80, \mathrm{df}=14, \mathrm{p}<.05$ ). Thus, for most behaviors, there are some differences in the magnitude of relationships between individual determinants, intention and behavior across organizations.

\section{Partial invariance of structural model}

Partial invariance tests were conducted to check where structural invariance was rejected for not printing e-mails and the switching behaviors (see Appendices A-B). Significant violations were only found for paths between habit, intention, and behavior. We also calculated the ratio between the lowest and the highest standardized factor path coefficients (from the reference model) of organizations. Finally, we examined the path coefficients of all organizations to localize the salient differences.

For not printing e-mails, paths between habit and behavior $\left(\Delta \mathrm{SB} \chi^{2}=14.55, \mathrm{df}=3, \mathrm{p}<.01\right.$, ratio= .04$)$, and intention and behavior $\left(\Delta \mathrm{SB} \chi^{2}=25.55, \mathrm{df}=3, \mathrm{p}<.001\right.$, ratio $\left.=.77\right)$ differed significantly across organizations. Unlike other organizations, company LB showed a significant path between habit and behavior (standardized $\mathrm{b}=.40$ ). For company $\mathrm{ZH}$, the effect of intention on behavior (standardized $\mathrm{b}_{\text {₹ु. }}$.82) was slightly higher than for other organizations. For switching off lights, organizational differences were found in the path between habit and intention $\left(\Delta \mathrm{SB} \chi^{2}=7.91, \mathrm{df}=2, \mathrm{p}<.05\right.$, ratio= .32$)$. Unlike other organizations, company LB did not have a significant coefficient for habit on intention. For switching off monitors, the path between habit and behavior differed $\left(\triangle \mathrm{SB} \chi^{2}=10.31, \mathrm{df}=2, \mathrm{p}<.01\right.$, ratio= 0.73). Company LB's coefficient for habit on behavior (standardized $b=.54$ ) was slightly lower than in other organizations.

In brief, the relationship strengths between intention, habit and behavior varied, but other associations between latent factors were equally strong for all organizations.

\section{Discussion}

Our study tested a model of individual determinants of office energy-related behaviors and in what respect this model differs across organizations. Our hypothesized model proved to fit the data well but did not always provide a complete account of all investigated behaviors. There were small interorganizational differences in the average reported behaviors, except for switching off lights, for which the differences were large. After we controlled for individual-specific influences, these 
organizational differences disappeared completely for printing behaviors and were largely reduced for switching behaviors.

\section{Individual-specific influences}

Intention was a stronger direct predictor of printing behaviors than habit, but the opposite was true for switching behaviors. Social-cognitive determinants and habit were generally significant predictors of intention (exceptions will be discussed below). Attitude was the strongest predictor of intention for all behaviors in total sample analyses, but in the group familiar with the relevant norm, perceived norm was a stronger predictor of intention not to print e-mails. Thus, attitude is not the strongest predictor of intention for office energy-related behaviors under all conditions. When relevant social norms are salient, perceived norms might play a more prominent role than the total sample results suggest. Having said that, it does appear that the effect of perceived norm is less consistent than that of attitude: the effect of perceived norm on intention to switch off lights was non-significant in both the total sample and the group familiar with the social norm.

Personal norm only had a significant effect on intention for two out of four behaviors. However, in the present study, the concept was only measured by one item which might have been an unreliable measure. Furthermore, although moral evaluation may be important, it can in some cases overlap with attitude to such a degree that its separate effect is not detectable. A similar reasoning applies to the nonsignificant effect of self-efficacy on intention to switch off monitors: we measured self-efficacy with a one-item measure of autonomy to perform a behavior, an aspect of self-efficacy that may be irrelevant for simple behaviors that do not affect others directly.

In two instances, we found an individual-specific organizational variable that explained additional variance in behavior. Most interestingly, the negative, unmediated effect of number of office mates on switching off lights illustrates how social-cognitive and habitual determinants may not capture the whole story. Having said that, we cannot rule out that the finding is due to more trivial factors such as the availability heuristic (i.e. lower estimates for mentally inaccessible behaviors, see Tversky \& Kahneman, 1974). Despite the carefully-worded measurement of behavior (i.e. "switch off lights when no office mates are present"), the behavior might have been less mentally accessible for employees with many office mates. Furthermore, the sociodemographic variable age had a direct negative significant effect on printing smaller. One simple explanation for this could be that eyesight deteriorates as age increases (Lo et al., under review-a).

\section{Organization-specific influences}

We found differences in the way the perceived norm constructs, and to a lesser extent attitude constructs, were manifested across organizations (i.e. equality of loadings was partially violated). The importance of the descriptive norm pertaining to superiors was lower for organizations in Limburg, which had a higher percentage of single-occupancy offices. One could hypothesize that employees in Zuid-Holland are more likely to share an office with their direct superiors which makes superiors' behavior more relevant. Again, average number of office mates might be related to interorganizational differences. For the experiential attitude construct, the adjective pair "unpleasant-pleasant" generally had considerably higher loadings than "easy-difficult". Interestingly, this was not the case for NGO ZH. One possible explanation is NGO ZH's organizational focus on development aid, which relates more strongly to normative motivations, and less to hedonic motivations, which are conceptually closer to pleasantness than difficulty (Lo et al., under review-a).

We also found many interorganizational differences in beliefs (i.e. equality of intercepts was consistently violated). However, (instrumental) attitude values of all examined behaviors did not differ 
across organizations - these were uniformly positive. Only experiential attitude values of printing behaviors differed significantly across organizations and were on average less positive. This could be due to interorganizational differences in printing facilities, although we could not test this hypothesis.

Finally, there were organizational differences in the path coefficients between habit, intention, and behavior. Thus, the predictive value of habit and intention differs across organizations, but that of social-cognitive determinants is stable.

\section{Limitations and future research directions}

The results of our study should be interpreted in the light of several methodological limitations. Firstly, participation in the online survey was voluntary. There were no formal mechanisms to ensure cooperation of individual employees or the organizations as a whole. Given the varying completion rates, it is possible that some of the differences found are due to selective participation of employees in the organizations. Lower scores in behavior in an organization do not necessarily imply that their employees are less "proenvironmental" if completion rates were higher compared to other organizations.

Furthermore, the type and availability of relevant physical facilities differed both between and within organizations. This could explain differences in (experiential) attitude, but there is insufficiently detailed information about the organizational contexts to verify this. More generally, we often could not establish a direct link between organizational determinants and variations in means of individual beliefs across organizations.

Another constraint was that we only obtained self-reported cross-sectional data, which meant that we neither obtained objective measures of behavior nor evidence to make claims regarding the direction of causality. Longitudinal research designs may overcome these shortcomings in future.

Finally, we measured personal norm and self-efficacy with a single item. Unreliable measurement may have caused unstable results across behaviors, although it might also have been the case that these were simply not relevant to all behaviors. Future research should further examine under what conditions these determinants play a role in different proenvironmental behaviors.

\section{Implications for interventions}

Aș interventions can be drawn. Both social-cognitive and habitual factors tend to be significant predictors of office energy-related behaviors.

Considering our earlier discussion on the caveats of focusing on the strongest predictor in relation to attitude compared to perceived norms, it would be ill-advised to target a single determinant without considering baseline levels of behavior, individual determinants and other contextual factors. For instance, although attitude was generally the strongest predictor of intention, (instrumental) attitude was already highly positive, leaving relatively little room for improvement through interventions.

The study results also suggest that for optimal effectiveness, interventions aiming at perceived norm change might need to tailor their content according to the relevant social referents in a specific organization. Having said that, tailoring might sometimes be too costly to be worthwhile. The perceived norm items in our study were relevant to employees of all participating organizations, only the extent to which this was the case varied.

Our study also shows that the role of habit should most certainly not be neglected because, for some behaviors, it predicts behavior better than intention. The fact that its relative effect compared 
to intention differs across organizations is also a factor to consider. Changing undesirable habitual behaviors through habit disruption aided by contextual change could be the preferred approach under the right (practical) conditions (Danner, Aarts, \& de Vries, 2008). Related to habit are influences on behavior that are implicit or unconscious. One such influence we examined was the effect of the number of office mates on employees' propensity to switch off lights. It is a reminder that other contextual factors such as the availability, type, and arrangement of physical facilities could also have such implicit or unconscious influences on behavior besides their explicit or conscious influences on individual determinants.

\section{Conclusion}

To conclude, this study explored an area previously neglected by research on proenvironmental behavior in organizations, namely that of organizational context. Similar to previous findings from private and household studies, an extended planned behavior framework proved very useful in explaining proenvironmental behavior in our study. The use of Multigroup SEM allowed us to examine in detail how the organizational context may influence (individual determinants of) behavior.

Interorganizational differences in individual determinants of office energy-related behaviors mainly manifested themselves in the strength of energy-related beliefs, and to a lesser extent in the degree to which beliefs were relevant indicators of the corresponding individual determinants. Equality of intercepts was violated in most factors, whereas equality of loadings was only violated in some perceived norm and attitude factors of printing behaviors. In addition, the model of office energyrelated behaviors revealed significant interorganizational variations in the strength of relationships between habit, intention, and behavior. 


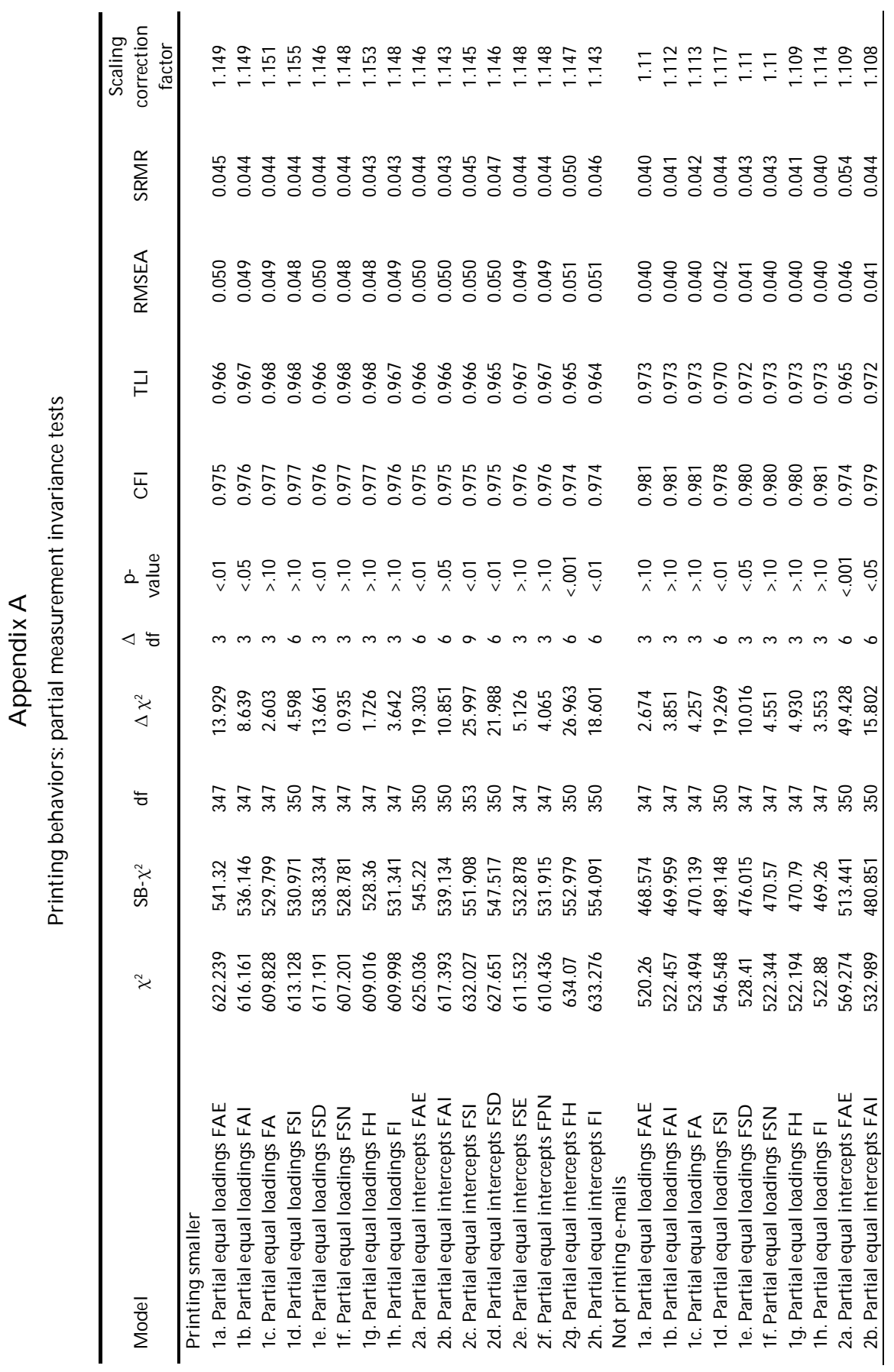




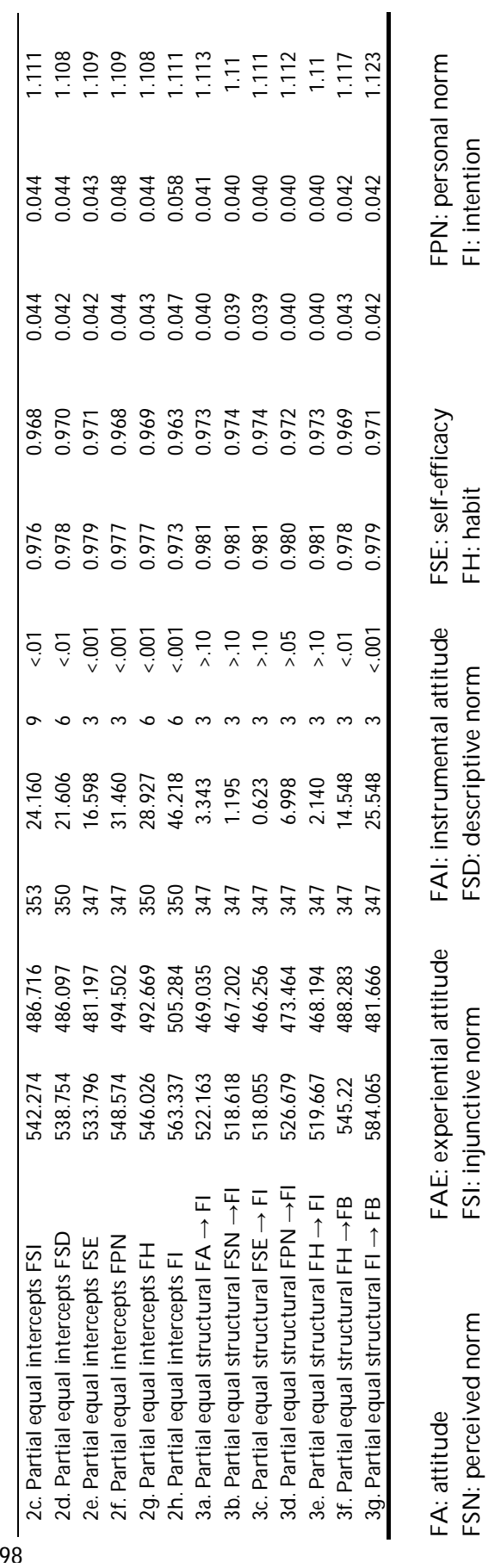




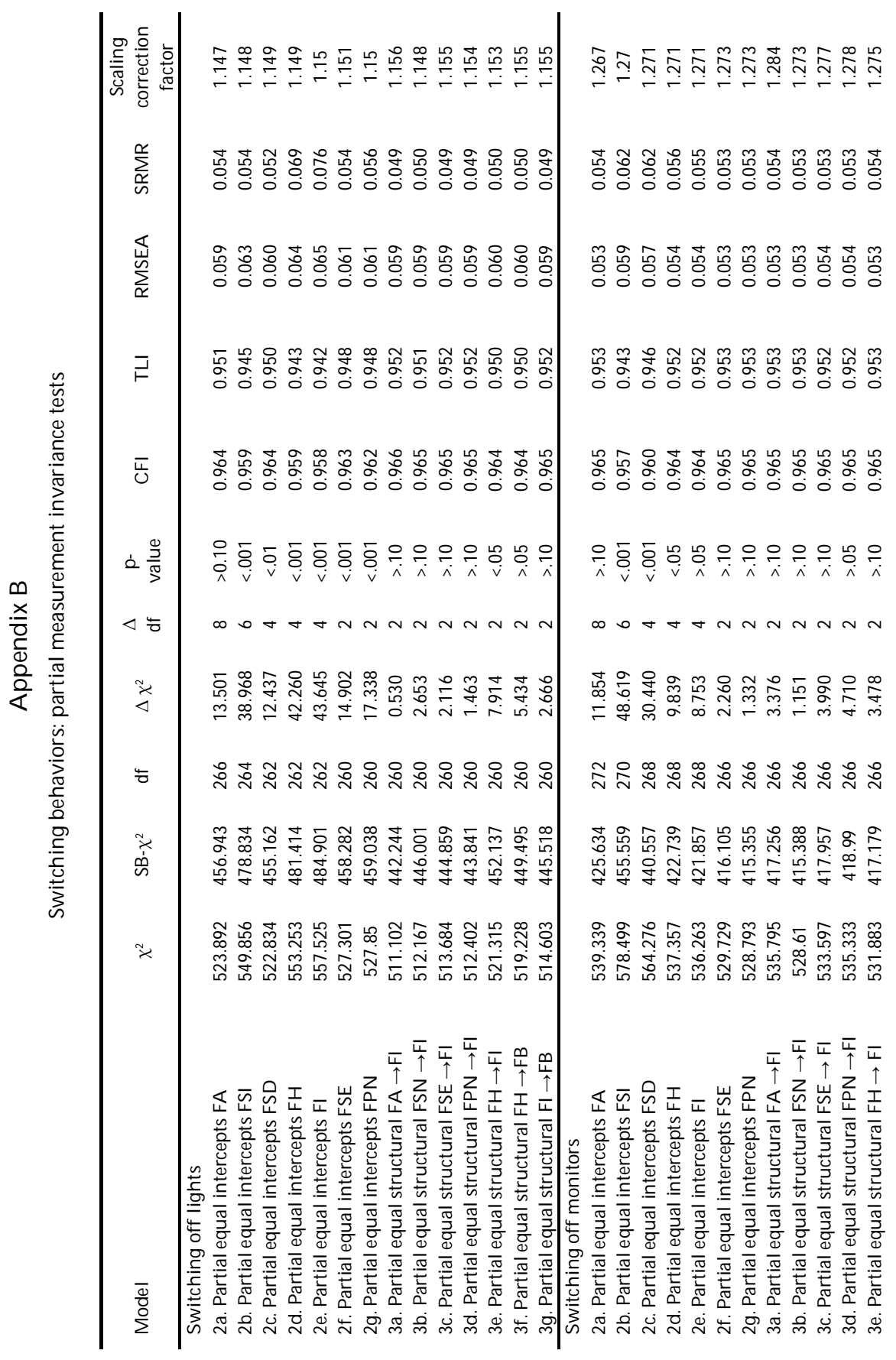




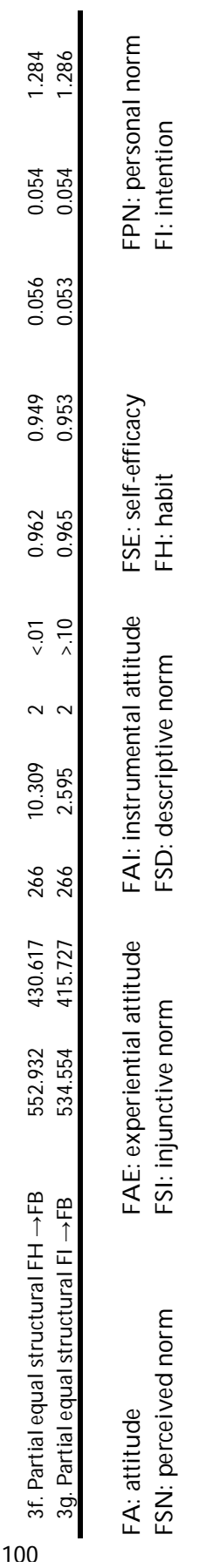




\title{
Chapter 6: \\ Proenvironmental Commuting Behaviors among Office Workers:
}

\author{
An Interregional and Intersectoral Comparison of a \\ Model of Individual Determinants ${ }^{7}$
}

\begin{abstract}
Introduction
Traffic congestion is a persistent social, economic, and environmental problem in many places around the world. Especially recurring traffic jams during rush hours are a major source of annoyance as well as economic and environmental damage. For these reasons, a good understanding of the determinants of commuting travel mode choice can be of considerable practical value. From a broader environmental perspective, once travel mode has been determined, other behaviors related to people's (car) commutes, such as car type and size, and one's driving style, are also of interest as these co-determine the total environmental impact of a person's commute.

Although reviews of "soft" transport policy measures, which include behavioral change programs, indicate that these tend to be effective, the mechanisms underlying their effectiveness are ill-understood (Cairns et al., 2008; Richter et al., 2010). Moreover, most reported (non-peer-reviewed) travel intervention studies lack methodological rigor and are likely to show reporting bias (Moser et al., 2008). In other words, it is still unclear which soft policy measures are truly effective, and if effective, why this is so.

A recent meta-analysis of the psychological determinants of car use revealed that socialcognitive variables - as derived from the Theory of Planned Behavior - and habit were good predictors of intention and behavior (Ajzen, 1991; Gardner et al., 2008). However, less is known about how factors external to the individual, such as region and the type of organization at which one is employed, impact on these individual determinants of behavior.
\end{abstract}

7 This chapter has been submitted for publication as:

Lo, S.H., van Breukelen, G.J.P., Peters, G.J. \& G. Kok, Proenvironmental Commuting Behaviors among Office Workers: an Interregional and Intersectoral Comparison of a Model of Individual Determinants, submitted in November 2010. 
Previous research on commuting behaviors, typically from a proenvironmental perspective, has mostly examined travel mode choice for private or commuting purposes of individuals within a confined geographical region (Aarts et al., 2000; Bamberg, 2006; Davidov, 2007; Gardner et al., 2010; Van Vugt et al., 1996; Verplanken et al., 2008). Some have studied residents from diverse geographical locations, but did not further examine regional differences (Steg, 2005; Thogersen, 2006). One exception is Bamberg et al.'s study on public transportation use in two distinct urban areas (Bamberg, Hunecke et al., 2007).

What is more, recent commuting behavior studies have almost exclusively focused on individualspecific determinants (Domarchi et al., 2008; Mann et al., 2006). This sharply contrasts with the substantial proportion of soft policy measures that have been initiated through the workplace (Cairns et al., 2008; Kearney et al., 1995-1996). In fact, little is known about organizational determinants of proenvironmental behavior more generally. Previous research on organizations and the environment has mainly investigated the effects of external determinants and organizational characteristics on organizational engagement with environmental sustainability (Etzion, 2007). Compared to household contexts, little research has addressed proenvironmental behavior in organizations at the individual, behavioral level of analysis (Abrahamse et al., 2005; Bamberg \& Moser, 2007; Bansal et al., 2006). More specifically, a recent review identified a lack of empirical interorganizational research examining interactions between the employee and the organization (Lo et al., in press).

Finally, apart from the lack of research on regional and organizational effects, another limitation in research scope is the focus on travel mode choice at the expense of other behaviors which also affect the environmental impact of people's commute, such as driving style and car type if commuting by car. In order to maximize the effectiveness of organizational interventions, it can be insightful to examine more commuting behaviors simultaneously. One benefit of examining various behaviors in one study is that their relative potential for change can be compared while keeping organizational context constant.

To address these research gaps, we studied commuting behaviors among office workers from various organizations in both the public/non-profit and private sector as well as two distinct geographical locations with varying degrees of public transport connectivity. We have targeted office workers because they form the largest share in the Dutch working population, and most likely in all developed countries (Statistics Netherlands [CBS], 2010).

This paper will present a model of individual determinants for various commuting behaviors, and test in which respects this model differs across organizations. We will first examine whether our model of individual determinants fits the data well. Then, we will investigate whether travel-related, sociodemographic, and individual-specific organizational background variables can further improve prediction of behavior. Finally, we will investigate similarities and differences between organizations More specifically, we are interested in how the results of the models of individual determinants vary across regions and sectors. The conceptual framework used for examining individual determinants and organizational determinants will be presented below.

\section{Individual Determinants}

Individual determinants are defined as determinants of a psychosocial nature that are relevant on the individual level. Although theories of proenvironmental behavior have been proposed in the literature, we chose to employ a framework that only contained general theoretical concepts commonly used to explain a wide range of social behaviors for two reasons. First, domain-specific theories such as Stern's 
Value-Belief-Norm (VBN) Theory have so far accounted for a smaller proportion of the variance in behavior than generic theories like the Theory of Planned Behavior (TPB) (Ajzen, 1991; Kaiser et al., 2005; Stern et al., 1999). Second, the use of commonly used, generic concepts may have the additional advantage of facilitating comparison with findings of behaviors from other domains, and thus lead to greater parsimony. As a result, we have included social-cognitive variables (i.e. attitudes; perceived norms; self-efficacy) and habit in our framework for individual determinants:

"Attitudes" are an individual's overall evaluation of a behavior (Eagly et al., 1993). In the specific context of travel mode choice, it is important to note that attitudes towards behavioral alternatives may also significantly influence one's choice (Gardner et al., 2010). Several subcomponents of attitudes can be distinguished. One distinction is that between instrumental and experiential aspects of attitudes (Fishbein et al., 2010). The former is connected to the outcome of a behavior while the latter is linked to the experience of engaging in a behavior. For certain categories of social behavior, it has also been found useful to emphasize the role of an individual's moral evaluation of a behavior. The moral component has often been referred to as "personal norm" or "moral norm"(Kaiser, 2006; Parker et al., 1995). While some suggest a lack of discriminant validity between personal norm and attitude, others maintain it should be considered a distinct construct (Bamberg, Hunecke et al., 2007; Kaiser, 2006).

Another social-cognitive component related to the individual in question is "self-efficacy" which refers to a person's evaluation of whether one has the necessary resources, knowledge and/or skills to attain a goal (Bandura, 1997), or more narrowly conceived, to perform a behavior (Ajzen, 1991). Evidently, perceptions of control are linked to objective external circumstances. In the context of commuting behaviors, for instance, it is obvious that travel mode options are influenced by the individual's commuting distance and the regional infrastructural constraints.

In contrast to attitudes, the influences of other people on the individual are reflected in "perceived norms", which are defined as the perception of other people's evaluation of a behavior. A useful distinction is that between injunctive norms, which concern others' approval/disapproval of one's own behavior, and descriptive norms, which refer to others' behavior (Schultz et al., 2007).

For social-cognitive variables to play a role in behavior, it should be possible to (partially) control the behavior on a volitional basis (Fishbein et al., 2010). Furthermore, awareness of its personal, social, or environmental relevance is also prerequisite. When such behaviors are repeatedly performed, they no longer require deliberative evaluation which has led many to argue that they become "habits", which are characterized by a degree of automaticity and unconsciousness (Fishbein et al., 2010; Verplanken et al., 2003). In this phase, contextual cues like time and place may play a more salient role in determining behavior than social-cognitive variables (Wood et al., 2005).

\section{Organizational Determinants}

Organizational determinants are defined as those influences on behavior specific to the organizational context. According to Tudor and colleagues, who presented a framework of organizational proenvironmental (management) behavior, five organizational factors are of relevance: organizational focus, organizational structure, organizational/site type and size, departmental type and size, and organizational culture (Tudor et al., 2008). Although the proposed framework provides a valuable aid for identifying relevant organizational characteristics, it mainly outlines indirect influences on (individual determinants of) behavior. Organizational size, for instance, can be hypothesized to affect the degree of interaction between organizational members, and can therefore indirectly influence the salience of perceived norms regarding proenvironmental behavior. 
Of the other factors included in their framework, organizational focus and organizational culture may most straightforwardly affect (individual determinants of) proenvironmental behavior. Organizational focus, defined as the primary aim of an organization, may be directly related to proenvironmental behavior. At least on the organizational level, it sets the priorities, which may or may not be aligned with environmental sustainability. One way to make a rough categorization of organizations in this respect is the public-private divide, where the primary aim of a public/non-profit organization is to provide services for society or the world at large, and private organizations' aim is to generate profit. Particularly relevant to commuting behaviors, is that the divide between public and private sectors is also closely linked to differences in organizational policies. While the provision of company cars to employees is common practice in private organizations, public organizations generally do not provide employees with cars.

Organizational culture comprises those elements that are shared by organizational members (Schein, 1992). It could indeed be seen as a broader concept which includes, or is at least interlinked with, organizational focus (Fernandez et al., 2003; Tudor et al., 2008). More specific crucial influences include that of the roles of top and middle management, who may disproportionately affect organizational culture (Fernandez et al., 2003). Previous research has indeed found that top and middle management play a crucial role in organizational proenvironmental behavior through their impact on employees (Andersson et al., 2005; Ramus et al., 2000; Siero et al., 1989; Tudor et al., 2007).

It is also important to note that possible differences between subpopulations within an organization have not been researched to the best of our knowledge. Organizational subpopulations can, but not exclusively, be defined on the basis of managerial status, employment duration, part-time versus full-time status, and departmental affiliations. In this paper, characteristics that define organizational subpopulations will be termed "individual-specific organizational variables".

Finally, specifically relevant to travel mode choice for commuting purposes is the geographical location of an organization. More generally, it should be repeated that commuting behaviors obviously do not depend solely on individual and organizational factors but also regional and societal factors such as the infrastructure and cultural influences.

\section{Research Questions}

In the light of the identified research gaps, the current paper will address the following questions for various commuting behaviors, namely travel mode choice, car purchase decisions, and driving style.

\section{Organizational differences in behavior}

(RQ1a) Are there interorganizational differences in the average of each behavior?

(RQ1b) If so, can these differences be explained by individual-specific influences?

\section{Individual-specific influences}

(RQ2a) Are the identified individual determinants predictors of intentions and behaviors? What is the magnitude of significant relationships?

(RQ2b) Does the magnitude of relationships between individual determinants, and intention and behavior differ for the subgroup of employees who were familiar with the relevant social norm? (RQ3) Do sociodemographic and individual-specific organizational variables explain additional variance in behaviors, over and above the individual determinants and intention? 
In addition, we will examine organizational similarities and differences for commuting travel mode choice:

\section{Organization-specific influences}

(RQ4) Is the factor structure of our model of individual determinants of behavior adequate for each region and sector in our sample?

(RQ5) Do individual determinants manifest themselves differently across regions and sectors? More specifically, are the loadings of indicators on corresponding latent factors equal across regions and sectors?

(RQ6) Do the average scores on relevant beliefs differ across regions and sectors?

(RQ7) Do the regression coefficients for predicting intention and behavior from individual determinants differ across regions and sectors?

\section{Methods}

\section{Participants and Procedure}

Employees from four organizations located in cities in the Dutch provinces Zuid-Holland (ZH) and Limburg (LB) were approached to take part in an online survey study. The sample of organizations consisted of two commercial companies (company ZH; company LB), a university (university LB), and a non-governmental organization (NGO ZH). In other words, we sampled one private and one public(/non-profit) organization in each region.

The choice for Zuid-Holland and Limburg as case studies was motivated by the contrasts between these regions, with Zuid-Holland being the most densely-populated, and Limburg one of the less populated provinces in the Netherlands (CBS, PBL, \& UR, 2010). This clearly has implications for the regional infrastructure in terms of public transport connectivity and the frequency of traffic congestion. Furthermore, both organizations in Zuid-Holland had more limited parking facilities for their employees, whereas organizations in Limburg had no (company LB) or fewer (university LB) parking restrictions.

Company ZH, university LB, company LB, and NGO ZH each participated with one to three office buildings, with a (combined) capacity of approximately 1000, 700, 450, and 350 people respectively. All organizations had some form of public commitment to environmental sustainability, but none had energy conservation as their primary organizational aim. Nevertheless, the NGO's core task, development aid, was increasingly perceived to be related to environmental sustainability because climate change had become a pressing issue in the countries where they operated.

Employees were approached by their own organization with the request to fill out the online questionnaire. It was emphasized that the study was conducted by independent researchers of a Dutch university, and only the general anonymized results would be reported to the organization. Except for employees in company LB, respondents were given the opportunity to participate in a raffle contest for $€ 20$ gift vouchers.

\section{Measures}

Commuting behaviors and the measures of their determinants were chosen based on findings from an earlier qualitative study conducted at the same organizations (Lo, Peters, \& Kok, under review-b). Interviews and focus groups with key informants and employees of the four organizations were 
conducted to identify possible determinants of office workers' commuting behaviors. Based on these findings, we selected a small number of behaviors for further investigation in the survey, relevant adjectives for the semantic differential scales for attitude measures, social referents for perceived norm measures, and beliefs to measure determinants. Due to survey-length constraints, some determinants were measured with only one item. Unless stated otherwise, all measures were rated on a five-point scale ranging from 1 to 5 .

\section{Commuting behavior}

We examined the behavior 'commuting by car' ("commute to work by car") among all respondents. Commuting by car was divided into 'short-distance commuting' ( $\leq 20 \mathrm{~km})$, and 'long-distance commuting' (>20km) for most analyses because travel mode options are heavily influenced by distance to work. For short-distance commuters, there are additional options of travelling by bicycle or even on foot. Besides, there can be differences in the quality of the short-distance public transport network and that of the long-distance network.

In addition, we investigated two 'car-related behaviors' among all regular car commuters irrespective of distance to work: 'buying an energy-efficient car' and 'driving economically' ("maintain an energy-efficient driving style").

Behavior was measured with one item beginning with "The past month/last time, I have...", rated on a scale ranging from never to always for commuting by car, and disagree to agree for car-related behaviors. Because of our cross-sectional survey design, we used behavior of the past month/ast time the behavior was relevant as a proxy for current behavior.

\section{Intention}

Behavioral intention was measured with two items, starting with "Next month/time, I expect..." (I1) and "Next month/year, I want..." (I2), rated on a scale ranging from never to always.

\section{Attitude}

Attitude towards behaviors was measured with a three- or four-item semantic differential scale with the adjective pairs "negative-positive" (A1), "unpleasant-pleasant" (A2), "useless-useful" (A3) and/or "difficult-easy" (A4). ${ }^{8}$ We used all four adjective measures to measure attitude towards driving economically. For this specific behavior, we hypothesized that "positive" and "useful" reflected instrumental aspects, whereas the "pleasant" and "easy" would reflect experiential aspects of a given behavior. For buying an energy-efficient car "difficult-easy" was not measured, and "useless-useful"

\footnotetext{
${ }^{8}$ The adjective pair "difficult-easy" is often used to measure self-efficacy, but has been found to correlate much more highly with experiential attitude in some studies (Fishbein et al., 2010). In the present study we also found this to be the case (e.g. $r=0.29$ cf. $r=0.70$ for commuting by car).
} 
was excluded from the commuting attitude measures. ${ }^{9}$ For commuting, attitudes towards alternative travel modes were measured in addition to a measure of 'attitude towards driving' ("attitude towards commuting by car"). Depending on one's distance to work, respondents were either presented with attitude measures for public transport only $(>20 \mathrm{~km})$ or public transport and bicycle $(<20 \mathrm{~km})$.

We also measured the specific belief whether a behavior was "financially advantageous" for the respondent because some effects of background variables may be mediated by perceived financial interests. This item was only used for background variable analyses.

\section{Personal norm}

In addition, we included a one-item morally evaluative measure, "I think employees of organization $X$ ought to..." (PN1), rated on a scale ranging from disagree to agree. ${ }^{10}$

\section{Perceived norm}

Injunctive and descriptive norm were modeled as first-order factors of a second-order perceived norm factor. The injunctive norm measure consisted of "My superior(s) think I should..." (ISN1), "My colleagues ..." (ISN2), and "People in my private life who are important to me..." (ISN3), rated on a scale ranging from disagree to agree with an additional option I really do not know. The descriptive norm items included "My superiors [do behavior X]" (DSN1), "My colleagues..." (DSN2), and "People in my private life who are important to me..." (DSN3), rated on a scale ranging from never to always, and the option I really do not know. The answer category I really do not know could be recoded into the scale center (neutral for injunctive norm, and sometimes for descriptive norm) for the total sample analyses, while allowing for a subgroup analysis of those respondents who were familiar with the relevant norm. This made examination of possible attenuation effects due to (frequent) absence of perceived norm possible. The operational definition of this subgroup was ability to gauge the injunctive norm of one's superiors.

\section{Self-efficacy}

Self-efficacy was measured with a single item "If I want to, I think I can manage to..." (C1), rated on a scale ranging from disagree to agree.

${ }_{9}^{9}$ Previous qualitative findings suggested that "useless-useful" was not a suitable instrumental attitude measure for travel mode choice and "easy-difficult" not appropriate for car purchase decisions. ${ }^{10}$ When speaking of the moral/normative dimension of relevant behaviors, results of the qualitative study showed that it was more natural for employees to speak of all employees rather than they themselves personally. As noted in the introduction, there is disagreement in the literature on whether personal norm is a component of attitude. Given that our personal norm-item refers to one's evaluation of what other people should do we kept it as a separate factor because it is conceptually different from the attitude items. 


\section{Habit}

For commuting by car, habit was measured with one item selected from Verplanken's index of habit strength, namely "The way I commute to work is an ingrained routine" (H1), rated on a scale ranging from disagree to agree (Verplanken et al., 2003).

\section{Background variables}

We measured three travel-related background variables: distance to work from home (in kilometers), number of weekdays travelling to the office, and a dummy variable for having a company car. Sociodemographic and individual-specific organizational variables were also considered background variables. The sociodemographic variables examined were gender, age, and educational level. A dummy variable for managerial status, employment duration (as expressed by the year in which one had joined the organization), and full-time equivalent (FTE) ranging from 0 to 1 were included as individual-specific organizational variables.

\section{Data Analysis}

We tested for interorganizational differences in average behavior with one-way ANOVA (RQ1a). We also tested whether such differences, if found, could be explained by individual-specific differences (i.e. scores on individual determinants and individual-specific organizational variables) by adding individual-specific variables as covariates with ANCOVA (RQ1b). Such differences would warrant further examination of how organizational characteristics may influence individual determinants of these behaviors, and thus indirectly influence behavior.

Once we had tested for organizational differences in behavior and examined to what extent these differences could be attributed to individual determinants, we continued with testing explanatory models of these behaviors. We used confirmatory factor analysis (CFA) and structural equation modeling (SEM) with MPlus version 6 for testing our model of individual determinants of commuting behaviors (Muthén et al., 1998-2010). First, we verified whether our baseline model fitted the data well (RQ2a). We also tested the baseline model on the subgroup of employees who were all familiar with the social norm (RQ2b). Then, we examined the effect of including background variables in our baseline model (RQ3).

Following this, we tested with multigroup analyses for interorganizational differences in our model of individual determinants of commuting by car. Limited sample sizes prevented us from conducting multigroup analyses for car-related behaviors. In these multigroup analyses, we focused on interregional and intersectoral comparisons. For a model to be compared across regions or sectors, a necessary condition is equality of factor structure, or configural invariance, which entails that items are associated with the same common factors in all groups (RQ4).

If equality of factor structure is tenable, further group comparisons can be meaningfully made. First, we tested for equality of factor loadings, or metric invariance, which means that latent constructs manifest themselves similarly across groups (RQ5). If equality of factor loadings is rejected, the substantial implication is that the relevance of at least some indicators differs across regions/sectors. In that case, partial invariance tests can identify which factors have items that load differently across regions and/or sectors. Also, we tested for equality of item intercepts which indicates whether groups have significantly different item means (RQ6). Again, partial invariance tests were conducted to examine which item means differed across regions and/or sectors. Finally, we tested for equality of the structural model to determine whether the regression coefficients of the individual determinants 
(exogenous latent factors) as predictors of intention and behavior (endogenous latent factors) had equal magnitudes across regions and/or sectors (RQ7).

\section{Results}

\section{Sample characteristics}

Of those who had started the questionnaire, the completion rates for company $\mathrm{ZH}$, company LB, university LB, and NGO ZH were 55\%,65\%,69\%, and 84\% respectively. Response rates were not calculated because the number of employees reached by the invitation could not be reliably established.

Of the total sample, 54\% was female, the mean age was $42(\mathrm{SD}=10.91)$, and $69 \%$ had received higher education. On average, respondents were employed for 0.9 FTE (full-time equivalent) $(\mathrm{SD}=0.16)$, mean employment duration was 12 years $(\mathrm{SD}=11.8), 17 \%$ of the respondents had a (senior) managerial position, and $22 \%$ had an office to themselves. Sociodemographic and organization-related characteristics of each organization's respondents are presented in Table 1.

\section{Table 1}

Sample characteristics by organization

\begin{tabular}{lccccc}
\hline & Total & NGO ZH & Company ZH & University LB & Company LB \\
\hline Sex (\% female) & $54 \%$ & $62 \%$ & $41 \%$ & $69 \%$ & $44 \%$ \\
Education & $69 \%$ & $81 \%$ & $78 \%$ & $82 \%$ & $75 \%$ \\
(\% higher education) & 42 & 43 & 42 & 40 & 46 \\
Age (years) & 10.9 & 9.8 & 10.9 & 11.5 & 10.3 \\
$\quad$ SD & 0.9 & 0.88 & 0.95 & 0.87 & 0.92 \\
FTE (0-1) & 0.16 & 0.14 & 0.13 & 0.20 & 0.17 \\
$\quad$ SD & 12 & 8 & 15 & 9 & 18 \\
Employment duration & 11.8 & 7.8 & 12.9 & 8.4 & 12.1 \\
$\quad$ (years) & $17 \%$ & $25 \%$ & $20 \%$ & $17 \%$ & $22 \%$ \\
Managerial position & & & & \\
\hline
\end{tabular}

\section{Organizational differences in behavior}

Descriptive and basic inferential statistics of each investigated behavior are presented by organization in Table 2, and descriptive statistics of beliefs are presented in Table 3. We conducted one-way ANOVA tests to examine whether mean differences in the behaviors between the organizations were significant (RQ1a). Interorganizational differences for both short- and long-distance commuting were significant and had large effect sizes (short: $\eta^{2}=0.276, p<.01$; long: $\eta^{2}=0.362, p<001$ ). By contrast, no significant differences were found for buying an energy-efficient car and driving economically sizes.

We tested with ANCOVA whether the observed interorganizational differences in commuting by car could be explained by differences in individual determinants (RQ1b; see Table 2). Individual determinants explained most to all of the interorganizational differences in commuting by car. For longdistance commuting, the effect of organization was non-significant after covariate adjustment. For short-distance commuting, the effect was reduced to a small effect size, but remained significant $\left(\eta^{2}=\right.$ 0.031, $\mathrm{p}<.01$ ). 
Table 2

Means, SDs and sample size of behaviors by organization

\begin{tabular}{|c|c|c|c|c|c|c|c|c|}
\hline & Total & $\begin{array}{c}\text { NGO } \\
\text { ZH }\end{array}$ & $\begin{array}{c}\text { Company } \\
\text { ZH }\end{array}$ & $\begin{array}{c}\text { University } \\
\text { LB }\end{array}$ & $\begin{array}{c}\text { Company } \\
\text { LB }\end{array}$ & $\mathrm{F}$ & $\begin{array}{c}\mathrm{p}- \\
\text { value }\end{array}$ & $\eta^{2}$ \\
\hline Commute $\leq 20 \mathrm{~km}$ & 2.35 & 1.62 & 2.36 & 2.16 & 4.23 & 65.94 & $<001$ & .276 \\
\hline$S D$ & 1.50 & 1.02 & 1.45 & 1.39 & 1.02 & 4.33 & $<01$ & .031 \\
\hline$N$ & 452 & 107 & 101 & 183 & 61 & & & \\
\hline Commute $>20 \mathrm{~km}$ & 2.89 & 1.52 & 3.02 & 3.02 & 4.51 & 72.34 & $<001$ & .362 \\
\hline$S D$ & 1.75 & 1.11 & 1.65 & 1.79 & 0.92 & 2.10 & $n s$. & \\
\hline$N$ & 386 & 113 & 138 & 54 & 81 & & & \\
\hline Buy energy-saving car & 3.40 & 3.29 & 3.57 & 3.30 & 3.35 & 0.66 & ns. & .007 \\
\hline$S D$ & 1.37 & 1.38 & 1.34 & 1.48 & 1.34 & & & \\
\hline$N$ & 288 & 21 & 82 & 64 & 121 & & & \\
\hline Driving economically & 3.94 & 4.10 & 4.09 & 3.78 & 3.90 & 1.17 & ns. & .012 \\
\hline$S D$ & 1.07 & 0.83 & 1.05 & 1.24 & 1.03 & & & \\
\hline$N$ & 288 & 21 & 82 & 64 & 121 & & & \\
\hline
\end{tabular}

Italics: corrected for differences in individual determinants using ANCOVA

\section{Individual-specific influences}

All investigated behaviors had a few to most items violating the normality assumption (i.e. skewness and/or kurtosis values $>1$ ). Because non-normality of indicators can lead to inflated ML $\chi^{2}$ goodness-offit statistics and underestimated standard errors, we chose to estimate the models with robust maximum likelihood (MLM) (Satorra et al., 1994). Unless stated otherwise, we followed Hu and Bentler's recommendations for evaluating goodness of fit, with around .95 and above for CFI and TLI, and around .08 and below for RMSEA and SRMR as indicators of good fit (Hu et al., 1999). Goodnessof-fit indices of the models are presented in Table 4 for commuting by car and Table 5 for buying an energy-efficient car and driving economically. In the remainder of this results section, these models will be further discussed.

Before we addressed our primary research concerns, we first tested our measurement models on the total sample with CFA to confirm the relationship between the latent factors (i.e. the individual determinants) and their observed indicators (i.e. the measurement items). We specified indicators of individual determinants and intention to only load on their own factor. Measurement errors were assumed to be uncorrelated, while all factors were allowed to correlate with each other.

Table 3

Descriptive statistics beliefs

\begin{tabular}{cccccccccc}
\hline & \multicolumn{2}{c}{$\begin{array}{c}\text { Commuting } \\
\text { short }\end{array}$} & \multicolumn{2}{c}{ Commuting long } & \multicolumn{2}{c}{$\begin{array}{c}\text { Buy energy- } \\
\text { saving car }\end{array}$} & \multicolumn{2}{c}{$\begin{array}{c}\text { Drive } \\
\text { economically }\end{array}$} \\
& $\mathrm{M}$ & $\mathrm{SD}$ & $\mathrm{M}$ & $\mathrm{SD}$ & $\mathrm{M}$ & $\mathrm{SD}$ & $\mathrm{M}$ & $\mathrm{SD}$ \\
\hline$N$ & 437 & & 381 & & 278 & & 278 & \\
Intention (I1) & 2.25 & 1.45 & 2.88 & 1.76 & 4.14 & 1.10 & 4.22 & 1.00 \\
Intention (I2) & 2.30 & 1.45 & 2.88 & 1.74 & 4.02 & 1.16 & 4.15 & 1.01 \\
\hline
\end{tabular}




\begin{tabular}{|c|c|c|c|c|c|c|c|c|}
\hline (Instrumental) attitude (A1) & 2.52 & 1.47 & 2.96 & 1.52 & 4.54 & .82 & 4.59 & .77 \\
\hline (Experiential) attitude (A2) & 3.10 & 1.61 & 3.44 & 1.55 & 4.12 & 1.00 & 4.14 & 1.04 \\
\hline (Instrumental) attitude (A3) & $\mathrm{N} / \mathrm{A}$ & & $\mathrm{N} / \mathrm{A}$ & & 4.53 & .83 & 4.57 & .78 \\
\hline (Experiential) attitude (A4) & 3.14 & 1.66 & 3.54 & 1.56 & N/A & & 4.03 & 1.06 \\
\hline Attitude public transport (A1) & 3.26 & 1.50 & 3.93 & 1.41 & N/A & & N/A & \\
\hline Attitude public transport (A2) & 2.72 & 1.44 & 3.25 & 1.56 & $\mathrm{~N} / \mathrm{A}$ & & $\mathrm{N} / \mathrm{A}$ & \\
\hline Attitude public transport (A4) & 2.90 & 1.45 & 3.25 & 1.58 & $\mathrm{~N} / \mathrm{A}$ & & $\mathrm{N} / \mathrm{A}$ & \\
\hline Attitude bicycle (A1) & 4.46 & 1.10 & $\mathrm{~N} / \mathrm{A}$ & & $\mathrm{N} / \mathrm{A}$ & & $\mathrm{N} / \mathrm{A}$ & \\
\hline Attitude bicycle (A2) & 4.02 & 1.38 & N/A & & $\mathrm{N} / \mathrm{A}$ & & $\mathrm{N} / \mathrm{A}$ & \\
\hline Attitude bicycle (A4) & 3.76 & 1.50 & $\mathrm{~N} / \mathrm{A}$ & & $\mathrm{N} / \mathrm{A}$ & & $\mathrm{N} / \mathrm{A}$ & \\
\hline Injunctive norm (ISN1) & $2.98^{\wedge}$ & 1.21 & $2.70^{\wedge}$ & 1.34 & 3.03 & 1.00 & 4.59 & .77 \\
\hline Injunctive norm (ISN2) & $2.74^{\wedge}$ & 1.05 & $2.49^{\wedge}$ & 1.11 & 2.94 & .92 & 4.14 & 1.04 \\
\hline Injunctive norm (ISN3) & $3.01^{\wedge}$ & 1.30 & $2.62^{\wedge}$ & 1.35 & 3.32 & 1.14 & 4.57 & .78 \\
\hline Descriptive norm (DSN1) & 3.25 & 1.46 & 3.45 & 1.51 & 2.61 & .96 & 4.59 & .77 \\
\hline Descriptive norm (DSN2) & 3.27 & 1.03 & 3.18 & 1.08 & 2.81 & .84 & 4.14 & 1.04 \\
\hline Descriptive norm (DSN3) & 3.37 & 1.09 & 3.39 & 1.15 & 2.90 & 1.00 & 4.57 & .76 \\
\hline Personal norm (PN1) & $3.85^{\wedge}$ & 1.18 & $3.56^{\wedge}$ & 1.20 & 3.03 & 1.00 & 3.74 & 1.03 \\
\hline Self-efficacy (SE1) & $3.72^{\wedge}$ & 1.48 & $3.41^{\wedge}$ & 1.59 & 4.14 & 1.05 & 4.26 & .89 \\
\hline Habit $(\mathrm{H} 2)$ & 3.63 & 1.45 & 3.15 & 1.65 & $\mathrm{~N} / \mathrm{A}$ & & $\mathrm{N} / \mathrm{A}$ & \\
\hline
\end{tabular}

$\wedge$ negatively worded item

The second-order perceived norm factor caused non-convergence of the commuting by car CFA models. After specifying separate though correlated factors for injunctive norm and descriptive norm, the CFA models had an acceptable fit for short- and long-distance commuting (see model 1 in Table 4). CFA results for car-related behaviors showed some goodness-of-fit indices slightly below conventional cut-off points. After inspection of the modification indices, we allowed for correlated errors between the injunctive and descriptive norm of important people in the private sphere (i.e. items ISN3 and DSN3). This minor modification improved the measurement models for car-related behaviors up to a satisfactory level (see model 1a-2a in Table 5).

Subsequently, we specified a SEM model to test the hypothesized relationships between the individual determinants, intention and behavior. We hypothesized that 1) the latent factors attitude, 


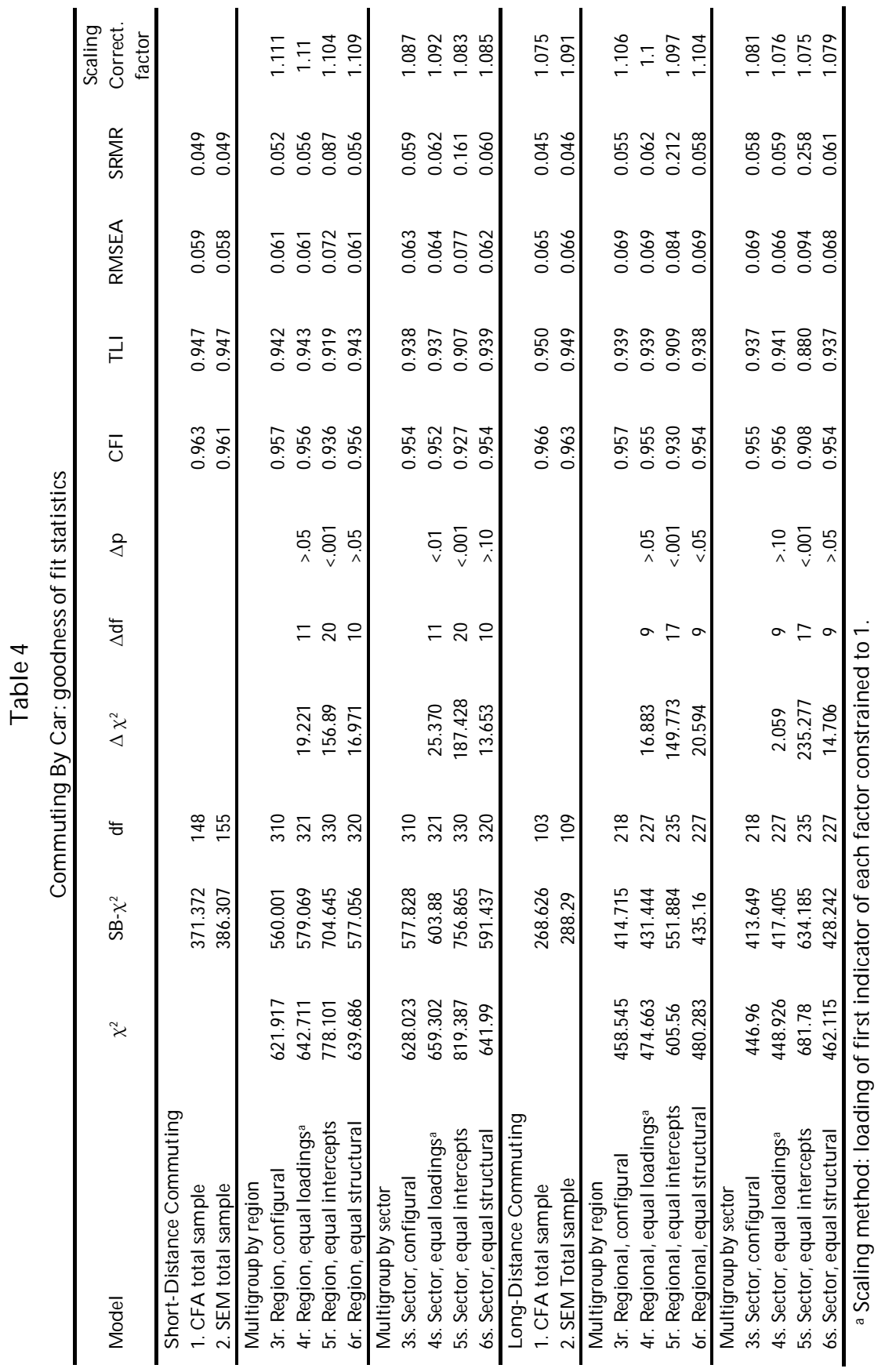




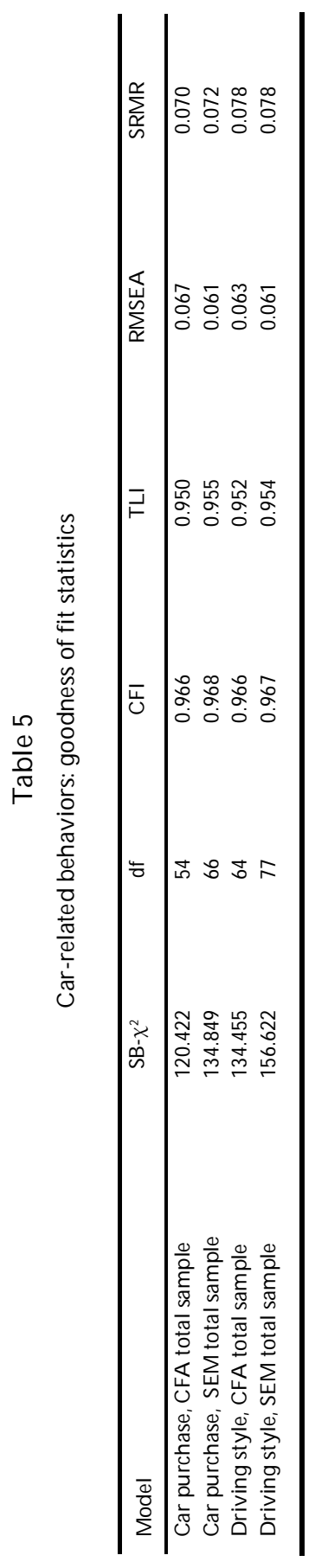


personal norm, social norm and self-efficacy all affected intention; 2) the latent factor habit affected both intention and behavior; 3 ) intention affected behavior. Exogenous latent factors were allowed to correlate freely because there were no hypotheses concerning the relationships between these factors. We tested the baseline model on the total sample (RQ2a; see model 2 in Tables 4-5) and the group of respondents familiar with social norms (RQ2b). Figures 1-4 show the standardized factor loadings and path coefficients of the baseline models for short-distance commuting, long-distance commuting, buying an energy-efficient car, and driving economically respectively.

The explained variance of behavior was higher than that of intention for short-distance commuting $\left(R^{2}\right.$ behavior $=0.91 / R^{2}$ intention $\left.=0.69\right)$, long-distance commuting $\left(R^{2}\right.$ behavior $\left.=0.88 / R^{2}{ }_{\text {intention }}=0.74\right)$, and driving economically $\left(R^{2}\right.$ behavior $=0.68 / R^{2}$ intention $\left.=0.74\right)$. This is likely due to the fact that intention is a very strong predictor of these daily behaviors. The reverse pattern was found for buying an energy-efficient car, where the explained variance of intention was higher than that of behavior $\left(R^{2}\right.$ behavior $=0.49 / R^{2}$ intention $=$ 0.69). This is to be expected because measurements of individual determinants at the time of the crosssectional survey presumably influence future intention rather than past decisions, which were often not made recently.

Returning to RQ2a, intention was a very strong predictor of behavior for commuting by car and driving economically, and a strong but relatively weaker predictor of buying an energy-efficient car. Attitude (towards commuting with all relevant transportation modes/a car-related behavior) and selfefficacy consistently had significant effects on intentions for all behaviors at the .05 level. Of all individual determinants, attitude (towards the examined behavior) was the strongest predictor of intention for all behaviors. Furthermore, attitude towards public transport was much more relevant for long-distance commuters than short-distance commuters, to the extent that its effect was comparable to that of attitude towards driving.

In contrast, personal norm did not have a significant effect on intention for any examined behavior. With regard to perceived norm, only the descriptive norm towards commuting by car had a significant effect on commuting by car. Compared to the total sample, regression coefficients for the subgroup familiar with social norms tended to differ slightly (i.e. difference <.10; RQ2b). The marginal role of perceived norm can therefore not be attributed to an absence of relevant social norms. Finally, habit had no significant effects on either commuting intention or behavior, except a very weak significant effect on intention for long-distance commuting (which might be a Type I error due to multiple testing as $\alpha=.05$ ).

\section{Background variables}

We tested for effects of background variables on the baseline models to examine whether background variables could account for variance in behaviors that individual determinants could not (RQ3). If so, effects of background variables on behavior are not (fully) mediated by individual determinants. We conducted tests on the total sample with all background variables as predictors of determinants, intentions, and behavior. Insignificant paths were removed; the model with the remaining paths was used to address our research questions.

The individual determinants mediated the effects of all background variables on commuting by car. Only distance to work had a small positive direct effect on buying an energy-efficient car (standardized $\beta=0.120, p<.001$ ). This direct effect on behavior was also unmediated by perceived financial interests. 


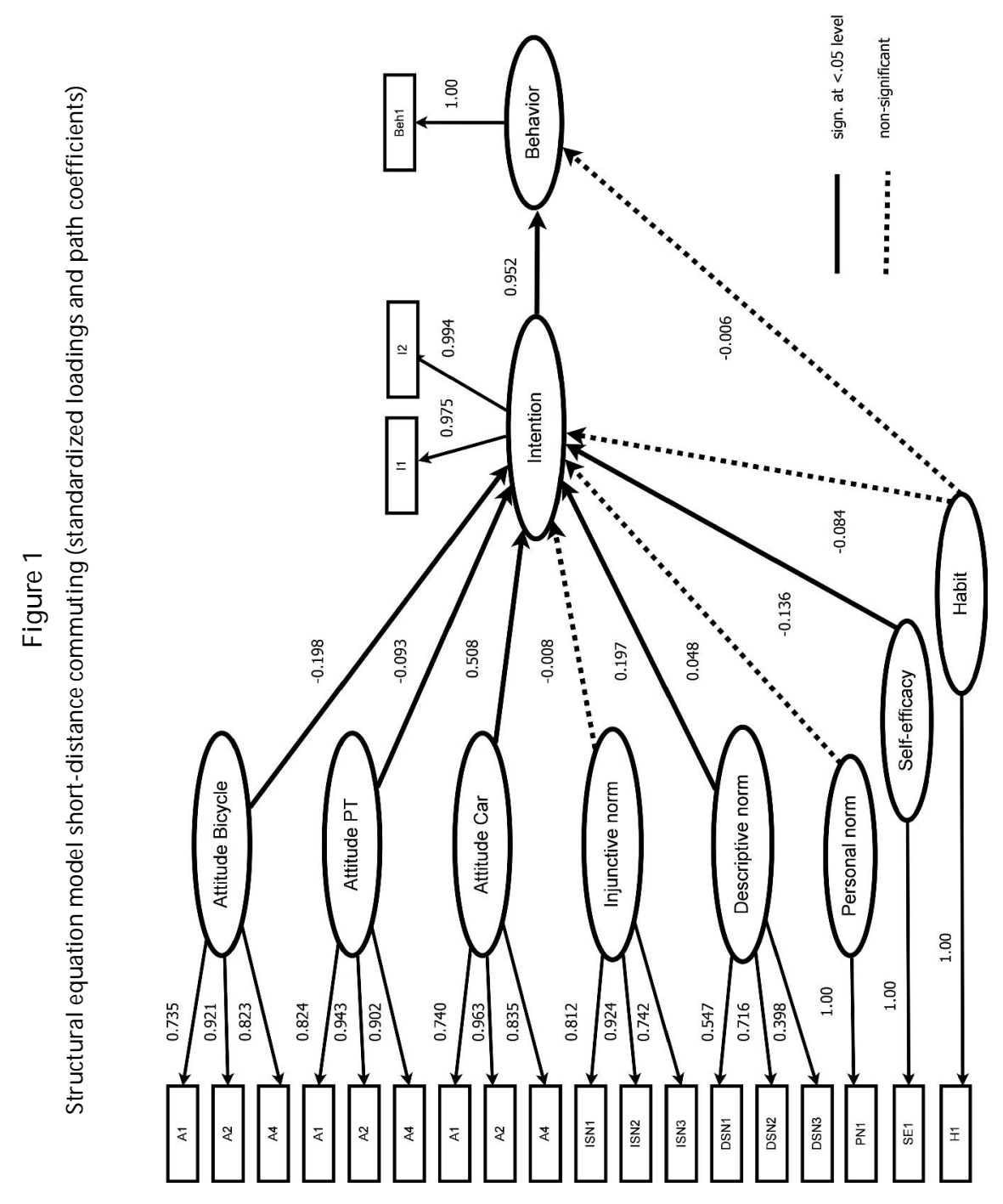




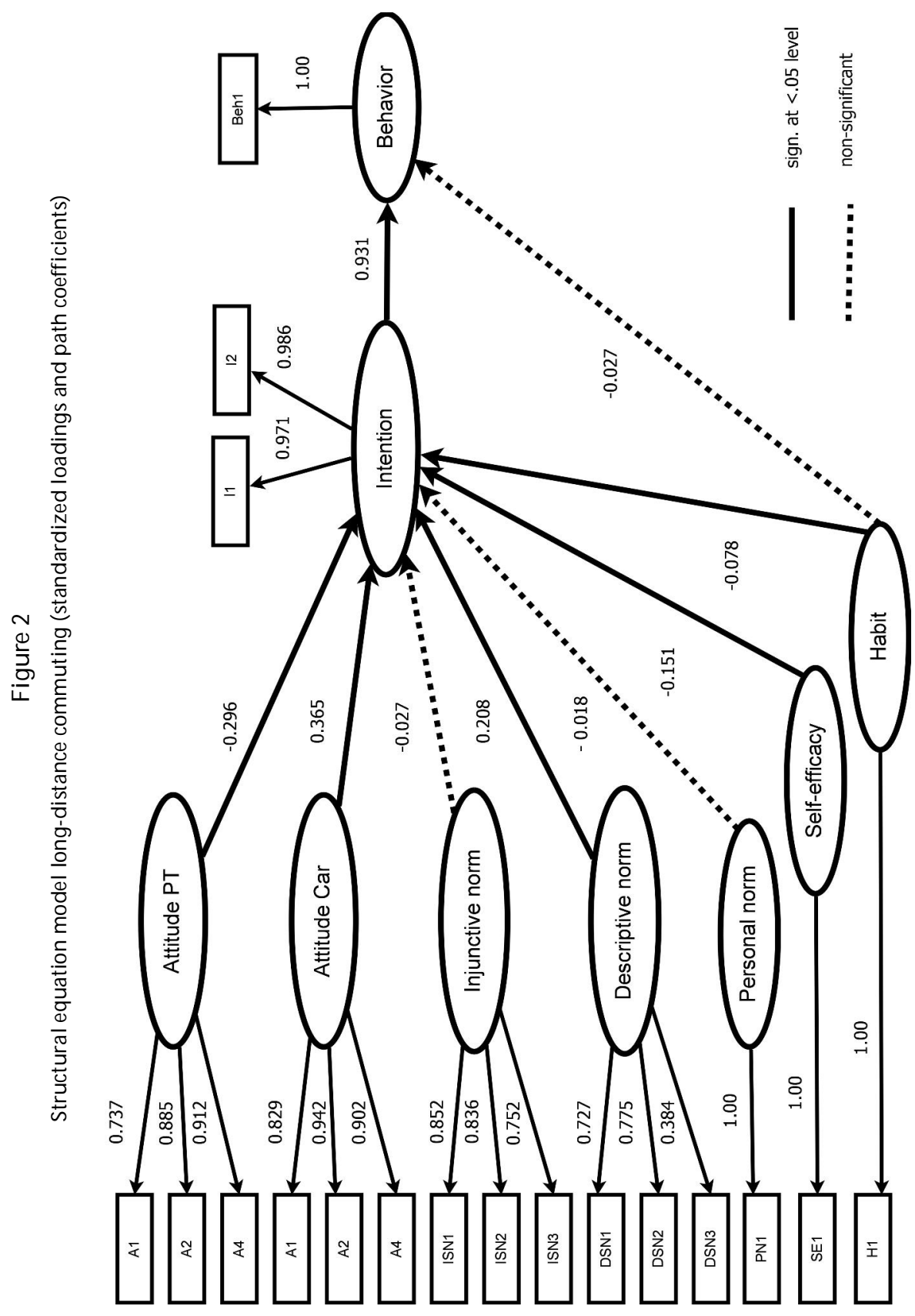




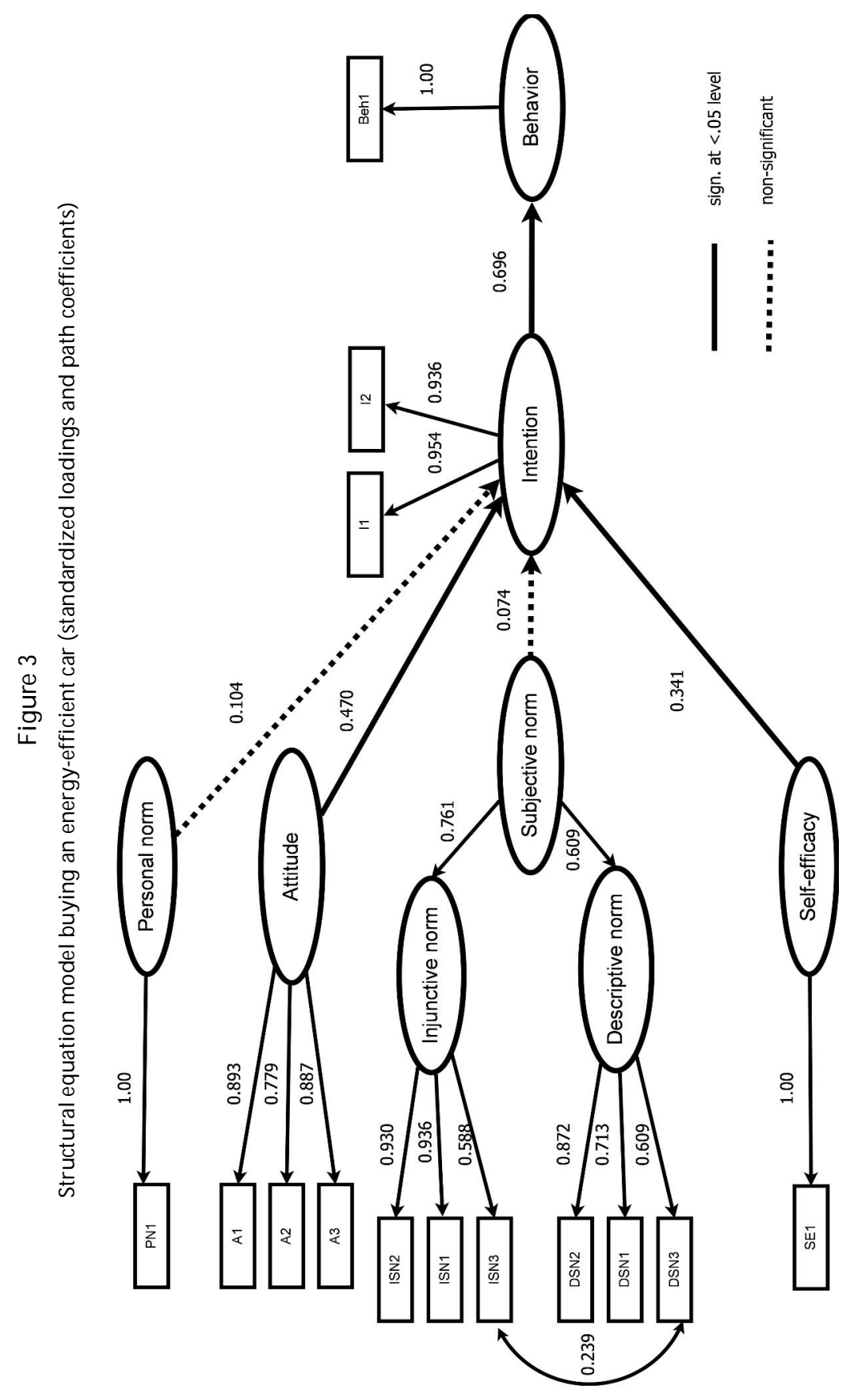




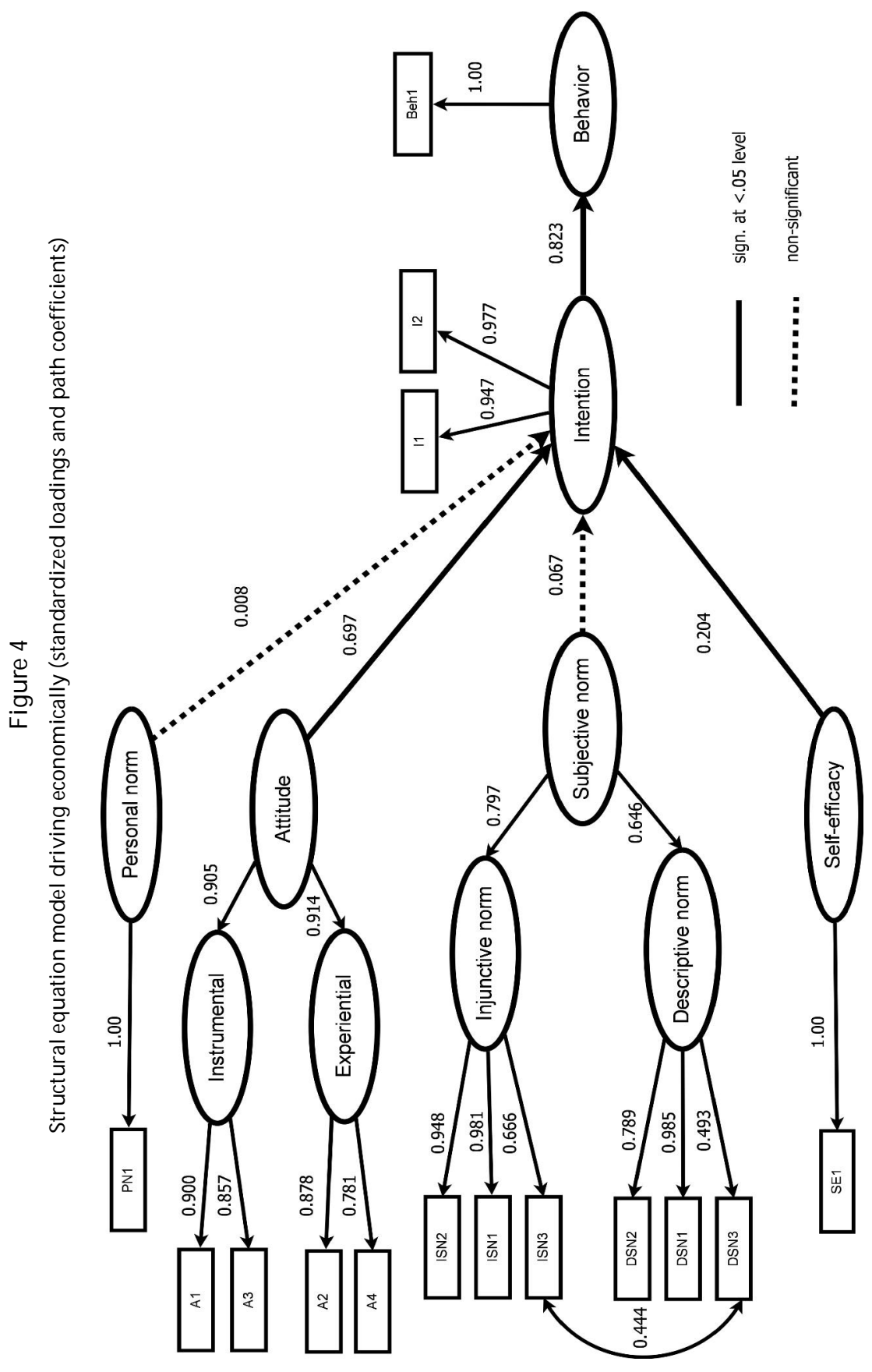




\section{Organization-specific influences}

The aim of the multigroup analyses was to test where there were regional (i.e. Zuid-Holland vs. Limburg) or sectoral (i.e. public vs. private) differences in the model of individual determinants of commuting by car.

\section{Configural model}

For a model to be compared across regions or sectors, a first necessary condition is configural invariance. We tested for configural invariance in a multigroup SEM, which is an omnibus test for the baseline model fits of each group (RQ4; see model 3r-3s in Table 4). The models show acceptable goodness-of-fit indices which entails that items are associated with the same common factors in all groups. The configural invariance model functioned as the reference model for all further multigroup analyses.

\section{Factor loadings}

We tested for equality of factor loadings in a Multigroup SEM by constraining these loadings to be equal across groups (RQ5a; see model $4 \mathrm{r}-4 \mathrm{~s}$ in Table 4). A scaled SB $\chi^{2}$ difference test revealed that equality of factor loadings across regions held for both short- and long-distance commuting (short: $\Delta \mathrm{SB} \chi^{2}=19.22, \mathrm{df}=11, \mathrm{~ns}$.; long: $\Delta \mathrm{SB} \chi^{2}=16.88, \mathrm{df}=9$, ns.), which implies that the factor loadings were equal between regions (Satorra et al., 2001). These findings suggest that the validity of measured beliefs as indicators of the theoretical determinants is equal across regions irrespective of distance. Across sectors, metric invariance held for long-distance commuting $\left(\triangle \mathrm{SB} \chi^{2}=2.06, \mathrm{df}=9\right.$, ns.), but was rejected for short-distance commuting $\left(\triangle \mathrm{SB} \chi^{2}=25.37, \mathrm{df}=11, \mathrm{p}<01\right)$. Thus, the relative importance of beliefs varies across sectors for short commuting distances but is equal for long distances.

\section{Partial measurement invariance of factor loadings}

To identify which factor loadings of short-distance commuting differed significantly across sectors, we conducted partial invariance tests by constraining the factor loadings of a single latent factor one at a time (see Appendix A). For factors with significantly different factor loadings, we calculated the ratio between the lowest, and the highest standardized factor loading (taken from the reference model) per item, and used this as an indicator of the magnitude of the differences. The lowest ratio of each factor and a qualitative interpretation of the interorganizational differences are reported below.

Equality of factor loadings was violated for the car attitude factor and injunctive norm factor (attitude car: $\Delta \mathrm{SB} \chi^{2}=10.37, \mathrm{df}=2, \mathrm{p}<01$, loading ratio= 0.95; injunctive norm: $\Delta \mathrm{SB} \chi^{2}=10.22, \mathrm{df}=2, \mathrm{p}<.01$, loading ratio $=0.72$ ). Thus, the relative importance of attitudinal measures and the opinion of social referents as indicators of the respective latent factors differ across sectors. For injunctive norm, the factor loadings in the reference model revealed that opinion of superiors had higher loadings on the injunctive norm factor in companies than in public organizations. For attitude towards driving, we did not further interpret the sectoral differences because the difference ratio showed that these were trivial.

To conclude, for short-distance commuting, equality of injunctive norm factor loadings is mildly violated across sectors. Bearing this exception in mind, the factor loadings as reported in Figures 1-4 should therefore be representative for all examined organizations. 


\section{Intercepts}

We had already established that the intercepts (i.e. means) of behavior itself differed across organizations (RQ1a), and that individual determinants could account for these (RQ1b). We would therefore expect item intercepts to differ significantly across organizations. Equality of intercepts was tested by constraining the item intercepts (except that of the behavior itself) to be equal across organizations in a multigroup SEM (RQ6; see model 5r-5s in Table 4). A scaled SB $\chi^{2}$ difference test indeed revealed that the equal intercepts model had a much worse fit compared to the configural invariant models across regions for both short- and long-distance commuting (regions, short: $\Delta \mathrm{SB} \chi^{2}=$ 156.89, $\mathrm{df}=20, \mathrm{p}<.001$; regions, long: $\left.\Delta \mathrm{SB} \chi^{2}=149.77, \mathrm{df}=17, \mathrm{p}<001\right)$. The same was concluded for the intersectoral comparison (sectors, short: $\Delta S B \chi^{2}=187.43, \mathrm{df}=20, \mathrm{p}<001$; sectors, long: $\Delta \mathrm{SB} \chi^{2}=235.28, \mathrm{df}=$ $17, \mathrm{p}<001)$. In brief, means of relevant beliefs were found to differ both across regions and sectors.

\section{Partial measurement invariance of item intercepts}

Partial invariance tests were conducted to check whether intercept equality could be upheld for some parts of the model. Violations were found for most individual determinants (see Appendices A-B). For long-distance commuting, equality of intercepts was rejected for all factors in both the interregional and intersectoral comparisons. For short-distance commuting, attitude towards cycling, self-efficacy, and habit were equal across regions. Attitude towards public transport and habit were equal across sectors.

\section{Structural model}

Equality of the structural model was tested by imposing equality constraints on path coefficients between latent factors (RQ7; see model 6r-6s in Table 4). Compared to the configural invariant model, equality of the structural model between regions held for short-distance commuting but not for longdistance commuting (short: $\Delta \mathrm{SB} \chi^{2}=16.97, \mathrm{df}=10$, ns.; long: $\Delta \mathrm{SB} \chi^{2}=20.59, \mathrm{df}=9, \mathrm{p}<.05$ ). That is, the magnitude of the hypothesized relationships between individual determinants, and intention and behavior are similar across regions for short distances, but significantly different for long distances. Equality of the structural model between sectors held for both short- and long-distance commuting (short: $\Delta \mathrm{SB} \chi^{2}=13.65, \mathrm{df}=10$, ns.; long: $\Delta \mathrm{SB} \chi^{2}=14.71, \mathrm{df}=9$, ns.). In other words, the magnitude of the relationships between latent factors is similar across sectors.

\section{Partial invariance of structural model}

Partial invariance tests were conducted to check where structural invariance between regions was rejected for long-distance commuting (see Appendix B). The only significant violation was found for the path between injunctive norm and intention $\left(\Delta \mathrm{SB} \chi^{2}=13.42, \mathrm{df}=1, \mathrm{p}<.001\right.$, ratio= .04$)$. Surprisingly, inspection of the structural pathway coefficients revealed that, unlike the non-significant coefficient in the total sample analysis, injunctive norm had a significant positive effect in Limburg and, as expected (because the items were negatively worded), a significant negative effect in Zuid-Holland (Limburg: standardized $\beta=.158$; Zuid-Holland: standardized $\beta=-.140)$. Because of this anomalous finding, we also examined the coefficients of each region for short-distance commuting to check whether a similar but less pronounced pattern could be detected, despite the fact that structural invariance between regions was non-significant. This time, we found a non-significant positive effect in Limburg, and a significant negative effect in Zuid-Holland. Thus, these regional contrasts might explain the lack of a significant relationship between injunctive norm and intention to commute by car in the total sample. 
This still leaves the question why we found a significant positive regression coefficient for long-distance commuting. Bivariate correlations between injunctive norm and behavior were significantly negative in both regions, although the correlation with behavior was stronger in ZuidHolland. Correlations between injunctive and descriptive norm were also no higher than .36. In brief, we could not find a straightforward explanation: it might be due to a Type I error, or an unknown confounding variable.

\section{Discussion}

Our study tested models of individual determinants of various commuting behaviors among office workers. In addition we examined in which respects the model for commuting by car (i.e. travel mode choice) differed across organizations, and more specifically across regions and sectors. Our hypothesized model proved to fit the data well but did not always provide a complete account of all investigated behaviors. There were large interorganizational differences in average travel mode choice but no differences in average car purchase decisions or driving style. After we controlled for individualspecific influences, these organizational differences in travel mode choice were substantially reduced (short-distance commuting) or disappeared (long-distance commuting).

\section{Individual-specific influences}

Intention was generally a very strong predictor of repeated behaviors (i.e. commuting by car and driving economically). For investment behaviors (i.e. car purchasing choices), intention was a strong though weaker predictor of behavior, which is probably due to the longer time lag between the performance of the behavior and the measurement of intention.

Of the social-cognitive determinants, in turn, attitude and self-efficacy consistently had significant effects on intention. Attitude (towards the examined behavior) was the strongest predictor of intention for all behaviors. Furthermore, attitude towards public transport was much more relevant for longdistance commuters than short-distance commuters, to the extent that its effect was comparable to that of attitude towards driving. This can be explained by the fact that short-distance commuters have more alternative travel mode options (i.e. bicycle and on foot). In contrast, personal norm was not a significant predictor of intention for any examined behavior. The role of perceived norm fluctuated between behaviors.

We also investigated habitual effects on commuting by car. Habit had no significant effects on intention and behavior, except a weak significant effect on intention to commute by car for long distances.

\section{Organization-specific influences}

The differences in commuting by car could be further examined in multigroup analyses by region and by sector. We found one non-trivial, significant sectoral difference in the way the injunctive norm construct was manifested for short-distance commuters: in companies, the opinion of superiors was more important to the overall injunctive norm than in public organizations.

More importantly, however, significant regional and sectoral differences in the averages of attitudinal, normative and control beliefs were the rule rather than the exception. For long-distance commuters, equality of intercepts was rejected for all factors in both the interregional and intersectoral comparisons. For short-distance commuters, only attitude towards cycling, self-efficacy, and habit did not differ significantly across regions. One interesting finding is that self-efficacy - in our study 
measured as the perception of autonomously deciding on one's commuting travel mode - did not vary across regions for short-distance commuting despite the regional differences in public transport connectivity. Both this finding and the weak effect of attitude towards public transport may be explained by the fact that attitude towards cycling had a relatively stronger effect on intention to commute by car for short distances. In other words, cycling is a more important alternative to the car than public transport for short commuting distances. Across sectors, only attitude towards public transport and habit did not differ significantly. This might imply that attitude towards public transport for short commuting distances are relatively uniform among people working in the same region.

Finally, we found that path coefficients between exogenous latent factors and endogenous latent factors tended to be similar across regions and sectors. However, there was one remarkable exception: the path from injunctive norm to intention was, as expected, negative in the Zuid-Holland region, but positive in the Limburg region. As this anomalous result in Limburg is inconsistent with theory and most empirical evidence (including that from the other region in this study), it likely reflects a Type I error, or possibly a confounding variable. This phenomenon has caused the non-significant effect of injunctive norm on intention in the overall sample, which is due to opposite effects in subgroups which cancel each other out in the total sample analysis.

\section{Limitations and future research directions}

The results of our study should be interpreted in the light of several methodological limitations. Firstly, participation in the online survey was voluntary. There were no formal mechanisms to ensure cooperation of individual employees or the organizations as a whole. Given the varying completion rates, it is possible that some of the differences found are due to selective participation of employees in the organizations.

Another constraint was that we only obtained self-reported cross-sectional data, which meant that we neither obtained objective measures of behavior nor evidence to make claims regarding the direction of causality. Longitudinal research designs may overcome these shortcomings in future.

Finally, we had measured personal norm with a single item. Conclusions drawn about the irrelevance of personal norm to commuting behaviors are solely based on the relevance of this single item rather than a comprehensive multi-item measure of the personal norm concept.

\section{Implications for interventions}

Several conclusions for interventions can be drawn. Attitude and self-efficacy were consistently found to be significant predictors of intention. Assuming a causal link, interventions should focus on these determinants of commuting behaviors.

In contrast, habit and personal norm were generally not significant predictors of commuting intention or behavior. The role of perceived norm is less clear. The overall perceived norm did not have a significant effect on car-related behaviors. Descriptive norm was a significant predictor of intention to commute by car, but injunctive norm was not. However, group comparisons of the structural model showed that the direction and significance of the injunctive norm effect differed between regions, when controlling for other determinants. In the light of these mixed results, normative elements should be avoided in interventions until their role is better understood. Similarly, stand-alone habit disruption techniques may also be ineffective if these are not accompanied by positive changes in attitude and selfefficacy. 


\section{Conclusion}

To conclude, this study explored an area previously largely neglected by research on commuting behaviors, namely that of organizational contextual factors. Similar to previous findings from private and household studies, an extended planned behavior framework proved very useful in explaining commuting behavior in our study. The use of Multigroup SEM allowed us to examine in detail how regional context and organizational sector may influence (individual determinants of) behavior. These interorganizational comparisons of commuting behaviors have shown that regional and sectoral differences are mainly associated with how strongly commute-related beliefs are held. Furthermore, the degree to which specific injunctive norm beliefs were relevant to the overall injunctive norm, and the effect of injunctive norm on intention sometimes also differed between organizations. 


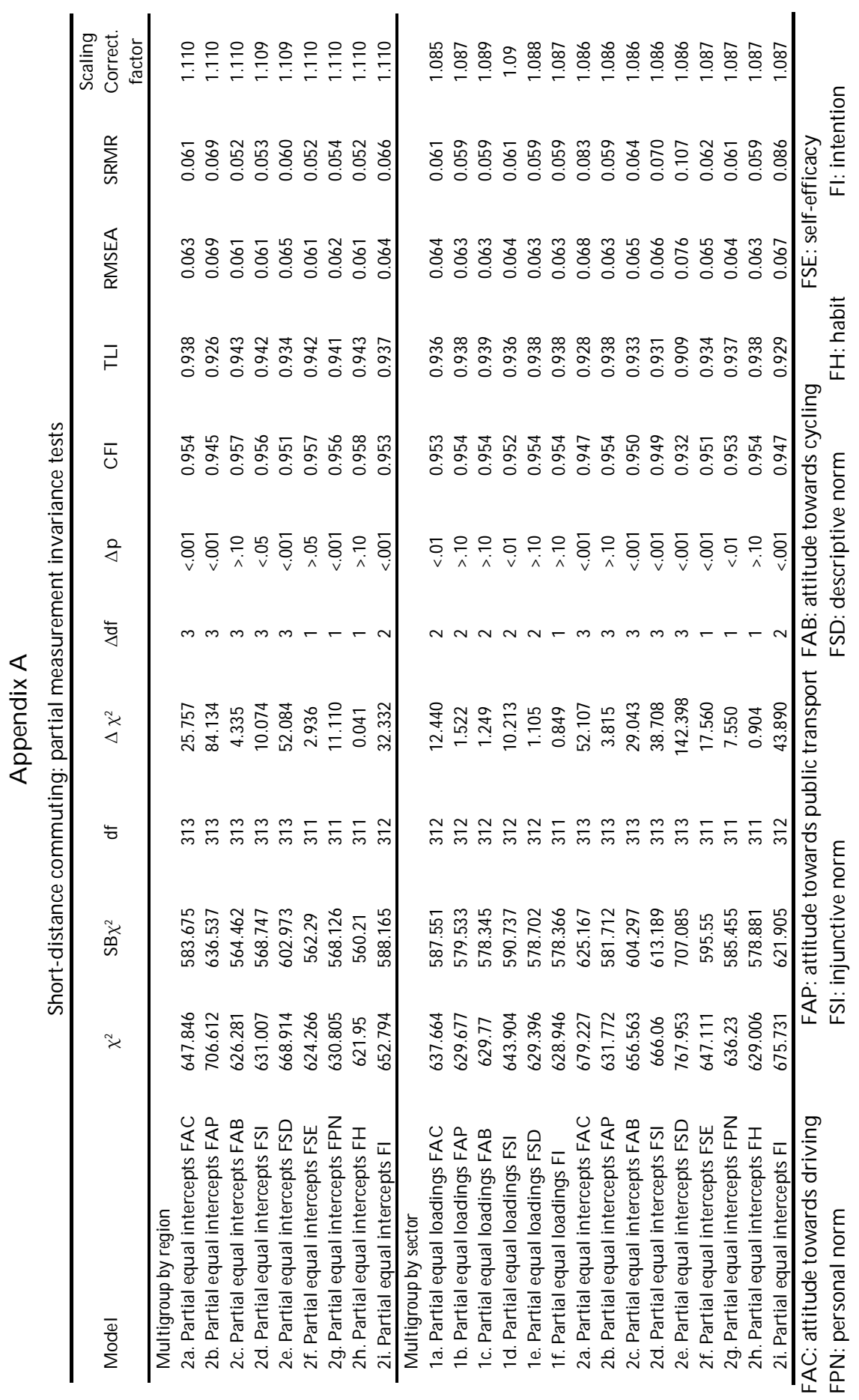




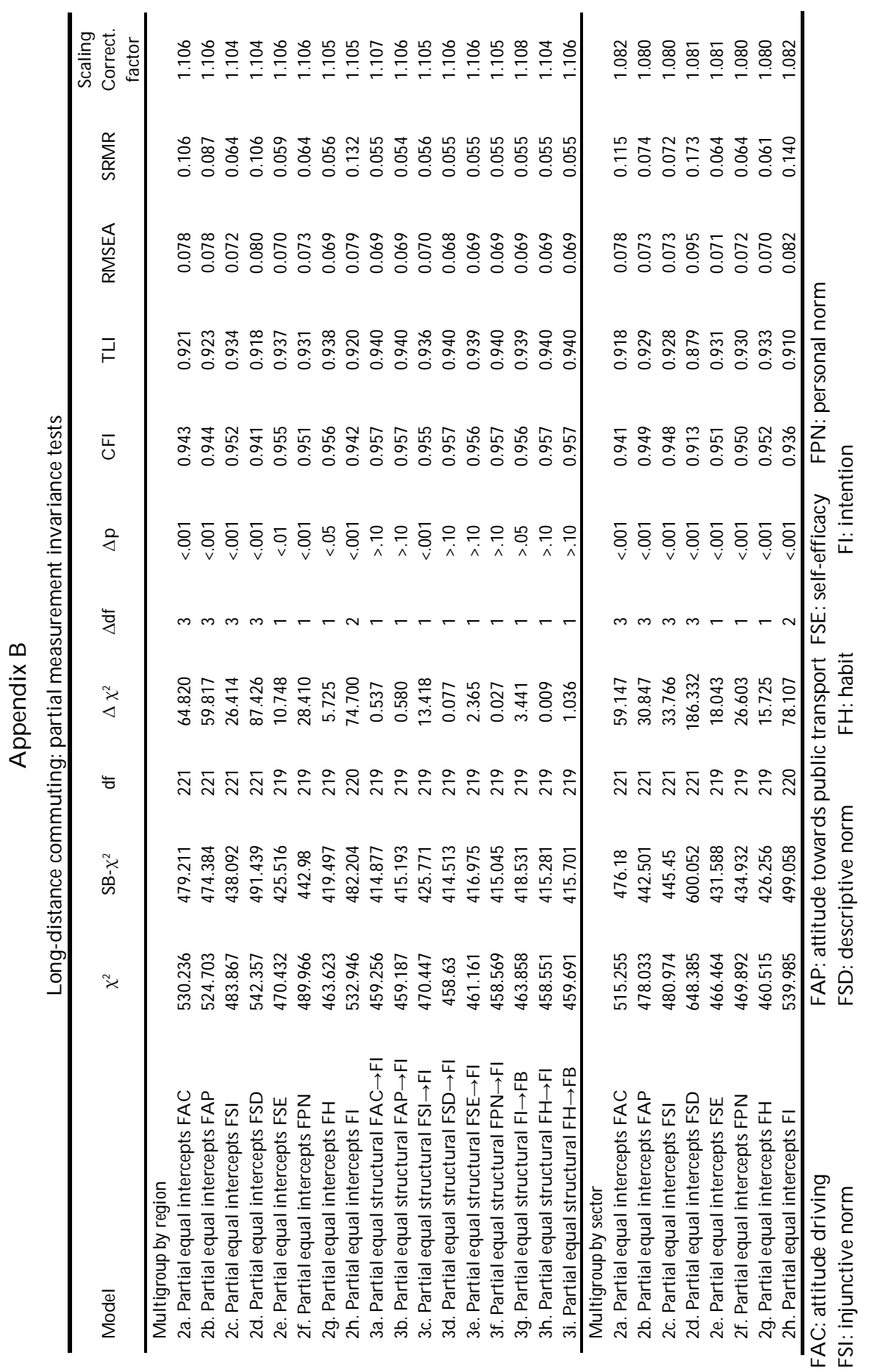





\title{
Chapter 7: \\ Business Travel Behaviors among Office Workers: An Interregional and Intersectoral Comparison of a Model of Individual Determinants ${ }^{11}$
}

\begin{abstract}
Introduction
Business travel consumes organizational resources directly via the cost of transport, and indirectly via time spent by employees traveling. From a societal point of view, transport is associated with problems such as traffic congestion and environmental pollution. For these reasons, a good understanding of the determinants of business travel frequency and alternatives to physical business travel can be of considerable practical value.

Previous research on work-related travel behavior has mostly examined individuals' travel mode choice for commuting purposes (Bamberg, Hunecke et al., 2007; Gardner et al., 2010; Van Vugt et al., 1996; Verplanken et al., 2008). However, compared to commuting, little research has addressed employee business travel - defined as work-related travel to an irregular place of work (Aguilera, 2008).

Furthermore, although reviews of "soft" transport policy measures, which include behavioral change programs implemented at the workplace, indicate that these tend to be effective, the mechanisms underlying their effectiveness are ill-understood (Cairns et al., 2008; Richter et al., 2010). Moreover, most reported (non-peer-reviewed) travel intervention studies lack methodological rigor and are likely to show reporting bias (Moser et al., 2008). In other words, it is still unclear which soft policy measures are truly effective, and if effective, why this is so.

To address these research gaps, we studied business travel behaviors among office workers from various organizations in both the public/non-profit and private sector, and two distinct geographical locations with varying degrees of public transport connectivity. We targeted office workers because they form the largest share in the Dutch working population, and most likely in all Western countries (Statistics Netherlands [CBS], 2010). Behaviors relevant to business travel include deciding whether to make a business trip or not, but also behavioral alternatives to traveling such as teleconferencing.
\end{abstract}

11 This chapter is in preparation for submission as:

Lo, S.H., van Breukelen, G.J.P., Peters, G.J. \& G. Kok, Business Travel Behaviors among Office Workers: an Interregional and Intersectoral Comparison of a Model of Individual Determinants. 
Teleconferencing through audio- or video-equipment has a lower environmental impact in general, and in particular if it can replace long-distance (air) travel (Toffel et al., 2004).

This paper's aim is to present a model of individual determinants for various business travel behaviors, and to test in which respects this model differs across organizations. We will first examine whether our model of individual determinants fits the data well. Then, we will investigate whether travel-related, sociodemographic, and individual-specific organizational background variables can further improve prediction of behavior. Finally, we will investigate similarities and differences between organizations. In particular, we are interested in how results of the model of individual determinants vary across regions and sectors. The conceptual framework used for examining individual determinants and organizational determinants will be presented below.

\section{Individual Determinants}

Individual determinants are defined as determinants of a psychosocial nature that are relevant on the individual level. We chose to employ a framework that only contained general theoretical concepts commonly used to explain a wide range of social behaviors because it may facilitate comparison with other types of behaviors. As a result, we have included social-cognitive variables (i.e. attitudes; perceived norms; self-efficacy) and habit in our framework for individual determinants:

"Attitudes" are an individual's overall evaluation of a behavior (Eagly et al., 1993). Several subcomponents of attitudes can be distinguished. One distinction is that between instrumental and experiential aspects of attitudes (Fishbein et al., 2010). The former is connected to the outcome of a behavior while the latter is linked to the experience of engaging in a behavior. For certain categories of social behavior, it has also been found useful to emphasize the role of an individual's moral evaluation of a behavior. The moral component has often been referred to as "personal norm" or "moral norm"(Kaiser, 2006; Parker et al., 1995). While some suggest a lack of discriminant validity between personal norm and attitude, others maintain it should be considered a distinct construct (Bamberg, Hunecke et al., 2007; Kaiser, 2006).

Another social-cognitive component related to the individual in question is "self-efficacy" which refers to a person's evaluation of whether one has the necessary resources, knowledge and/or skills to attain a goal (Bandura, 1997), or more narrowly conceived, to perform a behavior (Ajzen, 1991).

Evidently, perceptions of control are often linked to objective external circumstances. For instance, in the context of business travel behaviors, it is clear that travel frequency is influenced by (organizationimposed) job requirements.

In contrast to attitudes, the influences of other people on the individual are reflected in "perceived norms", which are defined as the perception of other people's evaluation of a behavior. A useful distinction is that between injunctive norms, which concern others' approval/disapproval of one's own behavior, and descriptive norms, which refer to others' behavior (Schultz et al., 2007). For business travel, especially the approval of managers may be of high relevance to one's own behavior because disapproval often makes business travel impossible (Arnfalk \& Kogg, 2003). However, one should also consider the possibility of absence of perceived norm, i.e. not knowing what others think and do (Siero et al., 1984).

For social-cognitive variables to play a role in behavior, it should be possible to (partially) control the behavior on a volitional basis (Fishbein et al., 2010). Furthermore, awareness of its personal, social, or environmental relevance is also prerequisite. When such behaviors are repeatedly performed, they 
no longer require deliberative evaluation which has led many to argue that they become "habits", which are characterized by a degree of automaticity and unconsciousness (Fishbein et al., 2010; Verplanken et al., 2003). In this phase, contextual cues like time and place may play a more salient role in determining behavior than social-cognitive variables (Wood et al., 2005).

\section{Organizational Determinants}

Organizational determinants are defined as those influences on behavior specific to the organizational context. According to Tudor and colleagues, who presented a framework of proenvironmental (management) behavior in organizations, five organizational factors are of relevance: organizational focus, organizational structure, organizational size, departmental type and size, and organizational culture (Tudor et al., 2008). Similar organizational determinants such as organizational sector, size, culture, and strategy have been researched for business travel (Aguilera, 2008). Although Tudor et al.'s framework does aid identification of relevant organizational characteristics, it mainly outlines determinants which may be too broad to be meaningfully related to individual behavior.

Organizational size, for instance, can be hypothesized to positively relate to geographical dispersion of an organization and consequently increase travel among employees who need to be in contact with others in the organization. In other words, organizational size may affect the baseline travel frequency of the average employee, but it does not determine an individual's choice to physically meet (and travel), call, e-mail, or arrange a teleconference meeting each time there is a need to communicate with others who are elsewhere.

Of the other factors included in Tudor et al.'s framework, organizational focus and organizational culture may be the ones most directly affecting business travel behavior. Organizational focus, defined as the primary aim of an organization, may heavily influence business travel. At least on the organizational level, it sets the priorities, which may or may not involve business travel as a means to achieve this aim. One way to make a rough categorization of organizations in this respect is the publicprivate divide, where the primary aim of a public/non-profit organization is to provide services for society or the world at large, and private organizations' aim is to generate profit. Particularly relevant to business travel, is that the divide between public and private sectors is strongly associated with differences in organizational policies. While the provision of company cars to employees is common practice in private organizations, public organizations do not provide employees with cars. Company cars may provide a positive incentive to travel more frequently by making travel more convenient, but also through negative incentives by requiring employees to make a minimum number of business trips with their company cars (Arnfalk et al., 2003; Lo et al., under review-b).

Organizational culture comprises those elements that are shared by organizational members. It could indeed be seen as a broader concept which includes, or is at least interlinked with, organizational focus (Fernandez et al., 2003; Tudor et al., 2008). Top and middle management may disproportionately affect organizational culture (Fernandez et al., 2003). Previous research has indeed found that top and middle management play a crucial role in employees' proenvironmental behavior, for instance, through influencing employees' perceived norm of these behaviors (Andersson et al., 2005; Ramus et al., 2000; Siero et al., 1989; Tudor et al., 2007).

It is also important to note differences in business travel behavior between subpopulations within an organization (Aguilera, 2008). Organizational subpopulations can, but not exclusively, be defined on the basis of managerial status, employment duration, part-time versus full-time status, and 
departmental affiliations. In this paper, characteristics that define organizational subpopulations will be termed "individual-specific organizational variables".

Finally, it is important to acknowledge that business travel does not depend solely on individual and organizational factors but also on regional and societal factors. The geographical location of an organization, and other regional and societal factors such as infrastructure and cultural influences obviously affect business travel as well.

\section{Research Questions}

In the light of the identified research gaps, the current paper will address the following questions for various business travel behaviors:

\section{Organizational differences in behavior}

(RQ1a) Are there interorganizational differences in the average of each behavior?

(RQ1b) If so, can these differences be explained by individual-specific influences?

\section{Individual-specific influences}

(RQ2a) Are the identified individual determinants significant predictors of business travel intentions and behaviors? What is the magnitude of the significant relationships found?

(RQ2b) Does the magnitude of relationships between individual determinants, and intention and behavior differ for the subgroup of employees who were familiar with the relevant social norm? (RQ3) Do travel-related, sociodemographic, and individual-specific organizational background variables explain additional variance in business travel intentions or behaviors, over and above the identified individual determinants?

In addition, we will examine organizational similarities and differences for domestic business travel behaviors:

\section{Organization-specific influences}

(RQ4) Is the factor structure of our model of individual determinants of behavior adequate for each region and sector in our sample?

(RQ5) Do individual determinants manifest themselves differently across regions and sectors? More specifically, are the loadings of indicators on corresponding latent factors equal across regions and sectors?

(RQ6) Do the average scores on relevant beliefs differ across regions and sectors?

(RQ7) Do the regression coefficients for predicting intention and behavior from individual determinants differ across regions and sectors?

\section{Methods}

\section{Participants and Procedure}

Employees from four organizations located in cities in the Dutch provinces Zuid-Holland (ZH) and Limburg (LB) were approached to take part in an online survey study. The sample of organizations consisted of two commercial companies (company ZH; company LB), a university (university LB), and a non-governmental organization (NGO ZH). In other words, we sampled one private and one public organization in each region. This sectoral divide also corresponded to companies being more 
geographical dispersed within the Netherlands than public organizations, which both had their office building(s) in only one city.

The choice for Zuid-Holland and Limburg as case studies was motivated by the contrasts between these regions, with Zuid-Holland being the most densely-populated, and Limburg one of the less populated provinces in the Netherlands (CBS et al., 2010). This clearly has implications for the regional infrastructure in terms of public transport connectivity and the occurrence of traffic jams.

Company ZH, university LB, company LB, and NGO ZH each participated with one to three office buildings, with a (combined) capacity of approximately 1000, 700, 450, and 350 people respectively. All organizations had some form of public commitment to environmental sustainability, but none had energy conservation as their primary organizational aim. Nevertheless, the NGO's core task, development aid, was increasingly perceived to be related to environmental sustainability because climate change had become a pressing issue in the countries where they operated.

Employees were approached by their own organization with the request to fill out the online questionnaire. It was emphasized that the study was conducted by independent researchers of a Dutch university, and only the general anonymized results would be reported to the organization. Except for employees in company LB, respondents were given the opportunity to participate in a raffle contest for $€ 20$ gift vouchers.

\section{Measures}

Business travel behaviors and the measures of their determinants were chosen based on findings from an earlier qualitative study conducted at the same organizations (Lo et al., under review-b). Interviews and focus groups with key informants and employees of the four organizations were conducted to identify possible determinants of office workers' business travel behaviors. Based on these findings, we selected a small number of behaviors for further investigation in the survey, relevant adjectives for the semantic differential scales for attitude measures, social referents for perceived norm measures, and beliefs to measure determinants. Due to survey-length constraints, some determinants were measured with only one item. Unless stated otherwise, all measures were rated on a five-point scale ranging from 1 to 5 .

\section{Business travel behavior}

We selected behaviors, which were most relevant for determining business travel frequency. For interorganizational comparisons, we examined two behaviors: 'domestic business trips' ("I consciously consider whether domestic business trips I want to make have sufficient added value compared to distance communication") and 'domestic teleconferencing' ("I use teleconference facilities to communicate with domestic contacts"). We also investigated the same behaviors in an international context - i.e. 'international business trips' and 'international teleconferencing' - but did not conduct multigroup analyses for these due to the small number of respondents making international business trips.

Only respondents who traveled on a minimum number of trips per year were included in the sample, assuming that a business travel behavior was (largely) irrelevant for those employees who scored below the cutoff points. The inclusion criteria for domestic business trips and domestic teleconferencing were $\geq 6$ trips and $\geq 4$ trips per year respectively. For international business trips and international teleconferences these were $\geq 2$ trips and $\geq 1$ trips per year. 
Behavior was measured with one item beginning with "The past year, I have...", rated on a scale ranging from disagree to agree for business trips, and never to very often for teleconferencing. Because of our cross-sectional survey design, we used behavior of the past year as a proxy for current behavior.

\section{Intention}

Behavioral intention was measured with two items, starting with "Next year, I expect..." (I1) and "Next year, I want..." (I2), rated on a scale ranging from never to always.

\section{Attitude}

Attitude towards each of the behaviors was measured on a semantic differential scale with the adjective pairs "negative-positive" (IA1), "useless-useful" (IA2), "unpleasant-pleasant" (EA1), and "difficulteasy" (EA2). ${ }^{12}$ We hypothesized that the former two pairs reflected instrumental aspects, whereas the latter would reflect experiential aspects. Instrumental and experiential attitude were modeled as firstorder factors of an overarching second-order attitude factor.

\section{Personal norm}

In addition, we included a one-item morally evaluative measure, "I think employees of organization $X$ ought to..." (PN1), rated on a scale ranging from disagree to agree. ${ }^{13}$

\section{Perceived norms}

Injunctive and descriptive norm were modeled as first-order factors of a second-order perceived norm factor. The injunctive norm measure consisted of "My superior(s) think I should..." (ISN1) and "My colleagues think I should..." (ISN2), rated on a scale ranging from disagree to agree with an additional option I really do not know. The descriptive norm items included "My superiors [do behavior X]" (DSN1) and "My colleagues..." (DSN2), rated on a scale ranging from never to always, and the option I really do not know. The answer category I really do not know could be recoded into the scale center (neutral for injunctive norm, and sometimes for descriptive norm) for the total sample analyses, while allowing for a subgroup analysis of those respondents who were familiar with the relevant norm. This made

\footnotetext{
12 The adjective pair "difficult-easy" is often used to measure self-efficacy, but has been found to correlate much more highly with experiential attitude in some studies (Fishbein et al., 2010). In the present study we also found this to be the case (e.g. $r=0.33 \mathrm{cf} . \mathrm{r}=0.68$ for domestic business trips). ${ }^{13}$ When speaking of the moral/normative dimension of relevant behaviors, results of the qualitative study showed that it was more natural for employees to speak of all employees rather than they themselves personally. As noted in the introduction, there is disagreement in the literature on whether personal norm is a component of attitude. Given that our personal norm-item refers to one's evaluation of what other people should do we kept it as a separate factor because it is conceptually different from the attitude items.
} 
examination of possible attenuation effects due to (frequent) absence of perceived norm possible. The operational definition of this subgroup was ability to gauge the injunctive norm of one's superiors.

\section{Self-efficacy}

Self-efficacy was measured with a single item "If I want to, I think I can manage to..." (C1), rated on a scale ranging from disagree to agree.

\section{Habit}

For teleconferencing, habit was measured with two items adapted from Verplanken's index of habit strength, namely "I automatically think of the possibility to use teleconference when I need to communicate with..." (H1), and "I routinely use teleconference to communicate with..." (H2), rated on a scale ranging from disagree to agree (Verplanken et al., 2003). We did not measure habit for business trips because previous qualitative findings suggested this was not perceived to be a determinant of these behaviors.

\section{Background variables}

We measured two travel-related background variables: distance to work from home (in kilometers) and having a company car (dummy variable). Sociodemographic and individual-specific organizational variables were also considered background variables. The sociodemographic variables examined were gender, age, and educational level. A dummy variable for managerial status, employment duration (as expressed by the year in which one had joined the organization), and full-time equivalent (FTE) ranging from 0 to 1 were included as individual-specific organizational variables.

\section{Data Analysis}

We tested for interorganizational differences in average behavior with one-way ANOVA (RQ1a). We also tested whether such differences, if found, could be explained by individual-specific influences (i.e. scores on individual determinants and individual-specific organizational variables) by adding individual-specific variables as covariates with ANCOVA (RQ1b). Such differences would warrant further examination of how organizational differences may influence individual determinants of these behaviors, and thus indirectly influence behavior.

Once we had tested for organizational differences in behavior and examined to what extent these differences could be attributed to individual differences, we continued with testing explanatory models of these behaviors. We used confirmatory factor analysis (CFA) and structural equation modeling (SEM) with MPlus version 6 for hypothesis testing of our model of individual determinants of business travel behaviors (Muthén et al., 1998-2010). First, we verified whether our baseline model fitted the data well (RQ2a). We also tested the baseline model on the subgroup of employees who were all familiar with the social norm (RQ2b). Then, we examined the effect of including background variables in our baseline model (RQ3). Attitude, personal norm, perceived norm, self-efficacy and habit were hypothesized to affect intention. Habit and intention, in turn, were hypothesized to affect behavior.

Following this, we tested for interorganizational differences in our model of individual determinants of domestic business travel behaviors with multigroup analyses. Limited sample sizes prevented us from conducting such analyses for international business travel behaviors. In these multigroup analyses, we focused on interregional and intersectoral comparisons. For a model to be 
compared across regions or sectors, a necessary condition is equality of factor structure, or configural invariance, which entails that items are associated with the same common factors in all groups (RQ4).

If equality of factor structure is tenable, further group comparisons can be made. First, we tested for equality of factor loadings, or metric invariance, which means that latent constructs manifest themselves similarly across groups (RQ5). If equality of factor loadings is rejected, the substantial implication is that the relevance of at least some indicators differs across regions/sectors. In that case, partial invariance tests can identify which factors have items that load differently across regions and/or sectors. We also tested for equality of item intercepts, which can indicate whether groups have significantly different item means (RQ6). Again, partial invariance tests were conducted to examine which item means differed across regions and/or sectors. Finally, we tested for equality of the structural model, i.e. whether the regression coefficients of the individual determinants (the exogenous latent factors) as predictors of intention and behavior (the endogenous latent factors) had equal magnitudes across regions and/or sectors (RQ7).

\section{Results}

\section{Sample characteristics}

Of those who had started the questionnaire, the completion rates for company $\mathrm{ZH}$, company LB, university LB, and NGO ZH were $55 \%, 65 \%, 69 \%$, and $84 \%$ respectively. Response rates were not calculated because the number of employees reached by the invitation could not be reliably established for company $\mathrm{ZH}$ and university LB.

Of the total sample, $54 \%$ was female, the mean age was $42(\mathrm{SD}=10.91)$, and $69 \%$ had received higher education. On average, respondents were employed for 0.9 FTE (full-time equivalent) (SD=0.16), mean employment duration was 12 years $(\mathrm{SD}=11.8)$, and $17 \%$ of the respondents had a (senior) managerial position. Sociodemographic and organization-related characteristics of each organization's respondents are presented in Table 1. 
Table 1

Sample characteristics by organization

\begin{tabular}{|c|c|c|c|c|c|}
\hline & Total & $\mathrm{NGO} \mathrm{ZH}$ & Company ZH & University LB & Company LB \\
\hline Sex (\% female) & $54 \%$ & $62 \%$ & $41 \%$ & $69 \%$ & $44 \%$ \\
\hline $\begin{array}{l}\text { Education } \\
\text { (\% higher education) }\end{array}$ & $69 \%$ & $81 \%$ & $78 \%$ & $82 \%$ & $75 \%$ \\
\hline Age (years) & 42 & 43 & 42 & 40 & 46 \\
\hline$S D$ & 10.9 & 9.8 & 10.9 & 11.5 & 10.3 \\
\hline FTE $(0-1)$ & 0.9 & 0.88 & 0.95 & 0.87 & 0.92 \\
\hline$S D$ & 0.16 & 0.14 & 0.13 & 0.20 & 0.17 \\
\hline $\begin{array}{l}\text { Employment } \\
\text { duration (years) }\end{array}$ & 12 & 8 & 15 & 9 & 18 \\
\hline$S D$ & 11.8 & 7.8 & 12.9 & 8.4 & 12.1 \\
\hline Managerial position & $17 \%$ & $25 \%$ & $20 \%$ & $17 \%$ & $22 \%$ \\
\hline
\end{tabular}

\section{Organizational differences in behavior}

Descriptive and basic inferential statistics of each investigated behavior are presented by organization in Table 2, and descriptive statistics of beliefs are presented in Table 3. We conducted one-way ANOVA tests to examine whether mean differences in the behaviors between the organizations were significant (RQ1a). Interorganizational differences for business travel behaviors were significant and had a medium effect size for domestic business trips, and a large effect size for international business trips, domestic teleconferencing, and international teleconferencing (dom. trips: $\eta^{2}=0.070$; int. trips: $\eta^{2}=0.115$; dom. teleconf.: $\eta^{2}=0.238$; int. teleconf.: $\eta^{2}=0.212$, all at $p<001$ ).

We tested with ANCOVA whether the observed interorganizational differences in business travel behaviors could be explained by differences in individual determinants (RQ1b; see Table 2). This was indeed the case for domestic business trips, and both domestic and international teleconferencing. The only exception was international business trips, for which the effect size of organization was reduced to a medium effect size, but did not disappear altogether after covariate adjustment $\left(\eta^{2}=0.062, p<01\right)$.

\section{Individual-specific influences}

All investigated behaviors had a few to most items for the latent factors violating the normality assumption (i.e. skewness and/or kurtosis values $>1$ ). Because non-normality of indicators can lead to inflated ML $\chi^{2}$ goodness-of-fit statistics and underestimated standard errors, we chose to estimate the models with robust maximum likelihood (MLM) (Satorra et al., 1994). Unless stated otherwise, we followed Hu and Bentler's recommendations for evaluating goodness of fit, with around .95 and above for CFI and TLI, and around .08 and below for RMSEA and SRMR as indicators of good fit (Hu et al., 1999). Goodness-of-fit indices of the models are presented in Table 4 for business trips and Table 5 for teleconferencing. In the remainder of this results section, these models will be further discussed. 
Table 2

Means, SDs and sample size of behaviors by organization

\begin{tabular}{|c|c|c|c|c|c|c|c|c|}
\hline & Total & $\begin{array}{c}\mathrm{NGO} \\
\mathrm{ZH}\end{array}$ & $\begin{array}{c}\text { Company } \\
\text { ZH }\end{array}$ & $\begin{array}{c}\text { University } \\
\text { LB }\end{array}$ & $\begin{array}{c}\text { Company } \\
\text { LB }\end{array}$ & $\mathrm{F}$ & $\begin{array}{c}\mathrm{p}- \\
\text { value }\end{array}$ & $\eta^{2}$ \\
\hline $\begin{array}{l}\text { Domestic } \\
\text { business trips }\end{array}$ & 3.77 & 3.94 & 3.47 & 3.64 & 4.38 & 10.19 & $<.001$ & .070 \\
\hline$S D$ & 1.30 & 1.09 & 1.40 & $1 . .34$ & 0.98 & 1.26 & $n s$. & \\
\hline$N$ & 411 & 79 & 176 & 77 & 79 & & & \\
\hline $\begin{array}{l}\text { International } \\
\text { business trips }\end{array}$ & 4.10 & 4.23 & N/A & 3.41 & 4.68 & 12.40 & $<.001$ & .115 \\
\hline$S D$ & 1.19 & 1.08 & & 1.34 & 0.95 & 5.46 & $<01$ & .062 \\
\hline$N$ & 182 & 124 & & 44 & 25 & & & \\
\hline $\begin{array}{l}\text { Domestic } \\
\text { teleconference }\end{array}$ & 2.14 & 1.60 & 2.23 & 1.57 & 3.43 & 41.80 & $<.001$ & .238 \\
\hline$S D$ & 1.24 & 0.89 & 1.16 & 0.87 & 1.37 & 1.34 & ns. & \\
\hline$N$ & 404 & 95 & 184 & 69 & 58 & & & \\
\hline $\begin{array}{l}\text { International } \\
\text { teleconference }\end{array}$ & 2.13 & 1.91 & 2.40 & 1.64 & 3.56 & 28.63 & $<.001$ & .212 \\
\hline$S D$ & 1.27 & 1.11 & 1.22 & 1.01 & 1.31 & 2.63 & ns. & \\
\hline$N$ & 323 & 149 & 57 & 78 & 39 & & & \\
\hline
\end{tabular}

Italics: corrected for differences in individual determinants using ANCOVA

Table 3

Descriptive statistics beliefs

\begin{tabular}{lcccccccc}
\hline & \multicolumn{2}{c}{ Domestic } & \multicolumn{2}{c}{ International } & \multicolumn{2}{c}{ Domestic } & \multicolumn{2}{c}{ International } \\
& \multicolumn{2}{c}{ business trips } & \multicolumn{2}{c}{ business trips } & \multicolumn{2}{c}{ teleconference } & \multicolumn{2}{c}{ teleconference } \\
& $\mathrm{M}$ & $\mathrm{SD}$ & $\mathrm{M}$ & $\mathrm{SD}$ & $\mathrm{M}$ & $\mathrm{SD}$ & $\mathrm{M}$ & $\mathrm{SD}$ \\
\hline $\mathrm{N}$ & 376 & & 182 & & 404 & & 323 \\
Intention (I1) & 3.96 & 1.17 & 4.19 & 1.16 & 2.62 & 1.14 & 2.60 & 1.16 \\
Intention (I2) & 3.90 & 1.18 & 4.11 & 1.19 & 2.51 & 1.15 & 2.49 & 1.14 \\
(Instrumental) attitude (A1) & 4.31 & .89 & 4.44 & .952 & 3.93 & 1.04 & 4.07 & 1.03 \\
(Experiential) attitude (A2) & 3.90 & .96 & 4.01 & 1.03 & 3.43 & 1.12 & 3.47 & 1.12 \\
(Instrumental) attitude (A3) & 4.27 & .92 & 4.44 & .94 & 3.94 & .94 & 4.15 & .91 \\
(Experiential) attitude (A4) & 3.88 & 1.00 & 3.75 & 1.20 & 3.47 & 1.11 & 3.33 & 1.18 \\
Injunctive norm (ISN1) & 3.66 & 1.14 & 3.91 & 1.19 & 3.15 & 1.05 & 3.25 & 1.07 \\
Injunctive norm (ISN2) & 3.41 & 1.09 & 3.69 & 1.18 & 3.04 & 1.00 & 3.10 & 1.00 \\
Injunctive norm (ISN3) & 3.42 & 1.14 & 3.72 & 1.15 & $\mathrm{~N} / \mathrm{A}$ & & $\mathrm{N} / \mathrm{A}$ & \\
Descriptive norm (DSN1) & 3.50 & 1.05 & 3.78 & 1.21 & 3.01 & .87 & 2.94 & .92 \\
Descriptive norm (DSN2) & 3.49 & 1.04 & 3.71 & 1.19 & 2.85 & .89 & 2.87 & .88 \\
Personal norm (PN1) & 4.16 & .90 & 4.33 & .89 & 3.07 & 1.12 & 2.79 & 1.149 \\
Self-efficacy (SE1) & 3.78 & 1.10 & 4.29 & .88 & 3.50 & 1.20 & 3.57 & 1.166 \\
Habit (H1) & $\mathrm{N} / \mathrm{A}$ & & $\mathrm{N} / \mathrm{A}$ & & 2.39 & 1.33 & 2.81 & 1.441 \\
Habit (H2) & $\mathrm{N} / \mathrm{A}$ & & $\mathrm{N} / \mathrm{A}$ & & 2.22 & 1.34 & 2.23 & 1.353 \\
\hline
\end{tabular}

$\wedge$ reverse coded values 


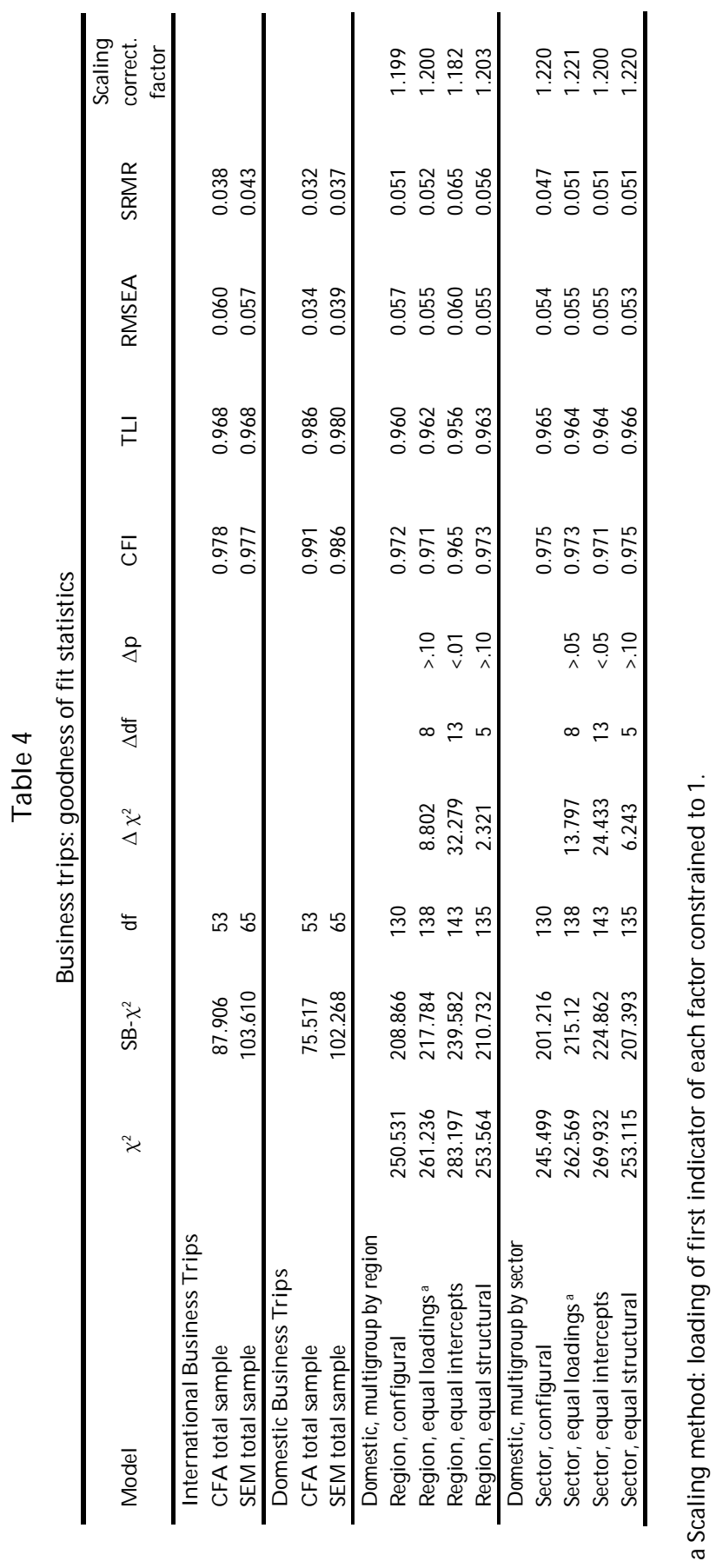




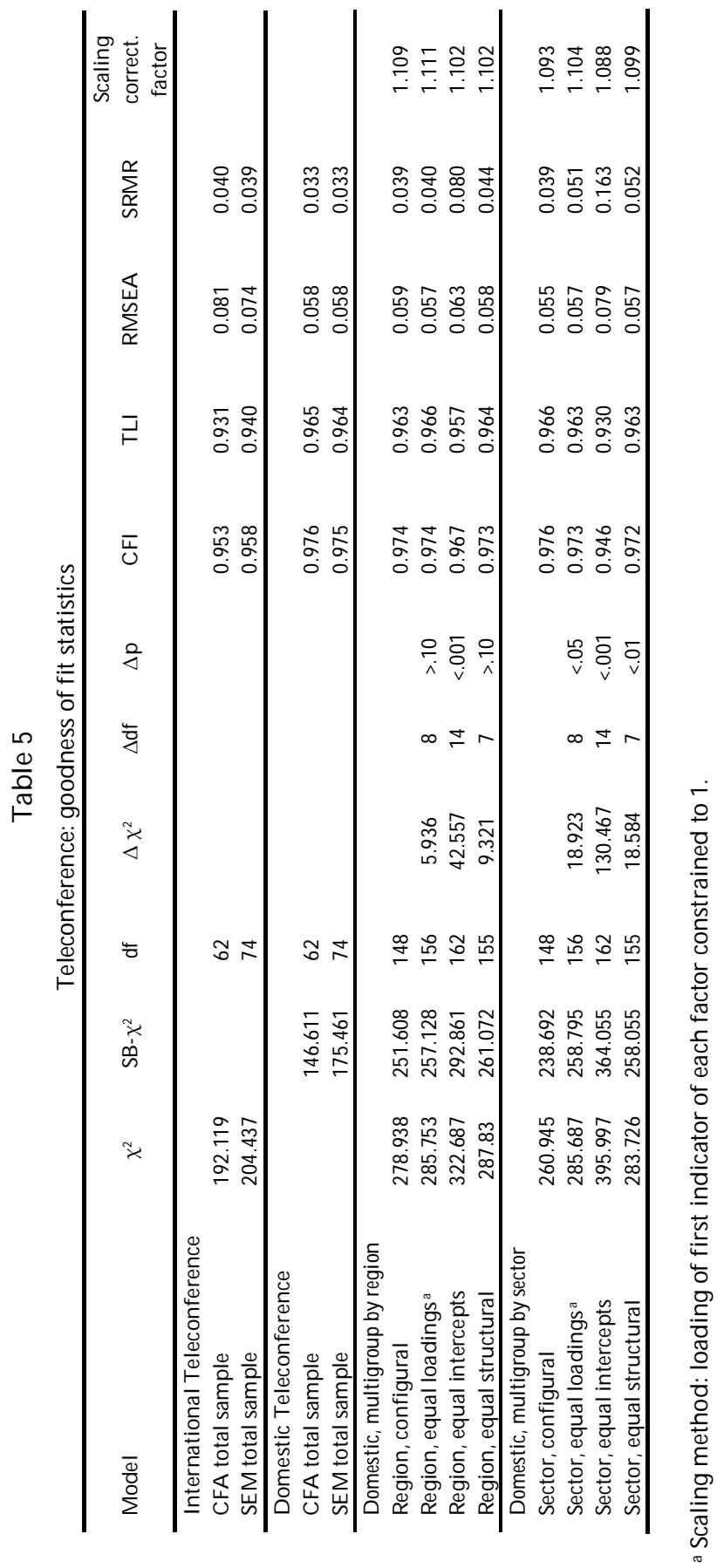


Before we addressed our primary research concerns, we first tested our measurement models on the total sample with CFA to confirm the relationship between the latent factors (i.e. the individual determinants) and their observed indicators (i.e. the measurement items). We specified indicators of individual determinants and intention to only load on their own factor. Measurement errors were assumed to be uncorrelated, while all factors were allowed to correlate with each other. All CFA models had an acceptable fit (see model 1 in Tables 4-5).

Subsequently, we specified a SEM model to test the hypothesized relationships between the individual determinants, intention and behavior. We hypothesized that 1) the latent factors attitude, personal norm, social norm and self-efficacy all affected intention; 2) the latent factor habit affected both intention and behavior; 3 ) intention affected behavior. Exogenous latent factors were allowed to correlate freely because there were no hypotheses concerning the relationships between these factors. We tested the baseline model on the total sample (RQ2a) (see model 2 in Tables 4-5), and the group of respondents familiar with social norms (RQ2b). For domestic business trips, the model with a secondorder attitude factor showed a satisfactory fit. However, for domestic teleconferencing, a model with a second-order attitude factor was prone to negative residual variances in some groups. We therefore collapsed the instrumental and experiential attitude factor into a single attitude factor for both domestic and international teleconferencing, which provided more stable solutions for these behaviors. Figures 1-4 show the standardized factor loadings and path coefficients of the baseline models for domestic business trips, international business trips, domestic teleconferencing, and international teleconferencing respectively. Path coefficients between parentheses indicate the estimated coefficients of individual determinants on intention and behavior for the subgroup familiar with the social norm.

The explained variance of behavior was higher than that of intention for domestic business trips $\left(R^{2}\right.$ behavior $=0.53 / R^{2}$ intention $\left.=0.47\right)$, domestic teleconference $\left(R^{2}\right.$ behavior $=0.72 / R^{2}$ intention $\left.=0.54\right)$, and international teleconference $\left(R^{2}\right.$ behavior $=0.67 / R^{2}$ intention $\left.=0.56\right)$. This is likely due to the fact that intention is a strong predictor of the behavior. The reverse pattern was found for international business trips, where the explained variance of intention was higher than that of behavior $\left(R^{2}\right.$ behavior $=0.38 / R^{2}$ intention $\left.=0.61\right)$. This is possibly because performance of this behavior fluctuates most over time. Measurements of individual determinants at the time of the cross-sectional survey presumably influence future intentions rather than past decisions, which were often made a longer time ago for international business trips than for the other three behaviors.

Returning to RQ2a, intention was a strong predictor of all behaviors. Habit was also a significant but weaker predictor of teleconference behaviors (and was not measured for business trips for reasoned mentioned in the Methods section).

Attitude, in turn, was the strongest predictor of intention for both business trip behaviors. In contrast, personal norm did not have a significant effect on intention for either business trip behavior. The other significant predictors for domestic business trips were perceived norm and self-efficacy; for international business trips only perceived norm was significant.

For both domestic and international teleconferencing, habit had the strongest effect on intention, (closely) followed by perceived norm. Personal norm had a significant, weak negative effect on intention to use teleconference facilities. This is possibly because, controlling for other determinants, a strong belief that others should teleconference might be associated with little use in the organization/department overall. This, in turn, may negatively affect an individual's own teleconference use (despite a positive attitude). Attitude only had a weak effect on domestic 
teleconferencing, and no significant effect on international teleconferencing. Self-efficacy had no significant effect on either domestic or international teleconferencing intention.

Compared to the total sample, standardized regression coefficients for the subgroup familiar with social norms differed considerably for the effects of perceived norms, habit, and self-efficacy on some of the behaviors (i.e. difference >.10; RQ2b). Except for domestic business trips, the coefficient of perceived norm had a magnitude comparable to that of the strongest predictor in the total sample. At the same time, the effect of the strongest predictor in the total sample was also reduced. For domestic teleconferencing, the effect of perceived norm even became substantially larger than that of habit.

\section{Background variables}

We tested for effects of background variables on the baseline models to examine whether background variables could account for variance in behaviors that individual determinants could not (RQ3). If so, effects of background variables on behavior are not (fully) mediated by individual determinants. We conducted tests on the total sample with all background variables as predictors of determinants, intentions, and behavior. Insignificant paths were removed; the model with the remaining paths was used to address our research questions.

Background variables had no direct effects on domestic business travel behaviors. Three background variables had a direct effect on international business travel behaviors: educational level had a negative, small effect on international business trips (stand. $\beta=-.168, p<01$ ), whereas being a manager and distance to work both had a positive but very small effect on international teleconferencing (manager: stand. $\beta=.074, \mathrm{p}<.05$; distance to work: stand. $\beta=.096, \mathrm{p}<01$ ).

We found that adding predictive background variables to the baseline model did not substantially alter the regression weights of the paths from determinants to intention and behavior. As the only significant effects of background variables on behaviors were unique to a single behavior, we excluded background variables from our multigroup analyses to facilitate comparison between these behaviors.

\section{Organization-specific influences}

The aim of the multigroup analyses was to test where there were regional (i.e. Zuid-Holland vs. Limburg) or sectoral (i.e. public vs. private) differences in the model of individual determinants of domestic business travel behaviors.

\section{Configural model}

For a model to be compared across regions or sectors, a first necessary condition is configural invariance. We tested for configural invariance in a multigroup SEM, which is an omnibus test for the baseline model fits of each group (RQ4; see model 3r-3s in Tables 4-5). The models show acceptable goodness-offit indices which entails that items are associated with the same common factors in all groups. The configural invariance model functioned as the reference model for all further multigroup analyses.

\section{Factor loadings}

Having established acceptable configural invariance, we tested for equality of factor loadings in a multigroup SEM by constraining these loadings to equal across groups (RQ5a; see model 4r-4s in Tables 


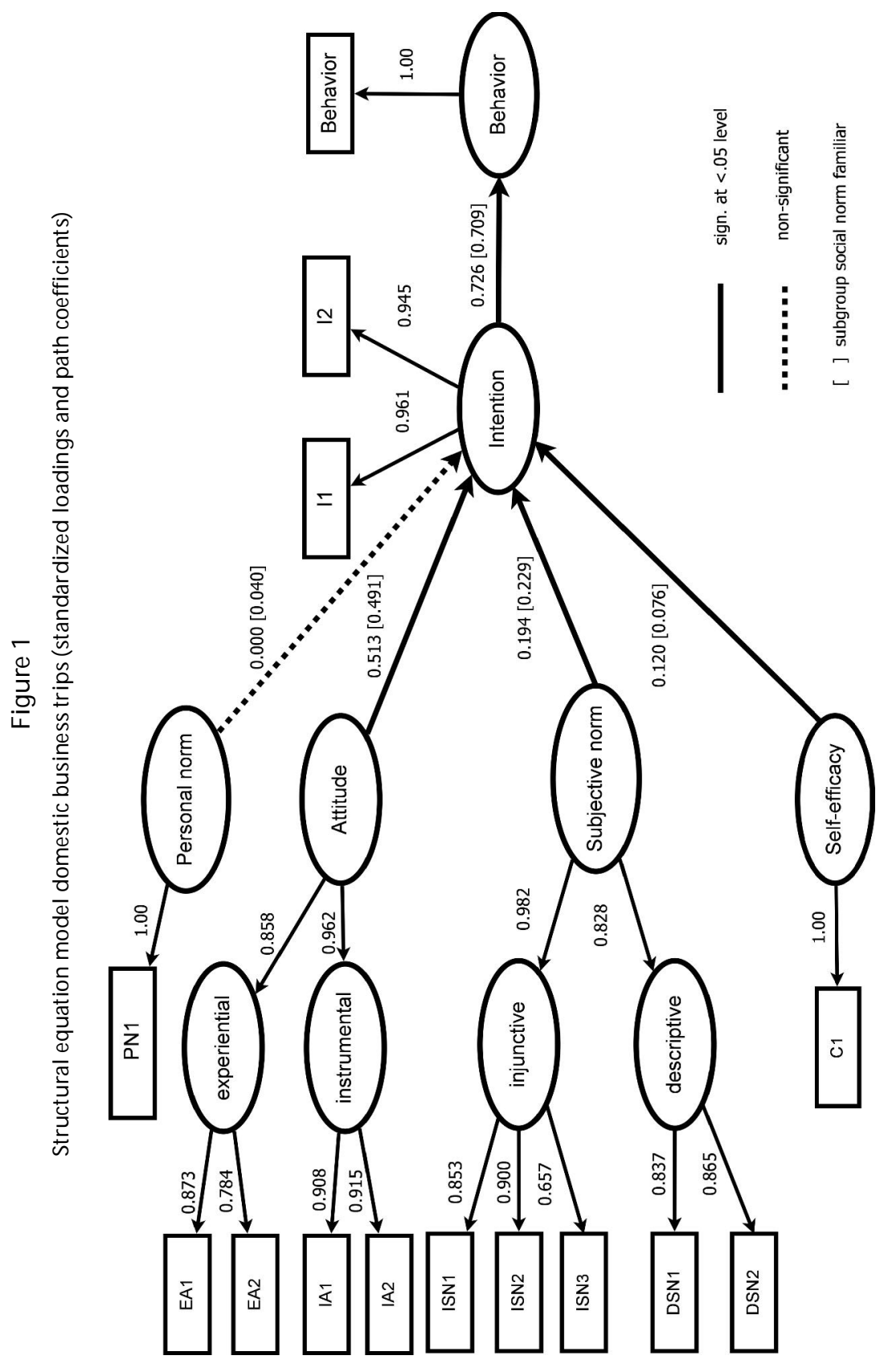




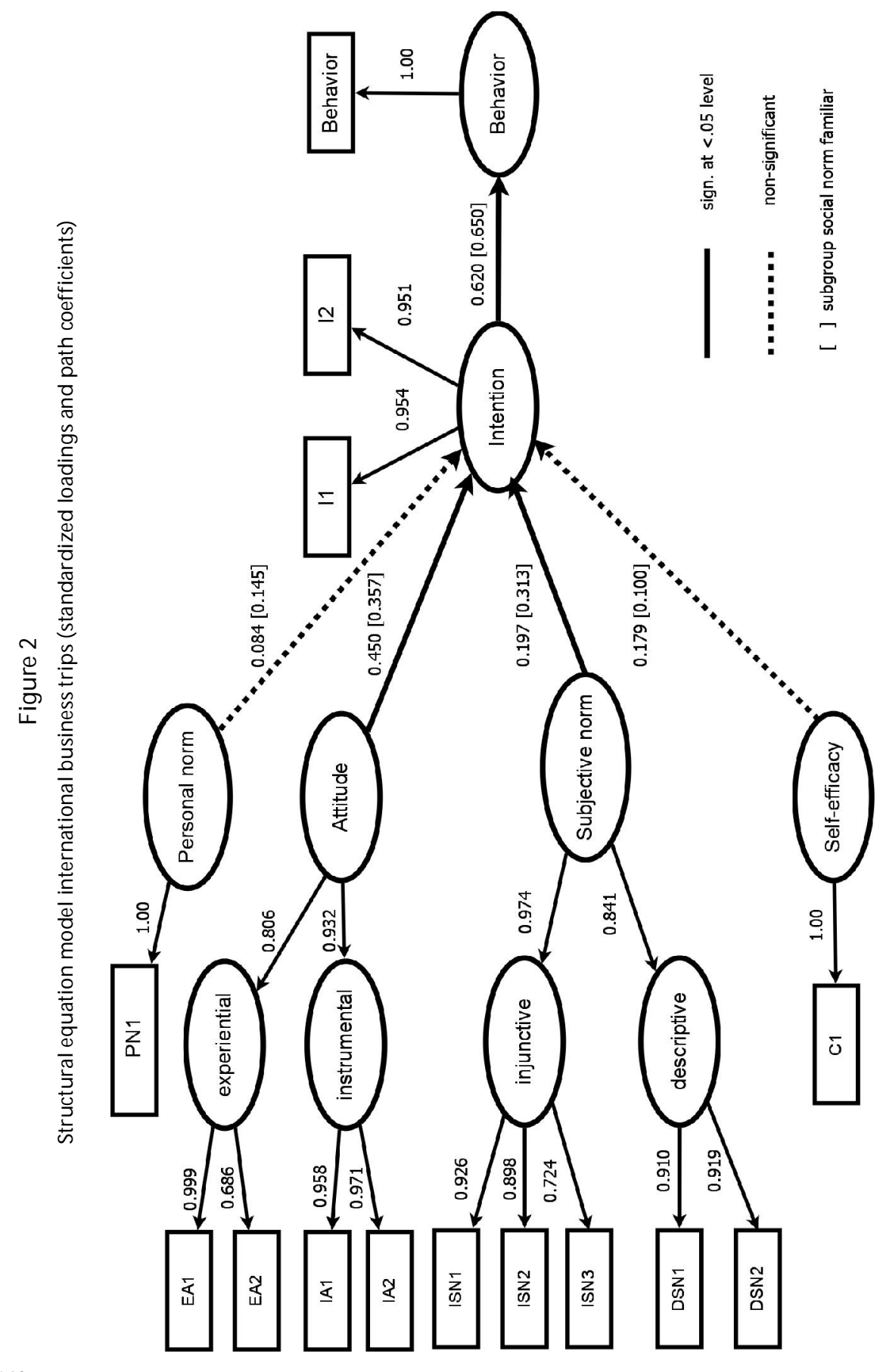




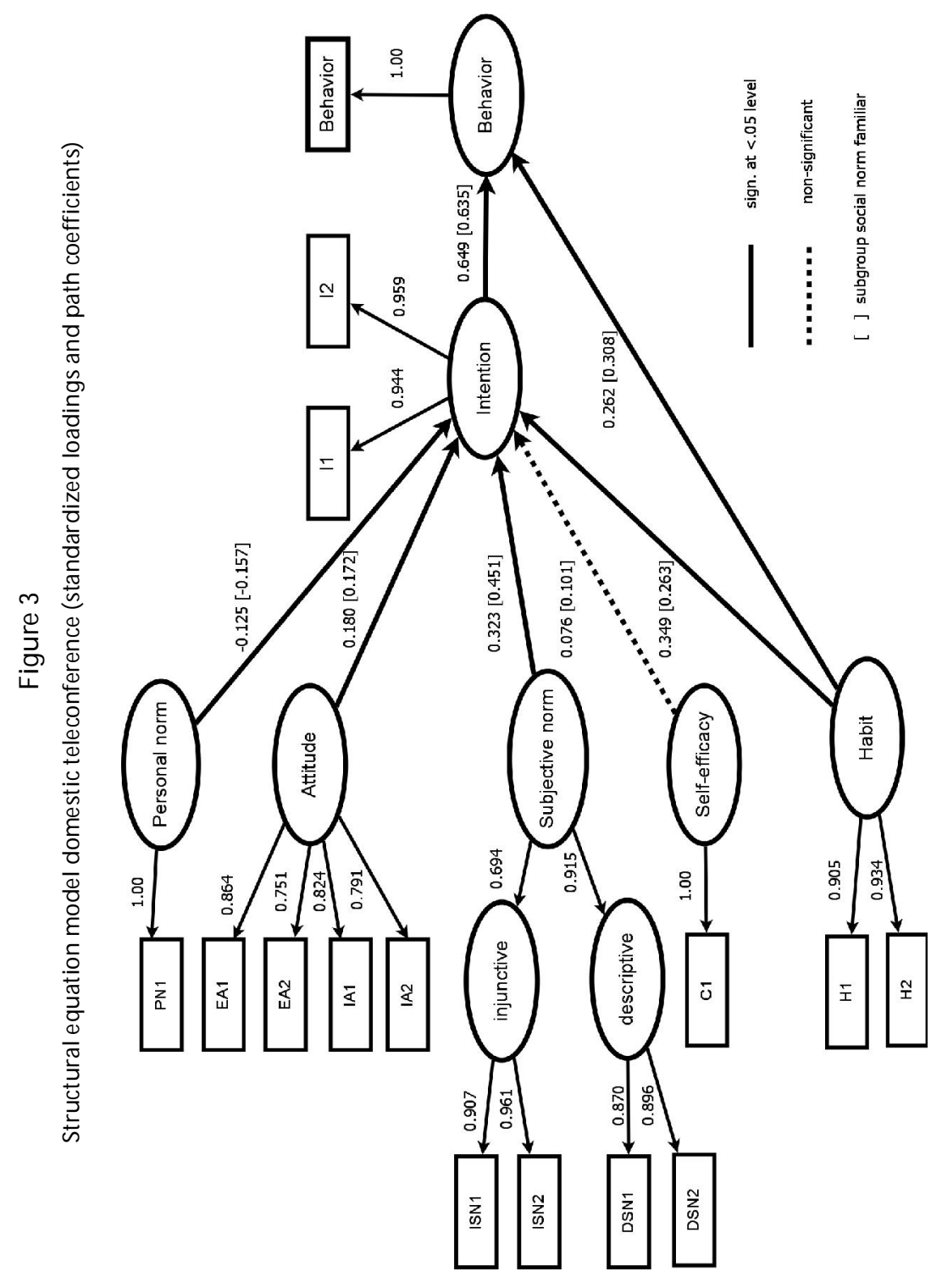




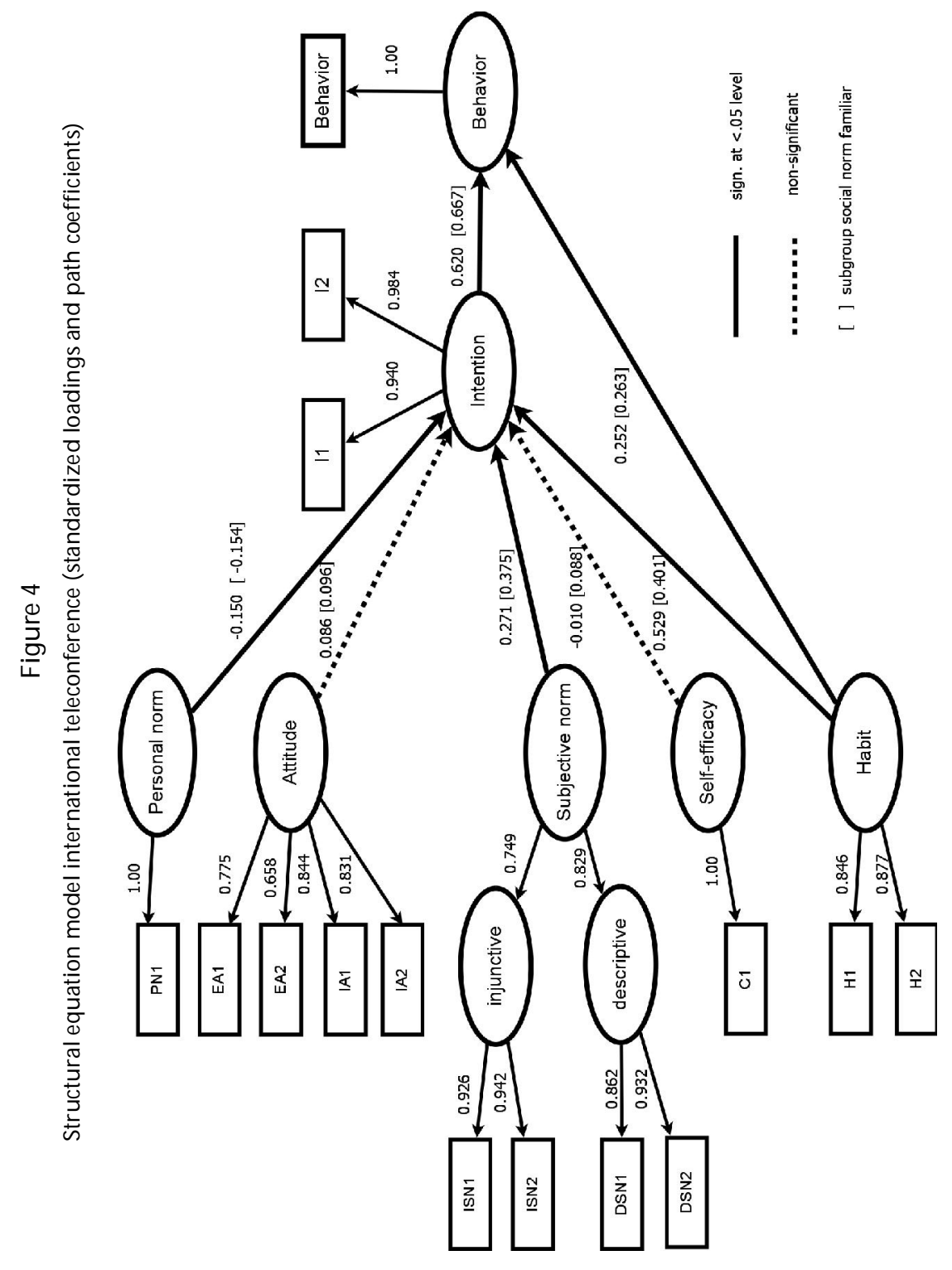


4-5). A scaled $\mathrm{SB} \chi^{2}$ difference test revealed that equality of factor loadings across regions held for both domestic business trips and domestic teleconferencing (business trips: $\Delta \mathrm{SB} \chi^{2}=8.80, \mathrm{df}=8, \mathrm{~ns}$.; teleconferencing: $\Delta \mathrm{SB} \chi^{2}=5.94, \mathrm{df}=8, \mathrm{~ns}$.) (Satorra et al., 2001). Hence, the relevance of measured beliefs to both domestic business travel behaviors is equal across regions. However, metric invariance across sectors held for domestic business trips, but was rejected for domestic teleconferencing (business trips: $\Delta \mathrm{SB} \chi^{2}=13.80, \mathrm{df}=8$, ns.; teleconferencing: $\Delta \mathrm{SB} \chi^{2}=18.92, \mathrm{df}=8, \mathrm{p}<05$ ). This implies that sectoral differences exist in the relative importance of beliefs concerning domestic teleconferencing.

\section{Partial measurement invariance of factor loadings}

In order to localize which factor loadings of domestic teleconferencing differed significantly across sectors, we conducted partial invariance tests by constraining the factor loadings of a single latent factor one at a time (see Appendix B). For factors with significantly different factor loadings, we calculated the ratio between the lowest, and the highest standardized factor loading (taken from the reference model) per indicator to check the magnitude of the violations. The lowest ratio of each factor and a qualitative interpretation of the interorganizational differences are reported below.

Equality of factor loadings was violated for the attitude factor and the second-order perceived norm factor (attitude: $\Delta \mathrm{SB} \chi^{2}=10.41, \mathrm{df}=3, \mathrm{p}<.05$, diff. ratio $=0.74$; perceived norm: $\Delta \mathrm{SB} \chi^{2}=4.22, \mathrm{df}=1$, $\mathrm{p}<05$, diff. ratio $=0.54$ ). Thus, the relative importance of attitudinal measures and the descriptive versus the injunctive norm to the respective latent factors differ across sectors. Inspection of the factor loadings in the configural invariant model revealed that, in public organizations, the "easy-difficult" item had much lower loadings on the attitude factor than in the companies. The data also shows that the descriptive norm had a very high loading on the second-order perceived norm factor in the companies but a very low loading in public organizations.

To conclude, across sectors, equality of factor loadings is violated in the attitude and perceived norm factors. Bearing these exceptions in mind, the factor loadings as reported in Figures 1-4 should be representative for all examined organizations.

\section{Equality of intercepts}

We had already established that the intercept (i.e. mean) of behavior itself differed across organizations (RQ1a), and that individual determinants could account for these (RQ1b). We would therefore expect item intercepts for determinants to differ significantly across organizations. Equality of intercepts was tested by constraining the item intercepts to be equal across organizations in a multigroup SEM (RQ6) (see model $5 \mathrm{r}-5 \mathrm{~s}$ in Tables 4-5). A scaled SB $\chi^{2}$ difference test indeed revealed that the equal intercepts model had a worse fit compared to the configural invariant models across regions for both domestic business trips and teleconferencing (business trips: $\Delta \mathrm{SB} \chi^{2}=32.28, \mathrm{df}=13, \mathrm{p}<01$.; teleconferencing: $\triangle \mathrm{SB} \chi^{2}=42.56, \mathrm{df}=14, \mathrm{p}<001$ ). The same was concluded for the intersectoral comparison (business trips: $\Delta \mathrm{SB} \chi^{2}=24.43, \mathrm{df}=13, \mathrm{p}<05$; teleconferencing: $\left.\Delta \mathrm{SB} \chi^{2}=130.47, \mathrm{df}=14, \mathrm{p}<001\right)$. In brief, means of beliefs of all behaviors were found to differ across regions as well as sectors.

\section{Partial measurement invariance of item intercepts}

Partial invariance tests were conducted to check whether the assumption of intercept equality could be upheld for some parts of the model. A few violations were found for domestic business trips, and many for domestic teleconferencing (see Appendices A-B). For factors with significantly different intercepts, we calculated the largest difference per factor between groups to check the magnitude of the violations 
(note that the maximum mean difference is 4 for a 1-5 scale). Finally, we provide a qualitative interpretation of interorganizational differences.

For business trips, attitude and self-efficacy were equal across regions. Perceived norm, personal norm, and intention all differed significantly between regions, but only descriptive norm (regarding colleagues; mean diff. $=.51$ ) showed a substantial difference with Limburg scoring higher than ZuidHolland. Thus, regions mainly differed in that respondents from Limburg perceive their colleagues to consider more consciously whether their domestic business trips had enough added value. Across sectors, intercepts only differed significantly for the injunctive norm factor which was also a very small effect (regarding colleagues; mean diff. $=.22$ ).

For teleconferencing, significant regional differences were found for all individual determinants of teleconferencing, except for intention. The largest differences were found for personal norm and habit with Limburg showing higher intercepts (personal norm: mean diff. $=.50$; habit: mean diff. $=.80$ ). Although the other intercepts showed regional differences of less than .50, there was a consistent pattern: employees from Limburg hold more favorable beliefs towards teleconferencing than employees from Zuid-Holland. Sectoral differences were found for all individual determinants, except for the injunctive norm factor. All beliefs were more positive in companies than in public organizations, all revealing mean differences approaching or exceeding .50. The largest differences were found for habit (mean diff.=1.05) and personal norm (mean diff.=.85).

To conclude, few interorganizational differences were found in the beliefs related to business trips. In contrast, we did find that Limburg and company employees had consistently more favorable beliefs towards teleconferencing.

\section{Structural model}

Equality of the structural model was tested by imposing equality constraints on path coefficients between latent factors (RQ7; see model 6r-6s in Tables 4-5). Compared to the configural invariant model, equality of the structural model between regions held for both domestic business trips and domestic teleconferencing (business trips: $\Delta \mathrm{SB} \chi^{2}=2.32, \mathrm{df}=5$, ns.; teleconferencing: $\Delta \mathrm{SB} \chi^{2}=9.32, \mathrm{df}=7, \mathrm{~ns}$.). Equality of the structural model between sectors held for business trips but not for teleconferencing (business trips: $\Delta \mathrm{SB} \chi^{2}=6.24, \mathrm{df}=5$, ns.; teleconferencing: $\Delta \mathrm{SB} \chi^{2}=18.58, \mathrm{df}=7, \mathrm{p}<01$ ). In other words, the magnitude of the hypothesized relationships between individual determinants on the one hand, and intention and behavior on the other hand are equal across regions for both business travel behaviors. Across sectors, these relationships are similar for business trips but significantly different for teleconferencing.

\section{Partial invariance of structural model}

Partial invariance tests were conducted to localize for which parts of the model for teleconferencing structural invariance between sectors was rejected (see Appendix B).

Partial invariance tests revealed that no single path coefficient differed significantly between sectors. In other words, the magnitude of the hypothesized relationships between individual determinants on the one hand, and intention and behavior on the other hand are practically similar across sectors despite the significant omnibus test. 


\section{Discussion}

Our study tested a model of individual determinants of business travel behaviors among office workers. To be more precise, we examined employees' decision-making with regard to making business trips and their use of teleconference facilities, in a domestic and international context. In addition, we examined in which respects the models for domestic business travel behaviors differed across organizations, and more specifically across regions and sectors. Our hypothesized model proved to fit the data well but did not always provide a complete account of all investigated behaviors. There were medium to large interorganizational differences in business travel behaviors. After we controlled for individual-specific influences, these organizational differences disappeared entirely or were at least substantially reduced.

\section{Individual-specific influences}

Intention was a strong, direct predictor of all business travel behaviors. Furthermore, habit was a significant but much weaker, direct predictor of teleconference behaviors.

Of the social-cognitive determinants, in turn, attitude had the strongest effect on intention to consciously consider the added value of both domestic and international business trips compared to distance communication. Perceived norm also had significant effects on both business trip intentions, but self-efficacy only on domestic business trip intention. In contrast, habit was the strongest overall predictor, and perceived norm the strongest social-cognitive predictor of intention to use teleconference facilities for both domestic and international contacts. Self-efficacy was not a significant predictor of either. Attitude was only significant for domestic teleconferencing, whereas personal norm had a small negative significant effect for both domestic and international teleconferencing. When controlling for other determinants, agreement with the personal norm item might reflect little use of teleconference facilities in the organization, and therefore have a negative effect on intention.

Finally, it should be noticed that in the subgroup familiar with the relevant social norm, the effect of perceived norm on intention tended to become considerably stronger. Although we were only unable to find such an effect for domestic business trips, the effect of perceived norm became comparable to that of the strongest predictor in the total sample for international business travel behaviors. For domestic teleconferencing, the effect even became substantially larger than that of habit.

\section{Organization-specific influences}

Differences in domestic business travel behaviors could be further examined in multigroup analyses by region and by sector. We only found considerable sectoral differences in the way the attitude and second-order perceived norm construct were manifested (i.e. in factor loadings) in domestic teleconference behavior: in companies, compared to public organizations, the easy-difficult item (an indicator of attitude) and descriptive norm were more important to their respective factors than the other attitude items and injunctive norm. For domestic business trips, factor loadings were similar across both regions and sectors.

More importantly, however, significant regional as well as sectoral differences in the strength of beliefs were found for both domestic business trips and teleconferencing. For business trips, the only remarkable difference was that a higher descriptive norm (i.e. colleagues were perceived to more consciously consider their domestic business trips) was found in Limburg compared to Zuid-Holland. This could be explained by the fact that Limburg is less centrally-located in the Netherlands than ZuidHolland. This entails that travel duration to meet domestic contacts tends to be longer for employees in 
Limburg which may stimulate conscious travel choices. For teleconferencing, many (relatively) large differences were found across regions and sectors. The general pattern was that Limburg and company employees had consistently more favorable beliefs towards teleconferencing than employees from Zuid-Holland and public organizations respectively. This may (again) be explained by regional differences in domestic travel distance, and associated to the fact that more teleconference facilities were available at the companies than in the public organizations.

Finally, we found that path coefficients between exogenous latent factors and endogenous latent factors were (practically) similar across regions and sectors. In other words, the structural model of domestic business travel behaviors can be considered equal between regions as well as sectors.

\section{Limitations and future research directions}

The results of our study should be interpreted in the light of several methodological limitations. Firstly, participation in the online survey was voluntary. There were no formal mechanisms to ensure cooperation of individual employees or the organizations as a whole. Given the varying completion rates, it is possible that some of the differences found are due to selective participation of employees in the organizations. Lower scores in behavior in an organization do not necessarily imply that their employees are less "conscious" of their business travel behaviors if response rates were higher compared to other organizations.

Another constraint was that we only obtained self-reported cross-sectional data, which meant that we neither obtained objective measures of behavior nor evidence to make claims regarding the direction of causality. Longitudinal research designs may overcome these shortcomings in future.

Finally, we measured personal norm with a single item. Conclusions drawn about the role of personal norm in business travel behaviors are solely based on the relevance of this single item rather than a comprehensive multi-item measure of the personal norm concept.

\section{Implications for interventions}

Several conclusions for interventions can be drawn. Attitude was found to be the most important predictor of intention to consider the added value of business trips, whereas habit and perceived norm were the most important predictors of intention to use teleconference facilities. Assuming a causal relationship between determinants and behavior, interventions should focus on these determinants of business travel behaviors. However, it would be ill-advised to target a single determinant without considering baseline levels of behavior, individual determinants and other contextual factors. For instance, although attitude was generally the strongest predictor of intention to consider the added value of business trips, we also found high means for instrumental attitude, which may imply that there is relatively little room for improvement through instrumental attitude (but more through experiential attitude) due to possible ceiling effects.

\section{Conclusion}

To conclude, this study explored an area previously largely neglected by research business travel behaviors. Similar to previous findings from private and household studies, an extended planned behavior framework proved very useful in explaining business travel behavior in our study. The use of Multigroup SEM allowed us to examine in detail how the regional context and organizational sector may influence (individual determinants of) behavior. Interorganizational comparisons of business travel behaviors have shown that regional and sectoral differences are mainly associated with how 
Chapter 7: Survey Study of Business Travel Behaviors

strongly business travel-related beliefs are held. Furthermore, organizational sector is related to the degree to which attitudinal and normative beliefs are relevant indicators of attitude and perceived norm towards teleconference use. 


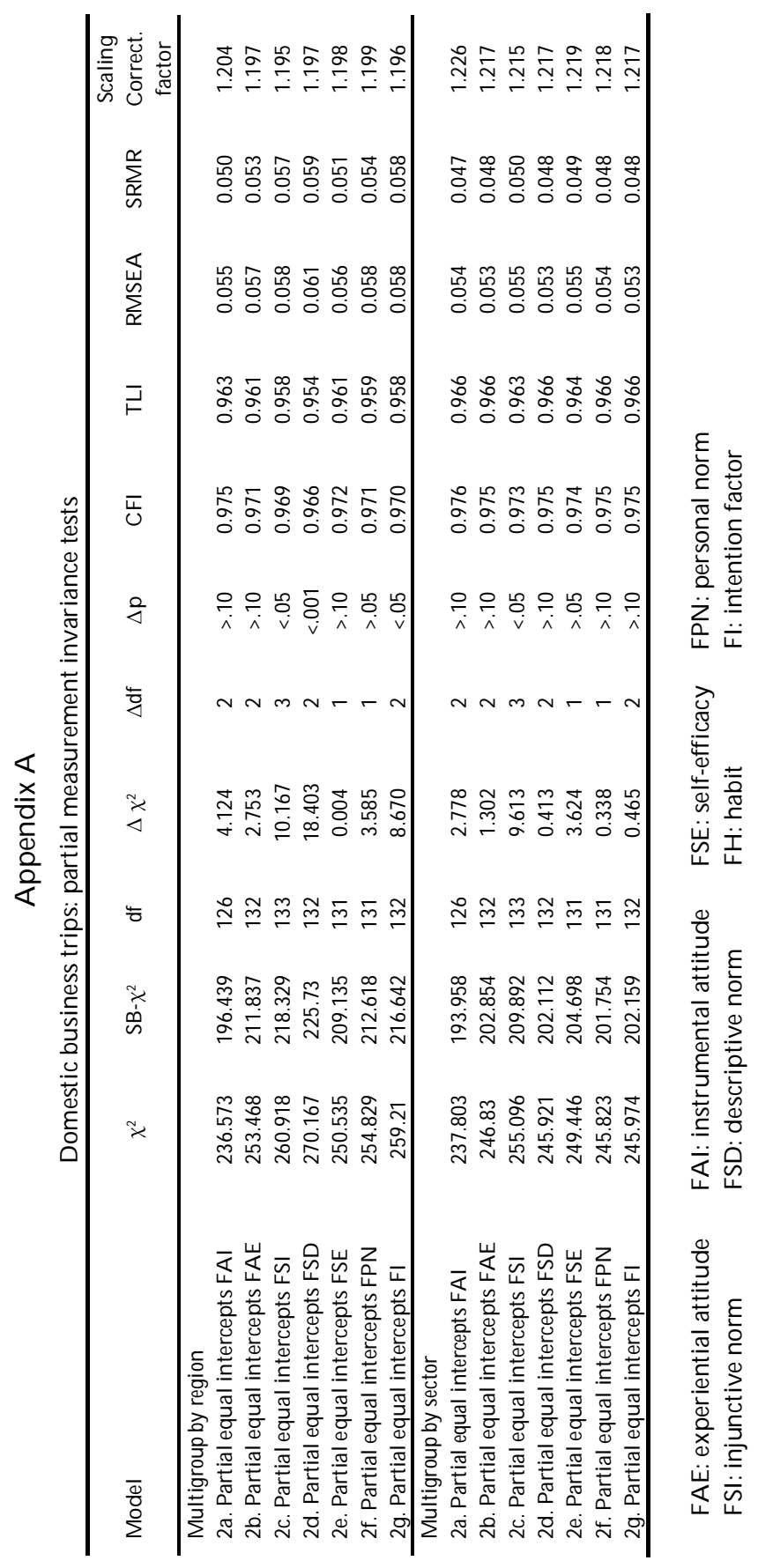




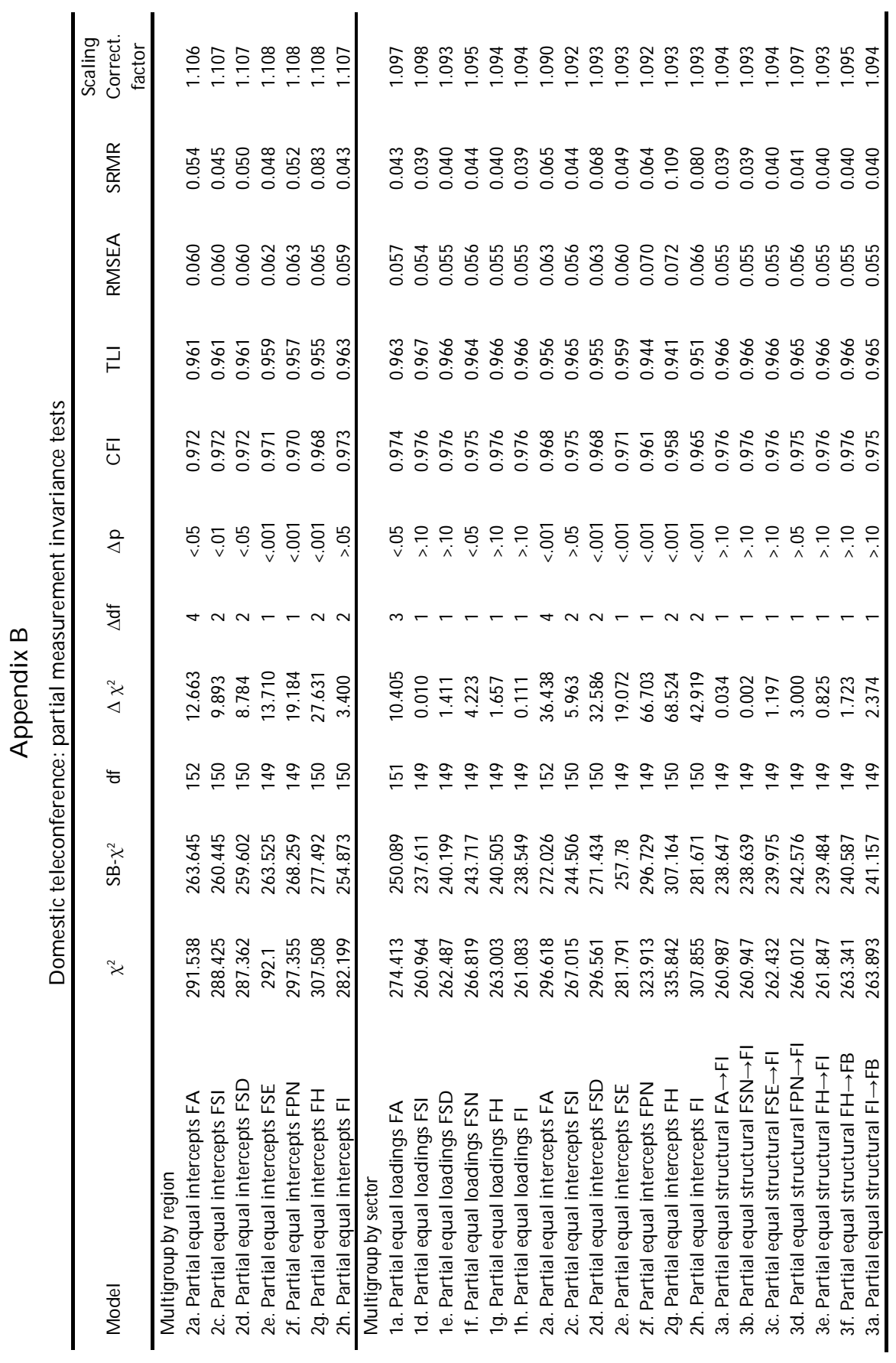





\section{Chapter 8: General Discussion}

In the general introduction, we described research on proenvironmental behavior in household and private contexts which suggested that reasoned action- extended with habit and a moral evaluation component - was currently the most useful framework for understanding proenvironmental behavior (Chapter 1). We also noted that relatively little research had studied proenvironmental behavior within organizations. The primary aim of this thesis was therefore to examine the determinants of energyrelated behaviors among office workers, and in particular the role of the organizational context.

Our first paper gave an overview of the existing empirical literature on determinants of and interventions for energy-related and other proenvironmental behaviors in organizations (Chapter 2). The subsequent papers presented empirical results of a research project conducted among office workers from a wide range of organizations. Our sample of organizations consisted of a non-profit organization (NGO) in the Dutch province Zuid-Holland, a commercial company in Zuid-Holland, a university in the Dutch province Limburg, and another company in Limburg. Thus, we had organizations from both the public and private sector as well as organizations from two regions in the Netherlands with different levels of population density and public transport connectivity represented in our sample. First, a qualitative study was conducted to identify relevant behaviors and their individual and organizational determinants. For this purpose, office workers were interviewed individually or in focus groups. We discussed the qualitative findings concerning behaviors that are performed in the office building in Chapter 3, and commuting and business travel behaviors in Chapter 4. Building on these qualitative findings and previous theoretical insights, a cross-sectional survey was designed which was disseminated among office workers in the same organizations. We reported and interpreted the quantitative survey results in Chapter 5 for energy-related behaviors in the office building, Chapter 6 for commuting behaviors, and Chapter 7 for business travel behaviors. Our aim was twofold. First, we simply aimed to gain a better insight into determinants of the behaviors of interest. Second, we were interested in the dynamics between the individual office worker and the organization. More specifically, we examined to what extent behavior could be explained by determinants on the individual level, and in which ways our model of individual determinants was affected by organizational differences. In this final chapter, we will synthesize the findings presented in the previous chapters and draw implications for theory, practice, and future research.

\section{Contribution to the understanding of proenvironmental behavior}

The literature review presented in Chapter 2 outlined many limitations and shortcomings in previous empirical studies. First of all, there was little research conducted on social norm and self-efficacy as determinants of proenvironmental behavior in organizational contexts. Second, qualitative findings were usually not accompanied by a description of the methodology and analysis. Third, results of the same study and across studies were frequently difficult to compare due to a lack of correspondence between the level of specificity of the determinant and the behavior. It was indeed found that the effect sizes of determinants could largely be accounted for by the degree of correspondence. Comparing the relative importance of determinants was further complicated by the heterogeneity of proenvironmental behaviors studied. This is due to the fact that the strongest predictor of one behavior is not necessarily 
also the strongest predictor of another had it been measured (in another study which was often not the case). And last but not least, no comparative research investigating the interplay between the individual and the organization was found.

We addressed these limitations of previous research in our research project as follows. First, we systematically and consistently examined the role of social norm and self-efficacy in both our qualitative and quantitative studies. Second, we conducted a full qualitative study for which we reported the methodology used, and compared and contrasted evidence in a systematic way. Third, we consistently measured all individual determinants at the same level of specificity as the behavior so that we could meaningfully compare the effect sizes of determinants of a behavior, but also compare the relative importance of a determinant across various behaviors. And last but not least, we analyzed how organizations may impact on individual determinants and behavior (and vice versa) in all our empirical studies.

\section{Determinants of energy-related behaviors in organizations}

In this thesis, we made a broad distinction between energy-related behaviors that take place within the office building and travel behaviors, which were further subcategorized in the empirical chapters. We aimed to examine all relevant (sub)categories of behaviors in our qualitative study, and selected some of these for further investigation in our quantitative survey study. Below, we will first discuss the determinants of behavior that were studied both qualitatively and quantitatively. Overall, qualitative results were in line with their corresponding quantitative results. Only a few (apparent) contradictions were found when comparing and contrasting qualitative and quantitative findings. Then, we will draw more general conclusions on the impact of the organizational context on energy-related behaviors that are relevant to office workers.

\section{Office energy-related behaviors}

In our qualitative study we found that general attitude towards office energy conservation was uniformly positive. Also in our quantitative study, we found that (instrumental) attitude towards the examined behaviors was equally positive across all organizations despite the fact that organizational differences were found for most other individual determinants. In other words, office energy conservation is positively evaluated irrespective of the specific organizational context. Experiential attitude towards printing behaviors (i.e. not printing e-mails and printing more pages on a sheet) did seem to differ interorganizationally which could be explained by the fact that printing facilities differed considerably between organizations. This also relates to a salient theme in the qualitative study: energy conservation was perceived to be a legitimate goal provided there are no other overriding interests such as work efficiency and personal comfort. The qualitative findings clearly indicated that printing behaviors were more commonly affected by trade-offs with work interest than switching behaviors (i.e. switching off lights and monitors) - the other quantitatively examined office energy-related behaviors. This is compatible with the finding that experiential attitude towards printing behaviors was relatively lower. In our qualitative study we also found that organizational foci were associated with differences in the relative importance of normative, gain, and hedonic motivations that underlie attitudes. Again, this was also to some degree reflected in quantitative differences in the relevance of attitudinal beliefs as indicators of the overall attitude factor.

In our qualitative study we did not analyze personal norm, or moral evaluation, separately from people's overall evaluation (i.e. attitude). Nevertheless, the findings described above do suggest that moral/normative evaluation was relevant to evaluating energy-related behaviors. Also in our 
quantitative study, we found that the separate personal norm factor had significant small effects on intention for some office energy-related behaviors (over and above that of other determinants). However, no significant (positive) effects were found for travel behaviors.

One apparent contradiction is the finding that self-efficacy was a much more dominant theme in the qualitative study than in the quantitative study - in which we found self-efficacy to have no or a small significant effect on intention. As discussed in the previous chapters, the modest effect may at least be partially due to the nature of the single item measuring self-efficacy. However, another qualitative finding was that the boundary between the concepts of attitude and self-efficacy was unclear and typical attitudinal adjectives such as "convenient" were often used interchangeably with efficacy adjectives such as "controllable". Moreover, we had indeed incorporated the item "difficult-easy" into the attitude factor of the quantitative studies.

Findings on the role of perceived norms generally showed a coherent picture. One important qualitative finding was that social norms were largely an implicit theme, sometimes characterized by an absence of perceived norm. There were obviously substantial differences in the percentage of respondents able to gauge the relevant norm depending on the type of behavior and the organization, but overall we did find that a substantial minority of the survey respondents had difficulty gauging social norms.

Another major qualitative finding was that social mobilization and other interventions with a distinctively social element were often perceived as one of the most promising avenues for future organizational change. Although we did not explore employees' opinions on strategies to reduce office energy use in our survey study, we did attempt to estimate to what extent current absence of social norm may have attenuated the potential effect of perceived norm in our models. Therefore, we also estimated the models with those respondents who had all indicated they were able to gauge the norm. For not printing e-mails, perceived norm became the strongest predictor of intention and thus implying that increasing the visibility of positive social norms may prove to be a very effective intervention. However, for another behavior, switching off lights, the effect of perceived norm was non-significant irrespective of whether respondents were familiar with the norm. This is in contradiction with the qualitative finding that perceived barriers to switching off lights were often of a socio-organizational nature.

One possible explanation for this is the strongly habitual nature of switching off lights for which habit was found to be a stronger quantitative predictor of behavior than intention. This type of habitual behaviors sometimes led interviewees in the qualitative study to wonder what the real reasons for their behavior were. This implies that either socio-organizational barriers to switching off lights are a false or incomplete explanation or the perceived norm measures did not adequately capture the specific nature of these socio-organizational barriers. Of course, it is also possible that both explanations are partially valid. The significant direct effect of number of office mates on behavior in the quantitative study suggests that there is at least some truth to the explanation that the effect of others is underestimated by respondents.

\section{Travel behaviors}

In our qualitative study we found attitude towards travel mode alternatives to vary considerably among office workers of different organizations but also within organizations. At the same time, we also found attitude to be the strongest determinant of commuting travel mode choice. Quantitative 
analyses further showed that variations in attitude towards commuting travel mode choice were significantly associated with both regional and sectoral differences, and also confirmed that attitude was the most important determinant.

Attitudes towards reducing business trips (where compatible with work interests) and teleconferencing (as a future alternative to travel) were generally positive, although statements were often qualified by adding that some traveling was necessary. Also the quantitative data showed no significant organizational differences in attitudes towards making business trips. However, some relatively small but significant differences were found between regions and sectors for teleconferencing. This is not necessarily in contradiction with the qualitative findings because the quality of teleconference facilities differed between organizations and the behavioral measure in the survey did not cover the topic of teleconferencing entirely.

Self-efficacy - or the ability to cope with or control external factors that influence travel behaviors - was also considered an important determinant by interviewees. However, similar to office energy-related behaviors, we found no or small significant effects for self-efficacy in the survey study. This could possibly be explained by the same reasons as discussed earlier for office energy-related behaviors.

Interestingly, both the qualitative and the quantitative study suggest that perceived norm does not play a noteworthy role in determining commuting travel mode choice, and a small role in decisions with regard to making business trips. In contrast, quantitative results show that perceived norm is a crucial determinant of teleconferencing despite the fact that this was not a salient theme in the qualitative study. For buying an energy-efficient car and maintaining a fuel-saving driving style we found no significant effects for perceived norm in the survey study even though social norms were a salient theme in the qualitative study. These contradicting findings may be due to the fact that salient social norms mainly prevailed among company car owners. The sample size for this subgroup of carcommuters was very small so we could not analyze this group separately in our quantitative analyses. Thus, the non-significant effects in the survey study might be due to insufficient statistical power.

Results concerning the role of habit in travel behaviors were once again consistent across the qualitative and quantitative study. Although interviewees acknowledged their travel mode choice was a habitual behavior, they emphasized this was a consequence rather than a determinant of their choice. Survey results also supported this conclusion: no to very small significant effects were found for habit as a predictor of intention or behavior. Teleconferencing, however, was found to be strongly influenced by habit in the quantitative study. Although the role of habit in teleconferencing was not a salient, explicit theme in the qualitative study, many interviewees did indicate that it was not customary to use teleconference in their organizations whereas a few in other organizations/departments did claim to use teleconference facilities on a regular basis.

\section{The impact of the organizational context}

Based on the previously discussed findings, we can conclude that the pattern of interorganizational similarities and differences in determinants of energy-related behaviors is largely dependent on the (sub)category of behavior examined. The qualitative study provided valuable, contextualized examples of why differences were found and facilitated interpretation of the survey results.

The multigroup structural equation modeling analyses conducted for the quantitative survey studies showed that organizational effects were mostly mediated through individual determinants of 
the investigated behaviors. Differences on the organizational level were generally reflected in the strength with which beliefs were held by respondents. These beliefs were used as indicators of our conceptual individual determinants, which we have discussed extensively in the previous two sections. In addition, we also found some but fewer organizational differences in the relevance of specific beliefs as indicators of the (latent) individual determinants. Finally, the strength of the relationships between individual determinants, intention, and behavior also varied in a few cases.

There were also some organizational influences that were not captured by our quantitative analyses but did surface in our qualitative analyses. First, both in our literature review and qualitative studies, the role of management is considered pivotal. In particular, management is perceived to be capable and responsible for initiating organizational change in the areas investigated. Second, our qualitative findings revealed some glimpses of unconscious influences on behavior. For instance, employees sometimes admitted they did not behave at work as they did at home despite the fact that their attitude towards a specific behavior was similar across contexts. Thus, unconscious influences may play a larger role in determining behavior than people are aware of. Thirdly, similar overall behavioral outcomes might be caused by dynamics of a completely different nature. In the case of teleworking, for instance, we found that in the NGO, organizational approval was low but employee attitude was very positive. The opposite pattern was found for the company in Limburg. As a result, interviewees from both organizations reported a modest teleworking practice in their respective organizations. Having said that, the organization's and the individual's influence on the behavioral outcomes are not necessarily equal. In our study of travel behaviors it was clear that there was sometimes a single overriding concern - be it organization-specific or individual-specific - that cancelled out the effect of other possible influences. An example of a dominant organization-specific concern is managerial control. One company employee made more business trips than he personally deemed necessary and desirable because management had set a target in the form of a minimum number of client visits per year. Finally, organizational influences may also remain undetected because opposing organizational influences affect employees' decision-making. For example, in the case of the NGO, there were conflicting norms regarding international travel. Reducing the number of trips and their associated costs were highly praised while at the same time, these trips were considered an essential element of their profession. In brief, we have demonstrated how generic models of individual determinants of behavior can be affected by context, and more specifically, the organizational context. Furthermore, we have offered some insights into how the organization may influence and interact with the individual in more specific and dynamic ways.

\section{General implications}

Based on the presented synthesis of results, we will draw some general conclusions for theory and practice below.

\section{Theoretical implications}

The theoretical implications of our research can be summarized as follows. Together with previous research findings, our results suggest that an extended reasoned action framework is indeed useful for understanding proenvironmental behavior irrespective of organization, and in household as well as organizational contexts. Personal norm was sometimes found to explain additional variance over and above traditional reasoned action variables, although we did not resolve the conceptual issue whether it 
should be incorporated into the attitude construct due to survey length constraints. Furthermore, our results also support the position that the boundary between attitude and self-efficacy is at times disputable. Finally, while the importance of social-cognitive variables may vary between behaviors, their effect appears to be relatively stable across contexts. The role of habit, however, varied between behaviors and sometimes also between contexts.

\section{Practical implications}

We compared and contrasted the determinants of all investigated behaviors earlier, and the practical implications for interventions targeting each specific behavior that we examined should be apparent. Hence, we will not repeat these here again. However, there are also more general practical conclusions to be drawn from our research findings.

Our results indicate that not all behaviors are equally suitable for small-scale organizational change interventions. Commuting travel mode choice, for instance, may only be affected significantly by structural changes at the regional or national level. Although draconic organizational-level interventions might also be effective, these may not always be feasible, or desirable for that matter. There seem to be fewer barriers to successful organizational change interventions targeting office energy-related behavior and business travel behaviors. The former category of behaviors generally requires relatively little effort to change or could be made less effortful by implementing some changes at the organizational level. One potential barrier is that organizations may perceive the (financial) benefit of desirable changes in office energy-related behaviors to be relatively low so that decisionmakers may not be sufficiently motivated to intervene. In contrast, the latter category of behaviors involves high (financial) stakes for the organizations. Business travel involves both transportation costs and loss of employee working time, although at the same time, business travel may be necessary for meeting organizational aims. Organizational decision-makers also tend to have relatively high levels of control over business travel in the form of budget allocation for business trips, and teleconference and other communication facilities. Thus, organizations may be both motivated and able to influence business travel behaviors. Having said that, the necessity of business travel is highly subjective and complex to evaluate. Although organizational decision-makers may possess powerful (financial) resources to control these behaviors, they might need to leave the evaluation of necessity up to the individual employee's discretion.

The interorganizational comparisons highlighted what similarities and differences across contexts one could expect. In most cases, the link between attitude, perceived norm, and self-efficacy on the one hand, and intention and behavior on the other hand was relatively stable across contexts. The only important distinction to make is between employees who can gauge the norms concerning the behavior of interest and those who are unfamiliar with it. In other words, it is important to keep in mind that the effect of norms can differ substantially depending on how salient these are. One possible implication is that the relative importance of each social-cognitive determinant may change as a result of an intervention. If the social norms regarding proenvironmental behaviors intentionally or unintentionally become more explicit in the course of an organizational-level campaign, their impact on behavior may also increase. Another determinant with a relatively unstable effect on behavior across contexts is habit. It is therefore important to determine to what extent habit affects the behaviors of interest in the specific context in which one aims to intervene. 
Although generalizations based on a sample of four organizations may be on the speculative side, it is relatively safe to assume that the role of attitude and self-efficacy in determining energy-related behaviors are fairly constant across organizations. Intervention components targeting these determinants could be developed and used (with slight alterations depending on what specific beliefs are known to be relevant) in different organizations.

\section{Study limitations and future research directions}

\section{Study limitations}

Inevitably, the conclusions that can be drawn from our empirical studies are limited by several methodological and other practical constraints. Some limitations were common to all reported empirical studies. First, there is a selection bias at both the individual and organizational level because participation in the research project was on a voluntary basis. Second, we employed a cross-sectional research design for both our qualitative and quantitative study. Therefore, we had no or very little information about determinants and behavior in the past and the future. Third, we relied heavily on self-report measures. Consequently, it is possible that the impact of conscious or socially-desirable determinants was systematically overestimated, whereas that of unconscious or socially-undesirable determinants was underestimated. For instance, experimental research has shown that normative influence is underestimated in self-reports compared to actual behavioral measures (Nolan et al., 2008). Thus, one could hypothesize that, compared to perceived norm, the relatively strong effect of attitude on intention to act proenvironmentally is due to employees' overestimation of the influence of attitude and an underestimation of that of social norm. Similarly, developments over time could not truly be examined, although the qualitative study offered some glimpses of interesting dynamics over time. Another related issue is that organizational differences, which are usually mediated through individual determinants, do not necessarily imply a causal link from organization to individual. After all, employees might be self-selecting into different organizations. Fourth, detailed objective information concerning organizational determinants and external circumstances was sometimes lacking so we could not always determine whether perceived (physical) organizational or external barriers indeed existed in employees' environment. In a similar fashion, we cannot predict how a change in the examined behaviors would affect total energy consumption of an organization. Fifth and finally, we focused on the individual determinants of behaviors and how these may mediate organizational influences. This led to the relative neglect of determinants external to the organization which might have been of high relevance as well.

Methodological and practical issues that concerned specific parts of our research were discussed earlier in the relevant chapters. However, one general point of discussion here is that the measurement of some behaviors was less problematic than that of others. Generally speaking, the simpler, daily behaviors could be measured with less ambiguity - and presumably less subjective judgment - than more complex investment behaviors such as business travel decisions. Although objective measures of business travel were available, such measures did not capture what was most interesting for our research purposes. For example, number of business trips made as a measure is too coarse and would primarily reflect differences in job requirements - which in turn were too complicated to operationalize if we had wanted to control for them. 


\section{Future research}

Our study limitations suggest that the following lines of future research may lead to valuable additional insights into proenvironmental behavior. First, if self-selection bias could be reduced by incentivizing organizations and individuals to participate in a future study this may avoid possibly biased results. Second, longitudinal and experimental research (with objective behavioral measures) may help clarify the direction of causality and avoid systematic biases due to use of self-report measures. Third, more detailed studies of environment-individual interactions by matching data from the environment and the individual in the form of case studies may provide a deeper understanding of these dynamics.

In addition, our discussion of determinants of energy-related behaviors in organizations suggest that more research is needed to determine under what conditions the relative importance of determinants may change. In our study, especially the role of perceived norm and habit were found to be unstable across populations and contexts. For this reason, the role of moderators deserves special attention. Experimental research from the social identity tradition has, for instance, found group identification to moderate the relationship between perceived norm and intention (Terry \& Hogg, 1996). In the context of household energy conservation, personal involvement has been found to moderate the effect of descriptive norm on behavior (Göckeritz et al., 2010). These are just two candidate moderators that may explain our divergent results for perceived norm. With regard to habit, there is evidence that habit itself is a moderator of the relationship between social-cognitive determinants and intention and/or behavior (Elliott, Armitage, \& Baughan, 2003; Thogersen, 2002; Trafimow, 2000). Further research in these areas may address the specific questions that the present studies have raised.

Finally, for maximum impact on the societal level, it is advisable to also consider other behaviors, such as eating and drinking habits, which are indirectly linked to energy use but that are nevertheless accounting for a large share of total energy use (Koneswaran \& Nierenberg, 2008; Weber \& Matthews, 2008).

\section{Conclusion}

This thesis has examined the determinants of a wide range of energy-related behaviors among office workers, and in particular the role of the organizational context. An extended reasoned action framework was proven to be useful for understanding proenvironmental behavior irrespective of organization, and in household as well as organizational contexts. The impact of organizational context on employees' behavior is mostly mediated through the strength by which relevant beliefs are held. Furthermore, there are some but fewer organizational differences in the relevance of specific beliefs as indicators of the individual determinants, and the strength of relationships between of individual determinants, intention, and behavior. Comparing results of the energy-related behaviors examined, organizational change interventions targeting office energy-related behaviors and business travel behaviors appear more feasible than those aimed at changing commuting travel mode choice. 


\section{References}

Aarts, H., \& Dijksterhuis, A. (2000). The automatic activation of goal-directed behaviour: The case of travel habit. Journal of Environmental Psychology, 20, 75-82.

Abrahamse, W., \& Steg, L. (2009). How do socio-demographic and psychological factors relate to households' direct and indirect energy use and savings? Journal of Economic Psychology, 30, 711-720.

Abrahamse, W., Steg, L., Vlek, C., \& Rothengatter, T. (2005). A review of intervention studies aimed at household energy conservation. Journal of Environmental Psychology, 25, 273-291.

Abrahamse, W., Steg, L., Vlek, C., \& Rothengatter, T. (2007). The effect of tailored information, goal setting, and tailored feedback on household energy use, energy-related behaviors, and behavioral antecedents. Journal of Environmental Psychology, 27, 265-276.

Aguilera, A. (2008). Business travel and mobile workers. Transportation Research Part a-Policy and Practice, 42, 1109-1116.

Ajzen, I. (1991). The Theory of Planned Behavior. Organizational Behavior and Human Decision Processes, 50, 179-211.

Ajzen, I., \& Fishbein, M. (1980). Understanding Attitudes and Predicting Social Behavior Englewood-Cliffs, NJ: Prentice-Hall

Ajzen, I., \& Fishbein, M. (2005). The influence of attitudes on behavior. In D. Albarracín, B. T. Johnson \& M. P. Zanna (Eds.), The Handbook of Attitudes. Mahwah, NJ: Erlbaum.

Andersson, L., Shivarajan, S., \& Blau, G. (2005). Enacting ecological sustainability in the MNC: A test of an adapted value-belief-norm framework. Journal of Business Ethics, 59, 295-305.

Arnfalk, P., \& Kogg, B. (2003). Service transformation - managing a shift from business travel to virtual meetings. Journal of Cleaner Production, 11, 859-872.

Bailey, D. E., \& Kurland, N. B. (2002). A review of telework research: findings, new directions, and lessons for the study of modern work. Journal of Organizational Behavior, 23, 383-400.

Bamberg, S. (2006). Is a residential relocation a good opportunity to change people's travel behavior? Results from a theory-driven intervention study. Environment and Behavior, 38, 820-840.

Bamberg, S., Ajzen, I., \& Schmidt, P. (2003). Choice of travel mode in the theory of planned behavior: The roles of past behavior, habit, and reasoned action. Basic and Applied Social Psychology, 25, 175-187.

Bamberg, S., Hunecke, M., \& Blobaum, A. (2007). Social context, personal norms and the use of public transportation: Two field studies. Journal of Environmental Psychology, 27, 190-203.

Bamberg, S., \& Moser, G. (2007). Twenty years after Hines, Hungerford, and Tomera: A new metaanalysis of psycho-social determinants of pro-environmental behaviour. Journal of Environmental Psychology, 27, 14-25.

Bandura, A. (1997). Self-Efficacy: The Exercise of Control. New York: Worth Publishers.

Bansal, P., \& Gao, J. J. (2006). Building the future by looking to the past - Examining research published on organizations and environment. Organization \& Environment, 19, 458-478.

Bartholomew, L. K., Parcel, G. S., Kok, G., Gottlieb, N., \& Fernández, M. E. (2011). Planning health promotion programs: an Intervention Mapping approach (3rd ed.). San Francisco, CA: Jossey-Bass.

Becker, L.-J., \& Seligman, C. (1981). Welcome to the energy crisis. Journal of Social Issues, 37, 1-7.

Boldero, J. (1995). The Prediction of Household Recycling of Newspapers - the Role of Attitudes, Intentions, and Situational Factors. Journal of Applied Social Psychology, 25, 440-462. 
Branzei, O., Ursacki-Bryant, T. J., Vertinsky, I., \& Zhang, W. J. (2004). The formation of green strategies in Chinese firms: Matching corporate environmental responses and individual principles. Strategic Management Journal, 25, 1075-1095.

Brothers, K. J., Krantz, P. J., \& McClannahan, L. E. (1994). Office Paper Recycling - a Function of Container Proximity. Journal of Applied Behavior Analysis, 27, 153-160.

Cairns, S., Sloman, L., Newson, C., Anable, J., Kirkbride, A., \& Goodwin, P. (2008). Smarter choices: Assessing the potential to achieve traffic reduction using 'soft measures'. Transport Reviews, 28 , 593-618.

CBS, PBL, \& UR, W. (2010). Bevolkingsomvang en aantal huishoudens, 1980-2010. from http://www.compendiumvoordeleefomgeving.nl/indicatoren/nl0001-Bevolkingsomvang-enhuishoudens.html?i=15-12

Cordano, M., \& Frieze, I. H. (2000). Pollution reduction preferences of US environmental managers: Applying Ajzen's theory of planned behavior. Academy of Management Journal, 43, 627-641.

Corraliza, J. A., \& Berenguer, J. (2000). Environmental values, beliefs, and actions - A situational approach. Environment and Behavior, 32, 832-848.

Daamen, D. D. L., Staats, H., Wilke, H. A. M., \& Engelen, M. (2001). Improving environmental behavior in companies - The effectiveness of tailored versus nontailored interventions. Environment and Behavior, 33, 229-248.

Danner, U. N., Aarts, H., \& de Vries, N. K. (2008). Habit vs. intention in the prediction of future behaviour: The role of frequency, context stability and mental accessibility of past behaviour. British Journal of Social Psychology, 47, 245-265.

Davidov, E. (2007). Explaining habits in a new context - The case of travel-mode choice. Rationality and Society, 19, 315-334

de Groot, G. M., \& Morgenstern, P. P. (2009). Energieverbruik en besparingspotentieel bedrijuen en instellingen [energy use and saving potential companies and institutions] (No. RIVM-rapport 609021086 2009): RIVM [National Institute for Public Health and the Environment].

Dietz, T., Gardner, G. T., Gilligan, J., Stern, P. C., \& Vandenbergh, M. P. (2009). Household actions can provide a behavioral wedge to rapidly reduce US carbon emissions. Proceedings of the National Academy of Sciences of the United States of America, 106, 18452-18456.

Domarchi, C., Tudela, A., \& Gonzalez, A. (2008). Effect of attitudes, habit and affective appraisal on mode choice: an application to university workers. Transportation, 35, 585-599.

Dunlap, R. E., Van Liere, K. D., Mertig, A. G., \& Jones, R. E. (2000). Measuring endorsement of the new ecological paradigm: A revised NEP scale. Journal of Social Issues, 56, 425-442.

Eagly, A. H., \& Chaiken, S. (1993). The Psychology of Attitudes. New York: Harcourt Brace Jovanovich College Publishers.

Egmond, C., Jonkers, R., \& Kok, G. (2006). A strategy and protocol to increase diffusion of energy related innovations into the mainstream of housing associations. Energy Policy, 34, 4042-4049.

Egri, C. P., \& Herman, S. (2000). Leadership in the North American environmental sector: Values, leadership styles, and contexts of environmental leaders and their organizations. Academy of Management Journal, 43, 571-604.

Elliott, M. A., Armitage, C. J., \& Baughan, C. J. (2003). Drivers' compliance with speed limits: An application of the theory of planned behavior. Journal of Applied Psychology, 88, 964-972.

Etzion, D. (2007). Research on organizations and the natural environment, 1992-present: A review. Journal of Management, 33, 637-664.

Fernandez, E., Junquera, B., \& Ordiz, M. (2003). Organizational culture and human resources in the environmental issue: a review of the literature. International Journal of Human Resource Management, 14, 634-656. 
Fineman, S. (1996). Emotional subtexts in corporate greening. Organization Studies, 17, 479-500.

Fishbein, M., \& Ajzen, I. (1975). Belief, attitude, intention, and behavior: an introduction to theory and research. Reading, MA: Addison-Wesley.

Fishbein, M., \& Ajzen, I. (2010). Predicting and Changing Behavior: The Reasoned Action Approach. New York: Taylor \& Francis Group.

Flannery, B. L., \& May, D. R. (2000). Environmental ethical decision making in the US metal-finishing industry. Academy of Management Journal, 43, 642-662.

Gardner, B., \& Abraham, C. (2008). Psychological correlates of car use: A meta-analysis. Transportation Research Part F-Traffic Psychology and Behaviour, 11, 300-311.

Gardner, B., \& Abraham, C. (2010). Going Green? Modeling the Impact of Environmental Concerns and Perceptions of Transportation Alternatives on Decisions to Drive. Journal of Applied Social Psychology, 40, 831-849.

Göckeritz, S., Schultz, P. W., Rendon, T., Cialdini, R. B., Goldstein, N. J., \& Griskevicius, V. (2010). Descriptive normative beliefs and conservation behavior: The moderating roles of personal involvement and injunctive normative beliefs. European Journal of Social Psychology, 40, 514-523.

Gonzalez-Benito, J., \& Gonzalez-Benito, O. (2006). The role of stakeholder pressure and managerial values in the implementation of environmental logistics practices. International Journal of Production Research, 44, 1353-1373.

Hardin, G. (1968). The tragedy of the commons. Science, 162, 1243-1248.

Harland, P., Staats, H., \& Wilke, H. A. M. (1999). Explaining proenvironmental intention and behavior by personal norms and the theory of planned behavior. Journal of Applied Social Psychology, 29, 2505-2528.

Hopper, J. R., \& Nielsen, J. M. (1991). Recycling as Altruistic Behavior - Normative and Behavioral Strategies to Expand Participation in a Community Recycling Program. Environment and Behavior, 23, 195-220.

Hu, L. T., \& Bentler, P. M. (1999). Cutoff criteria for fit indexes in covariance structure analysis: conventional criteria versus new alternatives. Structural Equation Modeling, 6, 1-55.

Humphrey, C.-R., Bord, R.-J., Hammond, M.-M., \& Mann, S.-H. (1977). Attitudes and conditions for cooperation in a paper recycling program. Environment and Behavior, 9, 107-124.

IPCC. (2007). Summary for Policymakers. In Climate Change 2007: The Physical Science Basis. Contribution of Working Group I to the Fourth Assessment Report of the Intergovernmental Panel on Climate Change. Cambridge: Cambridge University Press.

Jakobsson, C., Fujii, S., \& Garling, T. (2002). Effects of economic disincentives on private car use. Transportation, 29, 349-370.

Jones, R. E. (1990). Understanding Paper Recycling in an Institutionally Supportive Setting - an Application of the Theory of Reasoned Action. Journal of Environmental Systems, 19, 307-321.

Kaiser, F. G. (2006). A moral extension of the theory of planned behavior: Norms and anticipated feelings of regret in conservationism. Personality and Individual Differences, 41, 71-81.

Kaiser, F. G., \& Gutscher, H. (2003). The proposition of a general version of the theory of planned behavior: Predicting ecological behavior. Journal of Applied Social Psychology, 33, 586-603.

Kaiser, F. G., Hubner, G., \& Bogner, F. X. (2005). Contrasting the theory of planned behavior with the value-belief-norm model in explaining conservation behavior. Journal of Applied Social Psychology, 35, 2150-2170.

Kaiser, F. G., \& Scheuthle, H. (2003). Two challenges to a moral extension of the theory of planned behavior: moral norms and just world beliefs in conservationism. Personality and Individual Differences, 35, 1033-1048. 
Kaiser, F. G., \& Schultz, P. W. (2009). The Attitude-Behavior Relationship: A Test of Three Models of the Moderating Role of Behavioral Difficulty. Journal of Applied Social Psychology, 39, 186-207.

Kearney, A. R., \& De Young, R. (1995-1996). Changing Commuter Travel Behavior: Employer-Initiated Strategies. Journal of Environmental Systems, 24, 373-393. .

Kirk, R. E. (2007). Effect magnitude: a different focus. Journal of Statistical Planning and Inference, 137, $1634-1646$.

Koneswaran, G., \& Nierenberg, D. (2008). Global farm animal production and global warming: Impacting and mitigating climate change. Environmental Health Perspectives, 116, 578-582.

Lee, Y. J., \& DeYoung, R. (1994). Intrinsic Satisfaction Derived from Office Recycling Behavior - a CaseStudy in Taiwan. Social Indicators Research, 31, 63-76.

Lee, Y. J., DeYoung, R., \& Marans, R. W. (1995). Factors Influencing Individual Recycling Behavior in Office Settings - a Study of Office Workers in Taiwan. Environment and Behavior, 27, 380-403.

Lindenberg, S., \& Steg, L. (2007). Normative, gain and hedonic goal frames guiding environmental behavior. Journal of Social Issues, 63, 117-137.

Lo, S. H., Peters, G. Y., \& Kok, G. (in press). A review of determinants of and interventions for proenvironmental behaviors in organizations. Journal of Applied Social Psychology.

Lo, S. H., Peters, G. Y., \& Kok, G. (under review-a). Energy-Related Behaviors in Office Buildings: a Qualitative Study on Individual and Organizational Determinants.

Lo, S. H., Peters, G. Y., \& Kok, G. (under review-b). Pro-environmental Travel Behaviors among Office Workers: a Qualitative Study of Individual-level and Organizational-level Determinants.

Mann, E., \& Abraham, C. (2006). The role of affect in UK commuters' travel mode choices: An interpretative phenomenological analysis. British Journal of Psychology, 97, 155-176.

Marans, R. W., \& Lee, Y. J. (1993). Linking Recycling Behavior to Waste Management Planning - a CaseStudy of Office Workers in Taiwan. Landscape and Urban Planning, 26, 203-214.

Moll, H. C., Noorman, K. J., Kok, R., Engstrom, R., Throne-Holst, H., \& Clark, C. (2005). Pursuing more sustainable consumption by analyzing household metabolism in European countries and cities. Journal of Industrial Ecology, 9, 259-275.

Moos, M., Andrey, J., \& Johnson, L. C. (2006). The sustainability of telework: an ecological-footprinting approach. Sustainability: Science, Practice, and Policy, 3-14.

Moser, G., \& Bamberg, S. (2008). The effectiveness of soft transport policy measures: A critical assessment and meta-analysis of empirical evidence. Journal of Environmental Psychology, 28, 10-26.

Muthén, L. K., \& Muthén, B. O. (1998-2010). Mplus User's Guide. Sixth Edition. Los Angeles, CA: Muthén \& Muthén.

Nickerson, R. S. (2003). Psychology and Environmental Change. Mahwah, New Jersey: Lawrence Erlbaum Associates.

Nolan, J. M., Schultz, P. W., Cialdini, R. B., Goldstein, N. J., \& Griskevicius, V. (2008). Normative social influence is underdetected. Personality and Social Psychology Bulletin, 34, 913-923.

Oskamp, S. (2000). A sustainable future for humanity? How can psychology help? American Psychologist, 55, 496-508.

Parker, D., Manstead, A. S. R., \& Stradling, S. G. (1995). Extending the Theory of Planned Behavior - the Role of Personal Norm. British Journal of Social Psychology, 34, 127-137.

Perez-Lombard, L., Ortiz, J., \& Pout, C. (2008). A review on buildings energy consumption information. Energy and Buildings, 40, 394-398.

Ramus, C. A., \& Steger, U. (2000). The roles of supervisory support behaviors and environmental policy in employee "ecoinitiatives" at leading-edge European companies. Academy of Management Journal, 43, 605-626. 
Richter, J., Friman, M., \& Garling, T. (2010). Review of evaluations of soft transport policy measures. Transportation: Theory and Application, 2, 5-18.

Rogers, E. M. (1995). Diffusion of Innovations (4th ed.). New York: The Free Press.

Rosenthal, J. A. (1996). Qualitative descriptors of strength of association and effect size. Journal of Social Service Research, 21, 37-59.

Satorra, A., \& Bentler, P. M. (1994). Corrections to test statistics and standard enors in covariance structure analysis. In A. von Eye \& C. C. Clogg (Eds.), Latent variables analysis: Applications for developmental research (pp. 399-419). Thousand Oaks, CA: Sage.

Satorra, A., \& Bentler, P. M. (2001). A scaled difference chi-square test statistic for moment structure analysis. Psychometrika 66, 507-514.

Schein, E. (1992). Organizational culture and leadership. London: Jossey-Bass.

Scherbaum, C. A., Popovich, P. M., \& Finlinson, S. (2008). Exploring individual-level factors related to employee energy-conservation behaviors at work. Journal of Applied Social Psychology, 38, 818835.

Schultz, P. W., Nolan, J. M., Cialdini, R. B., Goldstein, N. J., \& Griskevicius, V. (2007). The constructive, destructive and reconstructive power of social norms. Psychological Science, 18, 429-434.

Schwartz, S. H. (1973). Normative explanations of helping behavior: a critique, proposal, and empirical test. Journal of Experimental Social Psychology, 9, 349-364.

Schwartz, S. H. (1977). Normative influences on altruism. In L. Berkowitz (Ed.), Advances in Experimental Social Psychology (Vol. 10, pp. 221-279). New York: Academic Press.

Sharma, S. (2000). Managerial interpretations and organizational context as predictors of corporate choice of environmental strategy. Academy of Management Journal, 43, 681-697.

Shippee, G.-E., \& Gregory, W. (1982). Public commitment and energy conservation. American Journal of Community Psychology, 10, 81-93.

Siero, F. W., Bakker, A. B., Dekker, G. B., \& vandenBurg, M. T. C. (1996). Changing organizational energy consumption behaviour through comparative feedback. Journal of Environmental Psychology, 16, 235-246.

Siero, S., Boon, M., Kok, G., \& Siero, F. (1989). Modification of driving behavior in a large transport organization: A field experiment. Journal of Applied Psychology, 74, 417-423.

Siero, S., Boon, M. E., Kok, G. J., Siero, F. W., \& Veen, P. (1984). Implementatie van energiebesparend gedrag in een grote organisatie. MEO, Tijdschrift voor Organisatiekunde en Sociaal Beleid, 38, 323-338.

Staats, H., Harland, P., \& Wilke, H. A. M. (2004). Effecting durable change - A team approach to improve environmental behavior in the household. Environment and Behavior, 36, 341-367.

Staats, H. J., Wit, A. P., \& Midden, C. Y. (1996). Communicating the greenhouse effect to the public: Evaluation of a mass media campaign from a social dilemma perspective. Journal of Environmental Management, 46, 189-203.

Statistics Netherlands [CBS]. (2010). Nationale Enquête Arbeidsomstandigheden; herkomst, duur, bedrijfsklassen Retrieved 31 May, 2010, from http://statline.cbs.nl/StatWeb/publication/?DM=SLNL\&PA=71205ned\&D1=5,1112\&D2=0\&D3=a\&HDR=T\&STB=G2,G1\&VW=T

Steg, L. (2005). Car use: lust and must. Instrumental, symbolic and affective motives for car use. Transportation Research Part a-Policy and Practice, 39, 147-162.

Steg, L., Dreijerink, L., \& Abrahamse, W. (2005). Factors influencing the acceptability of energy policies: A test of VBN theory. Journal of Environmental Psychology, 25, 415-425.

Stern, P. C. (2000). Psychology and the science of human-environment interactions. American Psychologist, 55, 523-530. 
Stern, P. C., Dietz, T., Abel, T., \& Guagnano, G. (1999). A value-belief-norm theory of support for social movements: the case of environmentalism Human Ecology Review, 6, 81-97.

Terry, D. J., \& Hogg, M. A. (1996). Group norms and the attitude-behavior relationship: A role for group identification. Personality and Social Psychology Bulletin, 22, 776-793.

Thogersen, J. (2002). Direct experience and the strength of the personal norm - Behavior relationship. Psychology \& Marketing, 19, 881-893.

Thogersen, J. (2006). Understanding repetitive travel mode choices in a stable context: A panel study approach. Transportation Research Part a-Policy and Practice, 40, 621-638.

Toffel, M. W., \& Horvath, A. (2004). Environmental implications of wireless technologies: News delivery and business meetings. Environmental Science \& Technology, 38, 2961-2970.

Trafimow, D. (2000). Habit as both a direct cause of intention to use a condom and as a moderator of the attitude-intention and subjective norm-intention relations. Psychology \& Health, 15, 383-393.

Tudor, T. L., Barr, S. W., \& Gilg, A. W. (2007). Linking intended behaviour and actions: A case study of healthcare waste management in the Cornwall NHS. Resources Conservation and Recycling, 51, $1-23$.

Tudor, T. L., Barr, S. W., \& Gilg, A. W. (2008). A novel conceptual framework for examining environmental behavior in large organizations - A case study of the Cornwall National Health Service (NHS) in the United Kingdom. Environment and Behavior, 40, 426-450.

Tversky, A., \& Kahneman, D. (1974). Judgments under uncertainty: Heuristics and biases. Science, 185, 1124-1131.

Uitdenbogerd, D., Egmond, C., Jonkers, R., \& Kok, G. (2007). Energy-related Intervention Success Factors: A Literature Review. Paper presented at the ECEEE Summer Studies of the European Council for an Energy Efficient Economy.

van der Pligt, J. (1996). Social Psychology and Environmental Issues. In G. R. Semin \& K. Fiedler (Eds.), Applied Social Psychology. London: SAGE Publications.

van Dril, A. W. N., \& Elzenga, H. E. (2005). Referentieramingen energie en emissies 2005-2010 [Reference estimates for energy and emissions 2005-2010] (No. RIVM-rapport 773001031/2005): RIVM [National Institute for Public Health and the Environment].

Van Vugt, M., Van Lange, P. A. M., \& Meertens, R. M. (1996). Commuting by car or public transportation? A social dilemma analysis of travel mode judgments. European Journal of Social Psychology, 26, 373-395.

Vermeulen, W. J. V., \& Hovens, J. (2006). Competing explanations for adopting energy innovations for new office buildings. Energy Policy, 34, 2719-2735.

Verplanken, B., \& Orbell, S. (2003). Reflections on past behavior: A self-report index of habit strength. Journal of Applied Social Psychology, 33, 1313-1330.

Verplanken, B., Walker, I., Davis, A., \& Jurasek, M. (2008). Context change and travel mode choice: Combining the habit discontinuity and self-activation hypotheses. Journal of Environmental Psychology, 28, 121-127.

Völlink, T., Meertens, R., \& Midden, C. J. H. (2002). Innovating 'diffusion of innovation' theory: Innovation characteristics and the intention of utility companies to adopt energy conservation interventions. Journal of Environmental Psychology, 22, 333-344.

Weber, C. L., \& Matthews, H. S. (2008). Food-miles and the relative climate impacts of food choices in the united states. Environmental Science \& Technology, 42, 3508-3513.

Weber, E. U. (2006). Experience-based and description-based perceptions of long-term risk: Why global warming does not scare us (yet). Climatic Change, 77, 103-120.

Winter, D. D. N. (2000). Some big ideas for some big problems. American Psychologist, 55, 516-522. 
Wood, W., Tam, L., \& Guerrero Witt, M. (2005). Changing circumstances, disrupting habits. Journal of Personality and Social Psychology, 88, 918-933. 



\section{Summary}

Environmental sustainability has received increasing societal attention over the past decades. Especially energy use has been a prominent issue because of the environmental pollutants released by fossil fuel consumption as well as energy security concerns. Considering the fact that energy use is the result of the interaction between technology and human behavior, it is unsurprising psychologists have already been involved in the study of energy-related behaviors since the first oil crisis. Most existing psychological research on proenvironmental behavior has been conducted in private or household contexts. In comparison, very little research has addressed energy use in organizations at the individual, behavioral level of analysis. This thesis aimed to address this research gap by systematically examining the determinants of a wide range of energy-related behaviors relevant to office workers. In particular, special attention was paid to the dynamics between the individual and the organization.

Following a general introduction in Chapter 1, we first present a review of the state-of-the-art in Chapter 2. Through systematic database searches, we found and analyzed 21 studies which had empirically examined determinants of and/or interventions for proenvironmental behavior in organizational contexts. The main conclusions were that, on the individual level, attitudinal determinants and past behavior showed the most consistent effects on proenvironmental behavior, whereas on the organizational level, management and physical facilitation were most frequently significant determinants of behavior. Findings related to other factors were less conclusive which was mostly due to lack of empirical research. Furthermore, we found no interorganizational research integrating the analysis of individual and organizational determinants.

The subsequent six chapters describe and discuss the empirical results of our research project on determinants of energy-related behaviors among office workers. We conducted an interview and focus group study and a survey study in four organizations with different characteristics in the Netherlands. Our sample consisted of a non-profit organization (NGO) in the province of Zuid-Holland, a commercial company in Zuid-Holland, a university in the province of Limburg, and another company in Limburg. In other words, we had organizations from both the public and private sector as well as organizations from two regions in the Netherlands with different levels of population density and public transport connectivity represented in our sample. The qualitative study aimed to identify behaviors relevant to office workers, and the individual and organizational determinants of these behaviors. In the quantitative study, we estimated, with the use of multigroup structural equation modeling, the magnitude of effects of determinants on intention and behavior as well as whether and how organizational differences are mediated through individual determinants.

The qualitative findings on energy-related behaviors which take place within offices are described in Chapter 3. Topics covered include lights, climate control, computer and printer use, private electric appliances, and flexible office spaces. The results indicate that, overall, work efficiency and productivity was prioritized over energy conservation. Self-efficacy was generally the most salient individual determinant, and social norm the least discussed determinant of current office energyrelated behaviors. Nevertheless, both self-efficacy and social norm elements were encountered in employees' proposed strategies to achieve future office energy-saving. Formal and informal aspects of the organizational context were found to equally affect individual determinants and their related behaviors. Facility managers' and general office workers' views differed in a few but important ways. 
Interorganizational comparison showed that differences in organizational foci were linked to the relative salience of normative, gain, and hedonic motivations.

Qualitative findings of commuting and business travel behaviors are reported in Chapter 4.

Topics covered include commuting travel mode, business trip frequency and travel mode, teleworking, and teleconferencing. The results indicate that irrespective of organizational focus, perceived changeability of travel mode choice was generally low, whereas that of teleworking and teleconferencing was relatively high. Another important, but implicit common theme was the subjective nature of necessity of work-related trips. Evidence from interorganizational comparisons suggests that organizational measures do not have uniform effects on employee behavior - which is partially due to differences in attitude and personal income. Attitudes, in turn, were related to the organizational focus and personal work-related travel frequency.

Chapter 5 presents the quantitative results for office energy-related behaviors. We selected four behaviors for further investigation: printing smaller, not printing e-mails, switching off lights, and switching off monitors. The results indicate that intention was the strongest direct predictor of "printing behaviors", whereas habit was the strongest predictor of "switching behaviors". Of the social-cognitive determinants, attitude was overall the strongest predictor of intentions. Organizational differences were mainly found in the strength with which most energy-related beliefs were held, and to a lesser extent, in the relevance of normative and attitudinal beliefs as indicators of corresponding individual determinants. Finally, some of the relationships between habit, intention, and behavior differed in their magnitude across organizations.

Chapter 6 reports the quantitative results for commuting behaviors. Topics covered include commuting travel mode choice, fuel-saving driving style, and purchase of energy-efficient cars. The results indicate that intention was very strongly related to travel mode choice and driving style, and strongly related to car purchase decisions. Only attitude and self-efficacy were consistently associated with intentions. Personal norm generally did not have a significant effect on commuting intention. Evidence for the roles of perceived norm and habit was mixed. Organizational differences were once more mainly found in the strength of commute-related beliefs. The degree to which specific injunctive norm beliefs were relevant to the overall injunctive norm and the effect of injunctive norm on intention also differed between organizations.

Chapter 7 describes the quantitative results for business travel behaviors, defined as deciding whether to make business trips and the use of teleconference facilities. The results indicate that intention was the strongest direct predictor of behavior. Attitude, in turn, had the strongest effect on business trip intentions. In contrast, habit and perceived norm were the strongest predictors of teleconference intention. Organizational differences were once again mainly found in how strongly business travel-related beliefs were held, and to a lesser extent, in the relevance of normative and attitudinal beliefs to one's overall attitude and perceived norm.

In the final chapter, Chapter 8 , we integrate the qualitative and quantitative research findings and provide a general discussion of the limitations of our research and suggestions for future research. It is concluded that an extended reasoned action framework has proven to be useful for understanding proenvironmental behavior irrespective of organization, and in household as well as organizational contexts. The impact of organizational context on employee behavior is mostly mediated through the strength by which relevant beliefs are held. Furthermore, there are some but fewer organizational differences in the relevance of specific beliefs as indicators of individual determinants, and the strength 
of relationships between of individual determinants, intention, and behavior. Comparing results of the energy-related behaviors examined, organizational change interventions targeting office energy-related behaviors and business travel behaviors appear more feasible than those aimed at changing commuting travel mode choice. 



\section{Samenvatting}

De afgelopen decennia heeft het milieu in toenemende mate in de maatschappelijke belangstelling gestaan. Vooral overmatig energieverbruik is een aandachtspunt geworden, zowel vanwege de milieuvervuiling die wordt veroorzaakt door het verbranden van fossiele brandstoffen als overwegingen met betrekking tot energiezekerheid. Gezien het feit dat energieverbruik het resultaat is van de interactie tussen technologie en menselijk gedrag, is het niet verwonderlijk dat psychologen zich al vanaf de eerste oliecrisis hebben beziggehouden met het bestuderen van energiegerelateerde gedragingen. Het meeste onderzoek over energiebesparend en ander milieuvriendelijk gedrag is uitgevoerd in privésituaties en onder huishoudens. Op het niveau van het individuele gedrag is er in vergelijking erg weinig onderzoek naar het energieverbruik in organisaties. Dit proefschrift heeft daarom als doel een bijdrage te leveren aan kennis over energieverbruik in organisaties door systematisch de determinanten van een breed scala aan energiegerelateerde gedragingen die relevant zijn voor kantoormedewerkers te onderzoeken. Hierbij wordt vooral aandacht geschonken aan de dynamiek tussen het individu en de organisatie.

Na een algemene inleiding in hoofdstuk 1 , wordt eerst een overzicht van de bestaande literatuur gegeven. Met behulp van systematische zoekopdrachten in een database, zijn er 21 studies gevonden en geanalyseerd die determinanten van en/of interventies voor milieuvriendelijke gedragingen in organisaties empirisch hebben onderzocht. De voornaamste conclusies waren dat, op het individuele niveau, attitude en het gedrag in het verleden het meest consistent invloed hadden op milieuvriendelijk gedrag, terwijl op organisatieniveau, management en materiële steun het meest frequent significante determinanten waren van het gedrag. Resultaten voor andere determinanten waren minder robuust wat vooral het gevolg was van het gebrek aan empirisch onderzoek. Daarnaast vonden we geen vergelijkend onderzoek onder verschillende organisaties dat de analyse van individuele en organisatiedeterminanten had geïntegreerd.

De volgende zes hoofdstukken beschrijven en bespreken de empirische resultaten van ons onderzoeksproject over determinanten van energiegerelateerde gedragingen onder kantoormedewerkers. We hebben een interview- en focus groepstudie en een vragenlijststudie uitgevoerd onder vier Nederlandse organisaties met verschillende kenmerken. Onze steekproef bestond uit een non-profit organisatie in Zuid-Holland, een commercieel bedrijf in Zuid-Holland, een universiteit in Limburg, en een ander bedrijf in Limburg. Er waren dus organisaties uit zowel de publieke als private sector en organisaties uit twee regio's in Nederland die verschillen in bevolkingsdichtheid en de kwaliteit van het openbaar vervoersnetwerk. De kwalitatieve studie had als doel om relevante gedragingen en de determinanten daarvan te identificeren. In de kwantitatieve studie berekenden we de relatieve grootte van de effecten van determinanten op intentie en gedrag en of hoe organisatieverschillen gemediëerd werden door individuele determinanten.

Kwalitatieve bevindingen over energiegerelateerde gedragingen die op kantoor worden uitgevoerd worden in hoofdstuk 3 beschreven. Onderwerpen die aan bod komen zijn verlichting, klimaatbeheersing, computer- en printergebruik, elektrische apparaten voor privégebruik, en flexibele werkplekken. De resultaten wijzen erop dat werkefficiëntie en productiviteit over het algemeen belangrijker worden geacht dan energiebesparing. Self-efficacy is doorgaans de meest saillante individuele determinant, en sociale norm de minst expliciet genoemde determinant, van 
energiegerelateerde gedragingen op kantoor. Desondanks komen zowel self-efficacy als sociale norm elementen voor in strategieën die medewerkers voorstellen om energie op kantoor te besparen. Zowel formele als informele aspecten van de organisatiecontext beïnvloeden individuele determinanten en de bijbehorende gedragingen in gelijke mate. Medewerkers van de facilitaire dienst en algemene medewerkers zijn veelal dezelfde mening toebedeeld, maar verschillen niettemin van inzicht op een aantal cruciale vlakken. Uit vergelijkingen tussen organisaties blijkt dat verschillen in organisatietype zijn gerelateerd aan de relevantie van normatieve, belanggerelateerde, en hedonistische motivaties.

Kwalitatieve bevindingen over woon-werkverkeer en dienstreizen worden beschreven in hoofdstuk 4. De onderwerpen die aan bod komen zijn keuze van vervoersmiddel, de frequentie van en vervoermiddelkeuze voor dienstreizen, telewerken, en teleconferenties. De bevindingen duiden erop dat onafhankelijk van het type organisatie, de waargenomen veranderlijkheid van vervoermiddelkeuze in de regel laag is, terwijl dat van telewerken en teleconferentie relatief hoog is. Een ander belangrijk, maar impliciet thema is dat de noodzaak van dienstreizen erg subjectief is. Evidentie van vergelijkingen tussen organisaties geeft aan dat maatregelen op organisatieniveau ongelijke effecten hebben op het gedrag van medewerkers, wat gedeeltelijk veroorzaakt wordt door individuele verschillen in attitude en inkomen. Attitudes zijn op hun beurt weer gerelateerd aan organisatietype en de frequentie waarmee een individu dienstreizen maakt.

Hoofdstuk 5 presenteert de kwantitatieve resultaten voor energiegerelateerde gedragingen op kantoor. Kleiner printen, geen e-mails printen, lichten uitdoen, en monitors uitdoen waren geselecteerd om verder te worden onderzocht in de vragenlijststudie. Uit de analyses bleek dat intentie de sterkste voorspeller is van printgedragingen, terwijl gewoonte dat is voor het uitzetten van licht en monitor. Attitude is op zijn beurt doorgaans de sterkste voorspeller van intentie. Er zijn voornamelijk organisatieverschillen in de sterkte van energiegerelateerde beliefs en in mindere mate in de relevantie van normatieve en attitude beliefs als indicatoren van de bijbehorende individuele determinanten. Daarnaast zijn er ook organisatieverschillen in de sterkte van de verbanden tussen gewoonte, intentie, en gedrag.

Hoofdstuk 6 rapporteert de kwantitatieve resultaten voor woon-werkverkeergedragingen. We hebben vervoermiddelkeuze, een zuinige rijstijl aanhouden, en het kopen van energiezuinige auto's onderzocht. Intentie is zeer sterk gerelateerd aan vervoermiddelkeuze en een zuinige rijstijl aanhouden en sterk gerelateerd aan autokeuze. Van de individuele determinanten, hebben alleen attitude en selfefficacy consistent een significant effect op intentie. Evidentie voor de rol van waargenomen norm en gewoonte verschillen meer tussen de diverse gedragingen. Organisatieverschillen werden weer voornamelijk gevonden in de sterkte van beliefs over woon-werkverkeergedragingen. De mate waarin injunctieve normatieve beliefs relevant zijn voor de injunctieve norm en het effect van injunctieve norm op intentie verschillen ook tussen organisaties.

Hoofdstuk 7 presenteert de kwantitatieve resultaten voor dienstreisgedragingen, welke gedefinieerd kunnen worden als beslissingen over het wel of niet maken van dienstreizen en het gebruik van teleconferentie faciliteiten. Intentie is de sterkste directe voorspeller van gedrag. Attitude heeft vervolgens weer het sterkste effect op dienstreisintenties; in tegenstelling tot teleconferentiegebruik waarvoor gewoonte en waargenomen norm de sterkste voorspellers zijn. Organisatieverschillen werden wederom voornamelijk gevonden in de sterkte van beliefs over dienstreizen en in mindere mate in de relevantie van attitude en normatieve beliefs als indicatoren van attitude en waargenomen norm. 
In het laatste hoofdstuk, hoofdstuk 8, worden de kwalitatieve en kwantitatieve onderzoeksresultaten geïntegreerd en de beperkingen van ons onderzoek en suggesties voor toekomstig onderzoek besproken. Er wordt geconcludeerd dat een uitgebreide versie van Reasoned Action als theoretisch kader nuttig is gebleken voor het begrijpen van milieuvriendelijk gedrag onafhankelijk van de specifieke organisatie, en in zowel privé- als werkomgevingen. De invloed van organisaties op het gedrag van medewerkers wordt grotendeels gemediëerd door de sterkte van relevante beliefs die men heeft. Daarnaast zijn er een klein aantal verschillen in de mate waarin specifieke beliefs relevante indicatoren zijn voor individuele determinanten en de sterkte van de relaties tussen individuele determinanten, intentie en gedrag. Ten slotte lijken interventies op organisatieniveau die zich richten op het veranderen van energiegerelateerde gedragingen op kantoor en dienstreisgedragingen, meer potentieel te hebben dan interventies die vervoermiddelkeuze voor woonwerkverkeer trachten te beïnvloeden. 



\section{Curriculum Vitae}

Siu Hing Lo was born in The Hague on 28 June 1983. She obtained her VWO (grammar school) diploma in 2001 at Christelijk Gymnasium Sorghvliet in The Hague. After graduating from secondary school, she was ready to venture into foreign lands, and spent the subsequent year in France and Spain where she passed state language exams of the respective countries. She studied International Relations and Psychology at the University of St Andrews, and was awarded a Master of Arts degree in 2006. During the exceptionally long Scottish summer holidays, she was also an intern at the government relations and political affairs branch of the Organization for the Prohibition of Chemical Weapons, and the human rights division of the Dutch Ministry of Foreign Affairs. In 2007, she obtained a Master of Science in Organizational and Social Psychology at the London School of Economics and Political Science. Since September 2007, she has been employed as a PhD candidate at Maastricht University. 


\title{
MGSoG Dissertation Series
}

\author{
Siu Hing lo \\ White Collars Green Sleeves: an Interorganizational Comparison of Determinants of Energy-Related \\ Behaviors among Office Workers \\ MGSoG Dissertation Series, nr 18 (2011)
}

Treena $\mathrm{Wu}$

Constraints to Human Capital Investment in Developing Countries:

Using the Asian Financial Crisis in Indonesia as a Natural Experiment

MGSoG Dissertation Series, nr 17 (2011)

Henry Espinoza Peña

Impact Evaluation of a Job-Training Programme for Disadvantaged Youths:

The Case of Projoven

MGSoG Dissertation Series, nr 16 (2011)

Florian Tomini

Between Family and Friends

Understanding the Interdependency of Private Transfers

MGSoG Dissertation Series, nr 15 (2010)

Michał Polalowski

The Institutional Transformation of Social Policy in East Central Europe:

Poland and Hungary in comparative and historical perspective

MGSoG Dissertation Series, nr 14 (2010)

Maha Ahmed

Defining, Measuring and Adressing Vulnerability:

The Case of Post Conflict Environments

MGSoG Dissertation Series, nr 13 (2010)

Pascal Beckers

Local Space and Economic Success

The role of spatial segregation of migrants in the Netherlands

MGSoG Dissertation Series, nr 12 (2011) 


\section{Victor Cebotari}

Complicting Demands in Ethnically Diverse Societies

Ethnopolitical Contention and Identity Values in Europe

MGSoG Dissertation Series, nr 11 (2010)

Dennis Gyllensporre

Competing and Complementary Perspectives on the EU as a Crisis Management Actor:

An Examination of the Common Security and Defence Policy through the Lenses of Idealism and Realism MGSoG Dissertation Series, nr 10 (2010)

Judit Vall Castello

Business Cycle and Policy Effects on Labour Market Transitions of Older and Disabled Workers in Spain MGSoG Dissertation Series, nr. 9 (2010)

Keetie Roelen

False Positives or Hidden Dimentions: the definition and measurement of child poverty

MGSoG Dissertation Series, nr. 8 (2010)

Denisa Maria Sologon

Earning Dynamics in Europe

MGSoG Dissertation Series, nr. 7 (2010)

Melissa Siegel

Money and Mobility: Migration and Remittances

MGSoG Dissertation Series, nr. 6 (2010)

Jessica S. Hagen-Zanker

Modest Expectations: Causes and effects of migration on migrant households in source countries

MGSoG Dissertation Series, nr. 5 (2010)

Mirtha R. Muniz Castillo

Human Development and Autonomy in Project Aid: Experiences from four

bilateral projects in Nigaragua and El Salvador

MGSoG Dissertation Series, nr. 4 (2009)

Christiane Arndt

Governance Indicators

MGSoG Dissertation Series, nr. 3 (2009)

Britta Augsburg

Microfinance - Greater Good or Lesser Evil?

MGSoG Dissertation Series, nr. 2 (2009) 
Geranda Notten

Measuring and Managing Poverty Risks

MGSoG Dissertation Series, nr. 1 (2008) 